Universidade de São Paulo Faculdade de Arquitetura e Urbanismo

\section{DIRETRIZES PROJETUAIS PARA UNIDADES DE URGÊNCIA EEMERGÉNCIA HOSPITALARES EFICIENTES}

\section{NELSON SCHIETTI DE GIACOMO}

Tese apresentada à Faculdade de Arquitetura e Urbanismo da Universidade de São Paulo - FAUUSP, como requisito parcial à obtenção de título de doutor sob a orientação do prof. Dr. Paulo Julio Valentino Bruna 
Autorizo a reprodução e divulgação total ou parcial deste trabalho, por qualquer meio convencional ou eletrônico, para fim de estudo e pesquisa, desde que citada a fonte.

e-mail: nelsongiacomo@yahoo.com.br 
Universidade de São Paulo Faculdade de Arquitetura e Urbanismo

\section{DIRETRIZES \\ PROJETUAIS \\ PARA UNIDADES \\ DE URGÊNCIA \\ E EMERGÉNCIA \\ HOSPITALARES \\ EFICIENTES}

\section{NELSON SCHIETTI DE GIACOMO}

Tese apresentada à Faculdade de Arquitetura e Urbanismo da Universidade de São Paulo - FAUUSP, como requisito parcial à obtenção de título de doutor sob a orientação do prof. Dr. Paulo Julio Valentino Bruna

Prof. Dr. Paulo Julio Valentino Bruna

Faculdade Arquitetura e Urbanismo

Universidade de são Paulo

$2^{0}$ membro

$3^{0}$ membro

$4^{0}$ membro

$5^{0}$ membro

São Paulo, de de 20II 

À minha mulher Glória, pela compreensão e cumplicidade.

Aos meus filhos, André e Talita, pela minha única e absoluta razão de buscar o ponto infinito.

Com incondicional amor, carinho e afeto. 



\section{Agradecimentos}

Ao professor Dr. Paulo Julio Valentino Bruna, pela orientação e enorme entendimento das circunstâncias que envolveram este trabalho.

À minha família, Glória, Talita, Matheus, André, Caroline, Gabriel e Amadeu, pela compreensão por estar ausente em tantos momentos.

Ao arquiteto Fabio Deguchi, pela amizade e ajuda e, ainda, à empresa canadense Cannon Design, pela presteza e colaboração. As Patrícias Ito e Manami, Cezar, Fernando e Lucas, pela ajuda na elaboração deste trabalho.

Às enfermeiras Eliane, Luiza Rita, Maria do Carmo, Rose Marie, Silvana e também aos Drs. Fahd Haddad e Luiz Koury, pelo auxílio e suporte técnico-operacional.

Aos professores Ana Virgínia Sampaio, Jorge Marão e Sidnei Guadanhim pelo apoio e interlocução.

Aos arquitetos Amanda Salvioni, Larissa Yoshihara, Nancy Cifuentes e Domingos Fiorentini, pelo apoio ao trabalho.

A Verônica Merlin e Lílian Lago pela formatação final deste projeto de pesquisa.

A todos que pacientemente conviveram comigo durante a elaboração deste trabalho. 

"Nenhum ponto finito tem sentido se não relacionar com um ponto infinito."

Jean Paul Sartre (1905-1980) 

GIACOMO, Nelson Schietti de. Diretrizes Projetuais para Unidades de Urgência e Emergência Hospitalares Eficientes.

Tese de doutorado. 390 p. 2011. Faculdade de Arquitetura e Urbanismo da Universidade de São Paulo.

\section{Resumo}

As especificidades inerentes ao perfil do paciente, nos seus aspectos físicos (estado grave) e emocionais (dor, risco de vida, angústia, sofrimento, medo, insegurança etc.) no atendimento das unidades de Urgência e Emergência de alta complexidade, proporcionam a particularidade que a referida unidade requer como estudo mais aprofundado. Com o objetivo de buscar este entendimento sobre os diversos aspectos envolvidos na assistência ao paciente em estado crítico é que o seguinte trabalho de pesquisa se concretiza. Aspectos que envolvam desde a compreensão do sistema operacional médico-enfermagem, apoio logístico-administrativo, técnico-construtivo, como suporte ao processo de concepção da arquitetura e reconhecer, principalmente, os aspectos humanoemocionais que se relacionam com o ambiente hospitalar. Com a análise sobre três Unidades de Urgência e Emergência de realidades totalmente distintas, no que se refere à abrangência populacional, socioeconômica e histórico-cultural, foi possível estabelecer parâmetros mais criteriosos sobre as tipologias estudadas. O presente trabalho objetiva abarcar os diversos aspectos envolvidos no processo projetual, os quais substanciarão as decisões para a geração da arquitetura, que consequentemente poderá contribuir para atingir a qualidade desejada. A arquitetura comportar-se-á como mais um instrumento do processo para que se obtenham Unidades de Urgência e Emergência eficientes, alta qualidade - espacial e operacional -, resolutividade, produtividade e principalmente mais humana. Além das considerações abordadas, a proposta deste trabalho também visa contribuir como fonte de pesquisa e abertura de discussão sobre o assunto, ainda pouco explorado e desenvolvido, nos seus diversos aspectos envolvidos com a geração do ambiente dos edifícios de saúde.

\section{Palavras-chave}

Arquitetura hospitalar. Unidades de Urgência e Emergência Diretrizes projetuais. Eficiência. Humanização do espaço. Ambiente hospitalar. 

GIACOMO, Nelson Schietti de. Project Guidelines for Efficient Hospital Urgency and Emergency Units. Doctorate Thesis. 2011. 390 p. Architecture and Urbanism College of São Paulo University.

\section{Abstract}

The special needs required to each different patient profile are related to several aspects such as physical and emotional aspects as physical condition pain, life-threaten, distress, suffering, fear, insecurity etc. The duty of the Urgency and Emergency units is of highly complexity and to provide a particular care it is required a deeper study. Therefore, having the objective of understand more about the varied aspects involved in the aid of patients in critic state, which is the aim of the following research. Aspects which involve the comprehension of the medical-nursing operational system, technician-constructivist and logistic-administrative support, are used to maintain the architectural concept process and recognize, mainly, the human-emotional aspects that are related within the hospital environment. Analyzing three Urgency and Emergency Units of entirely distinct realities taking into consideration their cultural history, socioeconomic context, and population scope, it was possible to establish criterion parameters about the typologies studied. The objective of this dissertation is gather the varied aspects involved in the project process, which will consolidate the decisions taken for the architectural planning, which may consequently contribute to reach the desired quality. The architecture will behave as another instrument in the process to obtain high quality efficient Urgency and Emergency Units with regards to spatial and operational aspects. Which will provide to those centers resoluteness, productivity and mainly turning them more human. Besides the considerations brought up, the proposal of this dissertation is also to contribute as research source and open discussions about the subject, even though, little was explored and developed with regards to the varied aspects involved with the planning of the health centers buildings environment.

\section{Key Words}

Hospitalar Architecture. Urgency and Emergency Units. Planning Guilines. Efficiency. Humanizing the Space. Hospital Environment. 



\section{Lista de Figuras}

Figura 1 - Planta Monastério de Cluny, França (1082). 50

Figura 2 - Perspectiva Monastério de Cluny $\quad 51$

Figura 3 - Hôtel-Dieu, França, 829 (séc. IX) 52

Figura 4 - Interior Hôtel-Dieu

Figura 5 - Planta Hospital Santo Espírito de Lubeck, 1286

Figura 6 - O Hospital da Renascença - Ospedale Maggiore, Milão, Itália (1460) 54

Figura 7 - Internação - Interior Ospedale Maggiore $\quad 54$

Figura 8 - Fachada - Ospedale Maggiore $\quad 55$

Figura 9 - Planta hospital projetado pelo arquiteto Fürttenbach, Alemanha (1635). 55

Figura 10 - Planta hospital projetado pelo arquiteto Fürttenbach, Alemanha (1655). 56

Figura 11 - Planta Sanatório Illenau, Alemanha (1837-42) 56

Figura 12 - Planta Hospital Commision de B. Poyet para a Academia de Ciências, La Roquette,

França (1788) 57

Figura 13 - Planta hospital de 1.200 leitos por Tenon e Poyet, França (1787). 58

Figura 14 - Detalhe da planta hospital de 1.200 leitos por Tenon e Poyet, França (1787) 59

Figura 15 - Proposta de B. Poyet para o novo Hôtel-Dieu (1785) 59

Figura 16 - Detalhe da proposta de B. Poyet para o novo Hôtel-Dieu (1785) 59

Figura 17 - Fachada frontal - novo Hôtel-Dieu de B. Poyet 60

Figura 18 - O Hospital da Era Industrial - Hospital Lariboisière, França (1846) 61

Figura 19 - Planta Santa Casa de Misericórdia de São Paulo, $1884 \quad 61$

Figura 20 - John’s Hopkins Hospital, USA, 1876 (séc. XIX) 62

Figura 21 - Internação octogonal - John’s Hopkins Hospital 62

Figura 22 - Apartamento individual e privado - John’s Hopkins Hospital (1885) 62

Figura 23 - Apartamento para isolamento - John’s Hopkins Hospital (1885) 64

Figura 24 - Planta Unidade de Internação - Rigshospital, Copenhagen (1910) 64

Figura 25 - Planta pavimento térreo - Hospital Beaujon, França (1932). 65

Figura 26 - Vista Hospital Beaujon, França (1932). 65

Figura 27 - Planta 2o pavimento do Hospital Triboro, para tuberculosos, New York (1941) 66

Figura 28 - Vista do Hospital Triboro, para tuberculosos, New York (1941) 67

Figura 29 - Hospital Pediátrico em Ortopedia, New York (1944) 67

Figura 30 - Croqui Goldwater Memorial Hospital, New York (1937) 67

Figura 31 - Hospital das Clínicas da Universidade de São Paulo - USP, São Paulo, SP (1944) 68 
Figura 32 - Hospital Israelita Albert Einstein, projeto do arquiteto Rino Levi, São Paulo, SP

Figura 33 - Maternidade da Universidade de São Paulo, projeto do arquiteto Rino Levi, São Paulo,

SP, (1945)

Figura 34 - Hospital Antônio Cândido de Camargo, projeto do arquiteto Rino Levi, São Paulo, SP,

Figura 35 - Estudo de fluxos para o Instituto Central do Câncer (1947) 70

Figura 36 - Foto abertura do evento (1953) 70

Figura 37 - Esquema do Sistema Hierarquizado de Saúde $\quad 74$

Figura 38 - Planta pavimento térreo. $\quad 76$

$\begin{array}{ll}\text { Figura } 39 \text { - Maquete do hospital } & 77\end{array}$

Figura 40 - Vista externa Pronto Socorro Municipal de Santos (1977) 77

Figura 41 - Vista externa McMaster Health Sciences Centre (1973) 78

Figura 42 - Planta pavimento térreo McMaster Health Sciences Centre (1973) 79

Figura 43 - Sistemas estrutural e de instalações do McMaster Health Sciences Centre (1973) 80

Figura 44 - Hospital e Maternidade Vila Nova Cachoeirinha (1968) 80

$\begin{array}{ll}\text { Figura } 45 \text { - Maquete } & 81\end{array}$

$\begin{array}{lr}\text { Figura } 46-\text { Maquete } & 81\end{array}$

Figura 47 - Perspectiva. $\quad 82$

Figura 48 - Planta pavimento térreo $\quad 82$

Figura 49 - Hospital Municipal Regional de Ermelino Matarazzo, São Paulo, SP - vista externa

Figura 50 - Implantação $\quad 83$

Figura 51 - Planta pavimento térreo $\quad 84$

$\begin{array}{ll}\text { Figura } 52 \text { - Pátio interno coberto } & 84\end{array}$

Figura 53 - Corte Longitudinal $\quad 84$

Figura 54 - Superfícies coloridas - Caracterizar espaços internos 84

Figura 55 - Hospital São Francisco, Ribeirão Preto, SP - vista externa de sua ampliação. $\quad 85$

Figura 57 - Hospital São Francisco, Ribeirão Preto, SP - detalhe da estrutura metálica. $\quad 85$

Figura 56 - Hospital São Francisco, Ribeirão Preto, SP - vista externa.

Figura 58 - Vista interna Recepção e espera - Hospital São Francisco - Ribeirão Preto, SP 85

Figura 59 - Hospital de Doenças do Aparelho Locomotor Sarah Kubitschek, Brasília - DF 86

Figura 60 - Corte esquemático do hospital 86

Figura 61 - Vista terraço das enfermarias - Hospital Sarah Kubitschek $\quad 87$ 
Figura 62 - Vista do terraço das enfermeiras

Figura 63 - Hospital do Aparelho Locomotor Sarah Kubitschek, projeto do arquiteto João Filgueiras Lima (Lelé), Fortaleza, CE (1991) 87

Figura 64 - Hospital Walter C. MacKenzie Health Sciences Centre - Edmonton, Canadá $\quad 88$

Figura 65 - Implantação do hospital $\quad 89$

$\begin{array}{ll}\text { Figura } 68 \text { - Vista interna - átrio central } & 90\end{array}$

Figura 66 - Sistema estrutural - modulação $\quad 90$

Figura 67 - Sistemas mecânicos de instalações $\quad 90$

Figura 69 - Vista interna -átrio central $\quad 90$

Figura 70 - Unidade de Internação - pavimento tipo 91

Figura 71 - Sistema de expansibilidade - crescimento e locação alternada de módulos $\quad 91$

Figura 72 - Vista externa $\quad 92$

Figura 74 - Vista externa $\quad 92$

Figura 73 - Vista interna $\quad 92$

Figura 75 - Vista interna $\quad 92$

Figura 76 - Vista interna $\quad 93$

Figura 78 - VHospital Geral de Pedreira, SP - detalhe da escada 93

Figura 77 - Vista externa

Figura 79 - Hospital Geral de Pedreira, SP - vista externa do edifício 93

Figura 83 - Vista externa $\quad 94$

Figura 80 - Vista externa $\quad 94$

Figura 81 - Vista externa $\quad 94$

$\begin{array}{ll}\text { Figura } 82 \text { - Vista interna } & 94\end{array}$

$\begin{array}{ll}\text { Figura } 84 \text { - Vista externa } & 94\end{array}$

Figura 85 - Vista externa $\quad 95$

Figura 86 - Vista externa $\quad 95$

Figura 87 - Vista externa $\quad 95$

Figura 88 - Vista interna $\quad 95$

Figura 89 - Croqui esquemático: organização de fluxos de urgência e emergência 133

Figura 90 - Croqui esquemático: fluxos de emergência cardiovascular $\quad 135$

Figura 91 - Croqui esquemático: fluxos de emergência em ortopedia e trauma 138

Figura 92 - Croqui esquemático: fluxos de emergência em obstetrícia 140

Figura 93 - Croqui esquemático: fluxos de emergência em pediatria 143

Figura 94 - Edinburg Children’s Hospital, Texas, USA 144 
Figura 96 - Croqui esquemático: organização do sistema de urgência e emergência e fluxos operacionais

Figura 97 - Croqui esquemático: sala de espera infantil e fraldário

Figura 98 - Croqui esquemático: fluxo, mobiliário e equipamentos sala de emergência 166

Figura 99 - Croqui esquemático: fluxo, mobiliário e equipamentos sala de emergência 167

Figura 100 - Croqui esquemático: zonas de atuação da equipe de assistência 168

Figura 101 - Ambulatory Care Center - University of North Carolina, Chapel Hill, North Carolina, USA

Figura 102 - Croqui esquemático: sala de procedimentos assépticos/suturas

Figura 103 - Croqui esquemático: sala de gesso, imobilização e redução de fraturas

Figura 104 - Hospital São Luiz / Anália Franco - sala de medicação

Figura 105 - Croqui esquemático: sala de conforto dos pais e acompanhantes

Figura 106 - Croqui esquemático: sala de atendimento aos familiares $\quad 179$

Figura 107 - Croqui esquemático: sala de coleta laboratorial 183

Figura 108 - Hospital São Luiz / Anália Franco - área de observação e repouso adultos 184

Figura 109 - Hospital Universitário, Londrina, PR - área de observação e repouso pediatria 185

Figura 110 - Croqui esquemático: posto de enfermagem, serviço e prescrição médica 187

Figura 111 - Croqui esquemático: depósito de materiais, medicamentos e arsenal 190

Figura 112 - Localização geográfica do centro urbano e espaço rural do município de Londrina

Figura 113 - Área de abrangência das unidade de saúde localizadas no espaço urbano de Londrina

Figura 114 - Distribuição espacial dos serviços de urgência e emergência analisados no espaço urbano de Londrina - 2010

Figura 115 - Hospital Universitário Regional Norte do Paraná, HU - vista aérea

Figura 116 - Implantação - Unidade de Urgência e Emergência no contexto hospitalar

Figura 117 - Hospital Universitário Regional Norte do Paraná, HU - vista externa

Figura 118 - Fases de Implantação do complexo hospitalar

Figura 119 - Implantação geral

Figura 120 - Planta - Pavimento inferior

Figura 121 - Planta - Pavimento Térreo

Figura 122 - Planta - Pavimento Superior

Figura 123 - Planta - Unidade de Urgência e Emergência 
Figura 125 - Recepção e espera adultos

Figura 126 - Posto de enfermagem (observação e repouso)

Figura 127 - Sala de observação e repouso pediatria

Figura 128 - Sala de observação e repouso gineco-obstetrícia

Figura 129 - Sala de observação e repouso adultos

Figura 130 - Fluxos externos e internos da Unidade de Urgência e Emergência

Figura 131 - Implantação geral

Figura 132 - Planta subsolo

Figura 133 - Planta - Pavimento térreo

Figura 134 - Planta - $1^{\circ}$ Pavimento

Figura 135 - Planta - 2 Pavimento

Figura 136 - Planta - $3^{\circ}$ Pavimento

Figura 137 - Fluxos externos e internos da Unidade de Urgência/Emergência

Figura 138 - Planta - Unidade Urgência/Emergência

Figura 139 - Perspectiva 1

Figura 140 - Perspectiva 2

Figura 141 - Niagara Health System - vista aérea: estágio da obra (2011)

Figura 142 - Hospital e Maternidade São Luiz / Anália Franco - vista aérea

Figura 143 - Hospital São Luiz/ Anália Franco - vista geral do edifício

Figura 144 - Entrada da Unidade de Urgência e Emergência

Figura 145 - Proposta esquemática do sistema estrutural empregado

Figura 146 - Proposta esquemática do sistema estrutural empregado

Figura 147 - Fluxos externos e internos da Unidade de Urgência e Emergência

Figura 148 - Entrada à Unidade - fluxo de urgência

Figura 149 - Entrada à Unidade - fluxo de emergência

Figura 150 - Planta - Unidade de Urgência e Emergência

Figura 151 - Sala de emergência (três boxes)

Figura 152 - Sala de suturas

Figura 153 - Posto de enfermagem

Figura 154 - Sala de emergência pediátrica

Figura 155 - Área de observação e repouso adulto 300

Figura 156 - Área de observação e repouso pediátrica

Figura 157 - Macrozoneamento e Sistema Operacional Unidade de Urgência e Emergência 303

Figura 158 - Vista dos shafts para instalações prediais 
$\begin{array}{ll}\text { Figura } 159 \text { - Vista do atrium central } & 308\end{array}$

$\begin{array}{ll}\text { Figura } 160 \text { - Vista do corredor interno } & 308\end{array}$

Figura 161 - Área de medicação e inalação pediátrica 309

Figura 162 - Croqui planta Hospital Sarah/ Brasília, DF 315

Figura 163 - Croqui corte esquemático/ perspectiva do Hospital Sarah/Brasília, DF 315

Figura 164 - Disciplina de fluxos e hierarquia dos eixos internos de circulação 331

Figura 165 - Fatores intervenientes no conforto ambiental das edificações 349

Figura 166 - Esquema explicativo do sistema de ventilação do Hospital Sarah - Salvador, BA 351

Figura 167 - Dartmouth-Hitchcock Medical Center, Lebanon/New Hampshire, USA 355

Figura 168 - St. Vincent Hospital West Pavilion, Portland/Oregon, USA 355

Figura 169 - Hospital de Mestre - Mestre/Veneza, Itália 357

Figura 170 - Hospital Infantil Sabará - São Paulo, SP 358

Figura 171 - Hospital Infantil Sabará - São Paulo, SP 358

Figura 172 - Children's Hospital at Yale New Haven Hospital, New Haven/Connecticut, USA 371 


\section{Lista de Siglas}

ABNT - Associação Brasileira de Normas Técnicas

AIS - Ação Integrada de Saúde

APO - Avaliação Pós-ocupação

APP - Área de Preservação Permanente

ATLS - Advanced Trauma Life Support

AVC - Acidente Vascular Cerebral

AVE - Acidente Vascular Encefálico

CAP - Caixa de Aposentadoria e Pensão

CAPS - Centro de Atenção Psicossocial

CCS - Centro de Ciências e Saúde

CEBES - Centro Brasileiro de Estudo em Saúde

CEM - Central de Esterilização de Material.

CEME - Central de Medicamentos

CIH - Comunicação de Internação Hospitalar

CONASP - Conselho Consultivo de Administração de Saúde Previdenciária

CPMF - Contribuição Provisória sobre a Movimentação Financeira

CURM - Central Única de Regulação Médica

DML - Depósito de Material de Limpeza

DMMH - Depósito de Material Médico-Hospitalar

DCV - Doença Cardiovascular

DATAPREV - Empresa de Processamento de Dados da Previdência Social

DNSP - Departamento Nacional de Saude Publica.

EAS - Estabelecimentos Assistenciais de Saúde

FUNRURAL - Fundo de Assistência ao Trabalhador Rural

GT - Grupo Técnico

IAP - Instituto de Aposentadoria e Pensão

IPMF - Imposto Provisório sobre Movimentação Financeira

IAM - Infarto Agudo do Miocárdio

IBC - Instituto Brasileiro do Café

IAPAS - Instituto de Administração da Previdência e Assistência Social

IAB - Instituto de Arquitetura Brasileira 
IASPI - Permanente Suplementary Artificial Lighting for Interior

INPS - Instituto Nacional da Previdência Social

INAMPS - Instituto Nacional de Assistência Médica da Previdência Social

IRC - Índice de Reprodução das Cores

LBA - Legião Brasileira de Assistência

MS - Ministério da Saúde

MOHLTC - Ministry of Health and Long Term Care

NHS - Niagara Health System

NRCC - Niagara Regional Cancer Centre

NOB - Normas de Operações Básicas

NOAS / SUS - Norma Operacional de Assistência à Saúde

OMS - Organização Mundial da Saúde

ONU - Organização das Nações Unidas

PCP - Parada Cardiopulmonar

PCR - Parada Cardiovascular Respiratória.

PNAD - Pesquisa Nacional por Amostra Domiciliar

PNE - Pessoas com Necessidades Especiais

PDC - Planning Desing and Compliance

PPA - Plano de Pronta Ação

PNS - Plano Nacional de Saúde

PGRSS - Plano de Gerenciamento de Resíduos dos Serviços de Saúde

PNH - Política Nacional de Humanização

PNHAH - Programa Nacional de Humanização de Assistência Hospitalar

PPP - Pré-parto, Pós-parto e Puerpério

PBL - Problem Based Learning

PACS - Programa de Agentes Comunitários de Saúde

PSF - Programa Saúde da Família

QUALISUS - Programa de Qualificação de Atenção as Urgências

RCP - Recuperação Cardio-pulmonar

RTP - Regional Traffic Planning

RFP - Request for Proposal

SE - Sala de Estabilização

SAMU - Serviço de Atendimento Móvel de Urgência

SND - Serviço de Nutrição e Dietética 
SOMASUS - Sistema de Apoio à Organização e Elaboração de Projetos e Investimentos em Saúde

SIATE - Serviço Integrado de Atendimento ao Trauma e Emergência

SINPAS - Sistema Nacional de Previdência Social

SUS - Sistema Único de Saúde

SNDS - Sistema Unificado e Descentralizado de Saúde

SAVT - Suporte Avançado de Vida ao Trauma

SBV - Suporte Básico de Vida

UBS - Unidade Básica de Saúde

UPA - Unidade de Pronto Atendimento

UTI - Unidade de Terapia Intensiva

USP - Universidade de São Paulo

UEL - Universidade Estadual de Londrina 

Sumário

I INTRODUÇÃO

I.I Objeto 35

1.2 Objetivos 39

$\begin{array}{ll}1.3 \text { Justificativas } & 40\end{array}$

I.4 Hipóteses 42

1.5 Descrição dos Capítulos 43

2 ARQUITETURA HOSPITALAR $\quad 47$

2.I Evolução Histórica do Edifício Hospitalar 49

3 POLIITICA BRASILEIRA DE ATENÇÃO À SAÚDE E SUAS TRANSFORMAÇÕES AO LONGO DO SÉCULO XX E INÍCIO DO SÉCULO XXI 97

3.I Evolução histórica, política e social e os modelos assistenciais de saúde no Brasil 99

3.2 A Lei Orgânica de Saúde e o SUS - Sistema Único de Saúde 105

$\begin{array}{ll}3.3 \text { Unidade de emergência - primeiras abordagens } & 107\end{array}$

$\begin{array}{ll}3.4 \text { Política nacional de atenção às urgência e emergências } & 109\end{array}$

3.5 Atual perfil do serviço de emergência ॥8

4 UNIDADE DE URGÊNCIA E EMERGÊNCIA PARA ATENDIMENTO DE ALTA COMPLEXIDADE $\quad 125$

4.I Conceituação 127

4.2 Tipologia por Característica de Atenção à Saúde |3|

4.2.I Unidade de Urgência e Emergência geral |3|

4.2.2 Unidade de Urgência e Emergência Cardiovascular I33

4.2.3 Unidade de Urgência e Emergência em Ortopedia e Trauma 136

4.2.4 Unidade de Urgência e Emergência em Obstetricia 138

4.2.5 Unidade de Urgência e Emergência em Pediatria 141

4.2.6 Unidade de Urgência e Emergência em Saúde Mental 144

\section{ASPECTOS FUNCIONAIS E OPERACIONAIS DOS ESPAÇOS QUE COMPÕEM A} UNIDADE DE URGÊNCIA E EMERGÊNCIA 149

5.I Subsistema de recepção, acolhimento e registro do paciente 158

5.I.I Entrada de veículos e pedestres/ estacionamento para veículos, motos e ambulâncias 158

5.I.2 Área de embarque e desembarque de pacientes $\quad 159$

5.I.3 Saguão/Salas de Espera para pacientes, familiares e acompanhantes $\quad 159$

5.I.4 Sanitários de público 163 
5.1.5 Estacionamento de macas e cadeiras de rodas

5.2 Subsistema de atendimento ao enfermo e familiares 164

5.2.I Sala de acolhimento com avaliação e classificação de risco 164

5.2.2 Sala de emergência $\quad 165$

5.2.3 Sala de higienização do paciente $\quad 169$

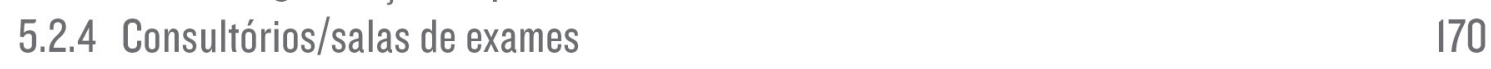

5.2.5 Salas de esperas intermediárias $\quad 170$

$\begin{array}{lll}5.2 .6 & 5.2 .6 \text { Sala do serviço social } & 171\end{array}$

5.2.7 Salas de procedimentos sépticos $\quad 171$

5.2.8 Sala de procedimentos assépticos/suturas $\quad 172$

5.2.9 Salas de pequenas cirurgias/procedimentos invasivos $\quad 173$

5.2.10 Sala de gesso, imobilização e redução de fraturas $\quad 175$

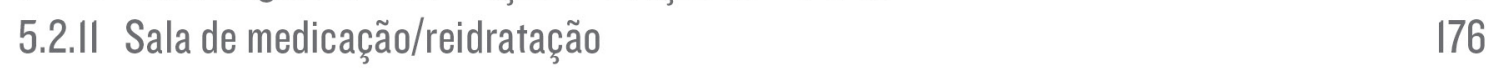

5.2.12 Sala de inalação/nebulização 176

5.2.13 Área de conforto dos pais e acompanhantes 177

5.2.14 Sala de atendimento a familiares $\quad 178$

5.3 Subsistema de apoio ao diagnóstico e tratamento 180

5.3.1 Sala de Exames Radiológicos 180

5.3.2 Sala de Exames de ultrassom $\quad$ |81

5.3.3 Sala de Eletrocardiografia contínua (Holter) 182

5.3.4 Sala de endoscopia alta 182

5.3.5 Laboratório de Urgência em Análises Clínicas 182

5.4 Subsistema de observação e repouso 183

5.5 Subsistema de apoio logístico e operacional 186

5.5.I Posto de enfermagem, serviço e prescrição médica 186

5.5.2 Estar médicos/quarto plantonistas $\quad 188$

5.5.3 Conforto de enfermagem e equipe de colaboradores 189

5.5.4 Salas de chefia médica e enfermagem $\quad 189$

5.5.5 Salas de discussão de casos $\quad 189$

5.5.6 Depósito de materiais/arsenal 190

5.5.7 Sala para guarda de equipamentos $\quad 191$

5.5.8 Expurgo ou sala de utilidades 192

5.5.9 Depósito de roupa suja e resíduos 192

5.5.10 Rouparia 193

5.5.II Sala de guarda de Hemocomponentes 193

5.5.12 Depósito de material de limpeza 194

5.5.13 Copa para pacientes 194

5.5.14 Área de guarda de pertences dos pacientes 195

5.5.15 Sala de estar para motoristas de ambulâncias 195 


\section{ESTUDOS DE CASOS}

6.I Hospital Universitário Regional Norte do Paraná (UEL) Londrina - PR 199

6.I.I Introdução 199

6.I.2 A unidade hospitalar no contexto urbano e sua inserção no sistema de saúde $\quad 209$

6.I.3 Implantação e fluxo externos 209

6.I.4 A Unidade de Urgência e Emergência no contexto do complexo hospitalar. 225

6.1.5 Estrutura física instalada. 229

6.1.6 Conformidade 233

6.I.7 Relação de Contiguidade e Fluxos Internos 234

6.1.8 Acessibilidade 238

6.1.9 Flexibilidade / Expansibilidade 239

6.I.10 Tecnologia ofertada. 240

6.I.II Sustentabilidade. 240

6.I.12 Conforto térmico e acústico 241

6.I.I3 Iluminação natural e artificial $\quad 242$

6.I.14 Humanização 243

6.2 Unidade de Urgência e Emergência (Niagara Health System) 244

6.2.I Introdução 244

6.2.2 O papel da Empresa Cannon Design 244

6.2.3 Localização do empreendimento 245

6.2.4 Niagara Health System 246

6.2.5 Memorial Explicativo sobre o Plano de Negócio - Niagara Health System 246

6.3 Unidade de Urgência e Emergência em alta complexidade (Hospital São Luiz/Anália Franco - São $\begin{array}{ll}\text { Paulo-SP) } & 287\end{array}$

6.3.I Introdução 287

6.3.2 A unidade hospitalar no contexto urbano 288

6.3.3 Concepção e Volumetria 289

6.3.4 Implantação e fluxos externos 290

6.3.5 A Unidade de Urgência e Emergência no contexto do complexo hospitalar 293

6.3.6 Relação de contiguidade funcional e fluxos internos 301

$\begin{array}{ll}6.3 .7 \text { Acessibilidade } & 305\end{array}$

6.3.8 Flexibilidade e Expansibilidade espacial 306

$\begin{array}{ll}6.3 .9 \text { Tecnologia ofertada } & 307\end{array}$

$\begin{array}{ll}\text { 6.3.10 Sustentabilidade } & 307\end{array}$

6.3.II Humanização 308 


\section{DIRETRIZES PROJETUAIS NA GERAÇÃO DA ARQUITETURA PARA UNIDADES DE}

URGÊNCIA E EMERGÊNCIA

7.I A Inserção da Unidade de Urgência e Emergência no Contexto Político de Atenção a Saúde do Paciente em Estado Crítico

7.2 A Inserção da Unidade de Urgência e Emergência no Contexto Urbano 317

7.3 A Inserção da Unidade de Urgência e Emergência na Abrangência do Lote 321

7.4 Fluxos Externos 323

7.5 Programa Físico-Funcional $\quad 324$

7.6 Macrozoneamento / Setorização 327

7.7 Relacionamento com Outras Unidades do Complexo Hospitalar 328

7.8 Circulação e Fluxos Internos à Unidade de Urgência e Emergência 328

7.9 Plano Diretor de Organização e Expansão Física 334

7.10 Expansibilidade e Flexibilidade Espacial 335

$\begin{array}{ll}7.11 & \text { Conformidade } \\ 740\end{array}$

7.12 Arquitetura e Infecção Hospitalar 340

7.13 Ergonomia e Acessibilidade $\quad 344$

7.14 Conforto Ambiental 348

7.14.1 Conforto Térmico 350

7.14.2 Conforto Acústico 352

7.14.3 Conforto Visual $\quad 354$

7.15 Tecnologia 361

$\begin{array}{ll}7.16 \text { Sustentabilidade } & 367\end{array}$

$\begin{array}{ll}7.17 \text { Humanização } & 370\end{array}$

8 CONCLUSÃO

9 REFERÊNCIAS BIBLIOGRÁFICAS 381 


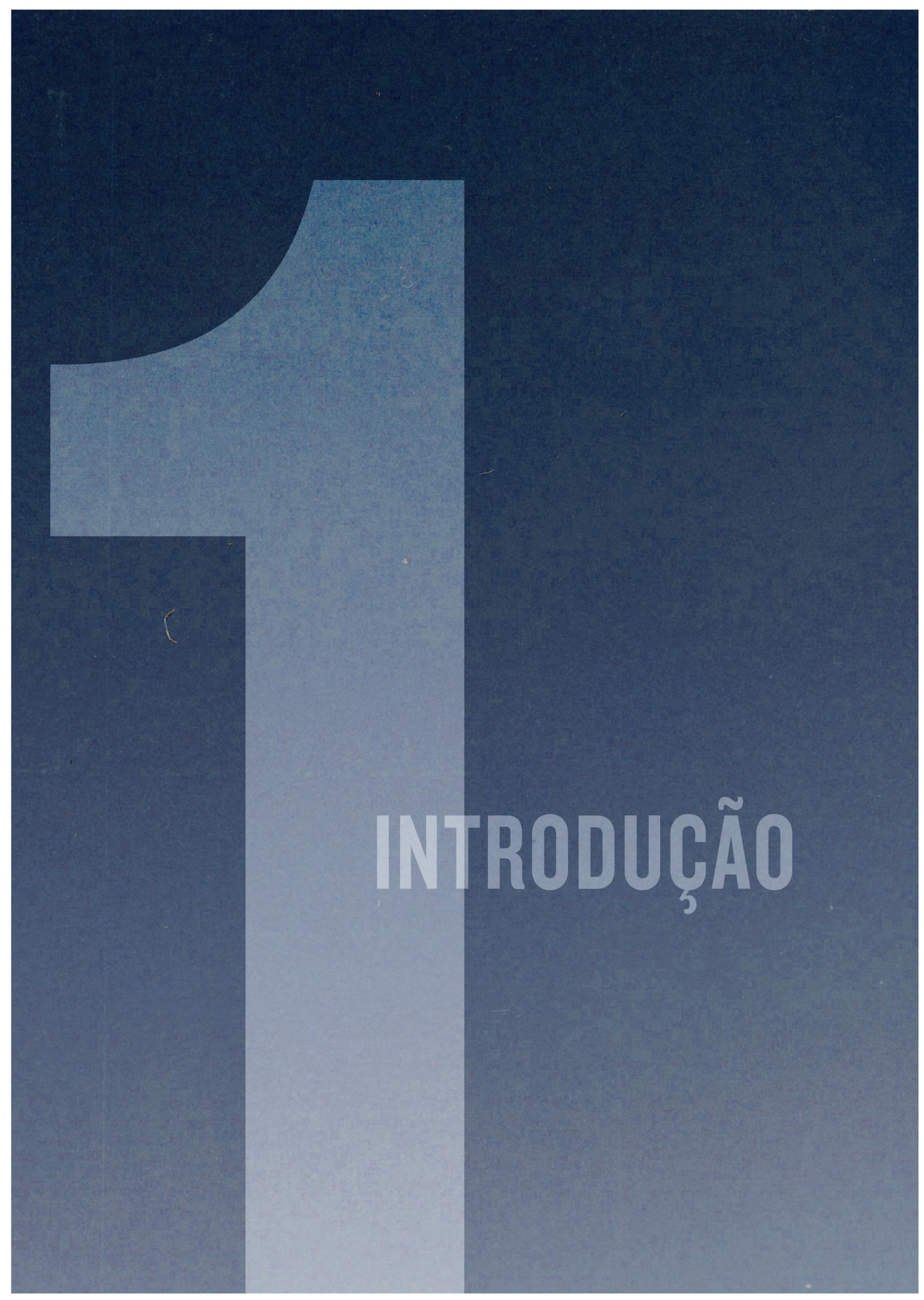



O edifício hospitalar tem se tornado um desafio para todos os profissionais de arquitetura no sentido de aglutinar todas as variações interferentes na sua complexa estrutura, onde a integração entre o edifício e o seu meio urbano, o interrelacionamento entre suas diversas unidades, os rápidos avanços tecnológicos e as grandes conquistas da medicina, direcionamnos para uma arquitetura extremamente racional. Porém, a sensibilidade do arquiteto é o meio conciliador de todas estas variáveis com as necessidades de o homem se relacionar com os espaços que utiliza.

A concepção, o dimensionamento e a organização do meio ambiente hospitalar têm sofrido muitas mudanças. A complexidade do programa físico, o perfeito agrupamento de serviços afins, os diversos fluxos de circulação interna e externa, conforto térmico, acústico e visual, legislação vigente, flexibilidade e expansibilidade espacial, instalações especiais, bioengenharia, alta tecnologia, sustentabilidade, segurança, infecção hospitalar, central de monitoração/ergonomia, acessibilidade, shafts etc., tudo isso impõe aos profissionais envolvidos uma visão sistêmica sobre o conjunto de variáveis e total conhecimento da área, por meio da sua experiência, competência e sensibilidade.

Os hospitais existentes, na maioria dos casos, ao invés de proporcionarem espaços agradáveis e convidativos aos seus 
usuários, parecem aliená-los ou intimidá-los. São projetados como que para mostrar poder ou força contra as doenças, provocando uma arquitetura ostensiva e bloqueadora das relações humanas, como se sofresse de uma distemia crônica. A linguagem do edifício é estranha para a maioria das pessoas. Sua imagem é seguramente de um lugar angustiante, onde se enfrenta a vida e a morte constantemente; onde obriga as pessoas a um confronto com as emoções e incertezas nos momentos mais críticos da existência humana: sofrimento profundo, dor, doença, ansiedade, vulnerabilidade, angústia e risco de morte.

O esforço na humanização dos espaços deve ser permanente, pois há a necessidade de melhorar as condições de alojamento, tratamento e sociabilização das relações humanas. Este nível de preocupação é o que possibilita o rompimento com a imagem do edifício hospitalar do passado, onde através de longos corredores, espaços confinados, escuros e/ou sombrios provocam, de alguma forma, a sensação de insegurança e medo.

A responsabilidade da intervenção do profissional arquiteto neste processo é muito grande. Somente com os cuidados de um projeto bem elaborado, respaldado na competência e na sensibilidade de se criar espaços que possam contribuir de maneira satisfatória na melhoria do bem-estar dos usuários, proporcionando espaços mais educados e inteligentes, formas mais positivas que reduzam, assim, ansiedades.

Segundo Toledo (2005, p. 13), no processo de humanização, a arquitetura poderá contribuir oferecendo ao usuário o domínio do seu espaço, por meio de uma escala adequada, e ainda utilizar os recursos da luz, som, ritmo, cores e texturas, permeabilidade visual no sentido de enriquecimento dos espaços, tornando-os mais íntimos, acolhedores e agradáveis.

Nesta linha de raciocínio é que o trabalho de pesquisa se apresenta. Primeiramente pela particularidade e especificidade em que a Unidade de Urgência e Emergência possui, mas também pela procura da qualidade conceitual dos projetos hospitalares, nos quais visa colocar o homem como o centro das preocupações.

As dificuldades de implantar princípios de humanização espacial nas Unidades de Urgência e Emergência são sempre maiores. Não somente pelo estado crítico em que se encontra o paciente, que na maioria das vezes corre risco de morte, mas também porque a sua relação com o meio ambiente hospitalar 
é de aversão, repulsa e ansiedade. O paciente não tem, naquele momento, qualquer relação de afetividade com o meio ambiente. É o momento de insegurança, vulnerabilidade e estresse à flor da pele. Para a equipe de médicos e paramédicos é também um momento de procedimentos claros e precisos, quase que matemáticos.

O tempo, percurso, agilidade, oferta de tecnologia, produtos médico-hospitalares e instalações adequadas são, em grande parte, fatores decisivos no sucesso do atendimento.

Neste quadro adverso e conturbado é que se encontra a particularidade da Unidade de Urgência e Emergência no contexto hospitalar, onde este trabalho visa aprofundar o conhecimento, mediante análises e propostas de diretrizes projetuais que venham a dar suporte aos profissionais envolvidos com a área, em especial o arquiteto, para que se obtenha um projeto arquitetônico desta unidade em estudo, com reconhecida eficiência e qualidade espacial.

Este serviço de atenção à saúde está subdividido pela sua crescente complexidade, sendoas unidades dePronto Atendimento (UPAS/Programa Qualisus), Unidades de Urgência e Emergência de baixa e média complexidade em hospitais do mesmo nível de assistência e as Unidades de Urgência e Emergência de alta complexidade, o foco e objeto desta pesquisa.

\section{I.I Objeto}

A produção da arquitetura no campo hospitalar no Brasil e no mundo, até o início dos anos 1960, é claramente identificada com a sobreposição dos aspectos funcionais e técnicos em relação à composição plástica do edifício. Este desequilíbrio promoveu uma produção arquitetônica, embora bastante funcional, mas também pouco criativa e espacialmente pobre, dura e árida.

Ao final da década de 1960, já com os primeiros ensaios da discussão e a aplicabilidade de novos conceitos sobre a relação médico/paramédicos com o paciente, iniciou-se a implantação do sistema de humanização nos serviços de atendimento ao enfermo.

À reboque desta nova visão, a arquitetura também obteve a oportunidade de rever seus conceitos de projeto, procurando 
agregar valores na geração dos espaços, possibilitando, desta forma, com que sejam mais agradáveis e acolhedores. Hoje, nesta linha de raciocínio, discute-se sobre a produção da arquitetura terapêutica, na qual se propõe que a qualidade espacial possa contribuir de forma significativa no processo de cura do paciente.

Tem-se aplicado esta proposta no complexo hospitalar e não somente nas áreas de atendimento ao público. Percebe-se também a necessidade de se estender estas preocupações a todo o grupo operacional, tendo em vista o permanente "clima" de intenso estresse durante o desempenho das suas atividades funcionais.

$\mathrm{Na}$ Unidade de Urgência e Emergência de alta complexidade, em particular, estas questões afloram de uma forma bastante intensa. Não somente pela gravidade e complexidade dos casos que chegam à unidade, mas também pelo crescente sentimento de angústia, ansiedade, insegurança e vulnerabilidade que o momento representa.

Estas unidades estão sempre agregadas ao complexo hospitalar e se utilizam desta estrutura de forma decisiva, quase que invariavelmente de unidades como: centro cirúrgico, obstétrico, unidades de terapia intensiva, centro de diagnóstico por imagem e análises clínicas e citológicas. Necessitam ainda, incondicionalmente, de unidades de apoio logístico, como: lavanderia, serviço de nutrição e dietética, almoxarifado, farmácia, esterilização de material, entre outros.

A Unidade de Urgência e Emergência de alta complexidade, acoplada aos hospitais gerais, tem um perfil de atendimento bastante amplo, isto é, a qualquer tipo de patologia clínica e/ ou cirúrgica. Porém, tem-se desenvolvido junto aos hospitais especializados outras tipologias destes serviços, tais como as Unidades de Urgência e Emergência em Ortopedia e Traumatologia, Cardiovascular, Obstétrica, Pediátrica, Saúde Mental, entre outras. Esta tendência cada vez mais se direciona a este modelo de atendimento, tendo em vista alguns particulares importantes, que se justificam de forma consistente, não somente pelo preparo, formação e qualificação da equipe de profissionais envolvida, mas também pelas características e perfil da população brasileira.

Segundo dados do IBGE (2008), - Data SUS (Documentação do Sistema Único de Saúde / M.S.) e Denatran (Departamento 
Nacional de Trânsito -, o Brasil possui o maior índice de mortes no trânsito do mundo, acima de 35.000 ocorrências por ano, o que representa em torno de 100 ocorrências/dia e acima de 04 mortes por hora. Por esta razão, é justificada a criação de Unidades de Emergência em traumas, principalmente, junto às áreas, constatadamente, de alto risco.

Sem dúvida, a geração de novos serviços nesta especialidade médica e a arquitetura lidam apenas com as consequências. Fatores como o alcoolismo, o desrespeito às leis de trânsito, excesso de velocidade, inobservância à sinalização urbana, baixa qualidade dos sistemas viários municipais e intermunicipais são as principais causas deste quadro estatístico de lamentável constatação.

Outro índice expressivo nos quadros estatísticos, segundo o IBGE (2008), é a proporção de mortes por causas violentas (homicídios, suicídios, latrocínios e acidentes de trânsito), entre os adolescentes e jovens, na faixa etária de 15 a 19 anos, essa taxa é de $68 \%$. A região Sudeste tem a maior taxa, em que $73 \%$ dos óbitos dessa faixa etária estão relacionadas a causas violentas.

Segundo dados divulgados pela ONG - Human Rights Watch/ Reporter Brasil - Agência de Notícias, ocorrem aproximadamente 50.000 homicídios por ano, o que representa 4160 ao mês, 138 ocorrências diárias e 06 mortes por hora, ou ainda, sendo mais drástico, 01 morte a cada 10 minutos.

As doenças cardiovasculares são também responsáveis pela grande demanda às Unidades de Urgência e Emergência, no Brasil e em todo o mundo.

Segundo Ishitani (2006, p. 01),

As doenças cardiovasculares (DCV) representam a primeira causa de morte no Brasil. Apesar da tendência de redução dos riscos de mortalidade por DCV no país e no mundo, algumas projeções indicam o aumento de sua importância relativa em países de baixa e média renda. A maior longevidade, associada ao possível aumento de sua importância das DCV por adoção de modos de vida com maior exposição a fatores de risco, são consideradas as principais razões deste incremento. Como fatores de risco estão o tabagismo e a inatividade física, além de dieta rica em gorduras saturadas, como conseqüente aumento dos níveis de colesterol e hipertensão. 
$\mathrm{Na}$ abrangência do atendimento às emergências, têm-se ainda momentos críticos, de comoção nacional ou até mundial. Casos como o vírus RNA-Ebola (Zaire/1976), vírus HIV/Aids (USA/1981) no início dos anos 1980, vírus H5N1-gripe aviária (China/1997), e vírus H1N1-gripe A (México/2009) provocaram grande afluxo de pacientes às Unidades de Emergência em todo o mundo.

No Brasil, a dengue tem se tornado um dos principais problemas de Saúde Pública. Esta doença, com alto índice de mortalidade, especialmente hemorrágica, ocorre com frequência após longos períodos de chuvas, em que atinge o seu maior nível de disseminação. Fatores como esses têm gerado e contribuído ainda mais para o já conturbado dia a dia das Unidades de Emergência.

Como agravante, tem-se ainda a grande distorção, mutilação e sucateamento do modelo de atenção à saúde brasileira. Proposto de forma piramidal, hierarquizado pelo nível de complexidade do seu atendimento, tem sido ao longo das ultimas décadas totalmente deturpado o seu papel na estrutura da saúde pública. Pelo não cumprimento ao que se estabelece no atendimento de enfermidades de baixa e/ou médias complexidades, os pacientes têm procurado os serviços terciários (alta complexidade) para a resolução dos seus problemas.

Isto, de forma significativa, tem acarretado a superlotação nas unidades, o aumento do estresse, cansaço e desânimo dos grupos operacionais e, por consequência, proporcionado reflexos negativos e deturpados na organização física das unidades em foco.

Neste contexto, em alguns casos bastante caótico e dilacerados, com a abrangência do atendimento nas diversas tipologias junto às Unidades de Urgência e Emergência de alta complexidade, é que o trabalho se apresenta com o objetivo de aprofundar o conhecimento e, assim, possibilitar a discussão e a geração de propostas e alternativas para a resolução da arquitetura, e de alguma forma contribuir para a melhoria da qualidade espacial da unidade em tela. 


\subsection{Objetivos}

A relação entre pacientes e o edifício hospitalar como um todo tem sido palco de inúmeros estudos por diversos profissionais envolvidos na área da saúde. Porém, a Unidade de Urgência e Emergência, dentro da contextualização exposta anteriormente, necessita de um estudo mais aprofundado, com o objetivo de detalhar e depurar as particulares que afetam os procedimentos realizados no campo do atendimento emergencial e seu envolvimento com o meio físico hospitalar.

O objetivo deste trabalho é desenvolver, mediante análises e proposições sobre diretrizes projetuais, o auxílio aos arquitetos para uma escolha mais facilitada de decisões e a aplicabilidade das propostas relacionadas ao meio físico das Unidades de Urgência e Emergência de alta complexidade.

Esta pesquisa centraliza-se nos diversos espaços que compõem a unidade em foco, os quais têm de ser definidos pelos arquitetos na fase da concepção do projeto, conectando assim as regras de uso com elementos relevantes dos espaços nos aspectos de funcionalidade, contiguidade, técnicos, escala, conforto térmico, acústico, visual, entre outros.

Complementarmente, a pesquisa visa um olhar mais abrangente sobre a unidade em estudo, procurando não delimitála geograficamente. A análise passa por uma visão contextualizada do complexo hospitalar, macrozoneamento espacial, programa físico-funcional, resoluções e normas vigentes, diversa tipologias de atendimento, relação espacial entre usuários e ambiente hospitalar construído. Além disso, procura-se compreender o atual momento da produção da arquitetura hospitalar, por meio da leitura de diversos exemplos de unidades de urgência e emergência em alta complexidade, implantadas em cidades brasileiras com diferentes portes, bem como uma unidade de emergência em fase de implantação, no Canadá.

Procura-se, assim, com este estudo, abrir a oportunidade de oferta e contribuição para a discussão na atividade profissional do arquiteto, mas também e, principalmente, estimular e alimentar o ensino acadêmico, promovendo a reflexão sobre o tema. 


\section{I.3 Justificativas}

Muito antes de focar a discussão em torno do Hospital e mais detalhadamente a Unidade de Urgência e Emergência de alta complexidade, é preciso compreender algumas interferências neste processo.

A primeira delas passa essencialmente pela formação acadêmica, que nos últimos 35 anos tem transformado não somente seu conteúdo como também a quantidade de profissionais formados. Isto não apenas na arquitetura, mas também nas diversas áreas de ensino.

$\mathrm{Na}$ área de arquitetura, disciplinas como comunicação visual, desenho do objeto (desenho industrial), cenografia e paisagismo faziam parte do conteúdo programático do ensino. Hoje, estas disciplinas tornaram-se praticamente cursos independentes. A formação mais abrangente do profissional arquiteto deu lugar a quase que exclusivamente ao projeto do edifício e/ou da cidade. Isto talvez se justifique pelo volume de informação ofertada e a real condição de assimilação, e, consequentemente, o conhecimento e domínio sobre o todo. Sem dúvida, esta discussão é tema para uma outra tese de doutorado.

Na medicina, como em outras áreas da saúde, procura-se alternativas metodológicas de ensino na busca de um melhor aprendizado. Como exemplo, o sistema PBL (Problem Based Learning), o qual se apoia na aquisição do conhecimento na resolução de fatos reais, e ainda aos problemas do dia a dia na atividade profissional. Além disso, ele está estruturado na formação de grupos de discussão e pesquisa, com a supervisão do professor da disciplina, na qual se procura esgotar as possibilidades e alternativas para o problema em análise.

Tradicionalmente, a formação médica vem cada vez mais direcionada para a formação do especialista. Este fato é reconhecido no mundo inteiro e assimilado como verdade. É fato consumado.

Edgar Graeff em uma palestra (1980), para uma plateia quase que predominantemente de arquitetos, fez uma observação curiosa de que dessa forma haveria no futuro o profissional médico do ouvido esquerdo e outro especializado no ouvido direito. Será que se chegaria a tanto? Seria um exagero? O que na 
essência se tem de verdadeiro nesta observação? A história dará as respostas.

$\mathrm{Na}$ arquitetura, este seguimento de especialistas na área hospitalar tem sido representado por profissionais de reconhecida capacidade como: Antonio Pedro Carvalho, Carlos Pompeu, Domingos Fiorentini, Giselda Visconti, Irineu Brietman, Jarbas Karman, João Carlos Bross, João Filgueiras Lima, Lauro Miquelin, Luis Carlos Toledo, Rino Levi, Roberto Cerqueira Cezar, Ziegbert Zanettini, entre outros.

O primeiro curso de Planejamento de Hospitais, ocorrido em abril de 1953 em São Paulo, pode ser considerado o marco inicial de referência na discussão da arquitetura hospitalar no Brasil. Nestes quase 60 anos de história, todos os profissionais citados acima, e tantos outros arquitetos que atuam nesta área por este Brasil afora, têm contribuído para aprofundar o conhecimento sobre o assunto.

Com a proliferação de cursos de graduação em arquitetura por todo o Brasil, e um número cada vez mais crescente de arquitetos formados, a área hospitalar tem sido o foco de atuação de diversos profissionais, não somente como "nicho de mercado", mas também atraídos pela complexidade e a apaixonante dinamicidade do tema.

Embora haja esta constatação de muitos profissionais envolvidos com a temática, pouca produção bibliográfica tem ocorrido. Mesmo as revistas mais conhecidas nacionalmente em arquitetura, como a Projeto Design, Finestra e $A U$, pouco tem explorado o assunto. A publicação de obras hospitalares tem sido matéria esporádica. Porém, com a realização de congressos na área e cursos de especialização, esta produção tende a aumentar.

Fora do Brasil, o tema tem sido mais frequentemente explorado, não somente por publicações de artigos, mas também na formação de grupos de estudos inseridos nas universidades, principalmente americanas e europeias.

Administradores hospitalares, economistas, médicos, enfermeiros, engenheiros, arquitetos, entre outros, têm avidamente buscado estas publicações com o intuito de ter o conhecimento sobre o conteúdo e também de perceber e discernir o grau de aplicabilidade no Brasil.

O cuidado com a "importação de modelos" deve estar sempre presente, procurando perceber o que efetivamente é benéfico 
para o processo que, sem dúvida, é de fundamental importância. Muitos desses "modelos", como a própria prática médica (pesquisa e procedimentos), a evolução do conhecimento, os avanços tecnológicos, transformação nos métodos de trabalho e a humanização do serviço, são experiências que vieram "de fora" para contribuir. No campo da arquitetura este perfil não é diferente.

Aos arquitetos, no campo físico, cabe-lhes a tarefa de proporcionar a adaptabilidade das soluções estrangeiras às reais condicionantes nacionais, como também aprimorá-las para o contexto da realidade brasileira.

A complexidade do tema, como abordada, requer ainda que o profissional arquiteto não se limite ao conhecimento do edifício na estreita visão do lote, mas extrapole o seu olhar e o enxergue na abrangência do contexto urbano, do seu entorno natural e edificado, na sua inserção no sistema de atenção à saúde ao nível municipal, estadual e federal.

$\mathrm{Na}$ prática profissional do arquiteto, quando da resolução do conteúdo programático e consequente desenvolvimento do projeto arquitetônico, há uma tendência muito forte em resolver as questões funcionais. Sem dúvida essas questões são de extrema importância para o bom desempenho da atividade médica e enfermagem, no entanto o arquiteto passa pela busca do ponto de equilíbrio do tripé estrutural da arquitetura: função, técnica e plástica (utilitas, firmitas, venustas).

Mediante o exposto, o tema é de relevante importância para um estudo mais depurado, considerando sua real aplicabilidade e abertura de discussão, e ainda para o futuro desdobramento de pesquisas sobre o assunto.

\section{I.4 Hipóteses}

Nesta pesquisa foram estabelecidas hipóteses de trabalho, com o propósito de orientar o seu desenvolvimento para que os objetivos supracitados pudessem ser atingidos. Tais hipóteses são apresentadas a seguir:

a) com a constante transformação na política nacional de saúde nas três esferas de gestão, procura-se refletir se a Unidade de Urgência e Emergência de alta complexidade está 
cumprindo o seu papel neste momento histórico, do ponto de vista assistencial, político, social e econômico e qual o seu reflexo sobre a arquitetura. Esta interface passa por contextualizar o que se estabelece como programa físico-funcional pela RDC $\mathrm{n}^{\circ} 50$ ANVISA - MS e a realidade das unidades em alta complexidade, não somente pela ordem numérica (dimensões mínimas e áreas), mas, principalmente, para o bom desempenho profissional e operacional;

b) com o aprofundamento dos estudos sobre a unidade, a conciliação e o equilíbrio entre a alta complexidade técnicaconstrutiva, a utilização de tecnologia de ponta em equipamentos e métodos de trabalho médico, e o processo de humanização dos espaços são utilizados para que possam efetivamente contribuir na recuperação do paciente. O caminho a ser percorrido será por meio de análise pormenorizada das diversas condicionantes/diretrizes projetuais que interferem no espaço físico da Unidade de Urgência e Emergência, de forma que possa ser um instrumento de apoio para profissionais e acadêmicos, principalmente em arquitetura, para se obter bons resultados em espaços adequados, acolhedores e, consequentemente, na geração de unidades eficientes e com melhores índices de desempenho e produtividade na saúde.

\subsection{Descrição dos Capítulos}

O desenvolvimento desta pesquisa está estruturado em oito capítulos, considerando-se a introdução como o primeiro. No capítulo 2, foi feita a análise da evolução da arquitetura do edifício hospitalar mediante sua história mundial e brasileira. O capítulo 3 caracteriza-se pela análise e contextualização do serviço de urgência e emergência no Brasil, por meio de normas, portarias e resoluções que estabelecem as diretrizes para todo o serviço e, em particular, a alta complexidade. No capítulo 4 foi feita uma análise mais específica sobre as Unidades de Urgência e Emergência de alta complexidade e sua tipologia pela característica de atenção à saúde. Já no capítulo 5 , foram analisados os diversos ambientes que integram a unidade em estudo, porém não somente os estabelecidos pelo programa físico-funcional mínimo da RDC n50/ANVISA, mas também outros que por diferentes necessidades funcionais, ou consequência das distorções do sistema de saúde municipal e/ou regional, complementam outros 
ambientes, de forma que a arquitetura dê respostas ao conforto e à humanização que o serviço requer. No capítulo 6 , foram feitas análises sobre três unidades de urgência e emergência, acopladas em hospitais de alta complexidade, com diferentes realidades; começando pela análise sobre o Hospital Universitário Regional Norte do Paraná, localizado em Londrina, cidade esta com aproximadamente 500.000 habitantes. A segunda análise feita foi sobre o Niagara Health System em construção em St. Catherine, região de Toronto/Ontário - Canadá, com a abrangência de aproximadamente 3.000.000 habitantes. O terceiro analisado foi o Hospital São Luiz/Anália Franco, localizado na cidade de São Paulo, capital.

Fizeram parte, ainda, do processo de estudos outras análises sobre Unidades de Urgência e Emergência não constantes neste trabalho, como: Santa Casa de Londrina, Hospital Mater Dei, Hospital Infantil de Londrina, Hospital Evangélico, Instituto do Câncer de Londrina, Hospital do Servidor de Curitiba, Santa Casa de Presidente Prudente, Hospital Unimed de Foz do Iguaçu, Pronto-Atendimento Infantil e Maternidade Municipal de Londrina, Policlínica Cascavel, Hospital São Lucas de Pato Branco e Cascavel, Hospital de Clínicas de Ribeirão Preto, Tulane University Medical Center - USA, Instituto de Psiquiatria em São Paulo, entre outros.

O capitulo 7 estabelece as diversas condicionantes e diretrizes projetuais envolvidas na elaboração do projeto de arquitetura, no seu sentido mais amplo. Iniciando com a contextualização do hospital como um todo, no âmbito do município e região, e seguindo pelas diversas considerações inerentes à obtenção de um trabalho arquitetônico consistente e de boa qualidade projetual. As considerações feitas são pertinentes ao pensamento arquitetônico, pelo entendimento sobre: inserção da unidade em estudo na abrangência da saúde local e/ou regional, passando pelas observações sobre o lote urbano; fluxos externos e internos; entorno edificado e natural; setorização e macrozoneamento; contiguidade funcional; programa físico; Plano Diretor de Organização e Expansão Física; expansibilidade e flexibilidade espacial; conformidade; infecção hospitalar; ergonomia e acessibilidade; conforto ambiental (térmico, acústico e visual); tecnologia; sustentabilidade e humanização; proporcionando assim reflexões para auxiliar os profissionais arquitetos e de 
outras áreas correlatas na elaboração e formatação dos projetos de Unidades de Urgência e Emergência de alta complexidade.

Para finalizar, o capítulo 8 traz as últimas considerações sobre a unidade em estudo, procurando, desta forma, obter a reflexão necessária. 



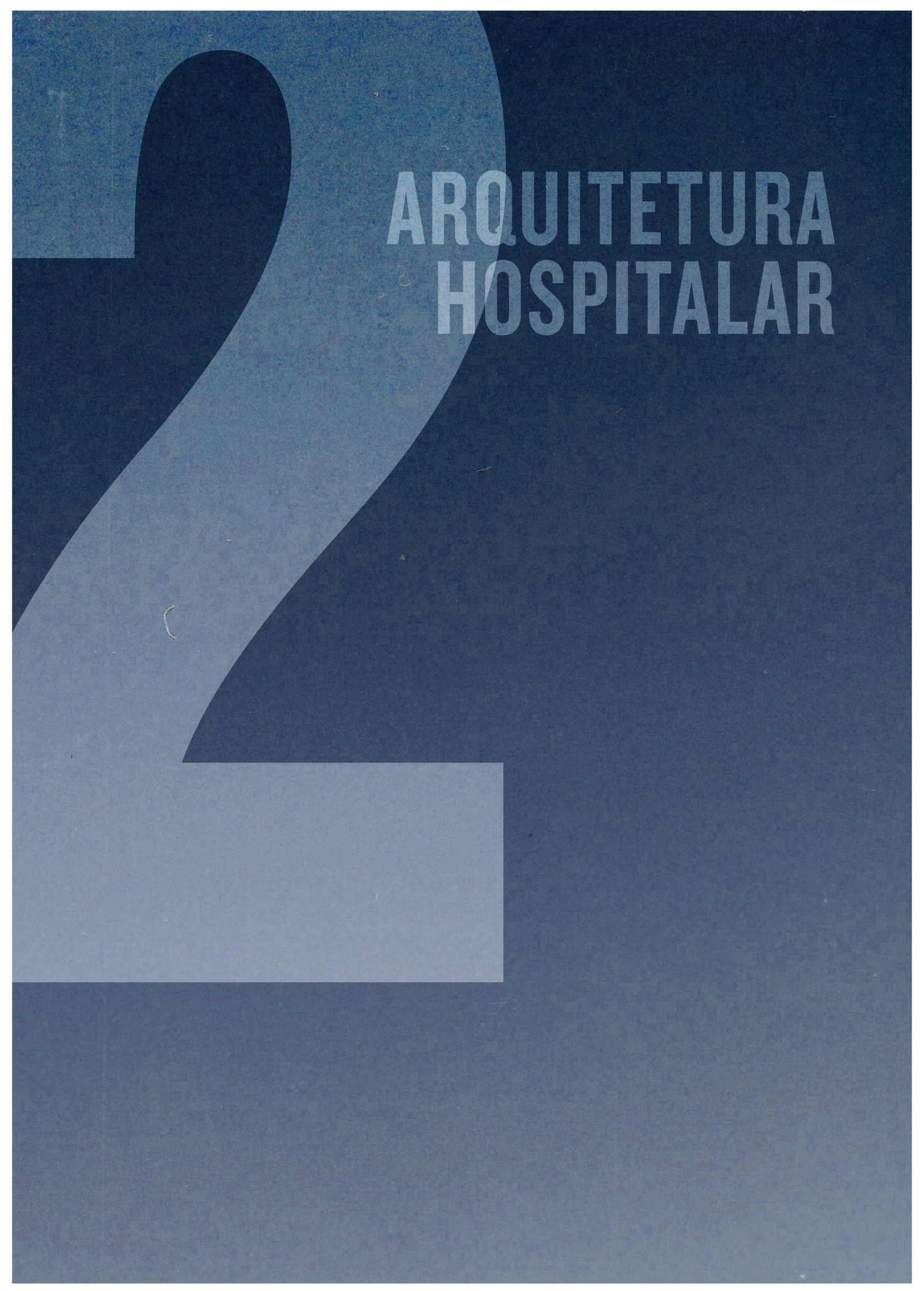





\section{I Evolução Histórica do Edifício Hospitalar}

Doença cria dependência. $\mathrm{O}$ doente necessita não somente de tratamento médico, mas também de cuidados e abrigo. Através da história, as sociedades têm aceitado tal necessidade como a responsabilidade da vida comunitária. Uma dessas instituições, o hospital, é hoje a base de qualquer sistema moderno de cuidados de saúde.

Para prover as necessidades dos pacientes, organizações estiveram sempre envolvidas com as variações econômicas, políticas, sociais e condições culturais que interferem na vida do homem; como, por exemplo, se o homem viveu nas cidades ou no campo, se sofreu escassez ou obteve abundância, a religião que este praticou e os valores que preza, o aprender, as artes e a ciência que deram forma para sua sociedade, enfim, todos estes aspectos têm afetado o desenvolvimento do hospital e a forma com que se tem obtido os serviços ofertados. Para ser entendido, o hospital tem sido modificado, pela sociedade da qual ele pertence o transformou e o mesmo leva ao futuro evidências do seu passado.

A sociologia histórica do edifício hospitalar, neste sentido, requer um delinear de condições políticas e econômicas, estrutura social, sistema de valores, organização cultural e as mudanças 
sociais relacionadas com as condições de saúde e necessidades da população nos vários períodos históricos.

O conceito de necessidade para a assistência social, no caso de uma doença, foi altamente desenvolvido durante a Idade Média. Esta foi a preocupação de mulçumanos, judeus e cristãos quando implantaram vários hospitais. Considerações religiosas e sociais foram aspectos importantes no desenvolvimento destas instituições, sendo os templos, provavelmente, os mais antigos estabelecimentos preocupados com tais cuidados. $\mathrm{O}$ mosteiro medieval possuía enfermarias para o alojamento de monges doentes, acomodação para viajantes e peregrinos. (Fig. 1 e 2).

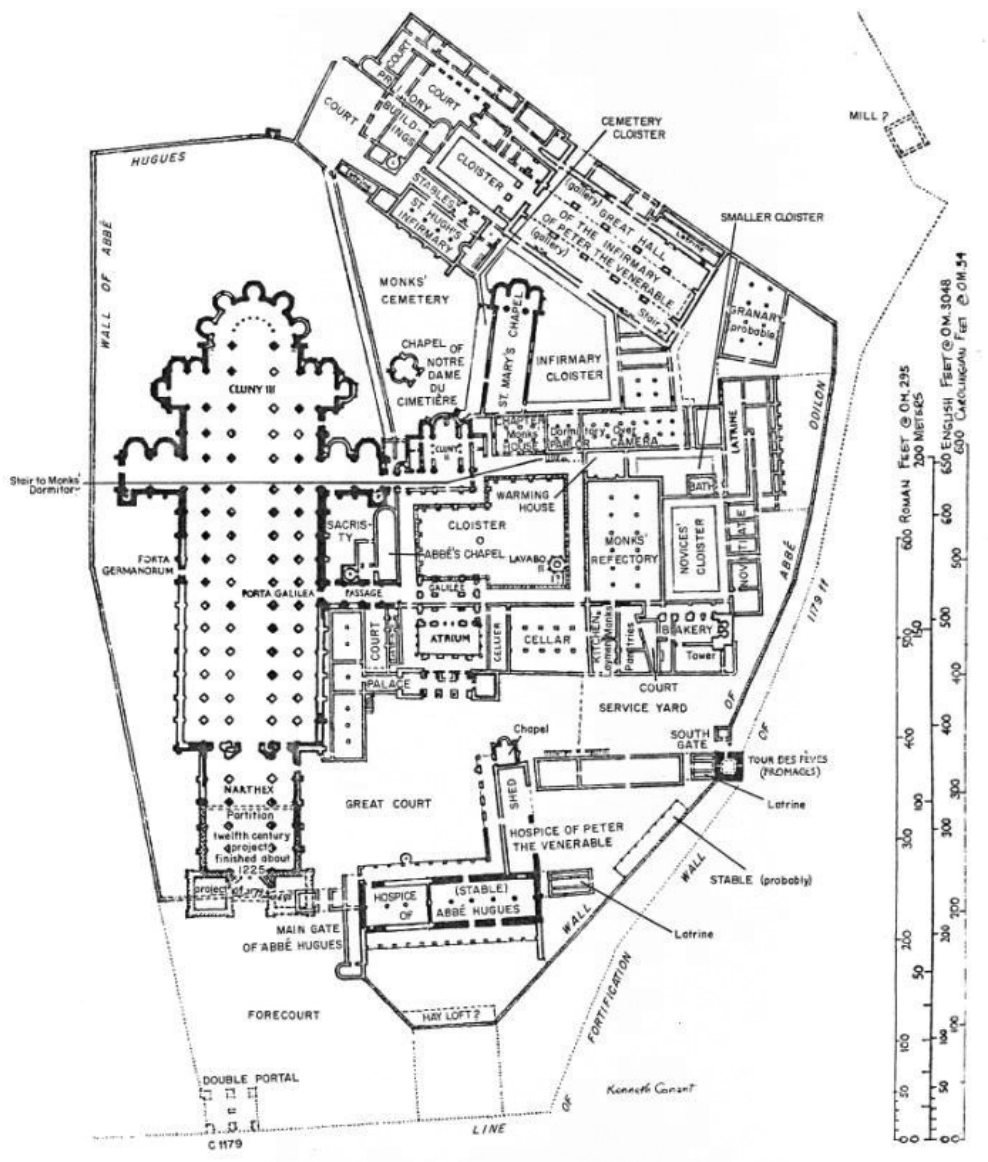

Figura 1 - Planta Monastério de Cluny, França (1082).

(Fonte: THOMPSON, J. D.; GOLDIN, G., 1975). 
Figura 2 - Perspectiva Monastério de Cluny.

(Fonte: THOMPSON, J. D.; GOLDIN, G. 1975).

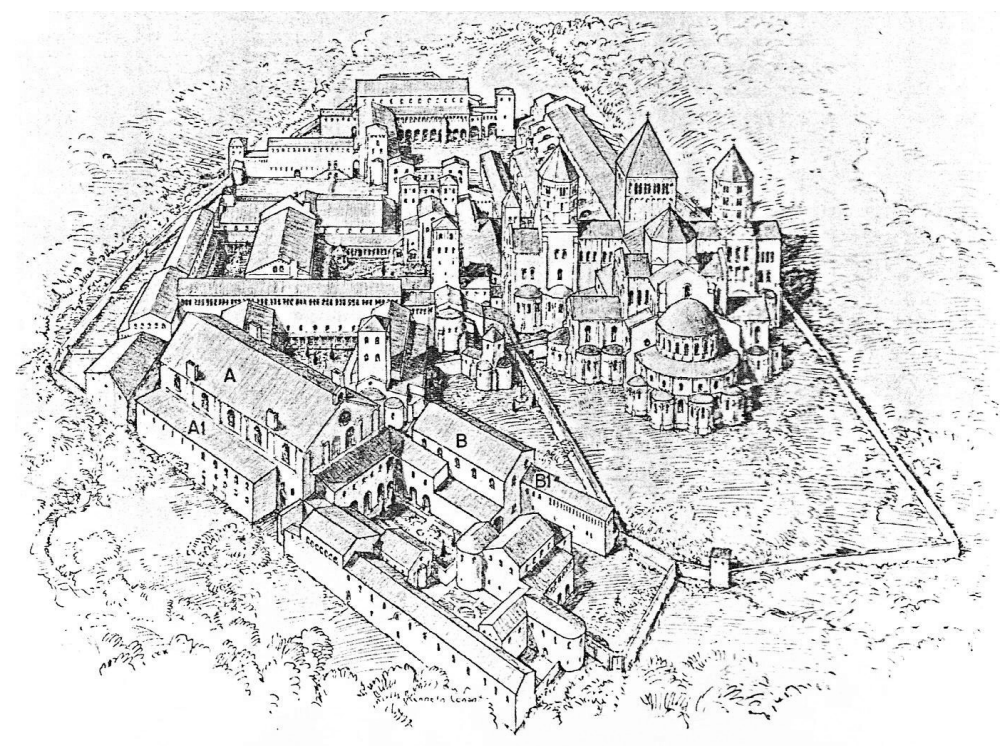

Durante a Idade Média, muitas instituições foram criadas devido a doações de reis, rainhas, ricos lordes e mercadores. Ao final do século XV, como resultado deste desenvolvimento, a Europa possuía uma boa rede hospitalar. O hospital medieval não foi somente um centro para cuidados médicos, mas também, e principalmente, uma instituição filantrópica e espiritual, assim sua meta era o socorro da alma e não do corpo. A cirurgia e a dissecação eram tidas como sacrilégios. Geralmente esta instituição tinha o clero em sua direção e assim os serviços religiosos eram conduzidos para a edificação da fé.

O financiamento do hospital medieval reflete suas origens e propostas. A caridade neste período histórico foi uma consequência de um dos mais fortes sentimentos da época: o desejo de salvação e purificação. Doações e oferendas, contribuições, terras e edifícios forneceram as bases financeiras para o hospital medieval.

Segundo Miquelin (1992, p. 42), a estrutura física dos edifícios hospitalares da Idade Média possuía como componente principal a nave, refletindo o avanço da tecnologia estrutural, a qual, por sua vez, permitia vãos maiores, melhorando muito as condições de iluminação e ventilação dos edifícios daquela época.

O planejamento das edificações surgidas ao final do século $\mathrm{X}$ alcança grandes avanços para a arquitetura hospitalar, principalmente pela separação entre as funções de alojamentos e logística e separação dos pacientes por patologias e sexo. O 
abastecimento de água passa a ser mais estudado em função da melhoria das condições de higiene.

Um marco fundamental na historia dos hospitais nesse período foi a construção do Hôtel Dieu, no período entre 651 a 829, na França (Fig. 3 e 4), no qual já havia separação em áreas: os peregrinos e os pobres ficavam ao sul da abside esquerda da igreja, enquanto hóspedes ficavam ao norte. Já a enfermaria para os monges, velhos e doentes, com sua própria capela, situava-se a nordeste. (PEVSNER, 1986, p. 189).

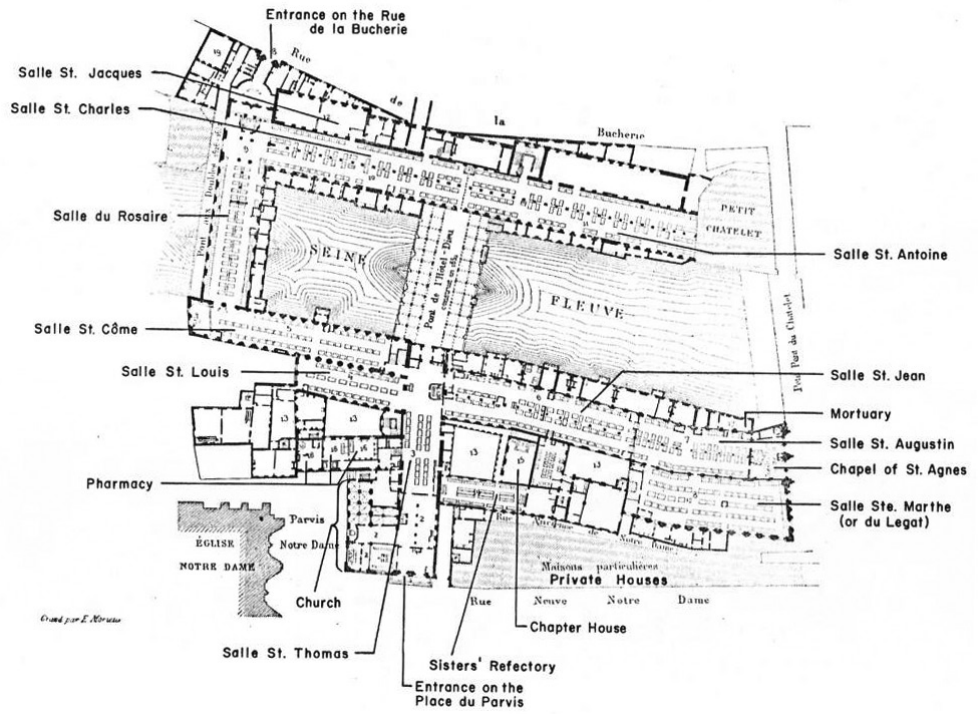

Figura 3 - Hôtel-Dieu, França, 829 (séc. IX).

(Fonte: THOMPSON, J. D.; GOLDIN, G., 1975).

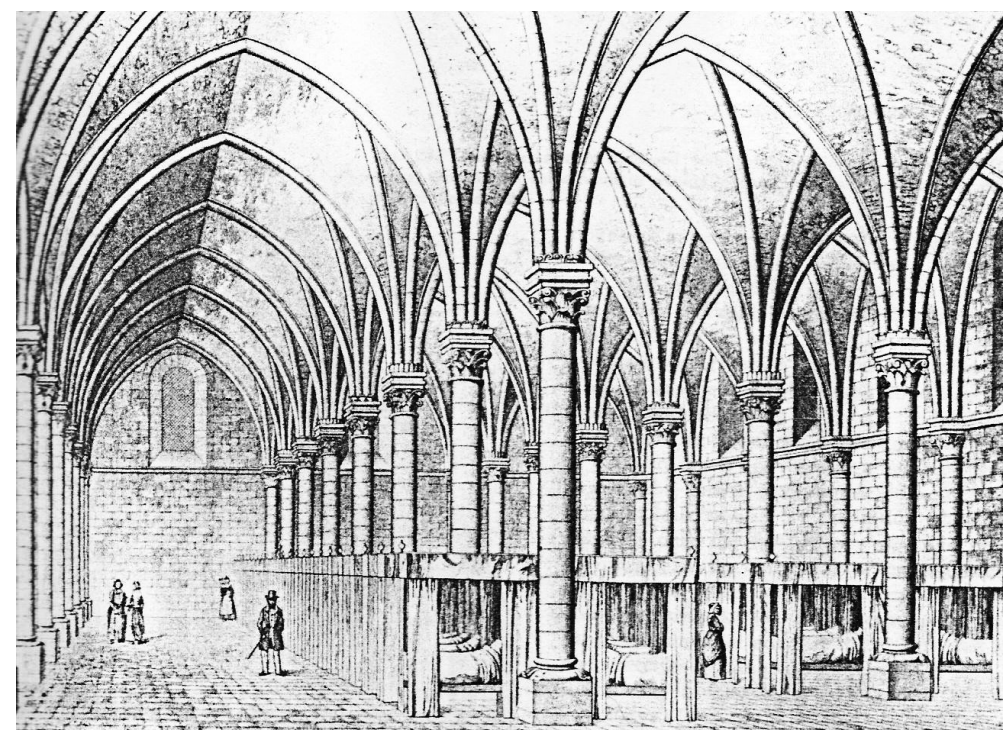

Figura 4 - Interior Hôtel-Dieu. (Fonte: THOMPSON, J. D.; GOLDIN, G., 1975). 
É interessante observar que a influência dos aspectos religiosos

Hospital Santo Espirito de Lubeck, 1286 Biblioteca de Artes Decorativas de Paris

01. Entrada

02. Vestibulo

03. Capela

04. Altar

05. Nave dos Leitos

06. Patio

07. Serviços
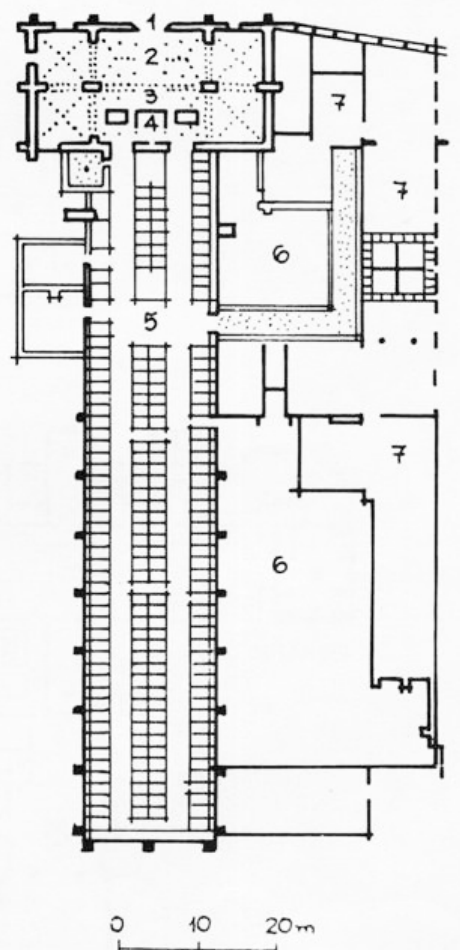
na geração do edifício hospitalar ocorre com muita intensidade, como demonstrada na planta do Hospital Santa Espírito de Lubeck, 1286. (Figura 5). Não somente na forma da nave, mas também no estabelecimento da hierarquia funcional.

A capela e o altar são espaços em "primeiro plano", colocando a área dos leitos como "pano de fundo" deste cenário.

O espaço do claustro surge como complementar à função de recuperação dos pacientes, este espaço ganha força na geração do edifício hospitalar nos períodos seguintes.

No início do século XVI, com o aumento do desemprego e de outros fatores que proporcionaram mudanças sociais foi desencadeada uma proposta em que o clero se desligasse da direção dos hospitais, passando então a adquirir um caráter mais institucional.

Figura 5 - Planta Hospital Santo Espírito de Lubeck, 1286. (Fonte: MIQUELIN, L. C., 1992.)
Neste mesmo período, teve início a associação da profissão médica, porém o médico ainda não pertencia ao hospital, o qual continuava independente. Pevsner (1986, p. 190) diz que, por volta do século XV, surgiu uma nova tipologia de hospitais, principalmente na Itália, sendo o primeiro exemplo o Hospital de Santa Maria Nuova, situado em Florença, criado em 1286 por Folco Portinari; em 1334, ganhou uma nova ala cruciforme masculina, e em 1669 uma segunda cruz para as mulheres foi acrescentada. Este formato em planta passou a predominar por toda a Renascença.

Outros exemplos de hospitais com planta cruciforme foram os de Pammatone, em Gênova, iniciado em 1422 e depois ampliado no século XVIII por Bartolommeo Orsolino, como também - Ospedale de Santa Maria Della Scala, em Siena; e o Ospedale Maggiore, em Milão, este último projetado por Florentine Filarete, por volta de 1456. (Fig. 6, 7 e 8). 


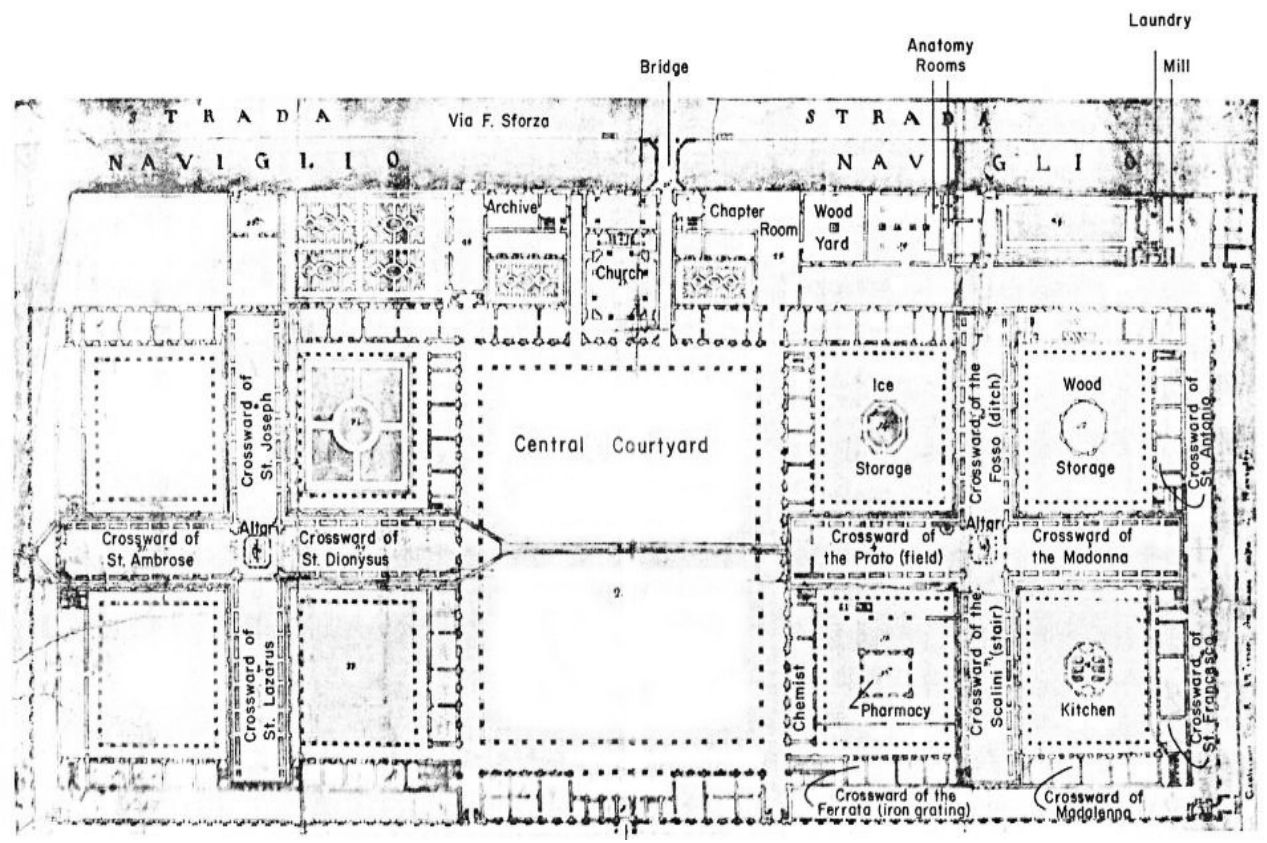

Figura 6 - O Hospital da Renascença - Ospedale Maggiore, Milão, Itália (1460).

(Fonte: THOMPSON, J. D.; GOLDIN, G., 1975).

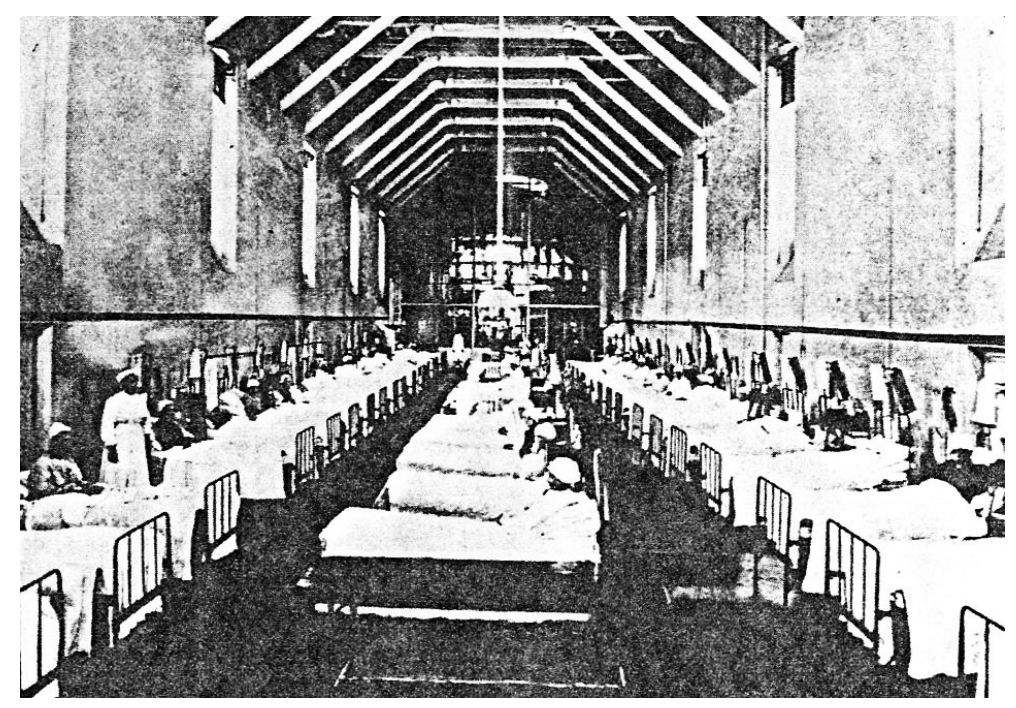

Figura 7 - Internação - Interior Ospedale Maggiore.

(Fonte: THOMPSON, J. D.; GOLDIN, G., 1975). 
Figura 8 - Fachada - Ospedale Maggiore.

(Fonte: PEVSNER, N., 1986).

Figura 9 - Planta hospital projetado pelo arquiteto Fürttenbach, Alemanha (1635).

(Fonte: THOMPSON, J. D.; GOLDIN, G., 1975).

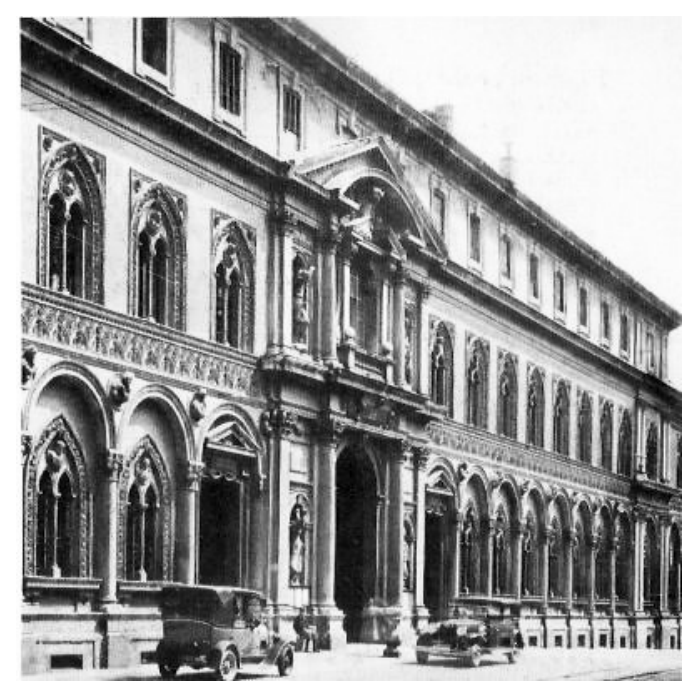

Somente no começo do século XVI, a planta hospitalar em forma de cruz apareceu na Inglaterra, Espanha e Alemanha, por meio da construção do Savoy Hospital, edificado por Henrique VII ao lado do Savoy Palace (Inglaterra), pelo Hospital Real de Santiago de Compostela, construído entre 1501 a 1511 (Espanha), e na Alemanha, o arquiteto Joseph Fürttenbach projetou dois exemplos clássicos (Fig. 09 e 10) na base conceitual dos princípios italianos. (THOMPSON; GOLDIN, 1975).

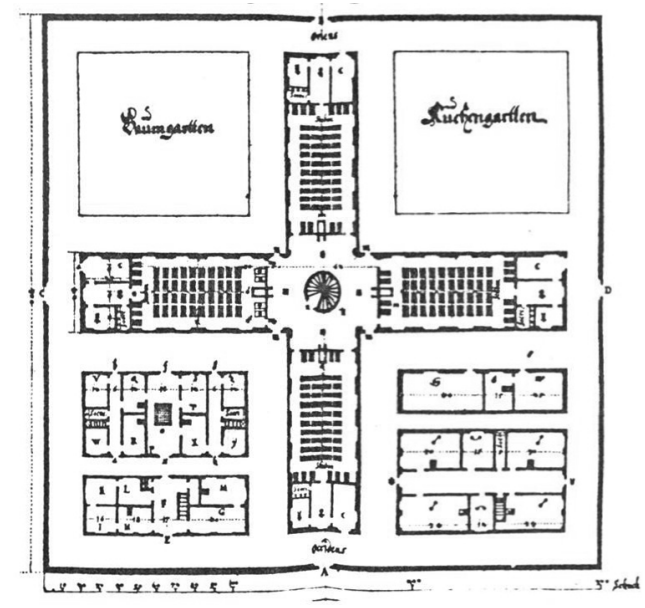


É interessante observar que a tipologia hospitalar, naquele momento, ainda recebia forte influência da igreja. Observa-se que o espaço do altar é ainda presente não somente como elemento funcional, mas também, como espaço organizador e gerador do projeto como um todo, determinando ainda a hierarquia volumétrica do conjunto arquitetônico.

Segundo Miquelin (1992, p. 86), o notável esquema de Filarete contém os elementos básicos das construções hospitalares para os próximos quatro séculos: pátios distribuidores, pórticos, alojamentos lineares, galerias e corredores estão organizados num plano cruciforme e a simetria do conjunto, com base no eixo principal de entrada passando sobre a capela. (Fig. 11).

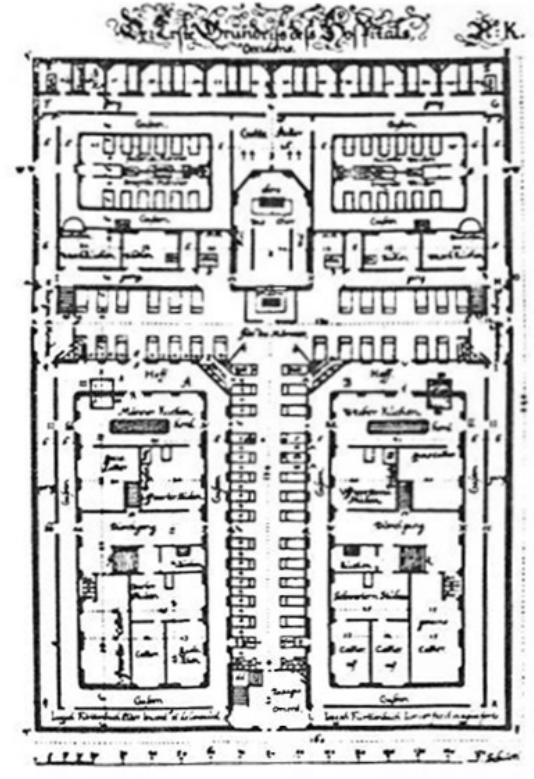

Figura 10 - Planta hospital projetado pelo arquiteto Fürttenbach, Alemanha (1655).

(Fonte: THOMPSON, J. D.; GOLDIN, G., 1975).

Figura 11 - Planta Sanatório Illenau, Alemanha (1837-42). (Fonte: THOMPSON, J. D.; GOLDIN, G., 1975).

O hospital da Era Industrial teve suas origens entre o século XVII e XVIII, marcado por todo processo que o incêndio no Hôtel-Dieu de Paris, ocorrido no ano de 1772, desencadeou. Este hospital era composto de uma estrutura enorme de alojamento de enfermos, isto significava uma lotação de 1.100 leitos individuais e aproximadamente 600 coletivos.

A reconstrução do edifício promoveu um grande momento de reflexão sobre o sistema de saúde francês utilizado até aquele momento. O médico francês Jacques Tenon, Lavoisier, Laplace e outros foram designados pela Academia Real de Ciências a realizar uma vasta pesquisa, com análise sobre vários hospitais franceses, bem como em outros países da Europa, onde, por meio de visitas aos locais de estudos, proporcionou uma leitura 
não apenas descritiva, mas principalmente o olhar crítico funcionalista. Esta análise, transformada mediante relatórios, foram publicadas em 1788 em uma obra intitulada "Memoires sur les Hôpitaux de Paris", a qual representa também o momento histórico de aproximação entre a profissão médica e os hospitais, do ponto de vista construtivo.

Segundo Kleber Silva (2005, p. 26), Tenon tratou os hospitais como objeto de estudo, como um paciente na busca de um processo terapêutico; esse modo de analisar o objeto representa uma grande mudança para a época. Os planos apresentados por Tenon foram desenvolvidos pelo arquiteto Bernard Poyet que codificara, em termos arquitetônicos, as recomendações de Tenon. (Fig. 12).

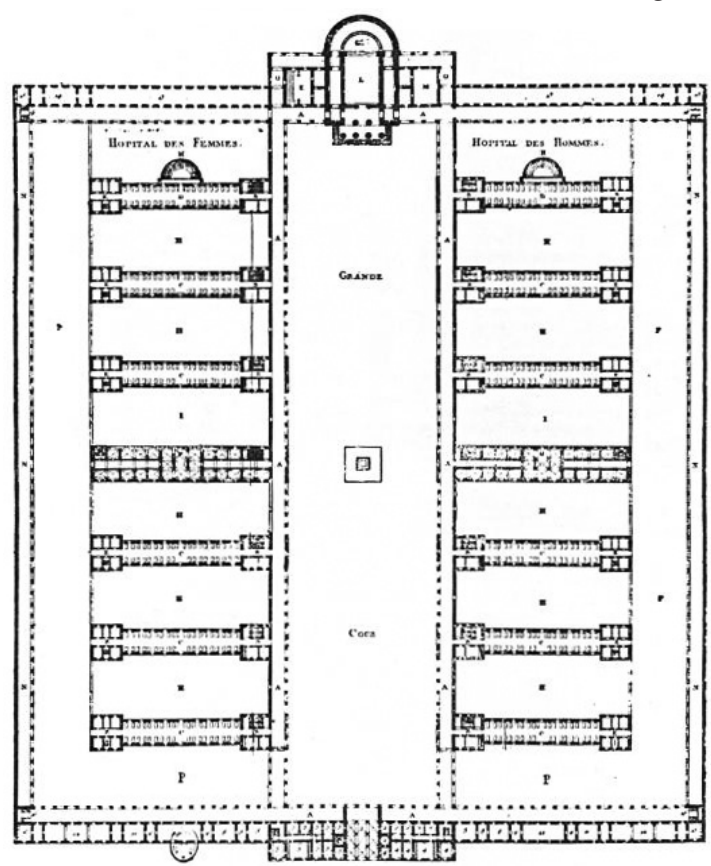

A partir da estruturação dos serviços médicos e espaços necessários para a realização das atividades terapêuticas, interligados por meio de um grande eixo de circulação se estabelece, assim, um modelo de organização funcional. Desta forma, inaugura-se aqui o modelo pavilhonar característico da Era Industrial. Esta proposta arquitetônica proporcionou ainda melhores condições de iluminação natural e aeração dos ambientes hospitalares. O aprofundamento dos estudos, até então realizados, foram interrompidos pela Revolução Francesa, em 1789.

De acordo com Góes (2004, p. 38), mediante os relatórios apresentados pela comissão, foi

Figura 12 - Planta Hospital Commision de B. Poyet para a Academia de Ciências, La Roquette, França (1788).

(Fonte: THOMPSON, J. D.; GOLDIN, G., 1975). da época, tais como:

- a capacidade do hospital nunca seria superior a 1.200 leitos;

- deveria ser reduzido o número de leitos por enfermaria;

- deveria haver maior isolamento entre as enfermarias;

- não deveria haver salas contínuas;

- as salas deveriam ser dispostas de modo a permitir a circulação do ar com abertura de todos os lados;

- os pavilhões deveriam ficar em ordem paralela;

- as fachadas deveriam ser uma ao norte e outra ao sul;

- deveria ser construído um só pavilhão destacado aos enfermos, ou dois pavimentos em caso de escassez de terrenos; 
- deveria haver permissão para três andares, em certos casos, sendo os mais elevados para os empregados, o térreo e o intermediário para os enfermos;

- deveriam tratar e implantar jardins entre os pavilhões.

Outros projetos arquitetônicos foram desenvolvidos por Poyet e Tenon, como o hospital exemplificado (Fig. 13 e 14) com capacidade para 1.200 leitos, em 1787.

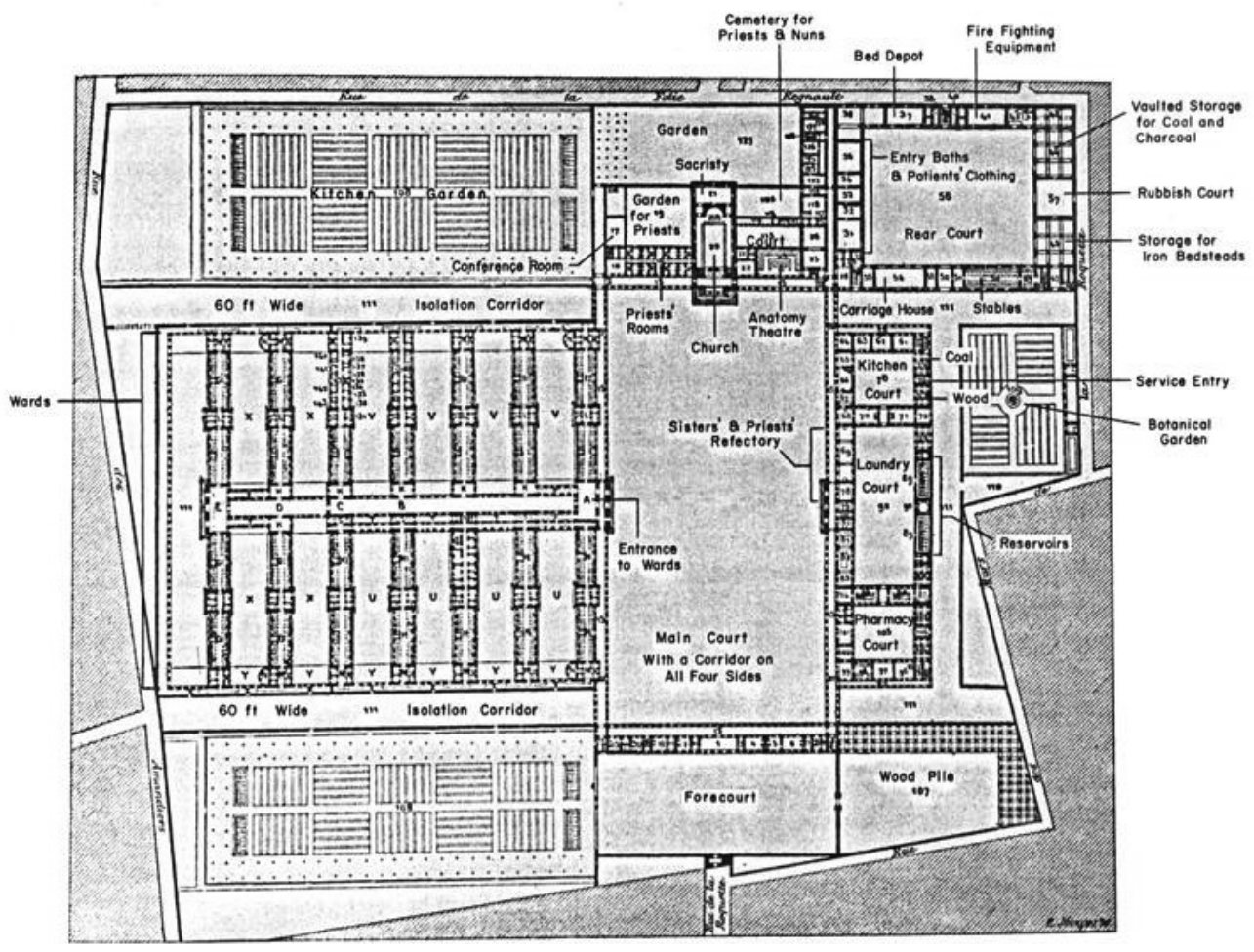

Figura 13 - Planta hospital de 1.200 leitos por Tenon e Poyet, França

(1787).

(Fonte: THOMPSON, J. D.; GOLDIN, G., 1975). 


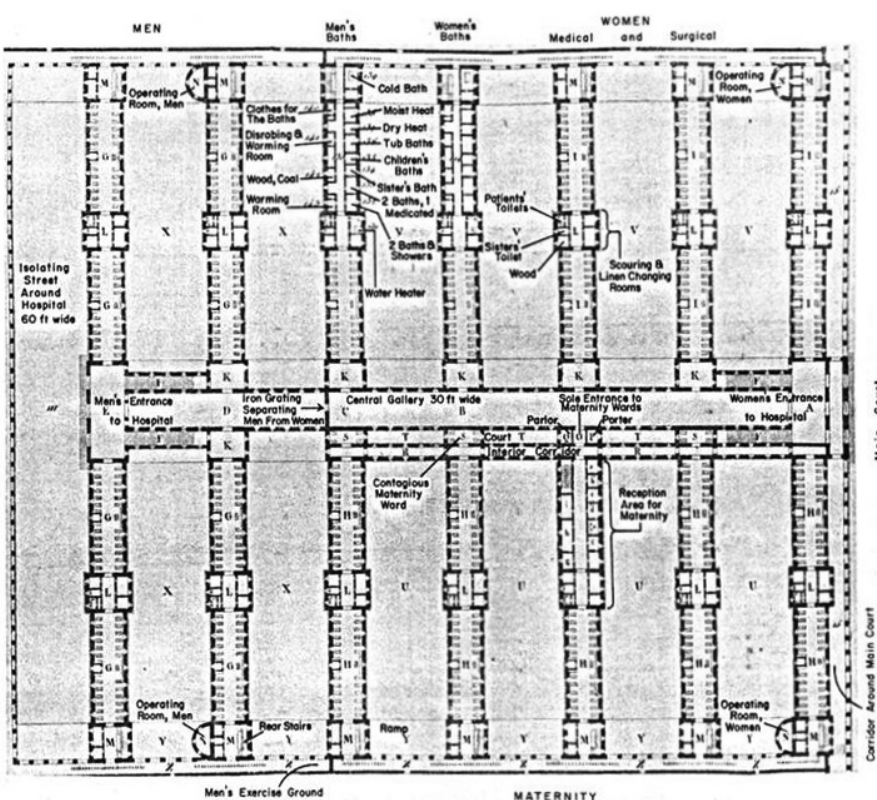

Observa-se que a estruturação do projeto baseia-se ainda em algumas condicionantes procedentes do período renascentista, como o grande pátio central e a entrada principal no eixo determinado pela capela. Vale lembrar que, a proposta apresentada por Poyet ao HôtelDieu (1785), em forma circular (Fig. 15, 16 e 17), promove uma nova leitura sobre a tipologia do edifício e o rompimento com o modelo do passado, porém não há importância do espaço religioso na

Figura 14 - Detalhe da planta hospital de 1.200 leitos por Tenon e Poyet, França (1787).

(Fonte: THOMPSON, J. D.; GOLDIN, G., 1975).

Figura 15 - Proposta de B. Poyet para o novo Hôtel-Dieu (1785).

(Fonte: THOMPSON, J. D.; GOLDIN, G., 1975).

Figura 16 - Detalhe da proposta de B. Poyet para o novo Hôtel-

Dieu (1785).

(Fonte: THOMPSON, J. D.; GOLDIN, G., 1975). organização geral do projeto.
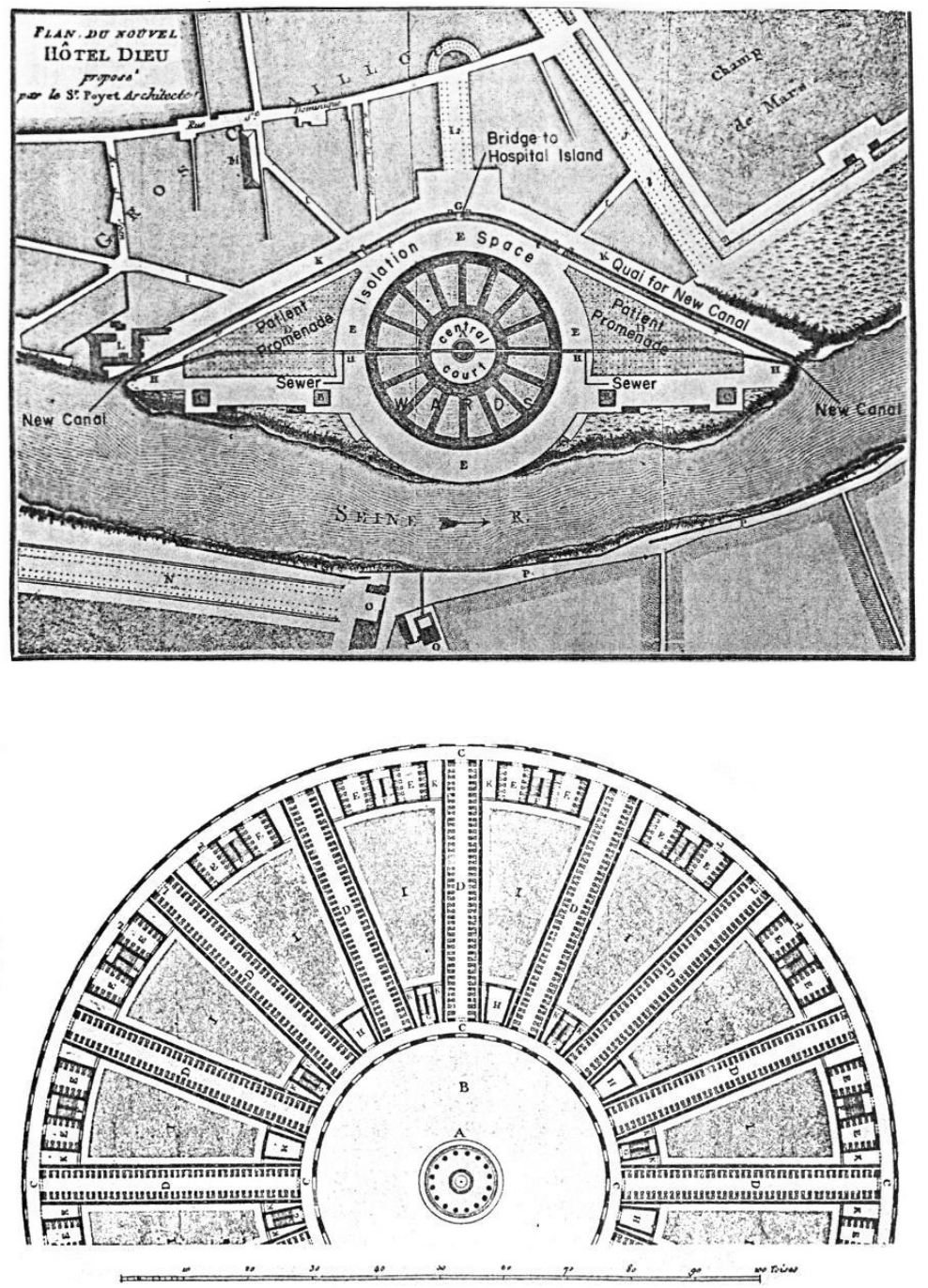


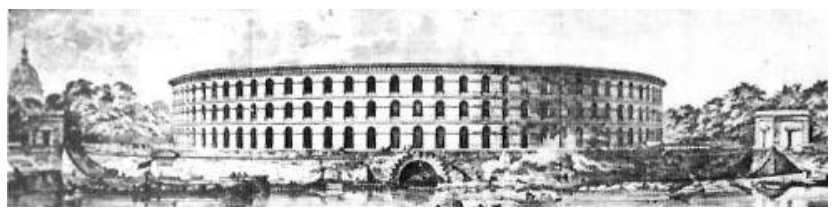

Novas práticas, novas tecnologias e novos conceitos como condições de salubridade remodelam o hospital, transformando-o no lugar ideal para os cuidados de saúde.

Em meados do século XIX, o médico cirurgião escocês Joseph Lister introduz os conceitos de assepsia, e lança as bases para a evolução da cirurgia, junto com a descoberta da anestesia. Neste mesmo período, o trabalho da enfermeira londrina Florence Nightingale destaca-se pelos seus esforços na melhoria da organização e higiene dos hospitais militares, que culminaram na importante redução da mortalidade de soldados ingleses durante a guerra da Crimeia (1853 - 1856).

As ações de controle sobre os ambientes como higiene, isolamento, individualização de cuidados (compressas individuais para limpeza das escaras), dieta controlada, redução do número de leitos e de pessoas circulando nas enfermarias foram capazes de cumprir com os seus objetivos. Tais ações estabeleceram uma organização funcional importante na disciplina de fluxos internos ao edifício hospitalar, estabelecendo assim, um eixo de circulação principal, com o papel de gerar outros eixos secundários, proporcionando maior autonomia e isolamento às unidades hospitalares. Reforça-se aqui os princípios do modelo pavilhonar, bem caracterizado pela proposta do Hospital Lariboisière, na França em 1854. (Fig. 18). Novamente, observa-se a influência dos conceitos renascentistas na organização do projeto arquitetônico, através da entrada principal, eixo que passa pelo grande pátio central, de simetria determinante na localização da igreja.
Figura 17 - Fachada frontal novo Hôtel-Dieu de B. Poyet. (Fonte: PEVSNER, N., 1986). 
Figura 18 - O Hospital da Era Industrial - Hospital Lariboisière, França (1846).

(Fonte: THOMPSON, J. D.; GOLDIN, G., 1975).

Figura 19 - Planta Santa Casa de Misericórdia de São Paulo, 1884.

(Fonte: MIQUELIN, L. C., 1992.)

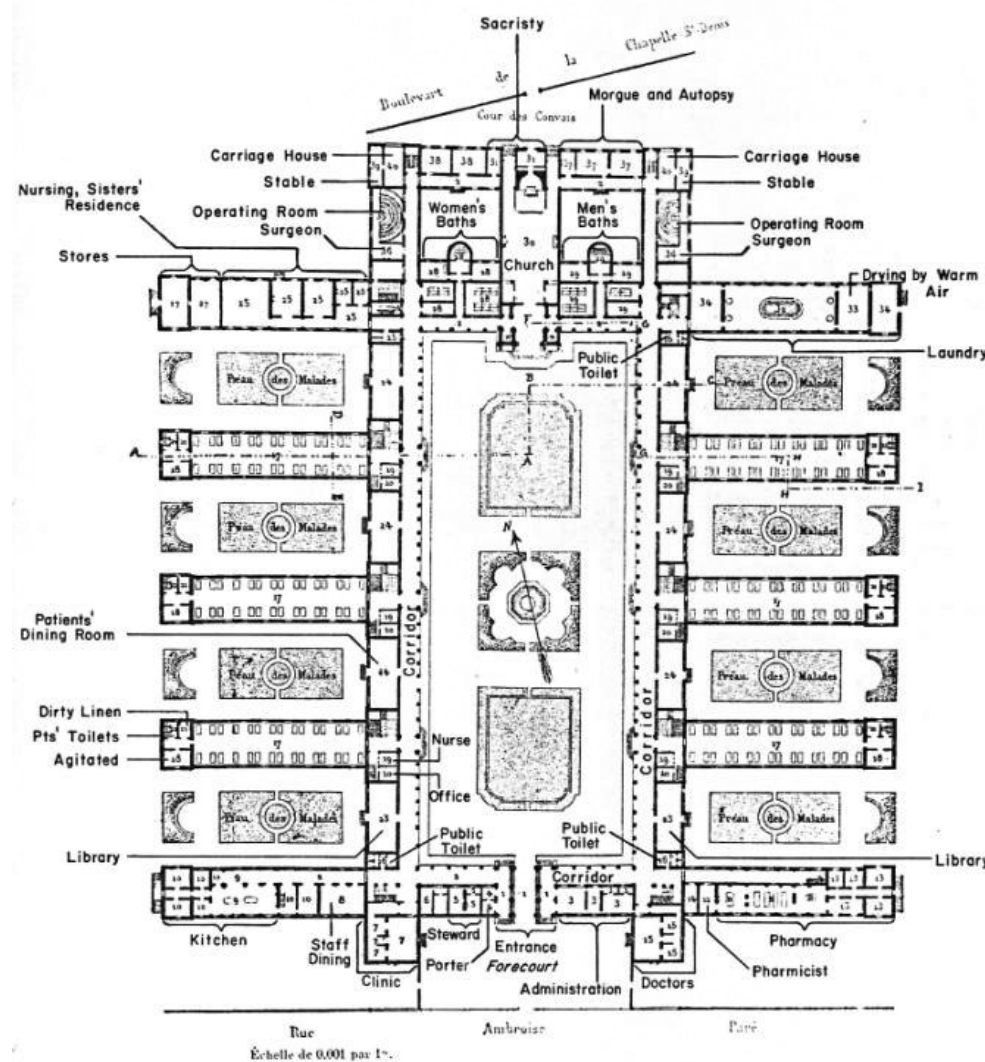

O reflexo deste projeto no Brasil atinge a proposta para a Santa Casa de Misericórdia de São Paulo, projetada pelo engenheiro italiano Luis Pucci, em 1884 (Fig. 19). Em 1876, ocorre a proposta de construção do Hospital John Hopkins em Baltimore, Maryland nos Estados Unidos (Fig. 20), onde também se observa a forte influência dos novos conceitos do edifício pavilhonar.

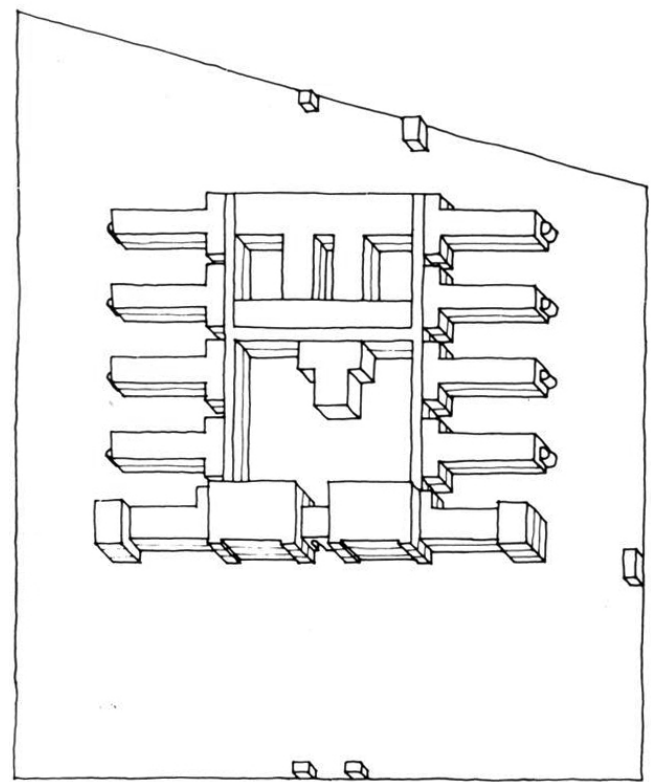


Embora a grande maioria dos blocos que constitui o edifício é de forma prismática, dois deles possuem uma forma octogonal proporcionando uma melhor supervisão dos pacientes pelo grupo de enfermagem. (Fig. 21). Além deste conjunto de unidades de internação para pacientes comuns, assistido nas grandes enfermarias dos pavilhões posteriores, observa-se duas outras unidades, constituídas nos blocos frontais de apartamentos individuais e privados. (Fig. 22). O hospital John Hopkins foi, até por volta de 1920, o modelo institucional e arquitetônico para outras construções hospitalares nos Estados Unidos.

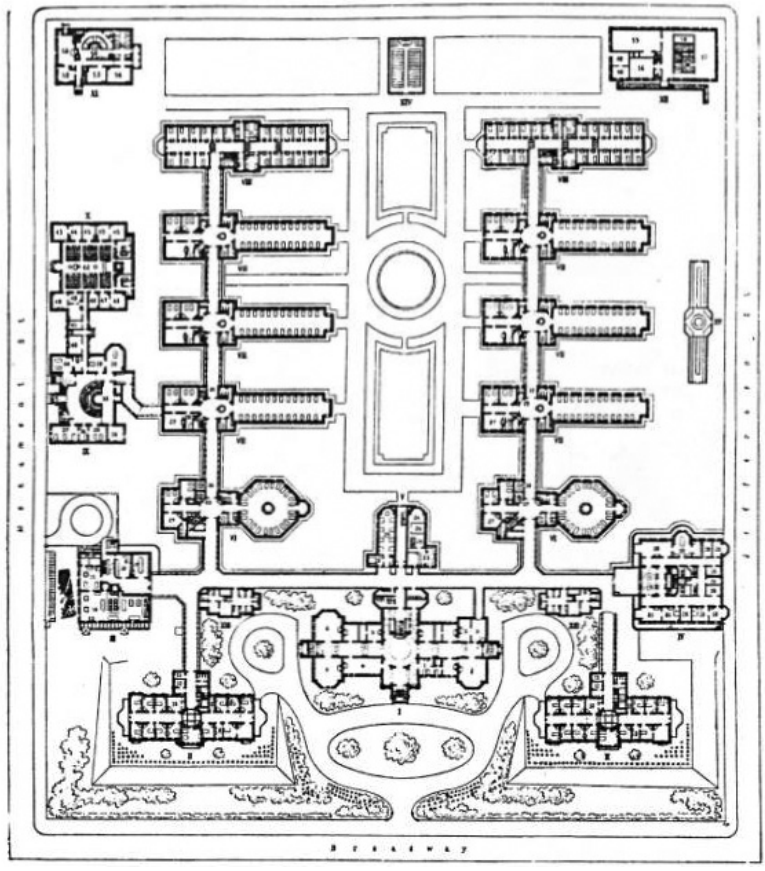

Figura 20 - John's Hopkins Hospital, USA, 1876 (séc. XIX).

(Fonte: THOMPSON, J. D.; GOLDIN, G., 1975).

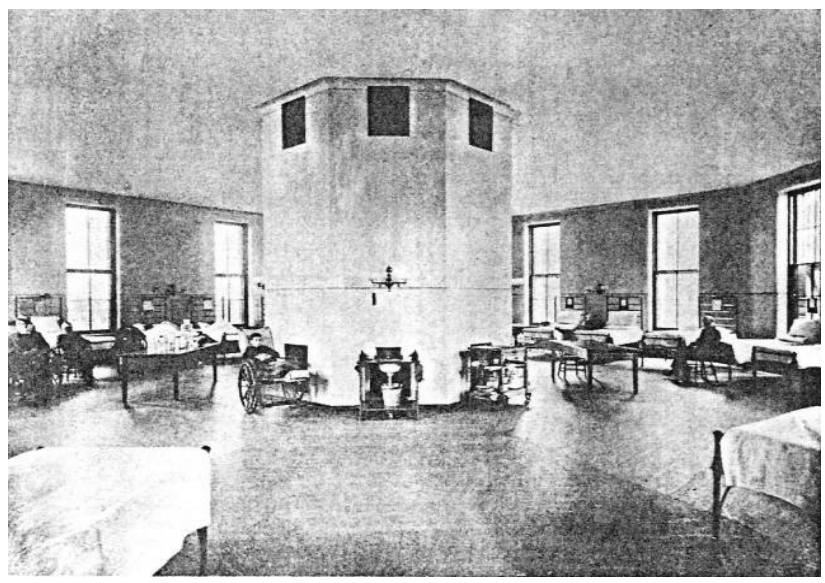

Figura 21 - Internaçãooctogonal - John's Hopkins Hospital. (Fonte: THOMPSON, J. D.; GOLDIN, G., 1975).

Figura 22 - Apartamento individual e privado - John's Hopkins Hospital (1885).

(Fonte: THOMPSON, J. D.; GOLDIN, G., 1975). 
Segundo Miquelin (1992, p. 54), alguns fatores causaram a decadência da anatomia pavilhonar, tais como as grandes distâncias internas a serem percorridas pelos funcionários, o custo do terreno, a escassez de mão de obra especializada em enfermagem, domínio tecnológico da estrutura metálica, da construção vertical, os elevadores, custos construtivos e operacionais, entre outros, causaram a insatisfação e promoveram a busca de novas propostas.

De acordo com Giacomo (2005, p. 18), na virada do século $\mathrm{XX}$, o hospital aumentou em tamanho e complexidade, tanto com o desenvolvimento da medicina, necessitando de novos e caros equipamentos, como também mudanças nas condições sociais e econômicas. Desta forma, foi alterado o financiamento dos cuidados médicos e criados novos padrões de utilização hospitalar. Os médicos começaram a usar o hospital para os seus pacientes particulares, e, ao mesmo tempo, eles não tinham nenhuma responsabilidade administrativa e financeira com o hospital. Por décadas, durante o século $\mathrm{XX}$, os serviços hospitalares foram aperfeiçoados, com o aumento de ambulatórios, serviços de radiologia, fisioterapia, análises clínicas etc. Muitos processos científicos ajudaram a melhorar o cuidado prestado aos pacientes, a medicina científica tornou-se institucional no hospital, os médicos tornaram-se essenciais para a sua operação, enquanto a instituição tornou-se indispensável para a comunidade.

O hospital pré-contemporâneo monobloco surge com a proposta de verticalização dos blocos que compõem o complexo hospitalar. Incorporando toda a tecnologia construtiva dos primeiros anos do século XX, apresenta-se como alternativa para a diminuição dos grandes percursos, aglutinação das unidades, disciplina funcional e adequação aos terrenos menores nos grandes centros urbanos.

Um novo perfil de atendimento surge neste período, pois com o aumento da complexidade dos serviços de diagnóstico, o tratamento individual e domiciliar torna-se inexequível. Este paciente passa a utilizar as instalações hospitalares, provocando o surgimento gradativo dos espaços de internações com maior privacidade.

O hospital monobloco, caracterizado pela predominância vertical na sua proporção volumétrica, fundamentalmente representa a sobreposição das unidades de internação, dentro das 
especialidades médicas e consolidando a base do edifício como o aglutinador dos serviços de atendimento externo ao paciente como também ao público em geral.

Segundo Miquelin (1992, p. 63), a anatomia típica de um edifício monobloco vertical da década de 1920 organiza as funções hospitalares em quatro setores básicos: no subsolo, localizam-se os serviços de apoio ainda fragilmente organizados; no térreo, localizam-se os consultórios médicos para consultas marcadas e casualidade (ancestrais das consultas de pronto-atendimento), e as áreas de eletromedicina ou raio-x; no primeiro pavimento, há o laboratório e serviços administrativos; nos pavimentos intermediários, estão as áreas de internação; e no último, o bloco operatório.

Nas décadas de 1910 e 1920, o modelo das enfermarias Nightingale começa um processo de transformação, não somente com o surgimento das acomodações individuais (Fig. 23), mas também para proporcionar maior privacidade ao paciente, foram introduzidas divisórias entre os leitos. (Fig. 24).

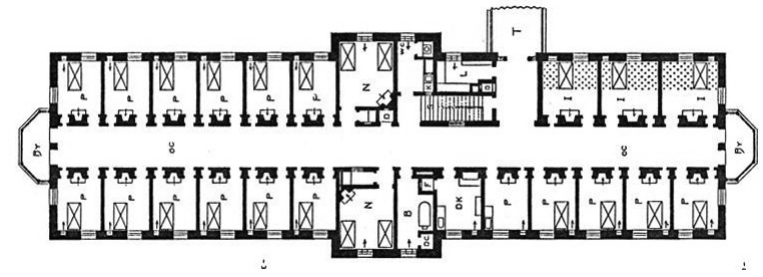

Figura 23 - Apartamento para isolamento - John's Hopkins Hospital (1885).

(Fonte: THOMPSON, J. D.; GOLDIN, G., 1975).

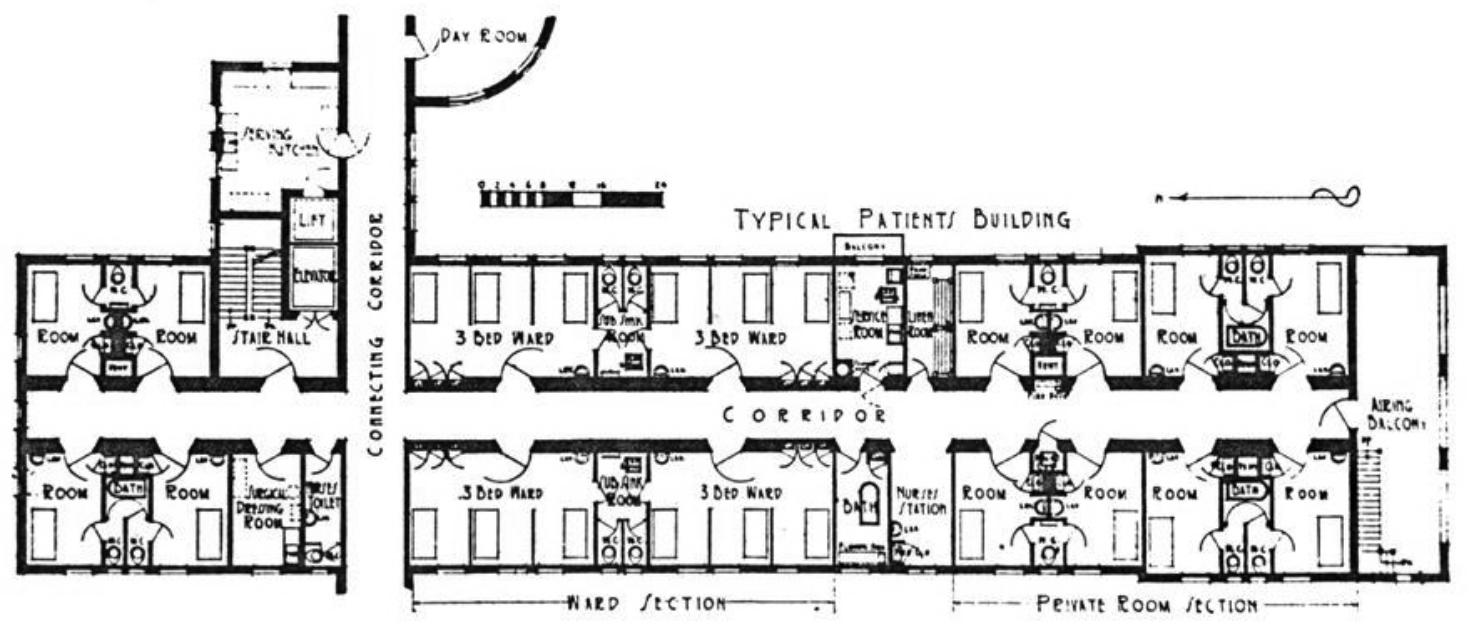

No início dos anos 1930, foi construído o Hospital Beaujon na França (Fig. 25 e 26), com capacidade para 1.400 leitos, distribuídos em 12 pavimentos. Sua estrutura formal em "pente" garantia o isolamento e a autonomia funcional, princípio do modelo pavilhonar, assim teve como eixo principal de circulação
Figura 24 - Planta Unidade de Internação - Rigshospital, Copenhagen (1910).

(Fonte: THOMPSON, J. D.; GOLDIN, G., 1975). 
o elemento gerador do partido arquitetônico. Esta construção representa a tipologia construtiva do período entre as duas grandes guerras mundiais, em que, segundo Toledo (2004, p. 11), este novo modelo incorpora duas importantes inovações tecnológicas, por meio do uso do concreto armado e de elevadores.

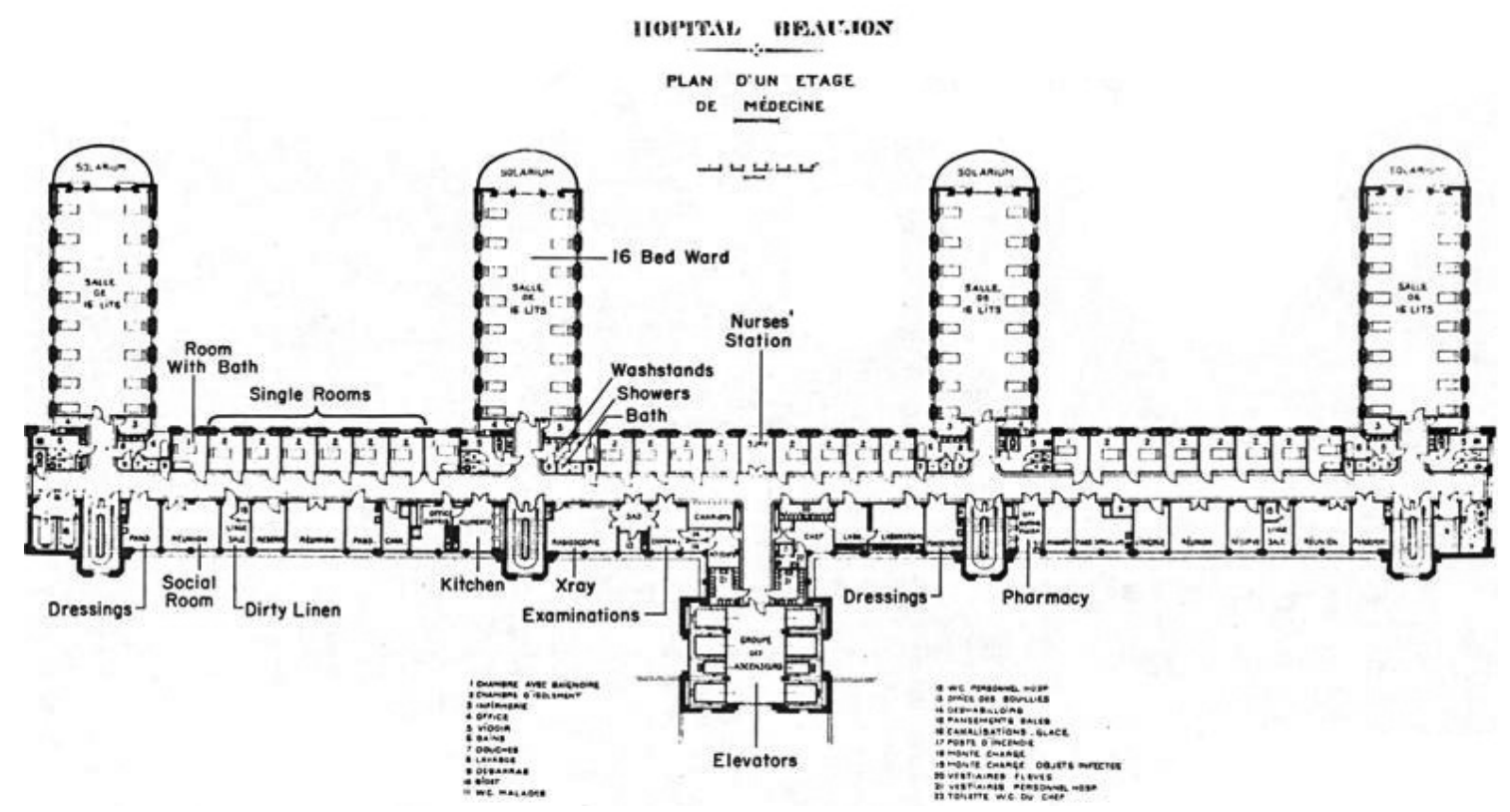

Figura 25 - Planta pavimento térreo - Hospital Beaujon, França (1932).

(Fonte: THOMPSON, J. D.; GOLDIN, G., 1975).

Figura 26 - Vista Hospital Beaujon, França (1932).

(Fonte: THOMPSON, J. D.; GOLDIN, G., 1975).

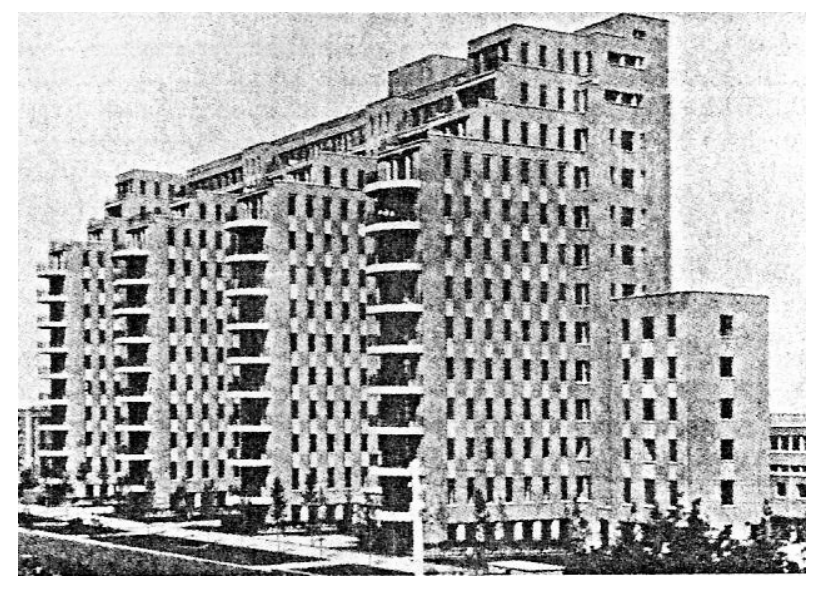


Ainda conforme Toledo (2004, p.13),

[...] o novo partido arquitetônico também permitia significativas economias no que se refere à construção do edifício hospitalar e sua posterior operação, à medida que racionalizava os sistemas de infra-estruturas, distribuição de alimentos, roupas, etc., e servia em unidades funcionais comuns os serviços de esterilização, lavagem de roupa $\mathrm{e}$ nutrição, antes localizadas em cada um dos pavilhões.

Outro exemplo de edifícios hospitalares construídos neste período foi o Hospital Triboro, em New York, 1941 (Fig. 27 e 28 ), onde, na sua organização volumétrica, procura-se manter a simetria e, a partir do núcleo central, articular as circulações horizontais secundárias das unidades que compõem o pavimento, bem como abrigar os eixos verticais de circulação (escadas e elevadores).

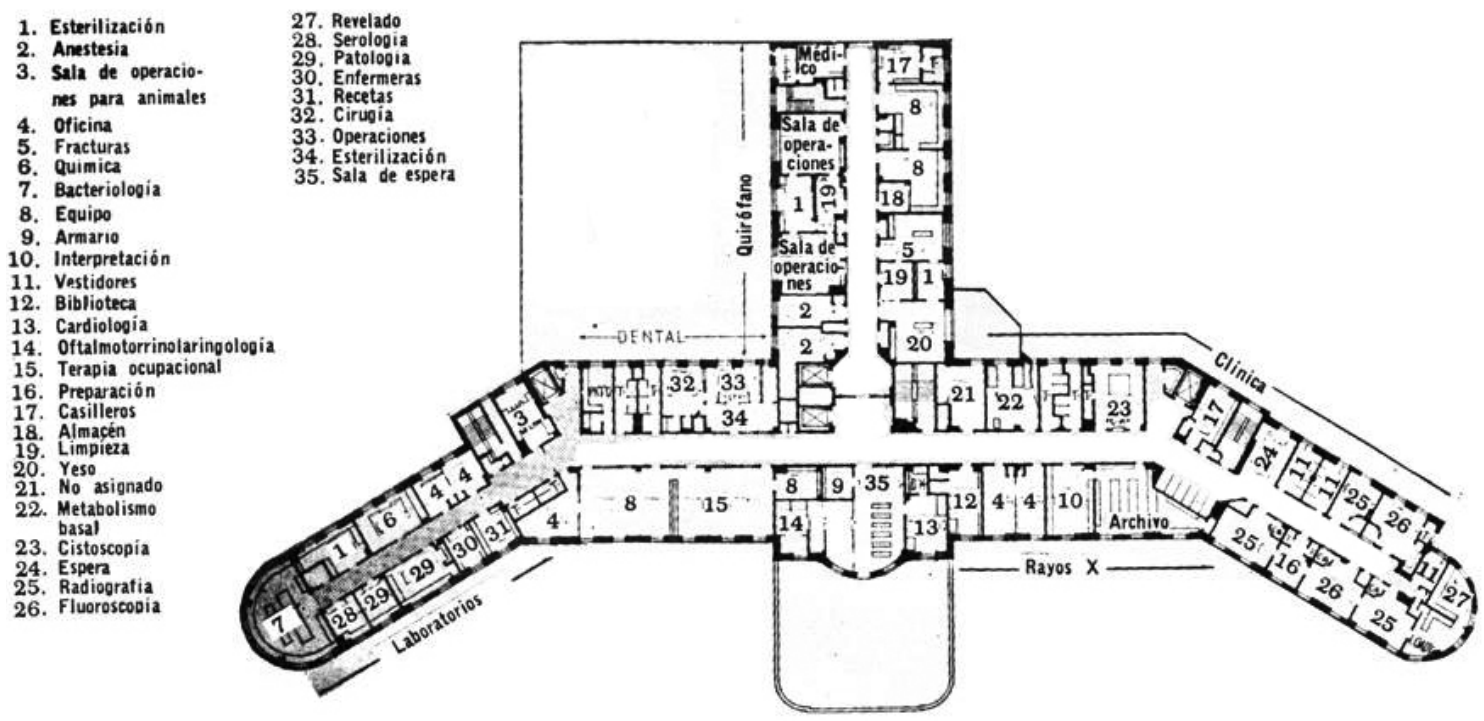

Figura 27 - Planta $2^{\circ}$ pavimento do Hospital Triboro, para tuberculosos, New York (1941).

(Fonte: ROSENFIELD, I., 1965). 
Figura 28 - Vista do Hospital

Triboro, para tuberculosos,

New York (1941).

(Fonte: ROSENFIELD, I., 1965).

Figura 29 - Hospital Pediátrico em Ortopedia, New York

(1944).

(Fonte: ROSENFIELD, I., 1965).

Figura 30 - Croqui Goldwater Memorial Hospital, New York

(1937).

(Fonte: ROSENFIELD, I.,1965).

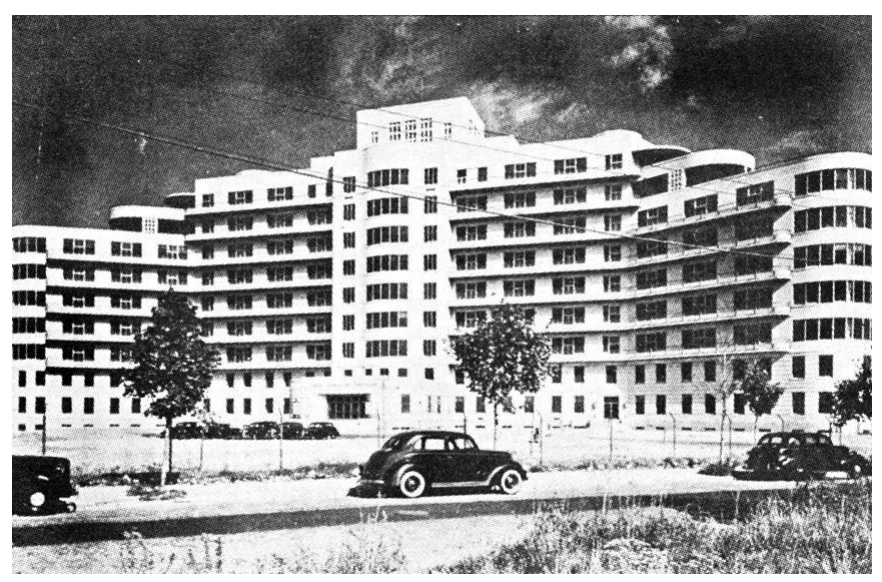

Outro exemplo deste período, o Hospital Pediátrico em Ortopedia, projetado por Rosenfield, em New York nos Estados Unidos (1944) (Fig. 29), possui na sua articulação formal os princípios defendidos pelo autor do projeto, baseado nas aberturas visuais, bem como dos ângulos mais favoráveis para insolação. (Fig. 30).
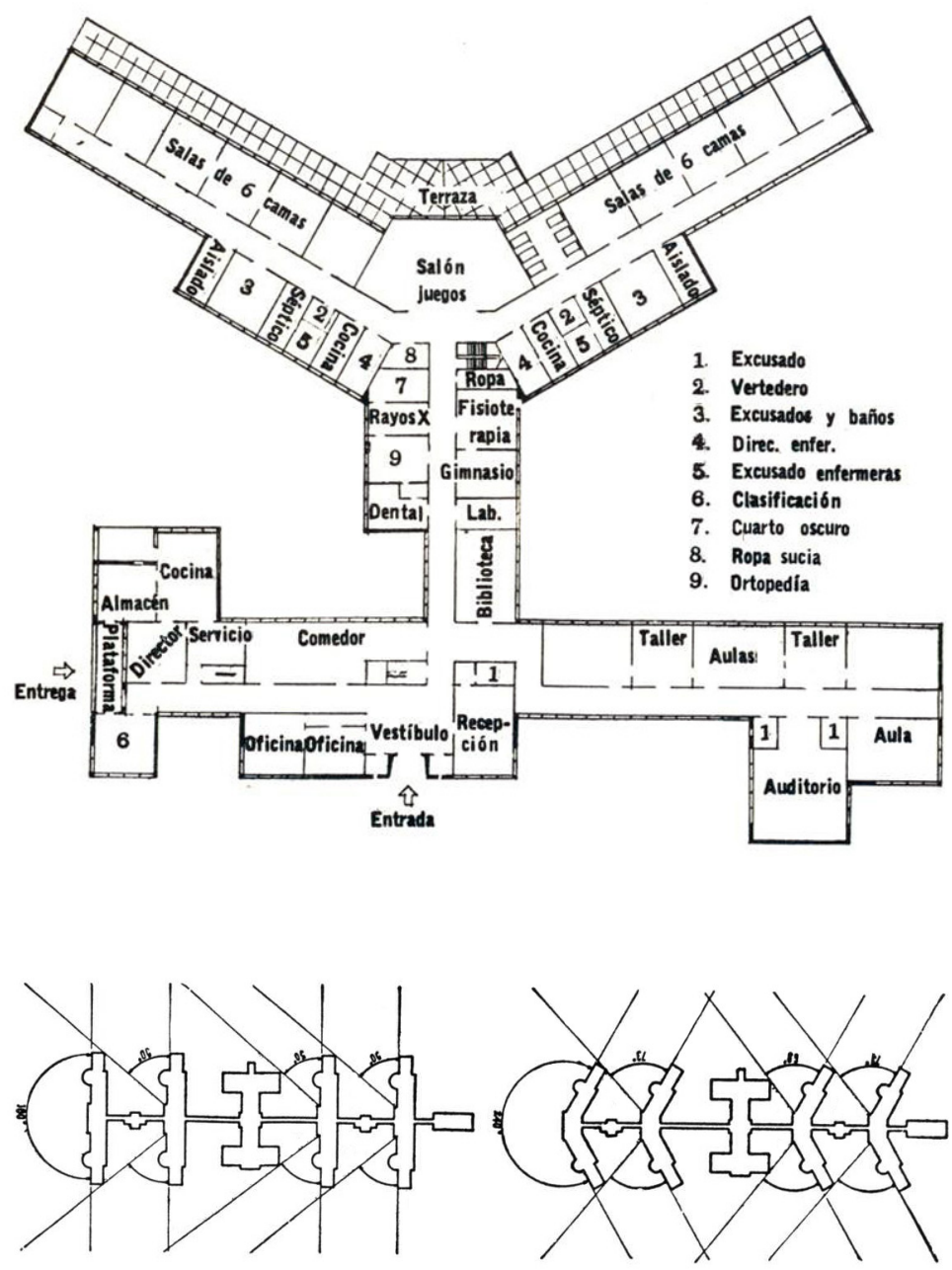
No Brasil, somente após os anos 1930, houve novas iniciativas que tentaram reestruturar os conceitos, padrões e normas das construções hospitalares. A partir daquele momento, a produção arquitetônica marcou a evolução do edifício hospitalar no país. A participação do arquiteto tornou-se indispensável e instituições importantes foram erguidas, como o Hospital das Clínicas da Universidade de São Paulo (Fig. 31) e o Hospital Israelita Albert Einstein. (Fig. 32). Entre as décadas de 1940 e 1960, arquitetos como Jorge Machado Moreira, Rino Levi e Jarbas Karman destacaram-se neste cenário. Moreira projetou em 1942 o Hospital das Clínicas da Universidade Federal do Rio Grande do Sul, em Porto Alegre, que é considerado um marco na arquitetura hospitalar no aspecto de ensino e já também apresentando conceitos sobre hotelaria hospitalar.

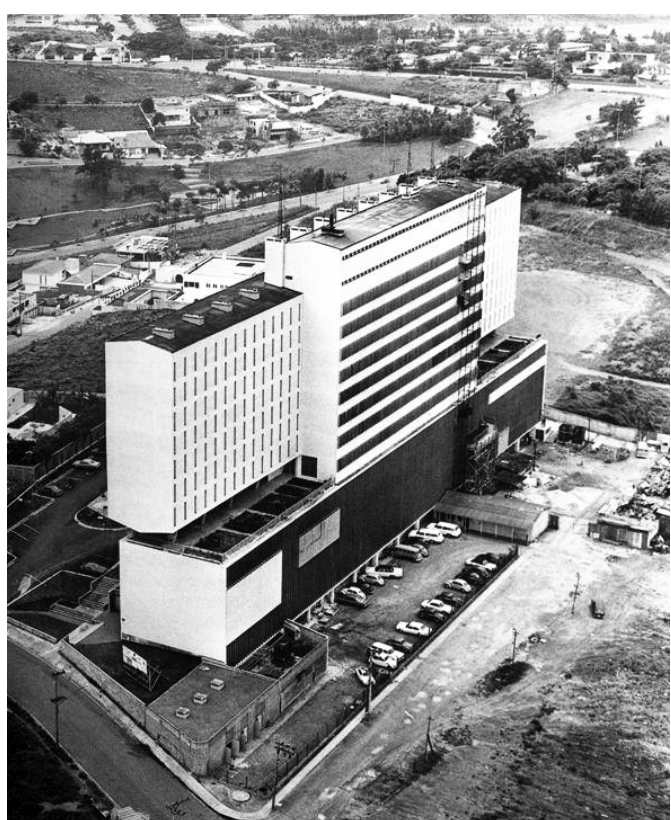

Em 1945, Rino Levi projetou a Maternidade da Universidade de São Paulo - USP (Fig. 33), obra que foi resultado de estudos profundos e contou com a colaboração de uma equipe multidisciplinar, formada por médicos e enfermeiros. Desta forma, desencadeou outros projetos, como o Hospital Antônio Cândido de Camargo do Instituto Central do Câncer (1947) em São Paulo. (Fig. 34).
Figura 31 - Hospital das

Clínicas da Universidade de São Paulo - USP, São Paulo, SP (1944).

(Fonte: INSTITUTO DE ARQUITETOS DO BRASIL, 1954).

Figura 32 - Hospital Israelita Albert Einstein, projeto do arquiteto Rino Levi, São Paulo, SP (1957).

(Fonte: LERER, B., 1996). 
Figura 33 - Maternidade da Universidade de São Paulo, projeto do arquiteto Rino Levi, São Paulo, SP, (1945). (Fonte: ANELLI, R.; GUERRA, A., 2001).

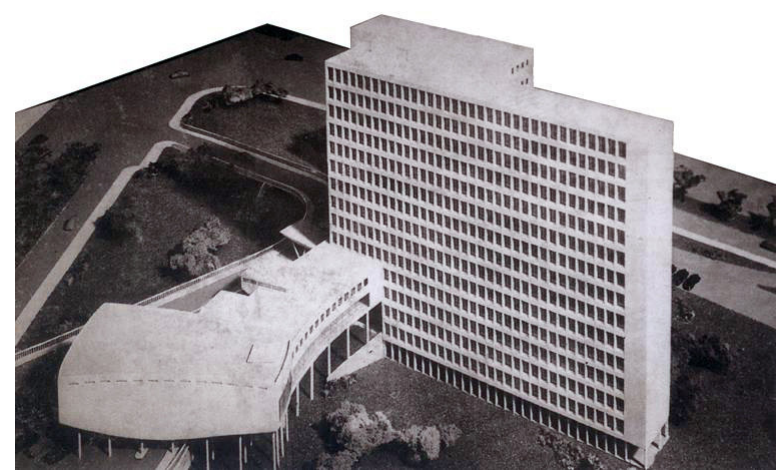

Figura 34 - Hospital Antônio Cândido de Camargo, projeto do arquiteto Rino Levi, São Paulo, SP, (1947).

(Fonte: ANELLI, R.; GUERRA, A., 2001).

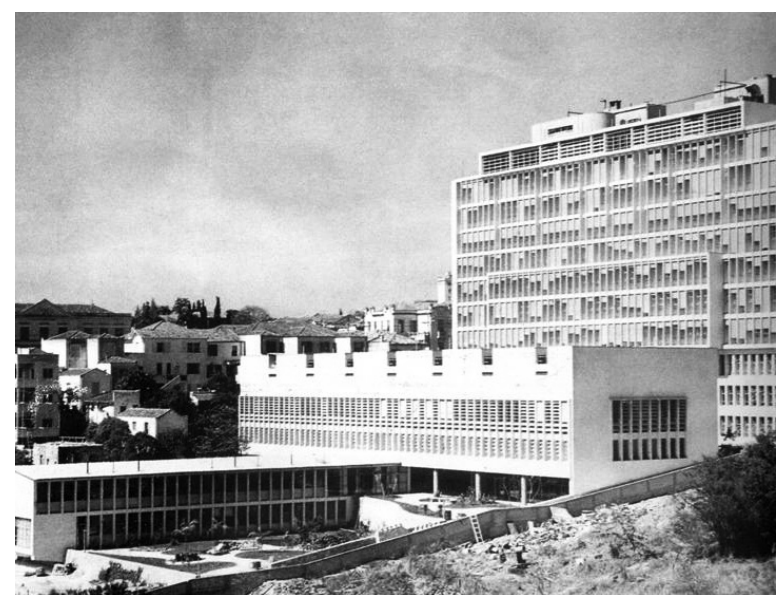

Nestes dois trabalhos, o arquiteto procurou estruturá-los a partir da leitura precisa das diversas circulações e fluxos internos. A organização geral do edifício se baseia em seu macrozoneamento funcional, bem como relações de contiguidade entre os espaços. Mediante o croqui perspectivado para o Instituto Central do Câncer, é possível interpretar a complexidade dos serviços e sua interatividade funcional. (Fig. 35). 
Grafico n.० 1

Esquema Geral da Circulasio do Hospital Antonio C do Camargo

Os acessos sáo feitos pelo 4.0 Pavimento. Devido à conformaçáo do terreno o Hospital tem 3 povimentos abaixo do nivel do rua.

Sás provistos 5 ocessos diferentes:

1.0 - Servico (moteriol a pessool subalterno

20 - Pronto Socorro isom de omergetncio pacientes tranipor.

tados em mocol

$33^{\circ}$ - Geral (pacientes para internaçóo, visitontes, médicos o. en

(ermeiros!

$40^{\circ}$ - Pacientes externos (poro consulta ou "otomento)

Toda o circuloşóo verticol e feito pelos 4 elevadores (vêr resposta a pergunto n. 1). A seperasáa dos elevadores em 2 grupos decorre

da necessidode do seporocao entre pagantes e grotuitos

O. 2 andares destinados o tratamentos o sonsultos estóo respectivamente $1,50 \mathrm{~m}$ abaixo e acima do $44^{\circ}$ pavimento o e èle ligados por rompos.
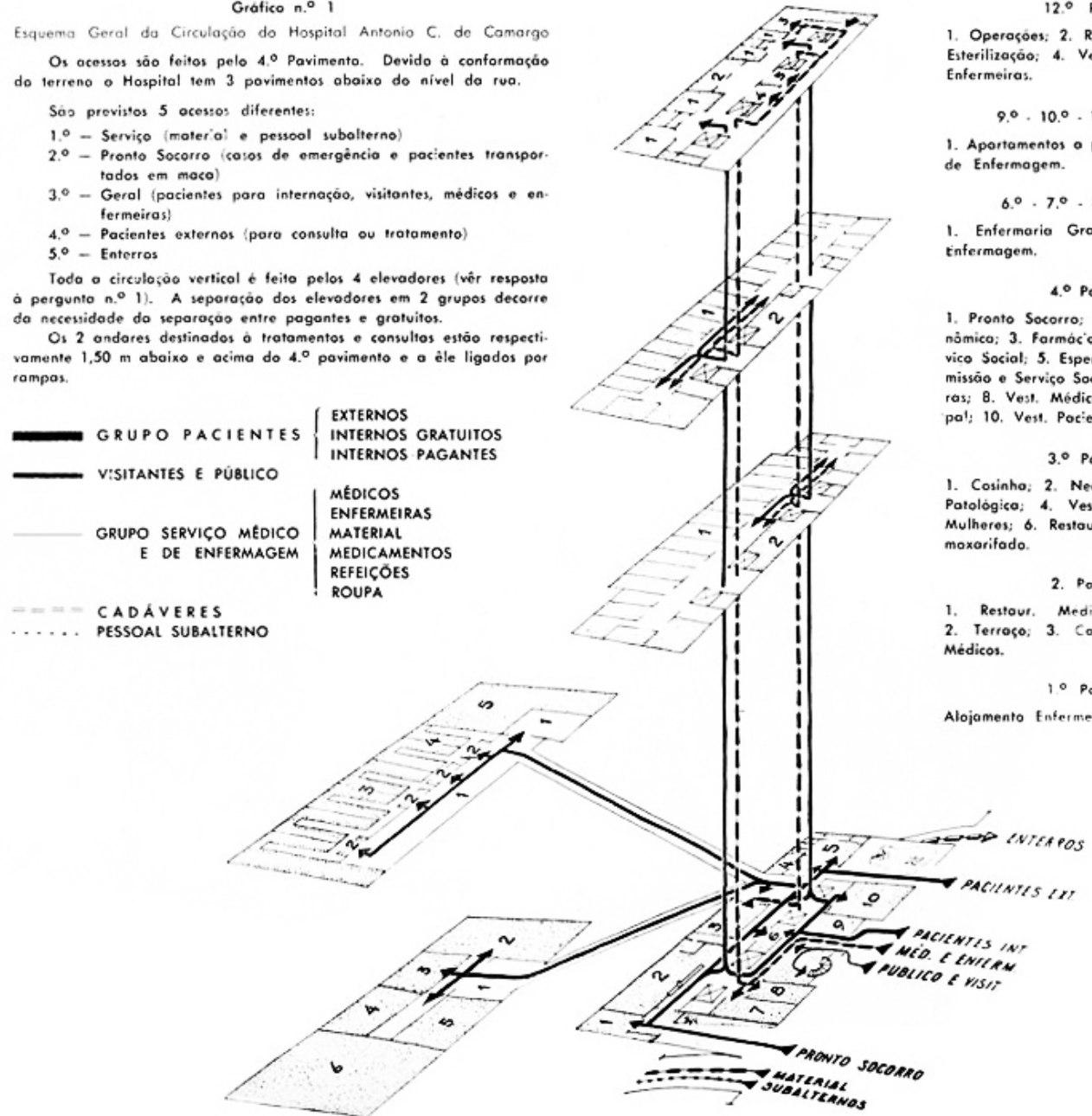

Figura 35 - Estudo de fluxos para o Instituto Central do Câncer (1947).

(Fonte: INSTITUTO DE ARQUITETOS DO BRASIL, 1954).

Na abertura do primeiro curso de Planejamento de Hospitais realizado no auditório do Museu de Arte de São Paulo, durante a semana de 13 a 17 de abril de 1953, Rino Levi como presidente do IAB (Instituto de Arquitetura do Brasil - departamento de São Paulo) expõe a importância do evento como um marco de referência nas discussões sobre o edifício hospitalar. (Fig. 36).

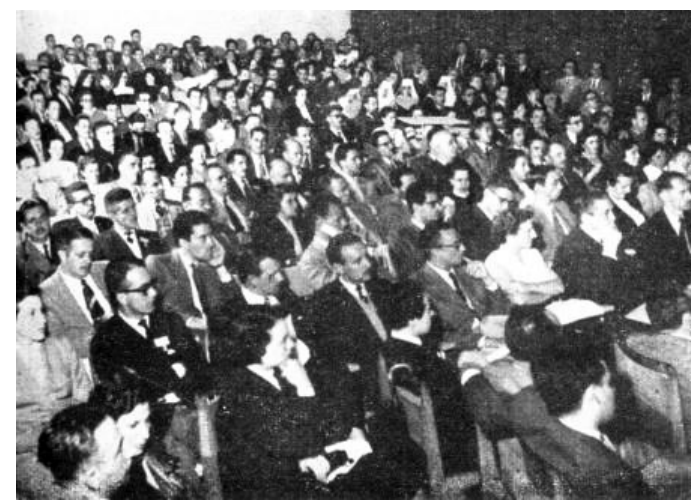

Figura 36 - Foto abertura do evento (1953).

(Fonte: INSTITUTO DE ARQUITETOS DO BRASIL, 1954). 
Ainda naquele momento, o arquiteto Roberto Cerqueira César (1953, p. 109) observou que,

[...] a complexidade do problema resulta não somente da necessidade de encontrar soluções flexíveis, que se adaptem a futuras modificações da organização interna, inevitáveis com a constante e vertiginosa evolução da medicina e, conseqüentemente, da técnica hospitalar em nossos dias.

Por meio deste depoimento, observam-se as preocupações ainda hoje preconizadas, como a flexibilidade espacial e a expansibilidade das edificações.

Como um dos organizadores deste evento, o arquiteto Jarbas Karman iniciou sua trajetória de envolvimento com a área de saúde e, ao longo destes últimos 50 anos, influenciou com seus estudos e propostas arquitetônicas toda uma legião de profissionais compromissados com o tema. Em 1957, participando do concurso de projetos para edificar o Hospital Santa Mônica em Belo Horizonte - MG, Karman inovou com a criação de minipostos de enfermagem em unidades de internação e também com a proposta de Unidade de Terapia Intensiva (UTI).

Durante toda a década de 1940, ao longo do período de guerra e pós-guerra, a construção de novas unidades hospitalares foi pequena. Observa-se neste período o avanço na construção de hospitais militares americanos junto aos países aliados, os quais tinham como proposta, a pré-fabricação construtiva e estes possuíam a capacidade variável entre 25 a 200 leitos. A préfabricação como sistema construtivo na área hospitalar surge no Brasil apenas nos anos 1970, pela iniciativa dos arquitetos João Carlos Bross (Consórcio BDSL, Siemens e Sewlease), João Filgueiras Lima nos projetos da Rede Sarah (1979), e ainda dos arquitetos Eduardo Kneese de Mello e Sidnei de Oliveira na obra do Ambulatório do INPS, em Tatuapé - SP, em 1973.

Com o acelerado crescimento do conhecimento no campo da medicina, a diversificação das especialidades médicas, a criação de inúmeros novos cursos de medicina, enfermagem entre outros, avanços tecnológicos na geração de equipamentos médicos hospitalares, o hospital, a partir dos anos 1950, passou por um processo de transformação no qual foi induzido a exercer o papel de abrigar toda esta complexidade de serviços e equipamentos em 
que as respostas nem sempre foram tão rápidas para acompanhar o ritmo e evolução daquele momento solicitado.

Algumas unidades hospitalares em determinadas especialidades espalhadas pelo mundo passaram a ser referências mundiais como Cleveland e Clínica Mayo nos Estados Unidos, onde extrapolaram o âmbito regional e se colocaram na vanguarda do tratamento médico, no uso de equipamentos de última geração, inovação das rotinas e procedimentos hospitalares, como também na criação de espaços compatíveis com o seu momento histórico.

O transplante do coração realizado pelo médico Christian Barnard, em 1967 e pelo Dr. Euriclydes Zerbini, em São Paulo (1968), o "bebê de proveta" realizado pelos doutores Patrick Steptol e Robert Edwards, na Inglaterra (1978), equipamentos de tomografia e ressonância magnética, no início dos anos 1980 e a clonagem da ovelha Dolly, por Ian Wilmut, na Escócia (1996) mostram a abrangência desta evolução. Talvez a magnitude quase que imensurável, se considerar que o desdobramento destes fatos, pesquisas e procedimentos vieram a refletir em outras áreas do conhecimento humano.

Ao final dos anos 1940, surge nos países europeus a proposta do Welfare State, devido à expansão do capitalismo após a Revolução Industrial e o movimento de um Estado Nacional, visando a democracia. O Welfare State é uma transformação do próprio Estado a partir das suas estruturas, funções e legitimidade. A proposta fundamenta-se na concepção de que existem direitos sociais indissociáveis a existência de qualquer cidadão.

Conforme Médice (1999, p. 3), todo o indivíduo tem o direito desde seu nascimento, a um conjunto de bens e serviços que deveria ser fornecido diretamente pelo Estado ou, indiretamente, mediante seu poder de regulamentação sobre a sociedade civil. Estes direitos compreendem desde a cobertura de saúde e educação em todos os níveis, até o auxilio ao desemprego; a garantia de uma renda mínima, recursos adicionais para sustentação dos filhos etc.

A proposta de descentralização dos serviços de saúde, ocorrido no início dos anos 1950 na Inglaterra, proporcionou uma melhor 
distribuição do atendimento ao paciente, promovendo eficácia dos serviços e ainda programas preventivos de vacinação, orientação educacional em diversas áreas de atuação como: uso de drogas, doenças sexualmente transmissíveis, aleitamento materno, gravidez etc.

O reflexo deste modelo de saúde ocorre no Brasil apenas em meados dos anos 1970, com a criação do Instituto Nacional de Alimentação e Nutrição do Funrural e, posteriormente, das Ações Integradas de Saúde (AIS) e do SUS (Sistema Único de Saúde).

O programa nacional de AIS, no âmbito do município, propôs a descentralização e a hierarquização dos serviços de saúde, mediante o atendimento ao paciente pelo nível da gravidade de atenção. Este programa estabelece três níveis de serviços, sendo que o primeiro (básico) será desempenhado pelas unidades básicas de saúde espalhadas no interior do seu perímetro urbano e ainda definidas pela abrangência do seu território, o qual compreende uma população de aproximadamente 3.000 habitantes.

O nível secundário com o atendimento intermediário de atenção à saúde foi o papel de referência e contrarreferência do paciente para os serviços médicos hospitalares até média complexidade. Faz parte deste grupo, o ambulatório geral e de especialidades, unidades mistas e hospitais de pequeno e médio porte.

O nível terciário, compreendendo os hospitais regionais e de grande porte, faz o papel de atender aos pacientes que necessitam de serviços de alta complexidade, conforme modelo apresentado pela Portaria 400 - Ministério de Saúde em 06/12/1977. (Fig. 37). 


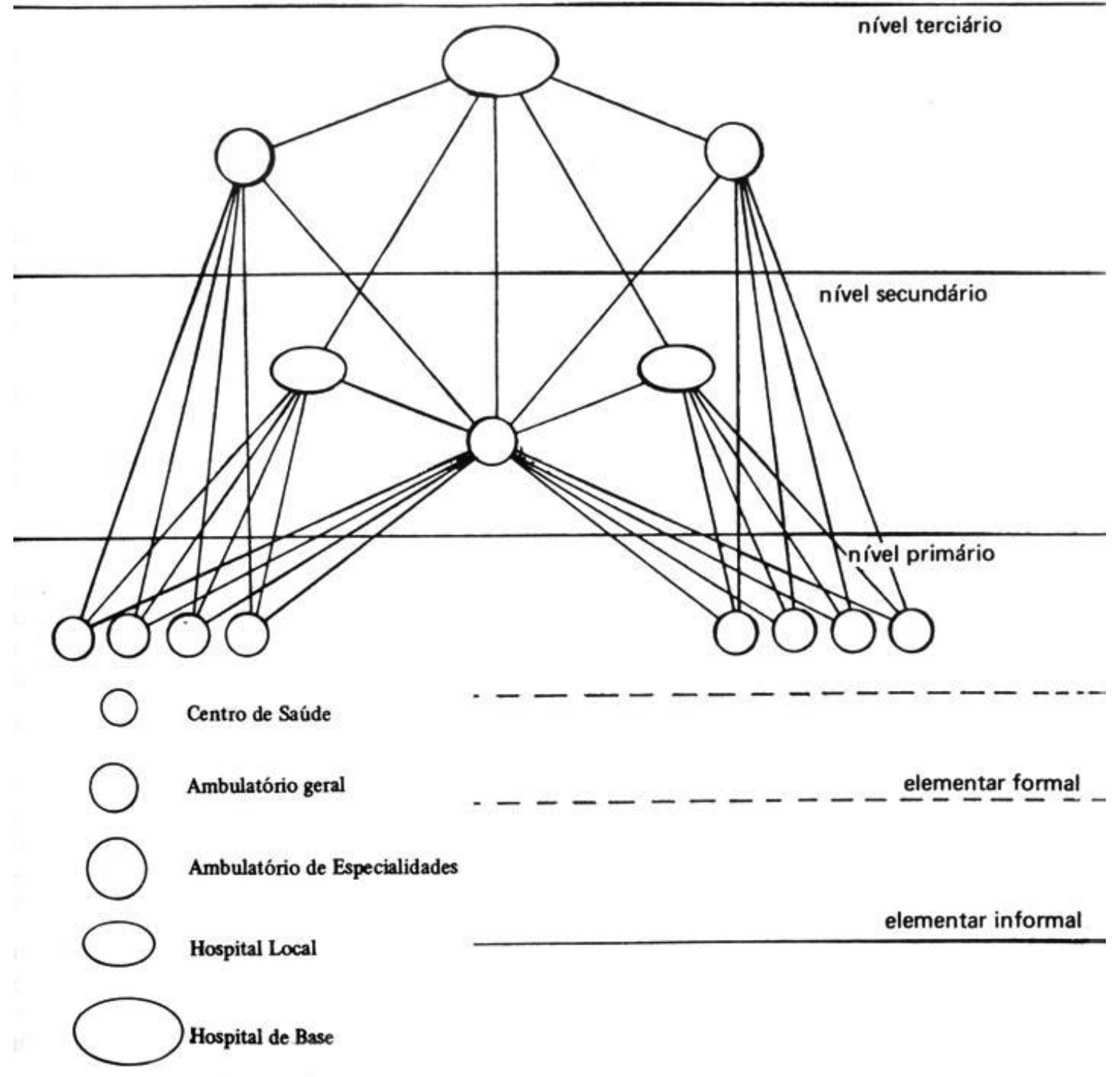

Figura 37 - Esquema do Sistema Hierarquizado de Saúde.

(Fonte: BRASIL, 1977).

Este modelo é positivo do ponto de vista de redução significativa do deslocamento de pessoas à busca dos serviços de saúde. A unidade de bairro (UBS) promove a proximidade com a vizinhança local, e o serviço descentralizado significa menor demanda por unidade, o que reflete no tempo de espera para o atendimento ambulatorial. Ao mesmo tempo em que esta mesma população deixa de procurar o serviço hospitalar, neste nível de complexidade, o ambulatório clássico de clínicas incrustado fisicamente no edifício hospitalar perde sua razão de ser. Portanto, o ambulatório dissocia-se da unidade hospitalar e implanta-se junto aos bairros. 
Concomitantemente com a reestruturação na política do atendimento dos serviços de saúde, surgem programas governamentais que vêm impactar na organização física das unidades hospitalares, como o alojamento conjunto das parturientes e recém-natos, a permanência dos pais junto ao leito pediátrico e a possibilidade de aproximação dos familiares junto aos leitos da Unidade de Terapia Intensiva, são apenas alguns exemplos de mudanças e interferência na organização física dos edifícios de saúde.

A partir dos anos 1960 e 1970, com o acelerado processo de urbanização brasileiro e consequente demandas por serviços essenciais, entre eles a saúde, levou o Ministério da Saúde a reorganizar as normas para edificação hospitalar. Ao longo deste período surgiram "normas e padrões de construções e instalações de serviços de saúde", as quais nortearam e disciplinaram as avaliações sobre os edifícios de saúde.

1965 - Projeto de Normas Disciplinadoras das Construções Hospitalares;

1977 - Normas e Padrões de Construções e Instalações de Serviços de Saúde (Portaria 400);

1994 - Normas para Projetos Físicos de Estabelecimentos Assistenciais de Saúde (Portaria 1884);

2002 - Regulamento Técnico para Planejamento, Programação, Elaboração e Avaliação de Projetos Físicos de Estabelecimentos Assistenciais de Saúde (RDC no 50 - ANVISA).

Além dessas portarias (normas e resoluções), o edifício hospitalar existente, ou ainda os novos empreendimentos, tiveram que se adaptar a outras legislações publicadas neste período; tais como:

1993 - NBR 9077 - Saídas de Emergências em Edifícios;

1990 - NBR 9050 - Adequações das Edificações e do Mobiliário Urbano à Pessoa Deficiente;

Portaria 985 - Centro de Parto Normal / SUS;

Portaria 1091 - Unidade de Cuidados Intermediários Neonatal;

Resolução 306 - Regulamento Técnico para Gerenciamento de Resíduos Sólidos nos Serviços de Saúde; entre outras.

No início dos anos 1970, em algumas cidades surgiram propostas de construções de hospitais públicos com o objetivo de 
melhorar o atendimento ao paciente e principalmente a busca da descentralização dos serviços e ainda o seu enquadramento no modelo nacional de atenção. Esta proposta visava, inicialmente, $o$ atendimento ao nível de baixa e média complexidade. Alguns exemplos desta proposta são:

- Hospital Municipal de Campinas - SP (Fig. 38)

- Arquitetura: Jorge Wilheim Consultores Associados

Jorge Wilheim arquiteto

José Magalhães Jr.

Área total de aproximadamente $8.130,00 \mathrm{~m}^{2}$

Capacidade de 380 leitos

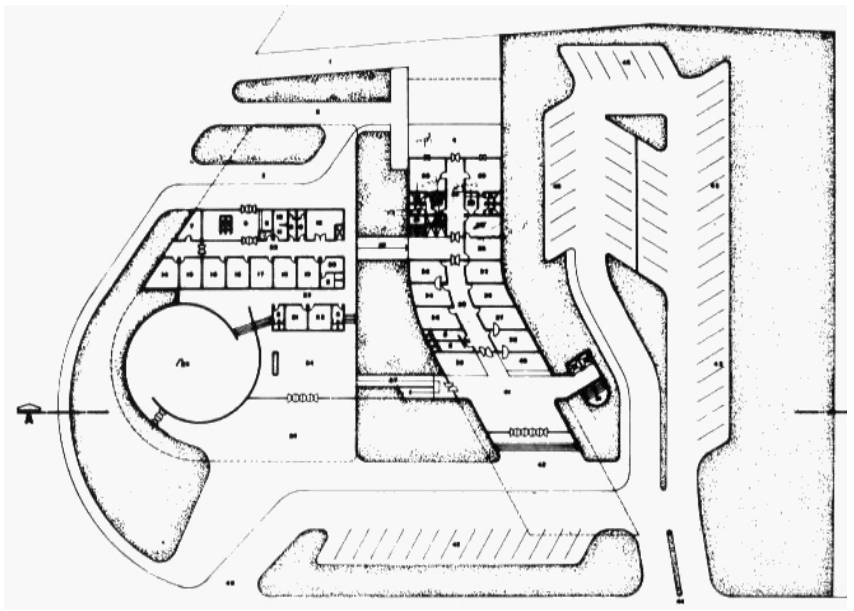

Figura 38 - Planta pavimento térreo.

(Fonte: Revista C. J. Arquitetura, 1977).

- Hospital Municipal de Santo André - SP (Fig. 39)

- Arquitetura: Rino Levi Arquitetos Associados Ltda.

Roberto Cerqueira César

Luis Roberto Carvalho Franco

Paulo Júlio Valentino Bruna

Área total de aproximadamente $22.700,00 \mathrm{~m} 2$

Capacidade de 250 leitos 
Figura 39 - Maquete do hospital (Fonte: Revista C. J. Arquitetura, 1977).

Figura 40 - Vista externa Pronto Socorro Municipal de Santos (1977)

(Fonte: Revista Projeto, 1980).

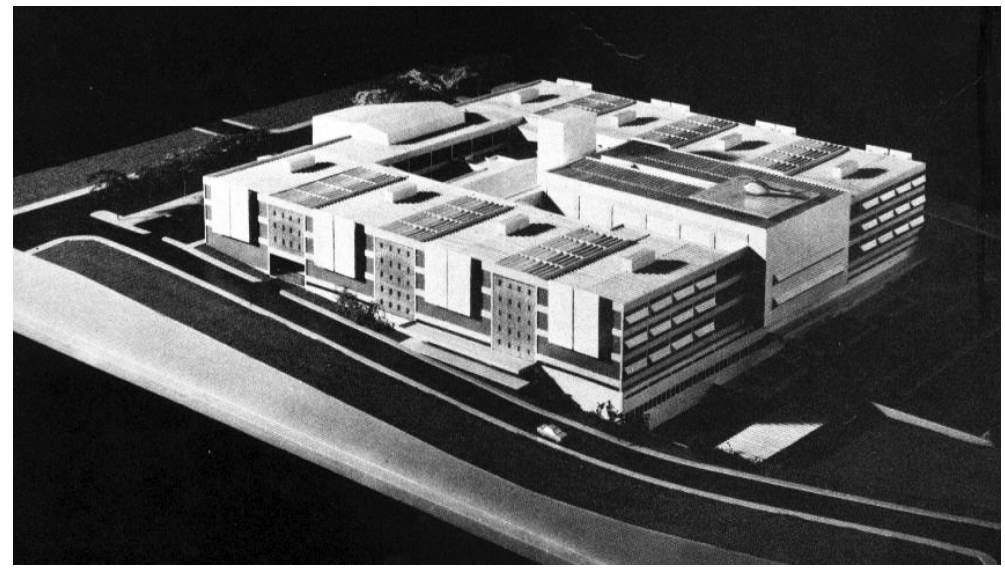

- Pronto Socorro Municipal de Santos - SP (Fig. 40)

- Arquitetura: Benno Michael Perelmutter

Oswaldo Corrêa Gonçalves

Área total de aproximadamente 2.300,00 m²

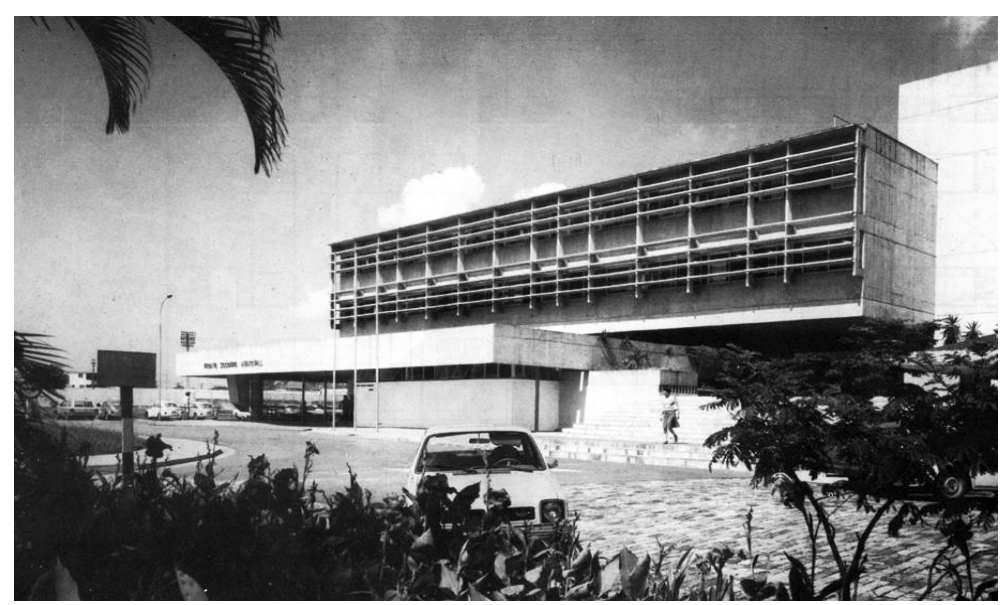

Durante os anos 1970, a produção mundial, no que se refere ao edifício hospitalar, possui no McMaster Health Sciences Centre uma das maiores referências na complexidade de serviços de saúde construída até aquele momento. (Fig. 41). 


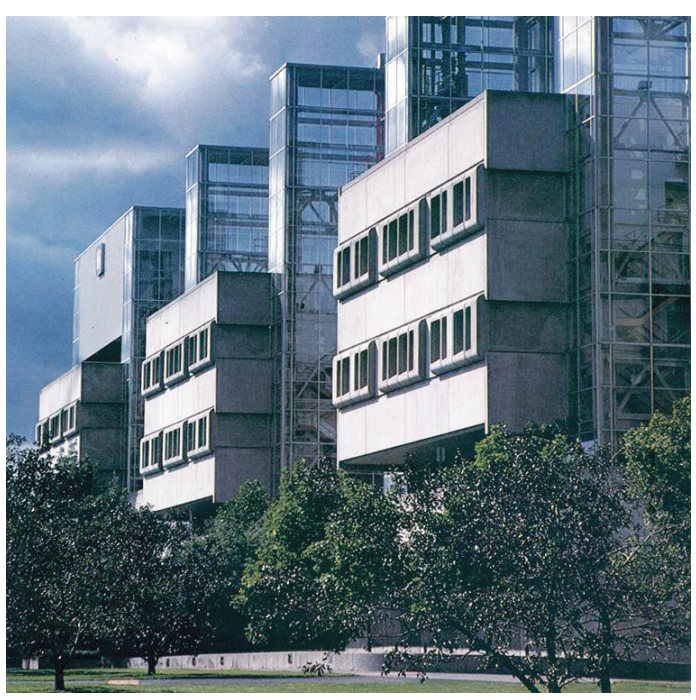

Com área de aproximadamente $196.000,00 \mathrm{~m}^{2}$ de construção, e 418 leitos para internação, possui em torno de $45.000,00 \mathrm{~m}^{2} \mathrm{de}$ área somente para ensino, pesquisa e programas de educação continuada. O complexo McMaster erguido na cidade de Hamilton em Ontário, no Canadá, e projetado pelo escritório Zeidler Roberts Partnership Architects, teve como proposta a incorporação da mais alta tecnologia construtiva e inserção de equipamentos de última geração. Os arquitetos apresentam soluções para a flexibilidade espacial, com a criação de "shafts" verticais onde abrigam, além de caixas de escadas e elevadores, todos os tipos de instalações utilizadas no complexo hospitalar. Além disso, propõem ainda o uso dos espaços intersticiais para instalações em geral, no plano horizontal, em grandes áreas do edifício, possibilitando assim manutenção facilitada e preventiva. (Fig. 42).
Figura 41 - Vista externa McMaster Health Sciences Centre (1973)

(Fonte: foto do autor). 


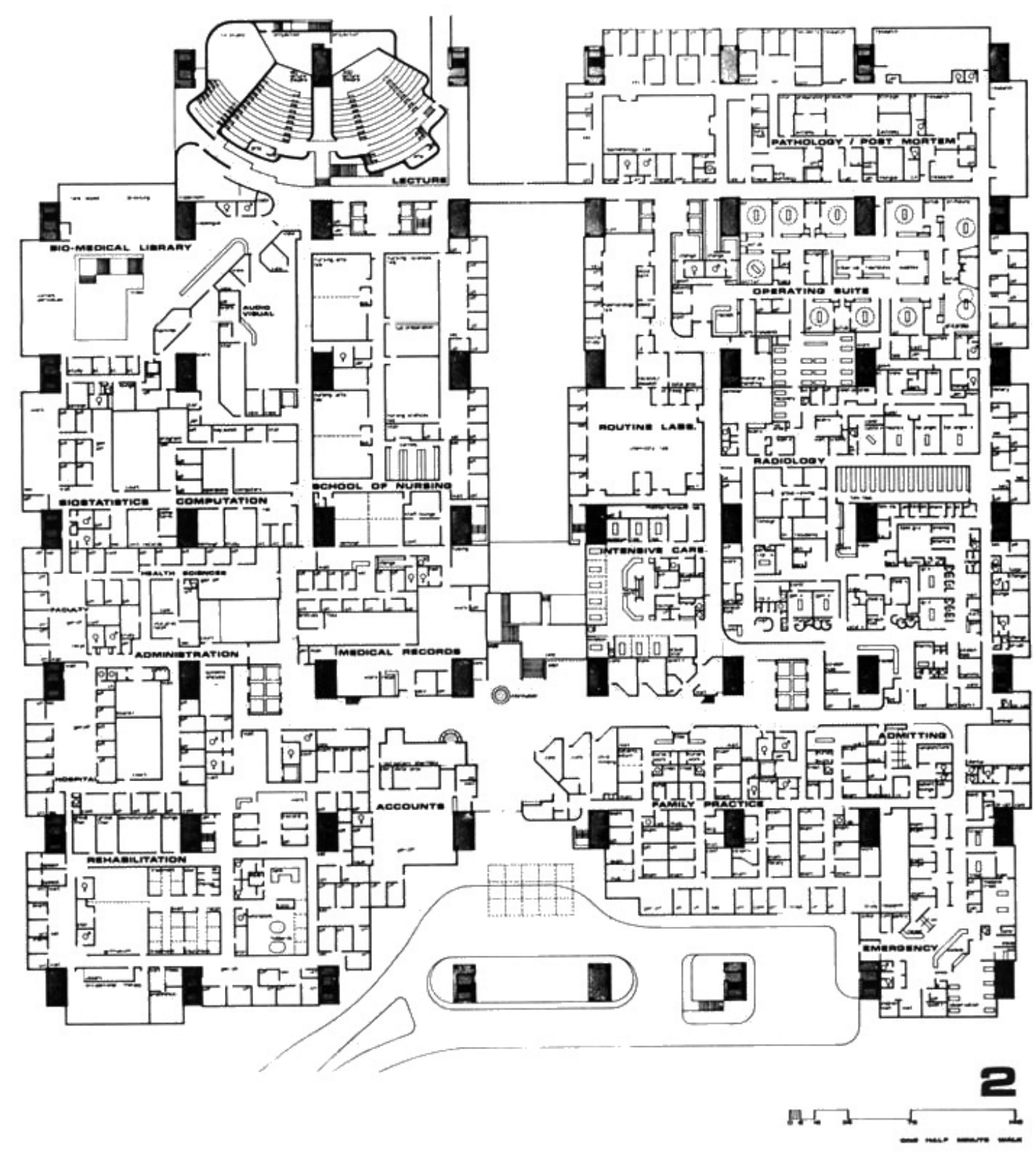

Figura 42 - Planta pavimento térreo McMaster Health Sciences Centre (1973)

(Fonte: autor).

Por meio da solução estrutural modular e articulada (Fig. 43), os arquitetos garantem a expansibilidade do edifício para momentos futuros, quando da necessidade de agregar novos serviços ou ainda com o crescimento de unidades existentes que sofreram aumento de demanda, ou até mesmo adequação para novos equipamentos, bem como alteração nos métodos de procedimentos médicos e de enfermagem. 
Quando da sua conclusão em 1973, o McMaster Health Sciences Centre com sua proposta plásticavolumétrica transmitia o pensamento daquele momento, em que a alta tecnologia na sua maior abrangência possível foi ofertada à população mundial. Talvez pelo uso de determinado tipo de materiais e a dureza dos seus volumes cúbicos, este transmitia a pequena "aproximação" com o seu usuário.

Não somente nos países europeus e nos Estados Unidos, mas também no Brasil ao longo dos anos 1960, 1970 e 1980, ocorre a criação de inúmeros
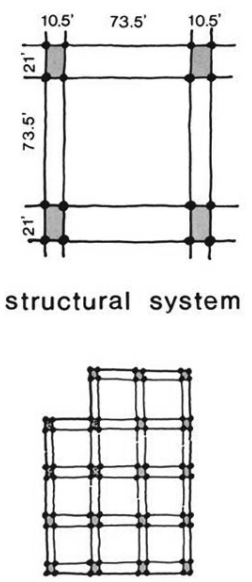

building system incremental growth

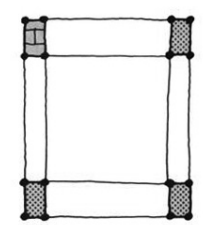

mechanical system air. piping, $\&$ electrical combined

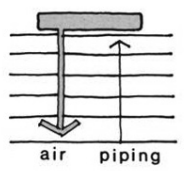

section cursos de medicina, enfermagem e em outros campos da saúde, provocando a necessidade de provir o local de trabalho para a prática profissional, sendo adequado para o desenvolvimento as atividades de atenção à saúde.

Por volta de 1968, por meio de concurso público da secretaria Figura 43 - Sistemas estrutural e de instalações do McMaster Health Sciences Centre (1973).

(Fonte: autor). de Higiene e Saúde da Prefeitura Municipal de São Paulo, o arquiteto Siegbert Zanettini com sua proposta arquitetônica conquista o primeiro lugar para o desenvolvimento do referido projeto da Maternidade Escola Vila Nova Cachoeirinha. (Fig. 44).

Com sua proposta inovadora na organização geral do projeto (macrozoneamento), a melhora da qualidade espacial das unidades e as preocupações com o entorno imediato propõe uma nova leitura ao segmento da arquitetura hospitalar.

Outros edifícios foram construídos para atender a este objetivo como, o Hospital das Clínicas da Universidade Estadual de

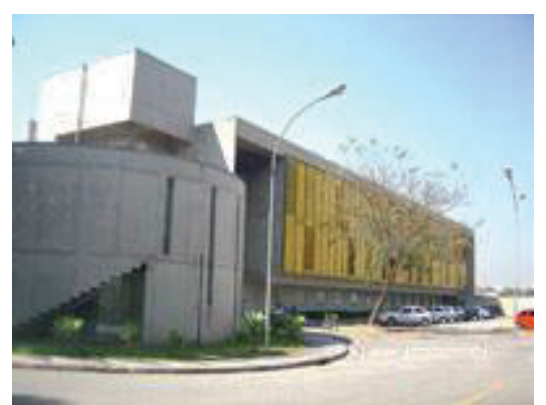

Figura 44 - Hospital e Maternidade Vila Nova Cachoeirinha (1968).

(Fonte: ZANETTINI, S., 2002). Campinas - SP (Fig. 45), o Hospital Universitário da Universidade de São Paulo - SP (Fig. 46), e o Hospital Escola Júlio de Mesquita Filho - Irmandade Santa Casa de Misericórdia de São Paulo - SP (Fig. 47 e 48).

- Hospital das Clínicas da Universidade Estadual de Campinas, $S P-1973$

Arquitetura BDSL - Bross, dos Santos e Leitner Arquitetura

Área total: $52.000,00 \mathrm{~m}^{2}$

Capacidade de 400 leitos 
Figura 45 - Maquete.

(Fonte: Revista C. J. Arquitetura, 1977)

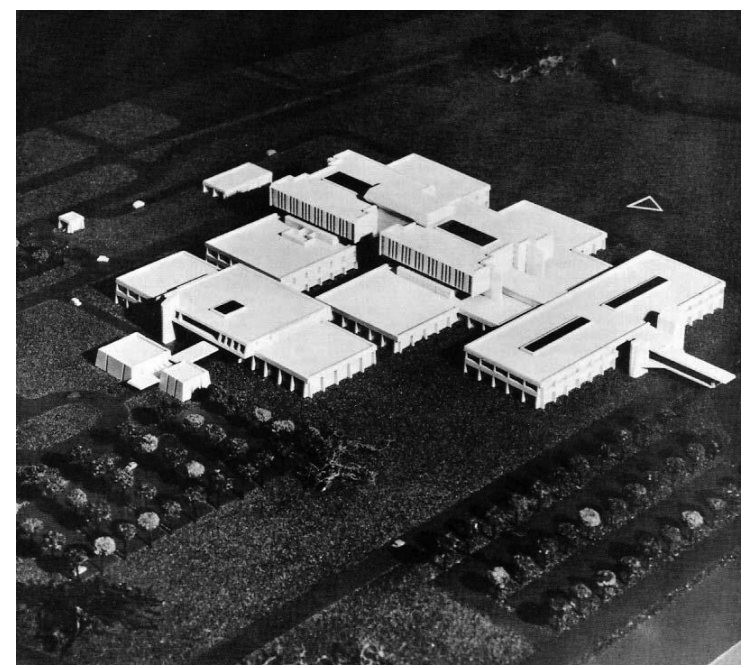

- Hospital Universitário da Universidade de São Paulo, SP - 1973 Cidade Universitária Armando de Salles Oliveira

Área de aproximadamente 67.500,00 m2

Capacidade de 416 leitos

Figura 46 - Maquete

(Fonte: Revista C. J. Arquitetura,

1977)

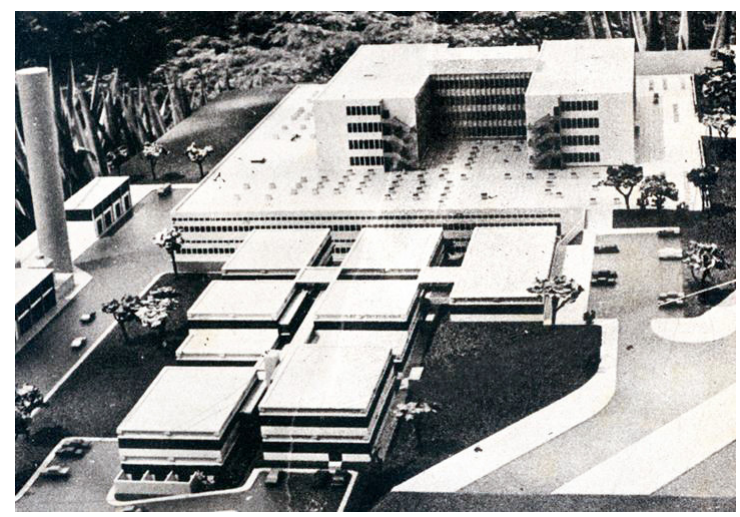

- Hospital Escola Júlio de Mesquita Filho - Irmandade Santa Casa de Misericórdia de São Paulo, SP - 1973

Arquitetura - Fábio Penteado / Teru Tamaki / Tito Lívio Francino / Eduardo de Almeida / Giselda Viscondi / Hércules Merigo

Área total: 73.790,40 m2

Capacidade de 400 leitos 


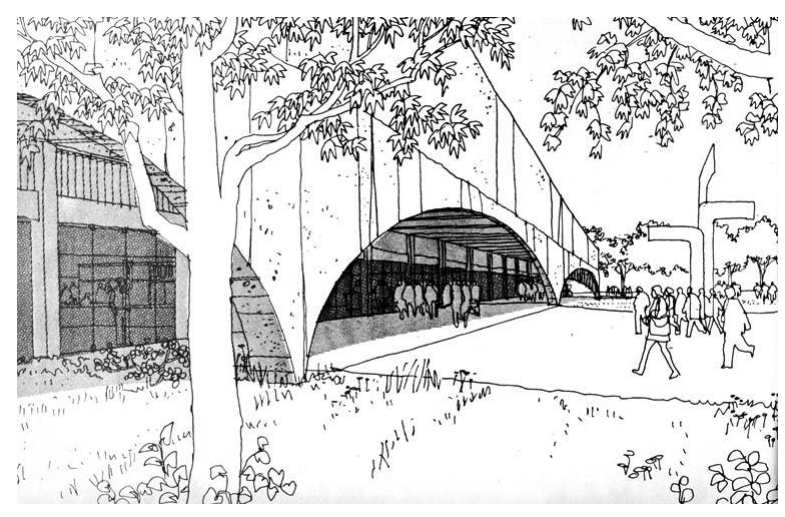

Figura 47 - Perspectiva.

(Fonte: Revista C. J. Arquitetura, 1977).

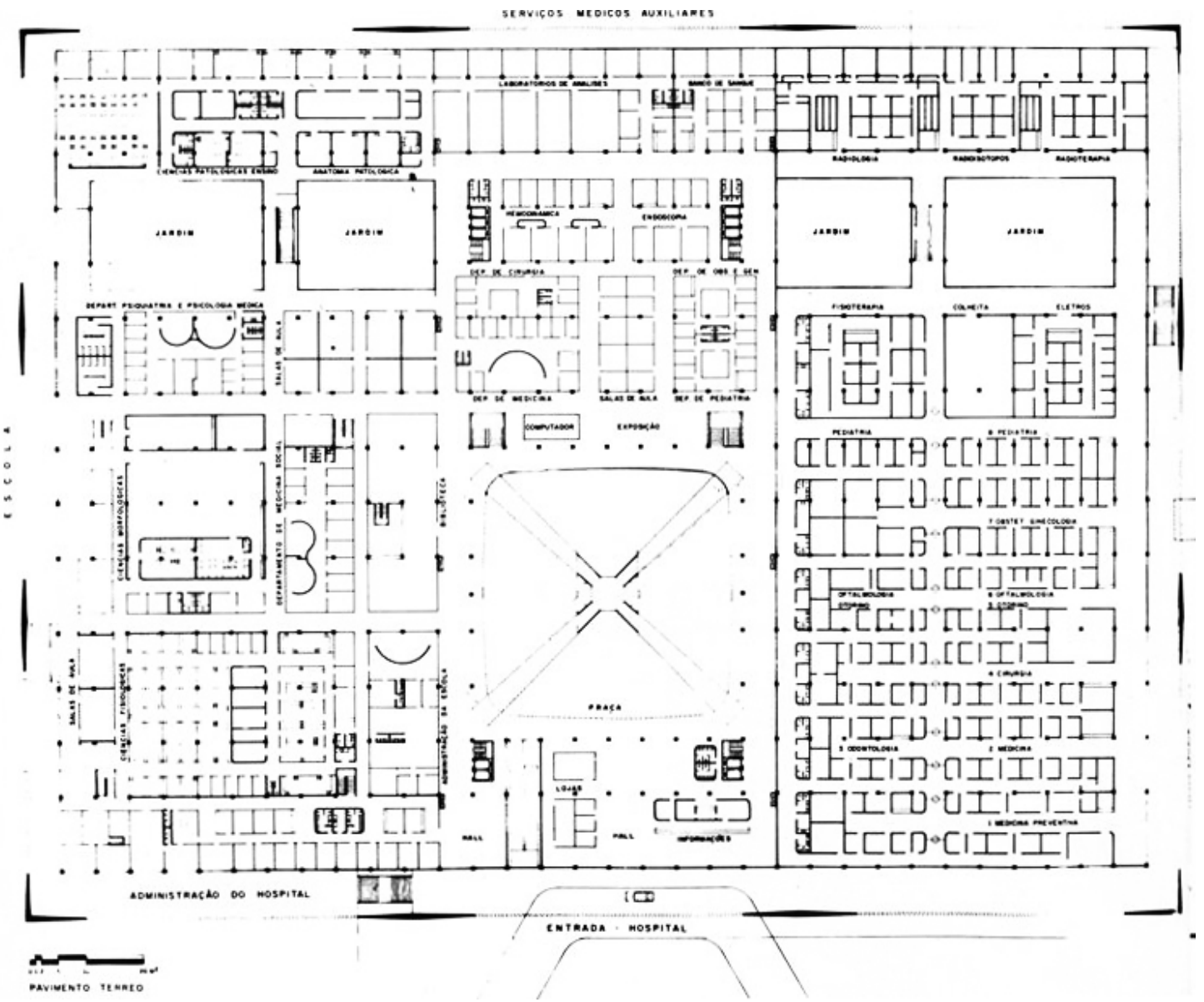

Como ressalta Karman (1980, p. 2), as instituições de saúde deveriam possibilitar o bom desempenho de todas as importantes funções que dela se espera. $\mathrm{O}$ bom resultado depende de alguns fatores como o lugar, o povo, os costumes, as condições sociais, culturais, econômicas, geográficas, desenvolvimento, densidade populacional, taxa de crescimento, recursos físicos e humanos, prevalência de doenças, endemias, distâncias, tamanho, existência ou não de rede hospitalar (referência e contrarreferência), vínculo com instituições vizinhas, programas sanitários, conceituação, se
Figura 48 - Planta pavimento térreo.

(Fonte: Revista C. J. Arquitetura, 1977). 
isolado, misto, se de apoio a alguma outra instituição, se aberto à clínica privada, se servindo de centro de diagnóstico etc.

Ainda com a política descentralizada de serviços, é neste momento que se inicia o processo da fragmentação do hospital em unidades autônomas, como o pronto-socorro, ambulatórios, centros de diagnósticos, laboratórios de análises clínicas, serviços de processamento de hemoderivados etc.

Nos anos 1980 em diversos países, e na década de 1990 no Brasil, acompanhando esta tendência de retirada dos serviços de baixa e média complexidade do interior do edifício hospitalar, surgem os serviços de Day-Hospital e Unidades de Pronto-Atendimento em algumas especialidades médicas como cardiologia, oftalmologia, otorrinolaringologia, cirurgia plástica, ortopedia etc.

Com um processo inovador para aquele momento (1985), o projeto e a execução do Hospital de Ermelino Matarazzo, do arquiteto Siegbert Zanettini, possibilitou a participação popular e equipe multidisciplinar para atingir melhor seus objetivos e atender às expectativas de seus usuários. (Fig. 49 a 54).

Figura 49 - Hospital Municipal

Regional de Ermelino Matarazzo, São Paulo, SP - vista externa (1985).

(Fonte: ZANETTINI, S., 2002)

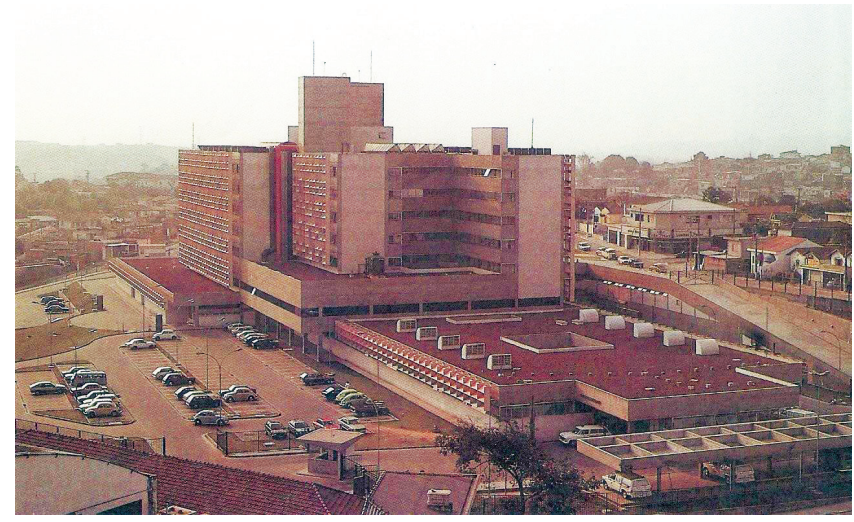

Figura 50 - Implantação

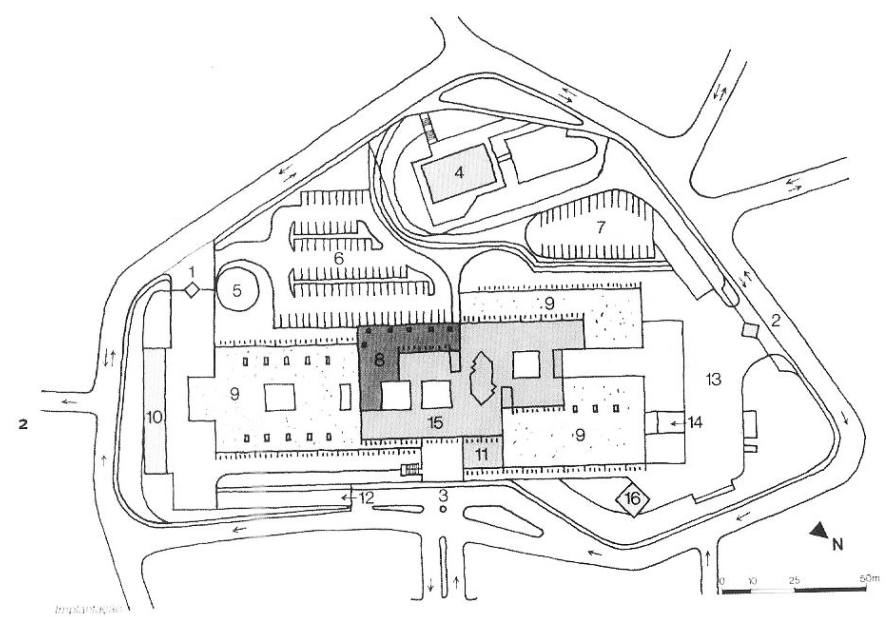

(Fonte: ZANETTINI, S., 2002) 

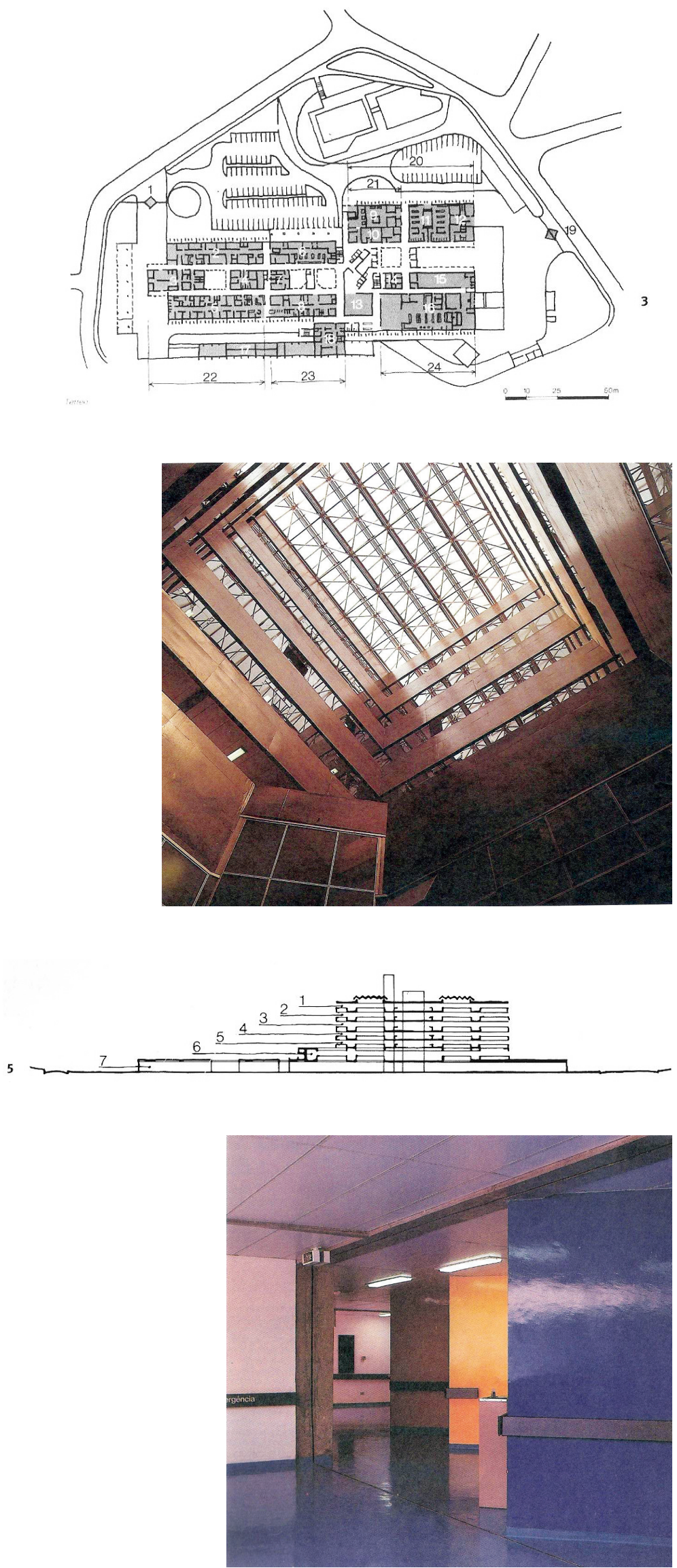

Figura 51 - Planta pavimento térreo

(Fonte: ZANETTINI, S., 2002)

Figura 52 - Pátio interno

coberto

(Fonte: ZANETTINI, S., 2002)

Figura 53 - Corte Longitudinal

(Fonte: ZANETTINI, S., 2002)

Figura 54 - Superfícies coloridas - Caracterizar espaços internos (Fonte: ZANETTINI, S., 2002) 
Este processo foi de encontro às transformações políticas e sociais que o país vivia, onde em 1982 houve, após vários anos de ditadura militar, as eleições para governadores e outros cargos públicos que promoveram a consolidação da democracia no Brasil.

A construção de Zanettini não se limitou apenas no citado processo. A partir dos anos 1980, o referido arquiteto propõe uma nova concepção construtiva para os padrões brasileiros, com o uso de estruturas metálicas, material este pouco comum nas importantes obras, onde na sua maioria era utilizado o concreto armado, como por exemplo o Hospital São Francisco, em Ribeirão Preto, SP. (Fig. 55 a 58).

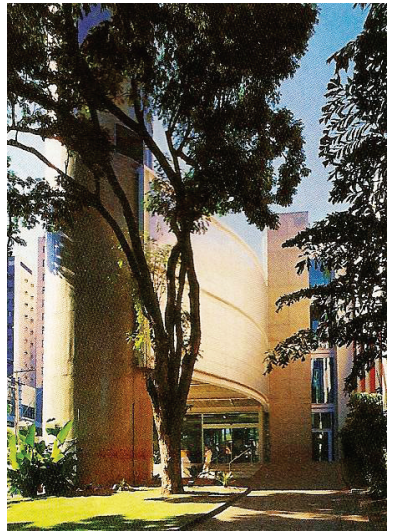

Figura 55 - Hospital São Francisco, Ribeirão Preto, SP vista externa de sua ampliação.

(Fonte: Revista $A U$, Ed. Especial, 2002)

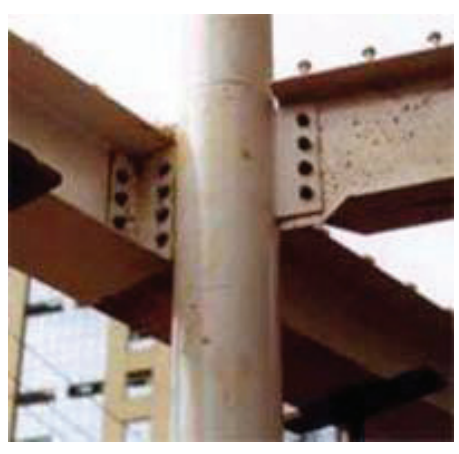

Figura 57 - Hospital São Francisco, Ribeirão Preto, SP detalhe da estrutura metálica. (Fonte: Revista $A U$, Ed. Especial, 2002)

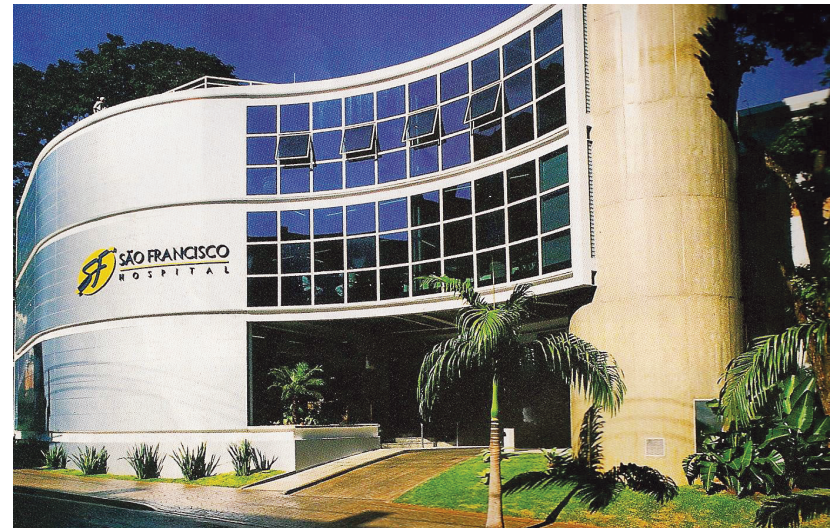

Figura 56 - Hospital São Francisco, Ribeirão Preto, SP - vista externa. (Fonte: Revista AU, Ed. Especial, 2002)

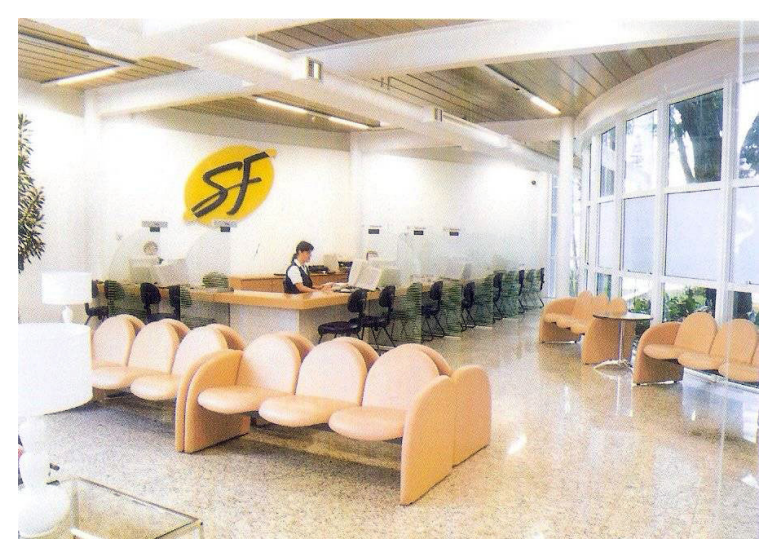

Figura 58 - Vista interna Recepção e espera - Hospital São Francisco Ribeirão Preto São Paulo

(Fonte: Revista AU, Ed. Especial, 2002) 
Em 1988, foi promulgada a nova Constituição Federal, a qual criou o Sistema Único de Saúde (SUS) e em 1990 o Congresso Nacional aprovou a Lei Orgânica do SUS que detalha o seu funcionamento e estabelece que "a saúde é direito de todos e dever do Estado". Como ressalta Giacomo (2005, p. 22), hoje, portanto, compete ao Ministério da Saúde uma série de atribuições para a organização do sistema de saúde no país, inclusive o de auxiliar no processo de produção do edifício hospitalar, o qual se tornou indispensável para a prática de uma boa medicina.

Durante as décadas de 1980 e 1990, o arquiteto João Filgueiras Lima, "Lelé", destacou-se por utilizar conceitos próprios aplicados diretamente ao projeto na área de ortopedia e traumatologia, junto aos hospitais da rede Sarah Kubitschek, como a humanização dos ambientes hospitalares, e ainda novas propostas ergonômicas para equipamentos de uso dos pacientes. Pode-se observar que a primeira proposta para o Hospital de Brasília, no final dos anos 1970 (Fig. 59, 60 e 61), construído em concreto armado, composto e articulado com painéis e cobertura pré-moldados, adiciona uma releitura do elemento arquitetônico "shed", com a finalidade básica de melhorar as condições de iluminação e ventilação natural no interior do edifício, o faz com um novo desenho e uma nova linguagem.
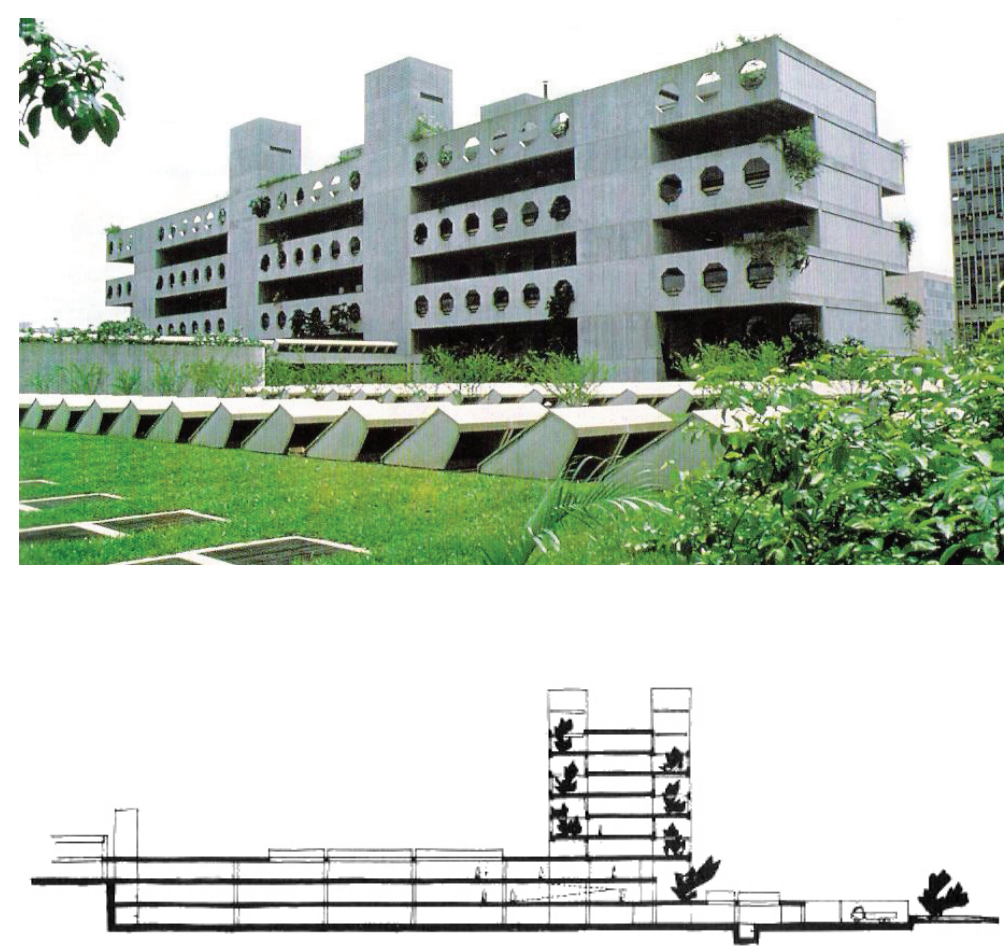

Figura 60 - Corte esquemático do hospital.

(Fonte: FUNDAÇÃO DAS PIONEIRAS SOCIAIS, 1980). 


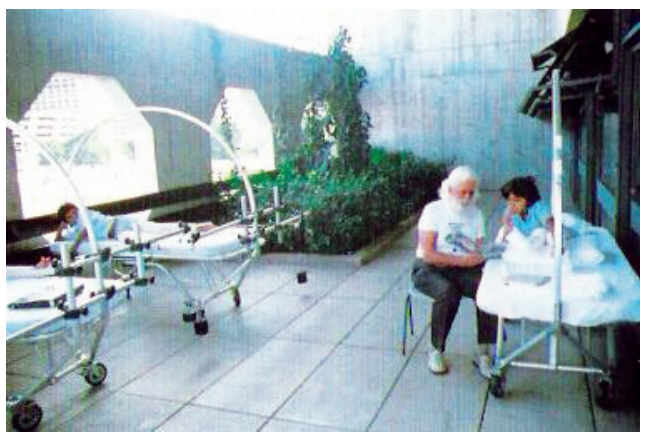

Ao mesmo tempo, resgata-se o espaço do terraço interligado às unidades de internação, onde encontramos no Hospital Weiblingen na Alemanha, em 1943 (Fig. 62), com o objetivo de atingir um tratamento mais humanizado ao paciente, melhorar as relações entre espaço interno com o externo, melhor insolação e ventilação natural para as unidades contíguas.

Figura 61 - Vista terraço das enfermarias - Hospital Sarah Kubitschek

(Fonte: INSTITUTO LINA BO e P. M. BARDI., 2000).

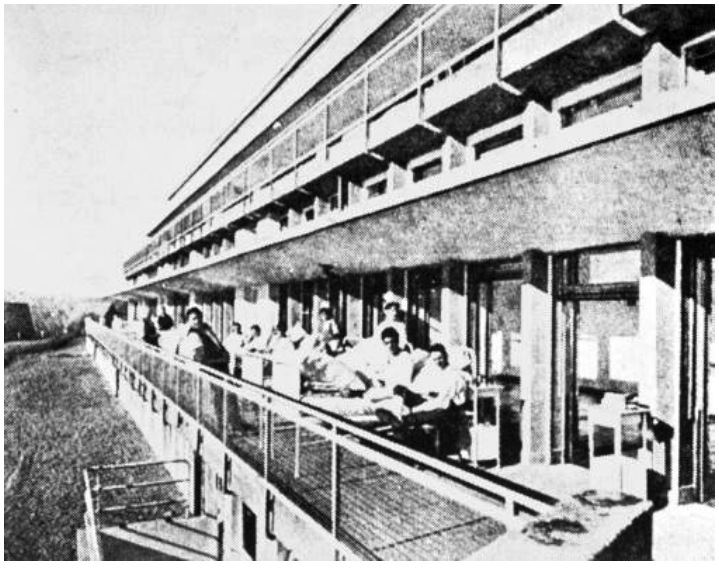

O trabalho de "Lelé" se modifica em termos de linguagem nas propostas dos hospitais da Rede Sarah para Salvador, Fortaleza (Fig. 63), Natal e Rio de Janeiro, onde diminui o uso do sistema estrutural em concreto armado e passa a utilizar as estruturas metálicas nos novos edifícios. Porém, o princípio básico conceitual relacionado ao paciente e sua interação com o ambiente hospitalar se mantém em todas estas novas experiências.

Em se tratando sobre humanização do espaço, têm-se nesta defesa todo um processo de transformação no atendimento médico / enfermagem em relação ao paciente, iniciado ao final dos anos 1970, no qual se procurou estabelecer uma relação mais próxima, mais interativa e até mesmo desmistificada entre as pessoas envolvidas no processo. Acredita-se que
Figura 62 - Vista do terraço das enfermeiras

(Fonte: ROSENFIELD, I., 1965). este processo foi o ponto de partida para uma revisão no modelo de ensino da medicina (início dos anos 1990), e posteriormente nas demais áreas da saúde como enfermagem, bioquímica, farmácia, assistência social, entre outras, que foi a implantação do sistema PBL de ensino (Problem Based Learning), com uma proposta mais humanística, enxergando o homem como um

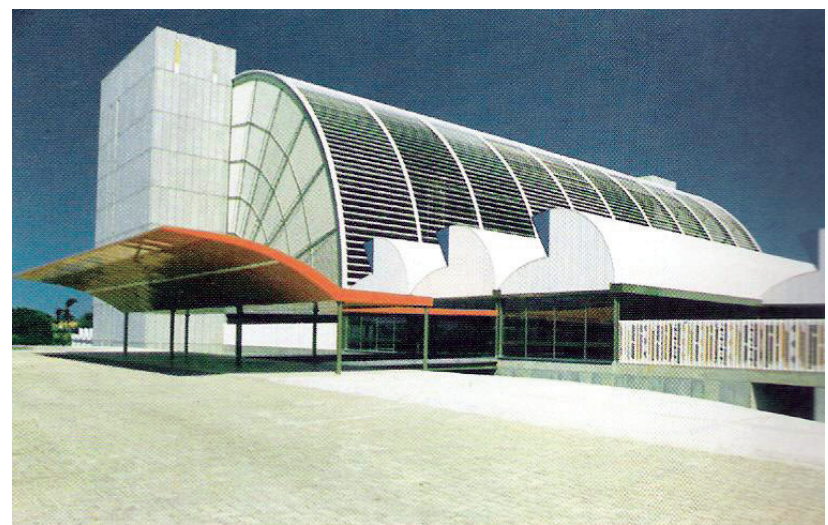


todo, desde o seu nascimento, infância, adolescência, fase adulta, senescência e morte. Enxergar o todo e, principalmente, incluílo no contexto urbano social, cultural, político, econômico e ecológico em que vivemos. O reflexo destes novos rumos ainda está por vir e intervir no ambiente hospitalar.

A preocupação com o processo da humanização no tratamento médico reflete na arquitetura, a partir da década de 1970 até os dias de hoje, na busca de respostas na linguagem arquitetônica. A partir disto, aos novos edifícios incorporam-se espaços de convivência, o atrium central, mezzaninos, resgata-se a praça urbana, propõe-se nova leitura aos espaços, com o intuito de transformar o espaço hospitalar de forma mais acolhedora, agradável e humana. Com esta atitude, pretende-se romper com o modelo arquitetônico do passado, em que espaços escuros e confinados reforçavam os sentimentos de angústia, dor, estresse e morte.

Nesses anos, vários projetos se reportam ao partido arquitetônico muito utilizado na concepção do edifício hoteleiro, com a materialização do grande vazio central, o atrium incorpora todos os pavimentos do edifício vertical, acentuando-se a praça, o espaço de convivência e proporcionando a monumentalidade espacial. O espaço do claustro dos antigos edifícios hospitalares, desde o período medieval é apresentado com uma nova leitura, recriado numa nova linguagem arquitetônica.

Como um dos expoentes na valorização destes princípios, destaca-se o Walter MacKenzie Health Sciences Centre, em Edmonton no Canadá (Fig. 64), projetado e construído no início dos anos 1980, com área de aproximadamente 114.000,00 $\mathrm{m}^{2} \mathrm{de}$ construção, distribuídos em vários blocos, onde abriga em torno de 600 leitos de internação.

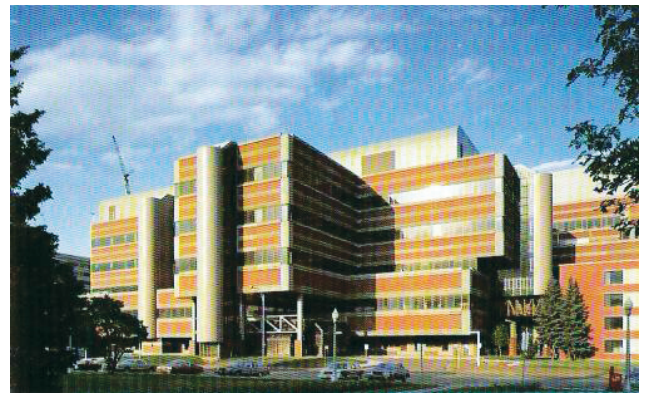

Com uma composição volumétrica no sistema monobloco, são Figura 64 - Hospital Walter nos detalhes que o projeto se diferencia. Inicialmente, por meio C. MacKenzie Health Sciences da implantação do edifício no terreno, observa-se que houve uma preocupação em posicioná-lo próximo às duas vias principais do acesso, as quais possibilitam um fluxo imediato de paciente, Centre - Edmonton, Canadá.

(Fonte: The Canadian Architect, 1984). principalmente daquele que se encontra em estado de emergência. (Fig. 65). Neste sentido, possibilita a liberação de grande área (de aproximadamente $50 \%$ do terreno) para estacionamento de veículos, áreas verdes, praças, além de um espaço de transição 
(público / privado) entre a área urbana e o interior do edifício, oferecendo ao usuário uma perspectiva geral do edifício e uma distância adequada para que o pedestre possa compreender, absorver e visualizar a magnitude do empreendimento.

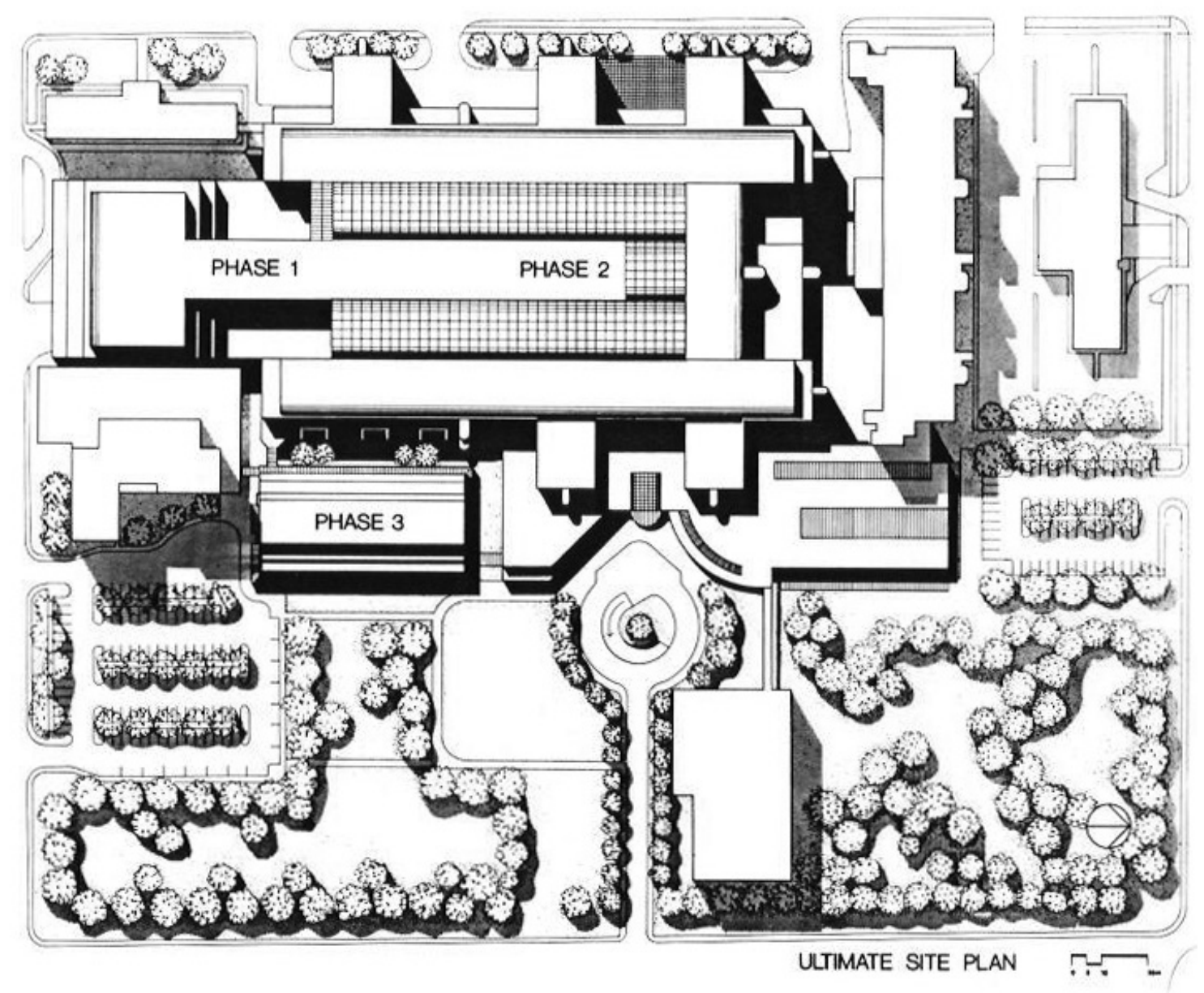

Figura 65 - Implantação do hospital.

(Fonte: The Canadian Architect, 1984).

Pode-se observar uma preocupação no partido arquitetônico quanto a garantia de flexibilidade e expansibilidade para o crescimento futuro do hospital, estabelecendo uma modulação estrutural nas dimensões de 9,60 x 19,20 m, permitindo uma organização das unidades hospitalares de forma racional, limpa e precisa. (Fig. 66). 

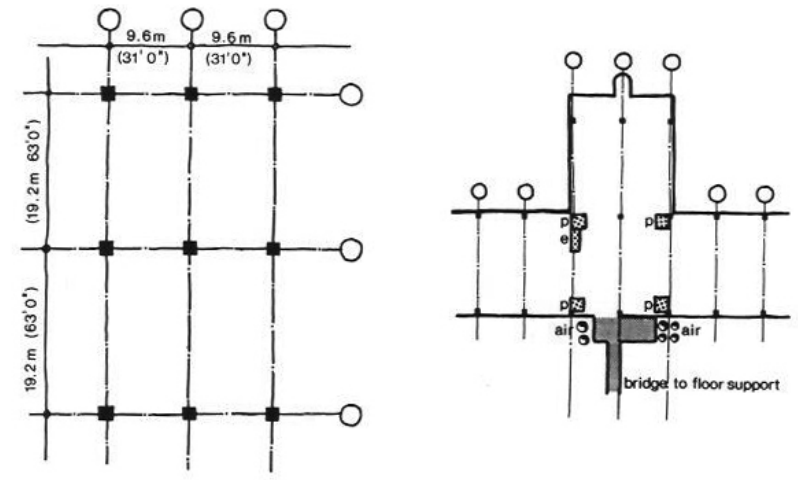

Ainda em sua concepção inicial, a opção do escritório Zeidler Roberts Partnership Architects em estabelecer que as instalações principais como ar condicionado e exaustão, gases medicinais e sistemas de energias em geral estivessem aparentes e colocadas na cobertura do edifício seria para proporcionar facilidade de conexão nos diversos pavimentos por meio de "shafts" e espaços intersticiais, como também proporcionar um aspecto mais industrial, em que a alta tecnologia espelhasse a complexidade do edifício hospitalar. (Fig. 67).

Com a intenção de trazer ao interior do edifício o espaço urbano, foram criados dois átrios centrais (east e west courtyards), os quais nascem no nível térreo e perfuram o edifício até o último pavimento das unidades de internação, resgatando o espaço das praças com a finalidade de contribuir com a convivência social. (Fig. 68). Com esta nova tipologia, buscaram-se as perspectivas e permeabilidade visual, a leveza, e principalmente a especialidade interna bastante diferenciada e inovadora. (Fig. 69).

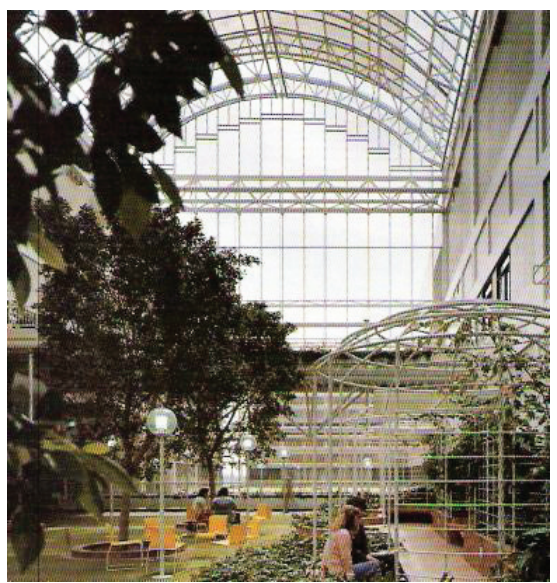

Figura 68 - Vista interna - átrio central.

(Fonte: The Canadian Architect, 1984).
Figura 66 - Sistema estrutural modulação.

(Fonte: The Canadian Architect, 1984).

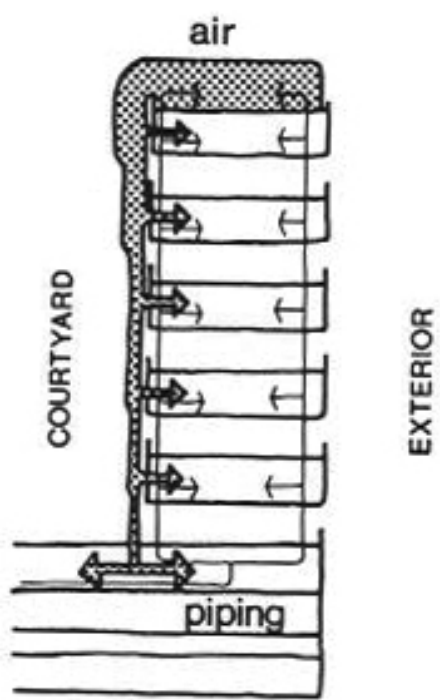

Figura 67 - Sistemas mecânicos de instalações.

(Fonte: The Canadian Architect, 1984).

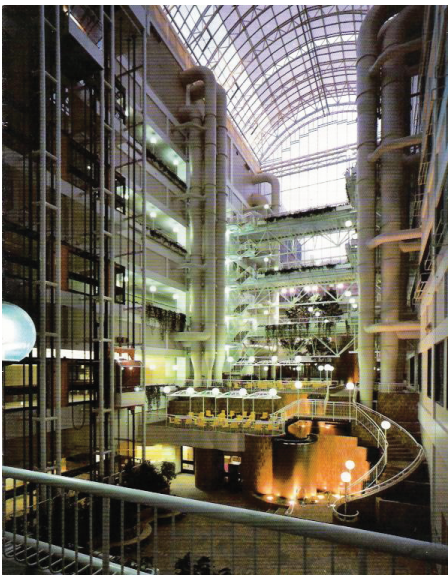

Figura 69 - Vista interna átrio central.

(Fonte: The Canadian Architect, 1984). 
As unidades de internação do hospital estão agrupadas em forma de " $\mathrm{T}$ ", constituídas de aproximadamente 60 leitos cada uma, e com estrutura de enfermagem e apoio logístico próprios. Pode-se observar pela composição das unidades de internação do pavimento tipo que cada módulo em "T" compõe-se de maneira que se expandisse a qualquer momento independentemente da estrutura já em funcionamento, potencializando o fator de expansibilidade como base do pensamento projetual. (Fig. 70 e 71).

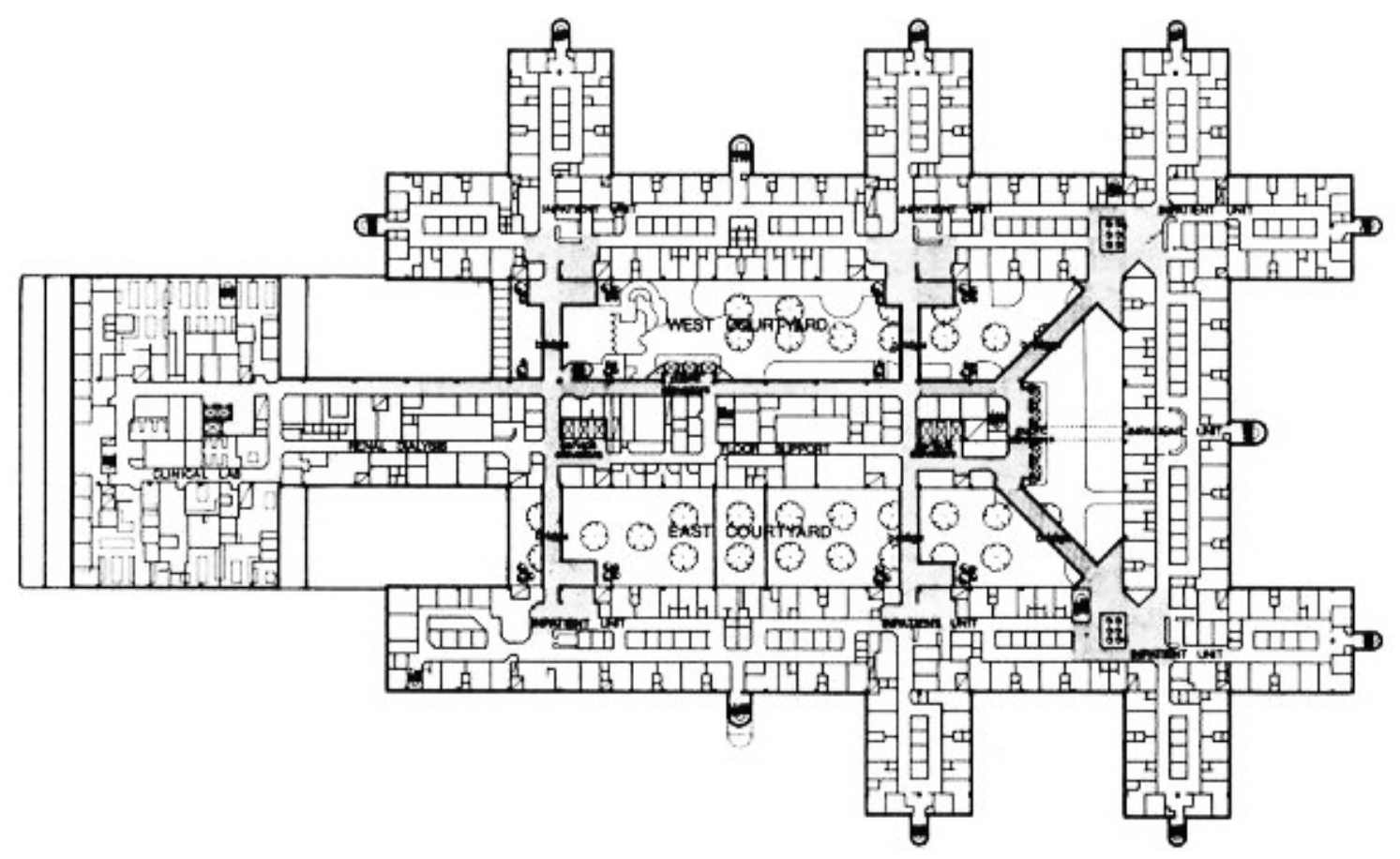

Figura 70 - Unidade de Internação - pavimento tipo.

(Fonte: The Canadian Architect, 1984).

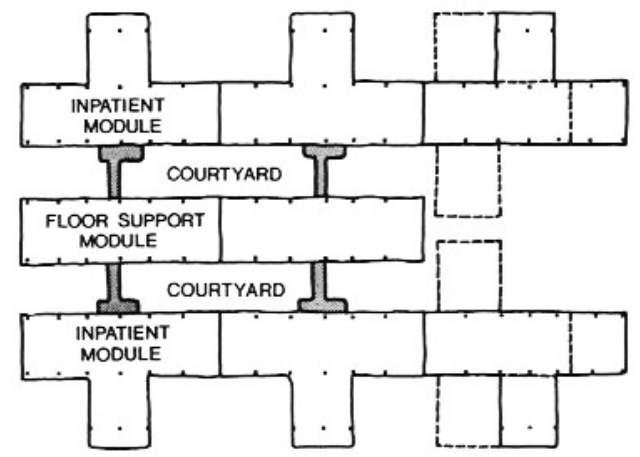

Figura 71 - Sistema de expansibilidade - crescimento e locação alternada de módulos.

(Fonte: The Canadian Architect, 1984). 
Nas duas últimas décadas do século XX, estes mesmos princípios da humanização espacial, limpeza, alta tecnologia construtiva, refinamento no detalhe arquitetônico, disciplina de fluxos externos e internos e relação de contiguidade espacial nortearam a produção brasileira e mundial. Exemplos como:

\section{- Hospital Albert Einstein - SP (Fig. 72 e 73)}

Arq. Jarbas Karman e Domingos Fiorentini

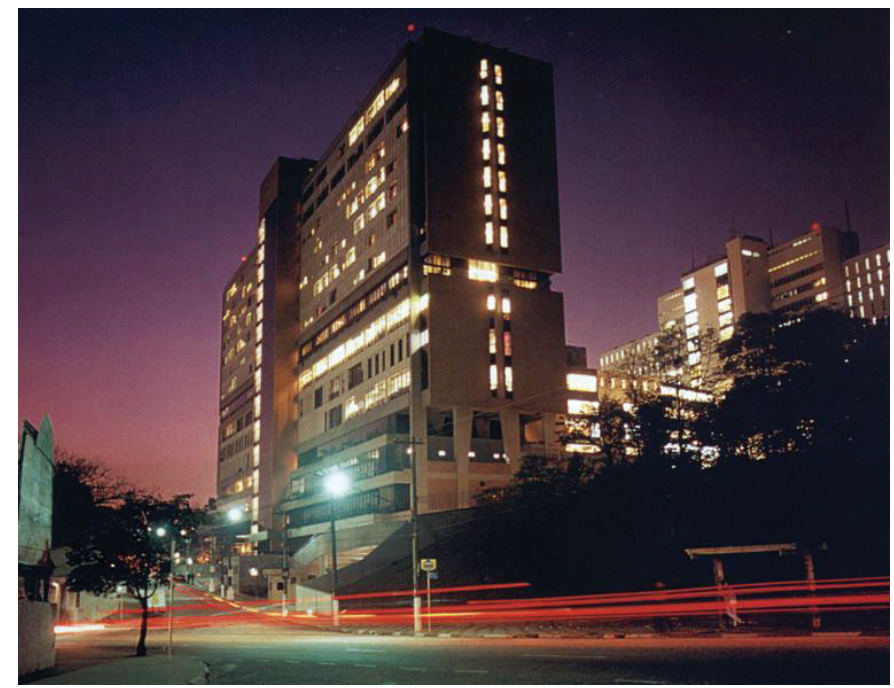

Figura 72 - Vista externa.

(Fonte: LERER, B., 1996).

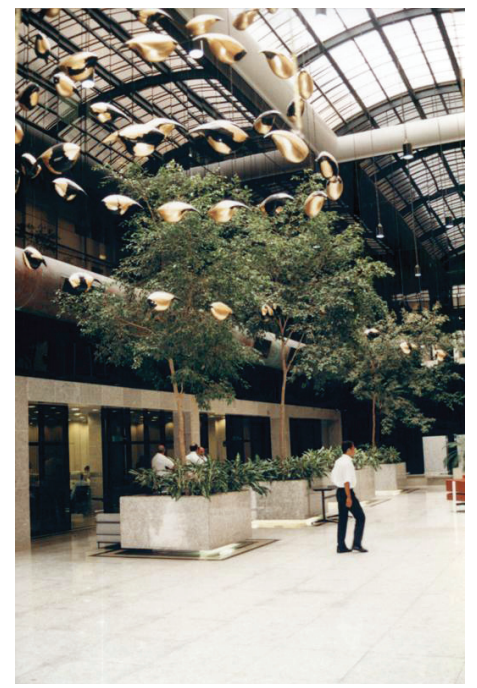

Figura 73 - Vista interna.

(Fonte: foto do autor).

- Hospital do Campo Limpo - SP (Fig. 74 e 75)

Arq. João Carlos Bross

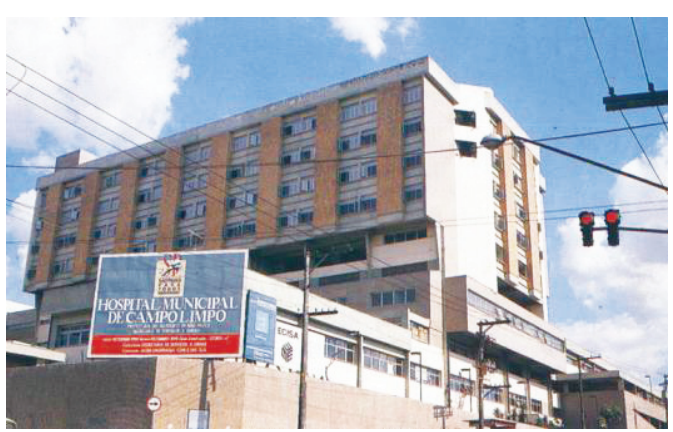

Figura 74 - Vista externa.

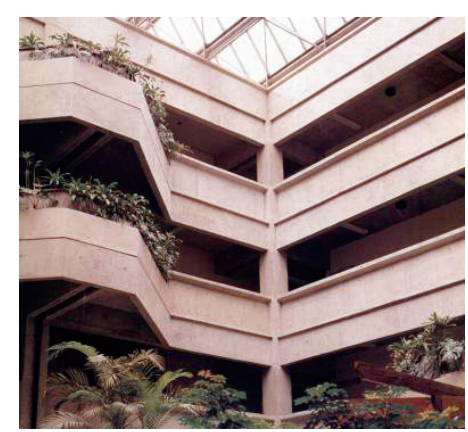

Figura 75 - Vista interna.

(Fonte: CUNHA, L. F. 1991) 
- Hospital do Coração - SP (Fig. 76 e 77)

Arq. Carlos Eduardo Pompeu

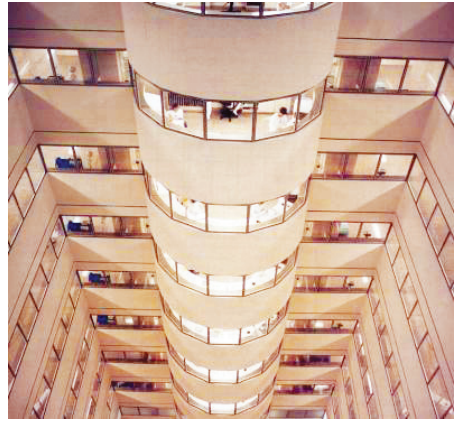

Figura 76 - Vista interna.

(Fonte: POMPEU, C. E., 1997).

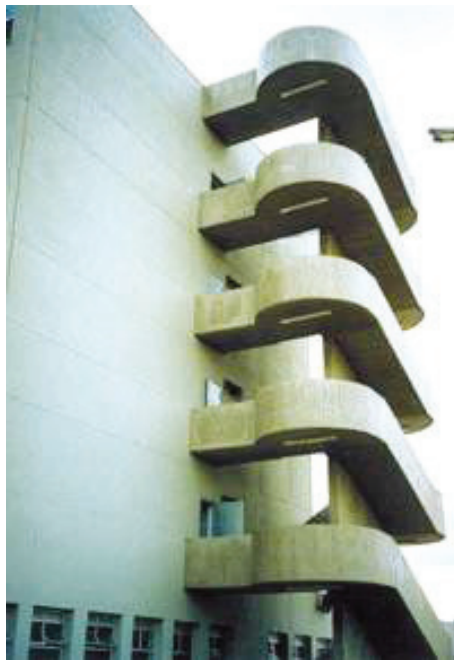

Figura 78 - VHospital Geral de Pedreira, SP - detalhe da escada.

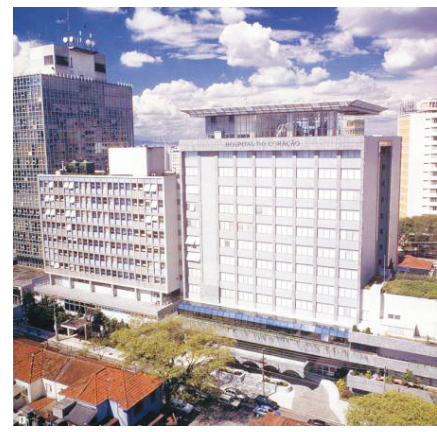

Figura 77 - Vista externa

(Fonte: POMPEU, C. E.;,1997).

- Hospital Geral de Pedreira - SP (Fig. 78 e 79)

Arq. Siegbert Zanettini

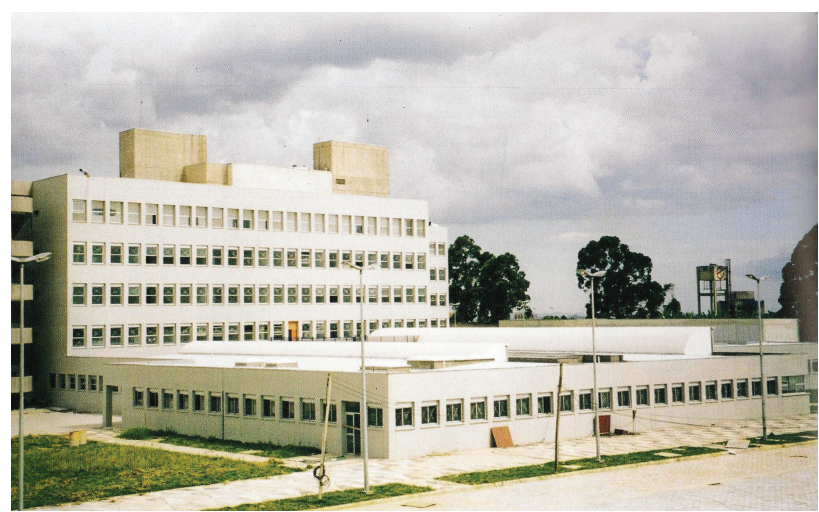

Figura 79 - Hospital Geral de Pedreira, SP - vista externa do edifício. (Fonte: ZANETTINI, S., 2002).

(Fonte: ZANETTINI, S., 2002) 
- Maternidade Municipal Lucila Ballalai - Londrina, PR (Fig. 80,81 e 82 )

Arq. Nelson Schietti de Giacomo
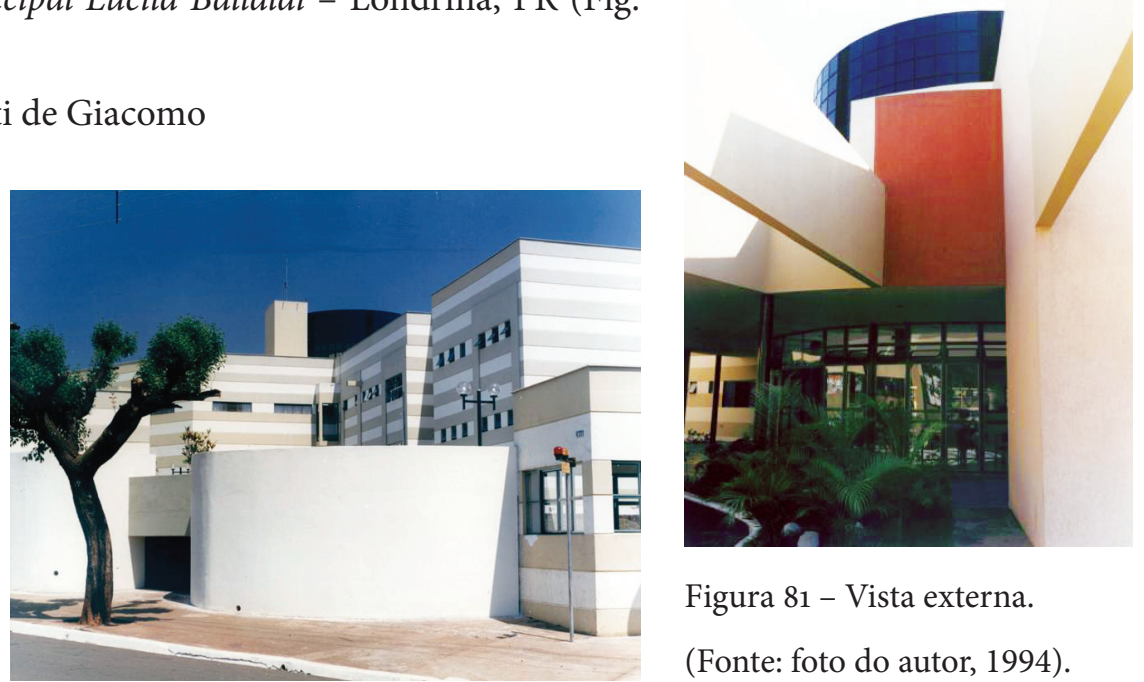

Figura 81 - Vista externa.

(Fonte: foto do autor, 1994).

Figura 80 - Vista externa

(Fonte: foto do autor)
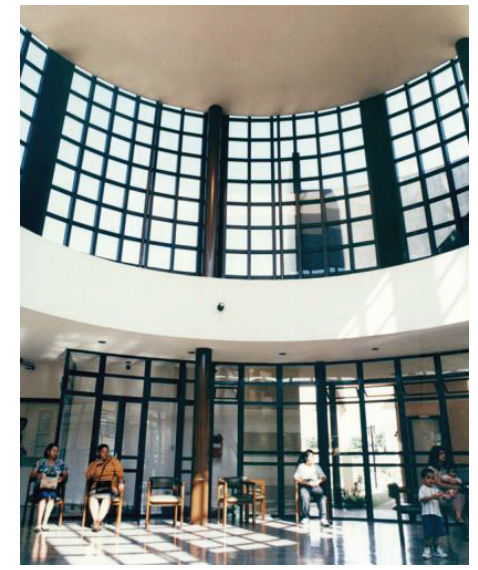

Figura 82 - Vista interna

(Fonte: Revista Projeto, 1994).

- Pronto Atendimento Infantil - Londrina, PR (Fig. 83, 84, 85,

86,87 e 88 )

Arq. Nelson Schietti de Giacomo

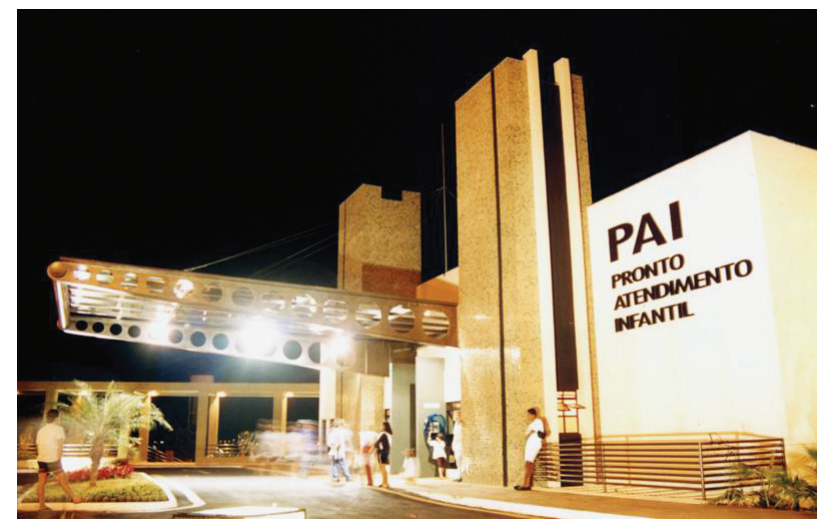

Figura 83 - Vista externa

(Fonte: foto do autor, 2000)

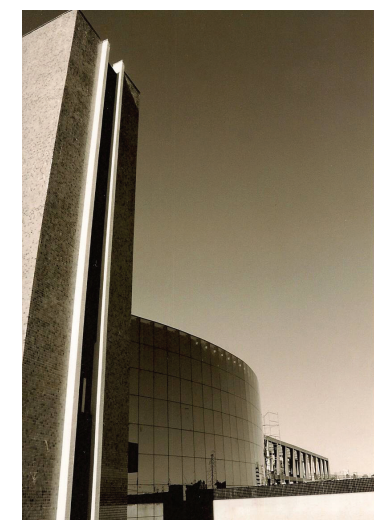

Figura 84 - Vista externa

(Fonte: foto do autor, 2000) 


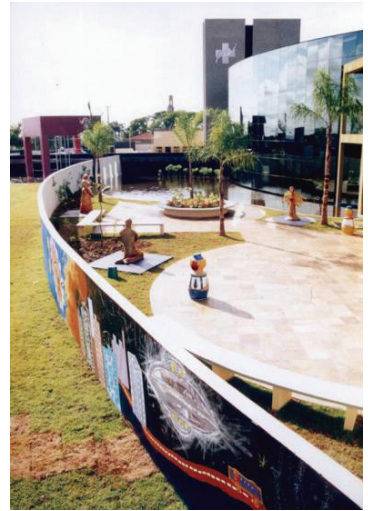

Figura 85 - Vista externa

(Fonte: foto do autor, 2000)

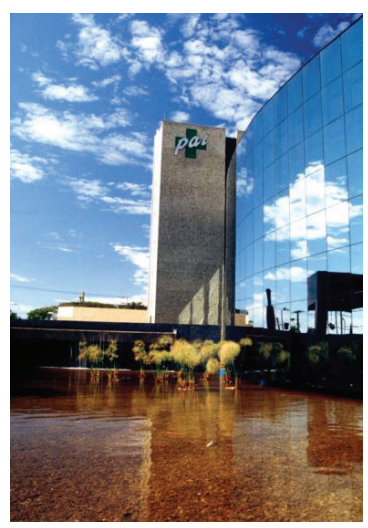

Figura 86 - Vista externa

(Fonte: foto do autor, 2000)

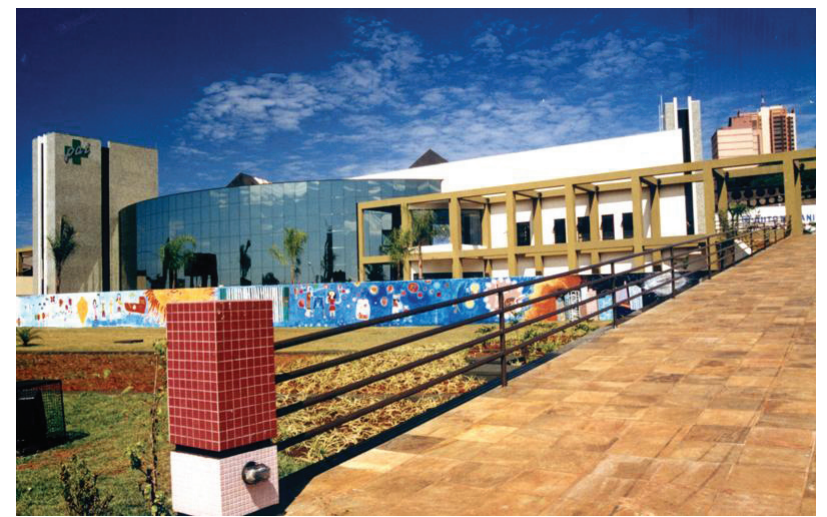

Figura 87 - Vista externa

(Fonte: foto do autor, 2000)

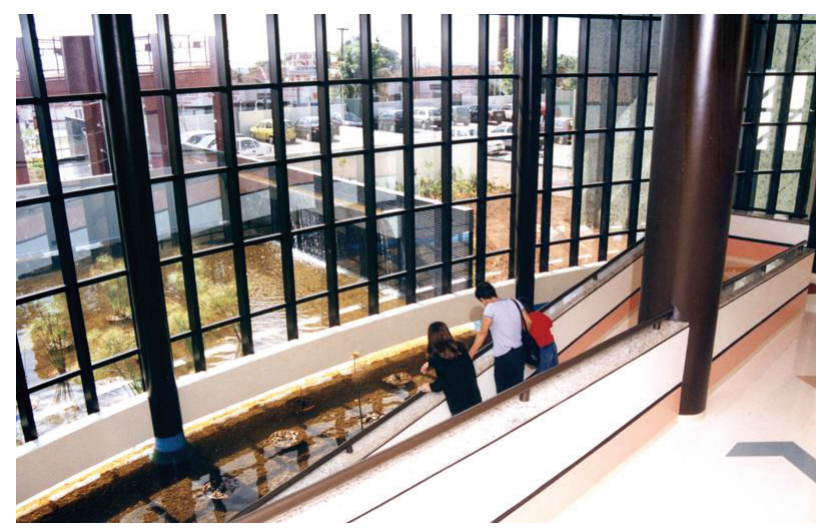

Figura 88 - Vista interna

(Fonte: foto do autor, 2000)

O processo de descentralização dos serviços de baixa e média complexidade torna o edifício hospitalar com características de abrigar alta complexidade médica, tecnológica e construtiva, e, desta forma, redireciona o perfil do hospital ao atendimento de apenas pacientes de alto risco.

Esta nova política acarreta a proliferação dos serviços autônomos como Pronto-Atendimento, Hospital-Dia, Centro Médico de Diagnóstico, entre outros, gerando a retirada deste perfil de paciente dos corredores e salas de espera dos hospitais, proporcionando agilidade no atendimento, diminuição no tempo de permanência hospitalar, e principalmente reduzindo a necessidade de leitos nas unidades hospitalares.

Desta forma, os leitos de média e longa permanência são destinados exclusivamente a cuidados de alto risco, os 
quais requerem equipes multidisciplinares de profissionais $\mathrm{e}$ tecnologia de última geração. Induz-se, assim, uma progressiva "desospitalização", sinalizando que deverá ser substancialmente reduzida a necessidade de leitos hospitalares para o nível de atenção à saúde no contexto de baixa e média complexidade.

Em seu artigo "Os edifícios de Saúde na Virada Século", Bross (1999, p.38) salienta que

[...] para que as instituições de saúde tenham êxito mantendo-se sempre na vanguarda das transformações, torna-se imperativo que dirigentes, arquitetos e engenheiros, compreendam como a instituição vai "produzir os serviços de atenção", analisando e estudando com o descurtínio quais as tendências futuras que impactarão sobre o processo e, em decorrência, sobre o edifício de sorte, a projetálo para a modernidade.

Com o advento da tecnologia da informação e as propostas para os edifícios baseados nos princípios de crescimento sustentável, um novo momento da arquitetura hospitalar já está em curso. 


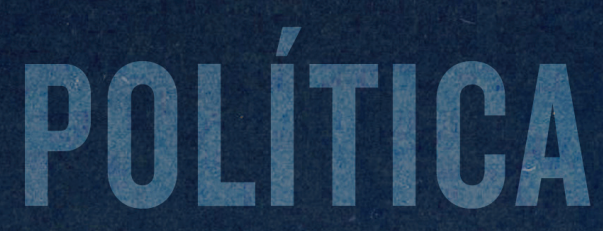

BRASILERA

DE ATENOAOA

SAUDE E SUAS

SAUL L

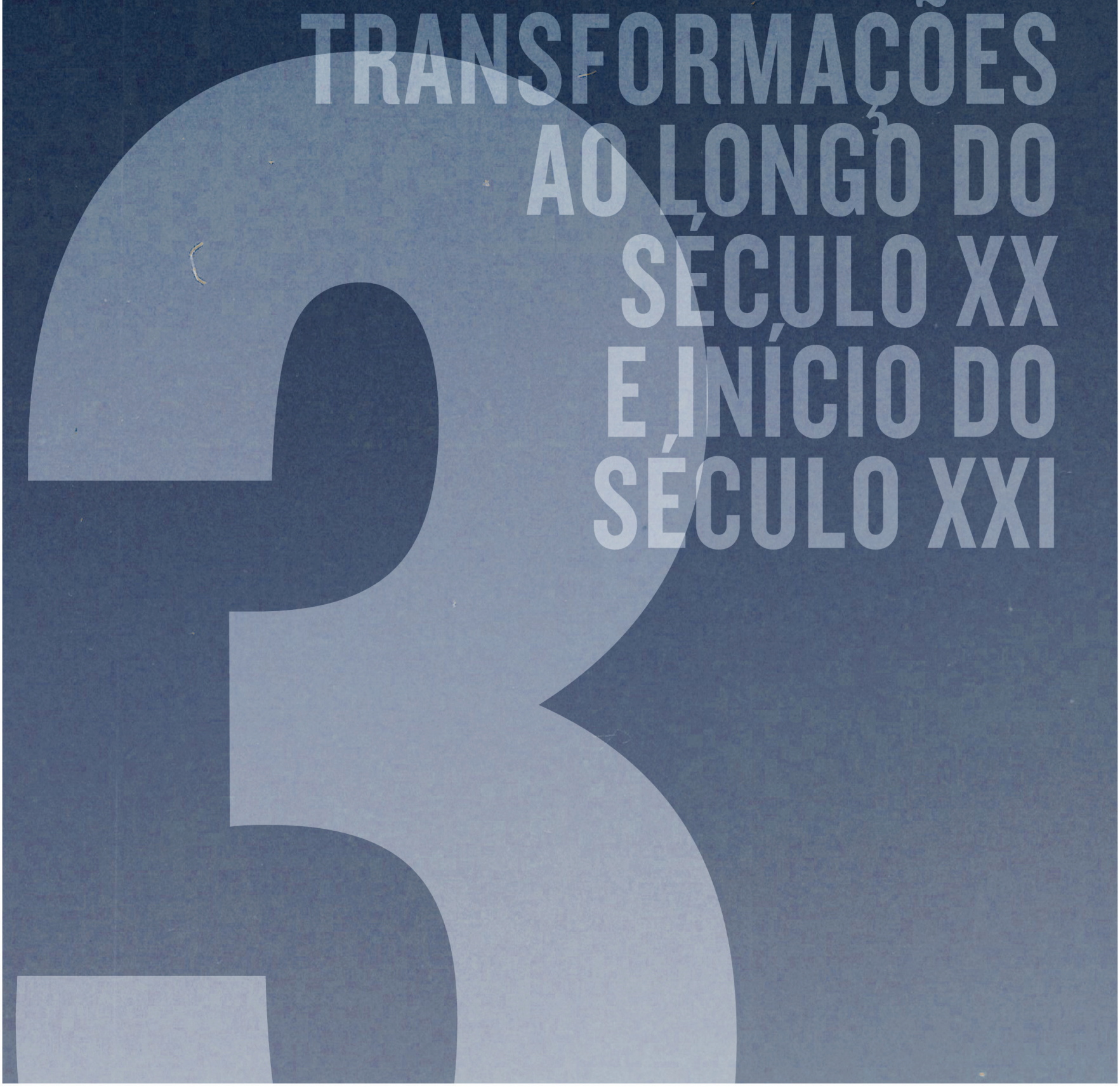





\section{I Evolução histórica, política e social e os modelos assistenciais de saúde no Brasil}

Durante os primeiros quatro séculos após o descobrimento do Brasil, pouco ou quase nada se tem como registro de uma política de assistência à saúde. As instituições hospitalares durante este período tinham o papel de abrigo às pessoas com algum distúrbio mental e/ou aos indigentes.

Nos primeiros anos do século $\mathrm{XX}$, mais intensamente no período pós Primeira Guerra Mundial, observa-se um movimento imigratório de europeus a busca de trabalho, principalmente no setor cafeeiro, o qual proporcionava naquele momento a maior riqueza nacional, bem como a expansão dos transportes ferroviários e marítimos, com a exportação do referido produto.

Este contingente acarretou um excedente populacional nas grandes cidades, provocando a desorganização urbana e sanitária, bem como o surgimento de um grande número de doenças infectocontagiosas como a peste, varíola, febre amarela, sarampo etc.

Por estes fatos, o Estado procurou traçar medidas de saneamento nas cidades onde a tarefa de implementá-las coube 
aos profissionais sanitaristas, com o propósito de retroceder o processo. Estas ações foram realizadas por:

- Rodrigues Alves - saneamento do Rio de Janeiro em 1902.

- Oswaldo Cruz - combateu a febre amarela no Rio de Janeiro, em 1903 e chefiou a Diretoria Geral de Saúde Pública criada em 1904.

- Carlos Chagas, Emilio Ribas e Saturnino de Brito - saneamento da cidade e do porto de Santos em 1906.

Durante as duas primeiras décadas do século $\mathrm{XX}$, surgem as leis reguladoras do processo do trabalho, proporcionando assim a promulgação da Lei Eloy Chaves, em 1923, criando as Caixas de Aposentadoria e Pensão (CAPs).

Também neste período as ações de Saúde Pública foram vinculadas ao Ministério da Justiça, em reforma promovida por Carlos Chagas, incluindo-se como responsabilidade do Estado, além do controle das endemias e epidemias, a fiscalização de alimentos e o controle dos portos e fronteiras. (BRASIL, 2006, p. 12).

O programa da Caps provia socorro médico para o trabalhador e seus familiares, subsidiando a aquisição de remédios, a aposentadoria e a pensão para os herdeiros em caso de morte, entre outros benefícios.

Com um cenário político - econômico mundial bastante conturbado, proporcionado pela quebra da bolsa de Nova York em 1929, houve ainda o declínio da cultura cafeeira e a revolução de 1930 no Brasil, fatos estes que provocaram mudanças importantes e o traçado de novos rumos para a sociedade brasileira. Surgem neste momento o código de leis trabalhistas e a criação do salário mínimo do trabalhador.

$$
\begin{aligned}
& \text { “O período de } 1930 \text { a } 1945 \text { é marcado pelo } \\
& \text { contencionismo e a capitalização dos recursos } \\
& \text { previdenciários e marcada centralização } \\
& \text { administrativa nas mãos do Estado, caracterizando a } \\
& \text { organização previdenciária nos moldes neoliberais do } \\
& \text { seguro social". (BRASIL, 2006, p. 13). }
\end{aligned}
$$

Naquele momento, a saúde vincula-se ao Ministério da Educação por meio do Departamento Nacional de Saúde Pública. Ainda neste período, foram criados os Institutos de Aposentadorias e Pensões de várias categorias como industriários, bancários, comerciários, funcionários públicos, entre outros. 
É interessante registrar neste período (1935/36) a realização do projeto arquitetônico do edifício do Ministério da Educação e Saúde (atual Palácio Gustavo Capanema) no Rio de Janeiro, por um grupo de arquitetos liderado por Lucio Costa, em que participaram Affonso Eduardo Reidy, Carlos Leão, Jorge Moreira, Ernani Vasconcellos e Oscar Niemeyer. $\mathrm{O}$ desenvolvimento do projeto apresentado teve como base os esboços originais e a incorporação dos preceitos racionais de Le Corbusier.

Durante a década de 1940 e mais enfaticamente após a Segunda Guerra Mundial, países europeus, mais precisamente a Inglaterra, implantou o programa "Welfare State" objetivando, entre outros, a reestruturação da previdência social.

Com base nestas influências, a política brasileira em saúde promove e implementa políticas sociais, mediante o crescimento significativo de rede assistencial pública já existente no país. Neste cenário foi criado em 1953 o Ministério da Saúde, justificado pelo crescimento das ações de saúde pública.

Durante o governo de Juscelino Kubitschek (1956 / 1960), com uma política de abertura ao capital estrangeiro, esta gera a insatisfação à classe trabalhadora e consequente instabilidade política - econômica e social no decorrer dos anos seguintes.

Em novembro de 1966, já no período militar, no âmbito de assistência social, todos os institutos que atendiam os trabalhadores do setor privado foram unificados no Instituto Nacional de Previdência Social (INPS).

Em 1968, o governo elabora o Plano Nacional de Saúde (PNS), que propõe ao médico sistema de livre escolha, em que seus honorários serão pagos em parte pelo cidadão e outra pela previdência pública. É ainda neste período que ocorre o grande desenvolvimento tecnológico e científico, o qual se instala na rede hospitalar.

Segundo consta na Regulação Médica das Urgências do MS/2006, o sistema previdenciário implantado teve as seguintes características:

- extensão da cobertura previdenciária de forma a abranger quase toda a população urbana e ainda parte da população rural. A política de concessão de assistência é assumida com um direito "consensual"; 
- orientação da política nacional de saúde para o privilegiamento da prática curativa, individual, assistencialista e especializada, em detrimento de medidas de saúde pública, de caráter preventivo e de interesse coletivo;

- criação de um complexo médico industrial responsável pelas elevadas taxas de acumulação de capital das grandes empresas internacionais de medicamentos e equipamentos médicos;

- desenvolvimento de um padrão de organização da prática médica orientada em termos delucratividade do setor de saúde e propiciando a capitalização da medicina e o privilegiamento do produtor privado destes serviços.

Em 1974, é aprovado o Plano de Pronta Ação (PPA), o qual dispõe sobre a desburocratização e a universalização dos atendimentos às urgências clínicas e cirúrgicas. Com o aumento da demanda aos serviços médicos - hospitalares, há consequentemente um crescimento significativo nas estruturas físicas existentes e o surgimento de novas unidades.

Em 1977 foi criado o Sistema Nacional de Previdência Social (Sinpas) com o objetivo de reorganizar, racionalizar e centralizar administrativamente a previdência. Dentro deste programa, o INPS (Instituto Nacional da Previdência Social) se reestrutura em três novos institutos:

- Instituto Nacional de Assistência Medica da Previdência Social (Inamps);

- Instituto de Administração da Previdência e Assistência Social (Iapas);

- Instituto Nacional da Previdência Social (INPS) - responsável pelas questões previdenciária.

Foram ainda neste período criadas:

- Empresa de processamento de dados da Previdência Social Dataprev;

- Central de Medicamentos (Ceme);

- Fundo de Assistência ao Trabalhador Rural (Funrural);

- Legião Brasileira de Assistência (LBA).

A realização da Conferência Mundial de Saúde de Alma-Ata, URSS (1978), teve como ponto central dos debates a proposta de priorização da atenção básica e das unidades primárias de saúde e o entendimento do sistema hierarquizado de saúde, como política assistencial nos três níveis de gestão. 
Com esta nova leitura e sobre os programas internacionais de assistência, a saúde surge no Brasil com vários movimentos sociais que fortaleceram a reabertura democrática e a reforma sanitária, tais como:

- surgimento de vários e novos municípios;

- administração dos municípios por governos de oposição e com experiências de implantação de redes de atenção básica a saúde, a partir de ação de profissionais da área de saúde coletiva;

- movimentos de trabalhadores de saúde;

- promoção de debates e publicações por meio do Centro Brasileiro de Estudos em Saúde (Cebes), os quais foram progressivamente sistematizando uma proposta alternativa ao modelo privatista;

- surgimento do movimento municipalista, por intermédio de encontro de secretários municipais de saúde;

- surgimento e fortalecimento do movimento popular de saúde, fortemente influenciado pelas comunidades eclesiais de base da igreja católica e de participação de militantes de esquerda na periferia das grandes cidades;

- o fim do bipartidarismo, a democratização e o ressurgimento do debate político e de propostas partidárias;

- resultado da reforma sanitária experimentada em alguns países;

Com a realização das eleições amplas no início dos anos 1980, a oposição ocupa diversos governos estaduais e municipais, possibilitando com a mudança a ocupação de cargos estratégicos, com profissionais compromissados com a nova política de assistência social.

Em 1983 implanta-se o Plano de CONASP (Conselho Consultivo de Administração de Saúde Previdenciária) e o surgimento das Ações Integradas de Saúde (AIS), os quais estabeleciam a regionalização e a hierarquização do Sistema de Saúde, com elementos de referência e contrarreferência e a criação de uma rede ambulatorial única, constituída de ambulatórios públicos e privados.

Com a realização da VIII Conferência Nacional de Saúde, na cidade de Brasília (março 1986) extraem-se três pontos como base de discussão:

- o conceito abrangente de saúde; 
- saúde como direito de cidadania e dever do Estado;

- instituição de um sistema único de saúde.

$\mathrm{Na}$ sequência dos fatos, em julho de 1987, o presidente José Sarney publica as diretrizes do Sistema Unificado e Descentralizado de Saúde (SNDS) que incorpora os princípios da reforma sanitária.

Mediante o grande debate ocorrido durante o processo da constituinte, como também reflexo das discussões geradas na VIII Conferência Nacional de Saúde, é instituído o Sistema Único de Saúde (SUS) o qual é homologado na promulgação de nova Constituição Brasileira, em 1988.

Em 1993, por meio de lei complementar, o então presidente da república Itamar Franco autorizou para 1994 a cobrança do Imposto Provisório sobre Movimentação Financeira (IPMF), o qual incide sobre todas as movimentações bancárias, exceto negociação de ações da Bolsa de Valores, saques de aposentadorias, seguro desemprego, salários e transferências entre contas correntes de mesma titularidade.

Segundo Gilson Carvalho (2009, p.2),

Este imposto fora criado com a destinação específica à Saúde Pública, onde por determinação da Constituição Federal do total arrecadado, 42,1\% deveriam ser direcionados para a saúde, $21,1 \%$ para o Fundo de Combate a Erradicação da Pobreza, 21\% para a Previdência Social e 15,8\% seriam apropriados para o orçamento fiscal, para aplicação livre de vinculações.

À época, a alíquota era de 0,25\%, durando até dezembro de 1994 quando, como estava previsto, fora extinto.

Dois anos depois, em 1996, o governo voltou a discutir o assunto, com a intenção novamente de direcionar a arrecadação deste tributo para a área da saúde. Foi então criada a CPMF, que passou a vigorar em 1997 com alíquota de 0,2\%.

Esta alíquota foi alterada em 1999 para 0,38\%, diminuiu para 0,30\% em 2001 e voltou a 0,38\% poucos meses depois. Em 2002, a CPMF foi prorrogada, o que ocorreu novamente em 2004.

Em 13 de dezembro de 2007 esta contribuição foi extinta em votação no Congresso Nacional, entre a defesa da sua permanência pelos situacionistas e a extinção pela oposição, com o discurso nas distorções em sua aplicabilidade. 
Segundo dados da Folha On-line de 15 de agosto de 2007, a arrecadação anual da CPMF em 2007 girou em torno de R\$ 32,5 bilhões de reais.

\subsection{A Lei Orgânica de Saúde e o SUS - Sistema Único de Saúde}

O artigo 196 da nova Constituição Federal estabelece que:

"A saúde é direito de todos e dever do Estado, garantido mediante políticas sociais e econômicas que visem a redução do risco de doença e de outros agravos e ao acesso universal e igualitário as ações e serviços para sua promoção, proteção e recuperação".

A proposta deste novo modelo de assistência (SUS) Sistema Único de Saúde ocorre mediante a Lei Orgânica de Saúde, lei no 8080 de setembro 1990. Porém, sobre ela ocorrem importantes vetos efetuados pelo presidente Collor de Mello, os quais geraram descontentamento junto à classe política e na sociedade em geral, provocando assim novas discussões sobre o assunto. Somente em dezembro de 1990, com a publicação da lei no 8142 , dá-se o texto final com a participação da comunidade na gestão do SUS, por meio das conferências de saúde (em todos os níveis) como mecanismo de participação e tomada das decisões.

A referida lei n $8142 / 1990$ dispõe ainda sobre as transferências intergovernamentais de recursos financeiros, criando os Fundos de Saúde em cada instância de governo.

A Regulação Médica das Urgências - MS/2006 estabelece que os princípios doutrinários do SUS são: (Regulação Médica das Urgências - MS) 2006

- Universalidade: todos os brasileiros possuem acesso gratuito às ações e serviços de saúde.

- Equidade: as instituições governamentais devem oferecer condições de atendimento igual para todos.

- Integralidade: o novo sistema garante a todos os brasileiros o direito de ser atendido desde a prevenção de doenças até os tratamentos de maior complexidade não fazendo qualquer distinção a qualquer tipo de doença.

Princípios organizacionais do SUS. 
- Regionalização: a rede de serviços ao atendimento da população deverá ser descentralizada e regionalizada, definida a abrangência do território a ser atendido, procurando uma distribuição geograficamente homogênea para permitir o acesso facilitado dos cidadãos aos serviços de atenção a saúde.

- Hierarquização: a rede de serviços com seus níveis de complexidade deve estabelecer uma hierarquia no atendimento aos cidadãos. As ações básicas de saúde absorvem a maior parte da procura pelos serviços, ficando o atendimento de segundo e terceiro nível de complexidade para a rede hospitalar de referência.

- Descentralização: transfere-se ao município e não mais ao governo federal a tarefa de coordenar e implantar a política de saúde local, porém esta deve estar em sintonia com as três esferas de governo. (A este processo dá-se o nome de municipalização).

- Participação: permite-se a participação de qualquer cidadão, através das suas entidades representativas junto aos conselhos municipais de saúde, na formulação das políticas de saúde em todos os níveis de complexidade. Permite-se ainda a discutir suas prioridades e fiscalizar a execução destas políticas e a utilização dos recursos financeiros.

- Resolutividade: o sistema deve estar apto, dentro do limite de sua complexidade e capacidade tecnológica, a resolver os problemas de saúde que levam um cidadão a procurar os serviços de saúde, em cada nível de assistência.

- Complementaridade do setor privado: ao sistema permite se utilizar da oferta do serviço privado quando por insuficiência do setor público ao atendimento ao cidadão.

O governo federal, a partir do início dos anos 1990, procura consolidar a municipalização dos serviços de saúde mediante a criação das NOBs (Normas de Operações Básicas) que dispõem os requisitos para que os municípios constituam seus sistemas de saúde de maneira sólida, eficiente e que sejam capazes de gerenciar seus recursos financeiros.

Os princípios mínimos de gestão municipal passaram por instituir um fundo municipal de saúde, criar o conselho municipal de saúde, traçar seu plano municipal de saúde e possuir recursos humanos e tecnológicos capazes de operar o sistema. 


\subsection{Unidade de emergência - primeiras abordagens}

O hospital, instituição prestadora de serviços, é conceituado pelo Ministério da Saúde como sendo

parte integrante de uma organização médica e social, cuja função básica consiste em proporcionar à população assistência médica integral, curativa e preventiva, sob quaisquer regimes de atendimento, inclusive o domiciliar, constituindo-se também em centro de educação, capacitação de recursos humanos e de pesquisas em saúde, bem como de encaminhamento de pacientes, cabendo-lhe supervisionar e orientar os estabelecimentos de saúde a ele vinculados tecnicamente. (OMS - Organização Mundial de Saúde, 1956 apud Brasil, 2006, p. 46).

O edifício hospitalar de nível terciário coloca-se dentro do sistema hierarquizado de saúde como o serviço de referência para o atendimento de média e alta complexidade. Para tanto, é necessário que este possua estrutura física, equipamentos, recursos humanos e organização adequada à recepção de pacientes para qualquer tipo de procedimento em saúde, e devolvê-lo à comunidade em condições satisfatórias de saúde.

Em 2001, o Ministério da Saúde publicou que as principais causas de mortalidade da população das regiões metropolitanas, na faixa etária entre 15 e 49 anos, são acidentes, envenenamentos e violências. Essas causas, quando consideradas em conjunto, superam as doenças cardiovasculares e neoplasias.

São também as mais importantes causas da incapacitação física permanente ou temporária dessa população, levando a perdas econômicas, previdenciárias e grandes dispêndios em tratamento de complicações na saúde dos pacientes. Isso pode ser evitado, uma vez que boa parte das complicações ocorre em função de atendimentos realizados de forma inapropriada durante a fase aguda. Para tanto, há a necessidade de melhor estruturar $\mathrm{o}$ atendimento (pré-hospitalar e hospitalar) imediato de forma a torná-lo resolutivo e eficaz, principalmente nos casos classificados como nível 1 (Emergência ou Urgência de prioridade absoluta) na hierarquia ao atendimento. 
O Ministério da Saúde (1995) define nove atribuições para os Estabelecimentos Assistenciais de Saúde (EAS). Entre elas, cinco são atribuições/fim, isto é, constituem-se funções diretamente ligadas à atenção e assistência à saúde. As quatro últimas são atribuições/meio que garantem o desenvolvimento das primeiras e de si próprias. As atribuições são as seguintes:

- realização de ações básicas de saúde;

- prestação de atendimento eletivo de assistência à saúde em regime ambulatorial;

- prestação de atendimento imediato de assistência à saúde;

- prestação de atendimento de assistência à saúde em regime de internação;

- prestação de atendimento de apoio ao diagnóstico e terapia;

- Prestação de serviços de apoio;

- formação e desenvolvimento de recursos humanos e de pesquisa;

- prestação de serviços de apoio à gestão e execução administrativa;

- prestação de serviços de apoio logístico.

Uma das "portas de entrada" deste sistema é por meio da unidade de urgência e emergência, as quais proporcionam o atendimento à pacientes com afecções agudas específicas, propiciando recursos eficazes para que suas necessidades sejam satisfeitas. São reconhecidas como áreas que condicionam meios para uma pronta avaliação médica do doente e facilidades que implementam uma ação terapêutica, com o trabalho de equipes especificamente treinadas.

Estas unidades operam agregadas ao complexo hospitalar com sua infra-estrutura de apoio logístico, prontas para atender aos pacientes com diferentes níveis de atenção e assistência, mediante uma ação sistematizada. Para atingir tal objetivo é necessário que haja o desenvolvimento contínuo de ações de enfermagem, investigação e avaliação contínua sobre a atuação profissional dos agentes de saúde, como também definição de áreas e facilidades técnicas adequadas.

Como foi referida anteriormente, a terceira atribuição listada pelo Ministério da Saúde para os EAS (Estabelecimentos Assistenciais de Saúde), diz respeito diretamente às unidades de emergências hospitalares. Dentre as muitas atividades executadas por esta unidade, algumas são previstas pelo MS (Ministério da 
Saúde - 1995) como atribuições fundamentais para esta área, às quais segundo o critério da gravidade (a unidade) e a complexidade do caso a ser tratado, tem-se:

- urgência de baixa e média complexidade: quando não há risco de vida;

- urgência de alta complexidade: quando não há risco de vida, porém o paciente apresenta um quadro crítico ou agudo;

- emergência: casos em que há risco de vida.

\subsection{Política nacional de atenção às urgência $e$ emergências}

O Sistema Único de Saúde (SUS), ao longo de seus 23 anos, tornou-se uma grande rede interligada de serviços.

Nesse período, o Brasil passou de um sistema que até 1988 garantia o acesso à saúde pública apenas aos trabalhadores filiados à Previdência, em torno de 30 milhões de pessoas, para o Sistema Único de Saúde, em que passou a atender 190 milhões de brasileiros, sendo que, em $80 \%$ dos casos, a dependência de rede pública é total. Apesar de todo o avanço político e social, os desafios permanecem enormes e o Ministério da Saúde tem estabelecido como prioridade, a resolução de problemas em suas deficiências de gestão e de estrutura.

Dentro do que se estabelece no sistema hierarquizado de saúde, grande parte dos seus problemas pode ser solucionada na atenção básica, a qual responde pelas ações de prevenção e promoção da saúde.

Porém, um dos gargalos do sistema é sem dúvida o atendimento de urgência e emergência nos hospitais em todo o país, que responde pelos segundo e terceiro níveis de atenção. Isto ocorre, mesmo que embora se tenha com a definição dos territórios da abrangência no atendimento básico, porque este serviço tem apresentado deficiência, principalmente no que se trata da resolutividade nas ações de saúde. Com isto, o público em geral procura as unidades de serviço de urgência e emergência, provocando a sua superlotação, acarretando problemas sérios e de grande relevância ao sistema de saúde. Vivenciam-se, há mais de uma década, prontos-socorros lotados devido a um deslocamento da população em direção a estes serviços, configurando-os como 
prestadores de atenção primária de assistência à saúde e, não de fato, destinada ao atendimento de urgências e emergências.

Ao longo dos últimos 10 anos, a discussão em torno do tema tem provocado uma série de medidas, normas, resoluções e portarias editadas pelo Ministério da Saúde, na busca de, inicialmente, um melhor entendimento do problema, e, posteriormente, prover o sistema de saúde de condições adequadas ao atendimento dos serviços de urgência e emergência. Estas medidas foram publicadas por meio da:

- Portaria GM/MS no 2923 - o9 de junho de 1998.

Estabelece o programa de apoio à implantação e inclusão dos hospitais nos Sistemas Estaduais de Referência Hospitalar em Atendimento de Urgências e Emergências.

\section{- Portaria GM/MS no 221 - 24 de março de 1999.}

Estabelece que os hospitais públicos e privados integrantes ou não do SUS, apresentem a Comunicação de Internação Hospitalar $(\mathrm{CIH})$.

\section{- Portaria GM/MS nº 479 - 15 de abril de 1999.}

Estabelece critérios para a classificação e inclusão dos hospitais nos Sistemas Estaduais de Referência Hospitalar em Atendimento de Urgências e Emergências.

\section{- Portaria GM/MS no 824 - 24 de junho de 1999.}

Aprova o texto de Normalização de Atendimento PréHospitalar.

O atendimento pré-hospitalar é um serviço móvel de emergência para atender ainda no local do acidente as vítimas de traumas ou emergências clínicas, garantindo a segurança no local, avaliando o estado do paciente, estabilizando os sinais vitais, imobilizando e transportando-o para a unidade hospitalar mais adequada.

Dentro do contexto desta portaria, estabeleceu-se para uma leitura mais didática a classificação das urgências em níveis.

- Nível 1: Emergência ou Urgência de prioridade absoluta. Casos em que haja risco imediato de vida e/ou a existência de risco de perda funcional grave, imediato ou secundário. 
- Nível 2: Urgência de prioridade moderada.

Compreende os casos em que há necessidade de atendimento médico, não necessariamente de imediato, mas dentro de poucas horas.

- Nível 3: Urgência de prioridade baixa.

Casos em que há necessidade de uma avaliação médica, mas não há risco de vida ou de perda de funções, podendo aguardar várias horas.

- Nível 4: Urgência de prioridade mínima.

Compreendem as situações em que o médico regulador pode proceder a conselhos por telefone, orientar sobre o uso de medicamentos, cuidados gerais e outros encaminhamentos.

Estabelece ainda o "conceito de potencialidade", em que qualquer caso inicialmente classificado em um determinado nível pode mudar sua colocação inicial em função do tempo de evolução, tipo de transporte e outros fatores, sendo, portanto, necessário estimar a gravidade potencial para cada caso.

\section{- Portaria GM/MS no 814 - o1 de junho de 2001.}

Revisão da portaria GM/MS no 824 de junho/1999, na qual estabelece o conceito geral, os princípios e as diretrizes da Regulação Médica das Urgências.

Estabelece a normalização dos serviços de Atendimento PréHospitalar.

\section{- Portaria GM/MS no 881 - 19 de junho de 2001.}

Institui o Programa Nacional de Humanização de Assistência Hospitalar (PNHAH).

Sobre o tema de Humanização nos serviços de saúde, vale destacar que, desde o final da década de 1970, o termo humanização tem sido utilizado com frequência no âmbito da saúde que busca na assistência hospitalar um maior cuidado com o paciente no que se refere ao respeito a sua individualidade, subjetividade e cultura em que se encontra.

Um dos focos é a mudança da cultura das organizações, viabilizando um contato humano em que prevaleça o respeito ao próximo, com a participação de todas as pessoas envolvidas no processo: usuários, profissionais de saúde, gestores e a 
comunidade. Além disso, cabe destacar o aumento do grau de corresponsabilidade dos diferentes personagens que constituem a rede SUS, simplificando mudanças na atenção aos usuários e na gestão dos processos de trabalhos; a valorização da dimensão subjetiva e social em todas as práticas de atenção e gestão, fortalecendo e estimulando processos integrados e promotores de compromisso; a garantia de condições para que os profissionais atuem de modo digno e participem como cogestores do sistema, incluindo o fortalecimento do trabalho em equipes multiprofissionais.

\section{- Portaria GM/MS no 2048 - 05 de novembro de 2002.}

Estabelece os princípios e diretrizes dos Sistemas Estaduais de Urgência e Emergência, define normas, critérios de funcionamento, classificação e cadastramento dos hospitais de urgência, determina a criação das coordenações do Sistema Estadual de Urgências e é composta de sete capítulos em que estão contemplados os seguintes tópicos:

- Cap. 1: Estruturação dos sistemas loco - regionais de atenção às urgências, dentro dos preceitos das NOAS SUS - (Norma Operacional de Assistência à Saúde);

O Sistema Estadual de Urgência e Emergência deve se estruturar a partir da leitura ordenada das necessidades sociais em saúde e sob o imperativo das necessidades humanas nas urgências. O diagnóstico destas necessidades deve ser feito a partir da observação e da avaliação dos territórios sociais com seus diferentes grupos humanos, da utilização de dados de morbidade e mortalidade disponíveis e da observação das doenças emergentes.

- Cap. 2: Diretrizes da Regulação Médica das Urgências;

A Regulação Médica das Urgências, baseada na implantação de suas Centrais de Regulação, é o elemento ordenador e orientador dos Sistemas Estaduais de Urgência e Emergência. As centrais, estruturadas nos níveis estadual, regional e/ou municipal, organizam a relação entre vários serviços, qualificando o fluxo dos pacientes no sistema e gerando uma porta de comunicação aberta ao público como um todo, por meio da qual os pedidos de socorro são recebidos, avaliados e hierarquizados. 
As necessidades imediatas da população ou necessidades agudas ou de urgências, são pontos de pressão por respostas rápidas. Então, o sistema deve ser capaz de acolher a clientela, prestandolhe atendimento e redirecionando-a para os locais adequados à continuidade do tratamento, mediante o trabalho integrado das Centrais de Regulação Médica de Urgências com outras Centrais de Regulação - de leitos hospitalares, procedimentos de alta complexidade, exames complementares, internações e atendimentos domiciliares, consultas especializadas, consultas na rede básica de saúde, assistência social, transporte sanitário não urgente, informações e outros serviços e instituições, como, por exemplo, as Polícias Militares e a Defesa Civil.

Estas centrais, obrigatoriamente interligadas entre si, constituem um verdadeiro complexo regulador de assistência, ordenador dos fluxos gerais de necessidade/resposta, que garante ao usuário do SUS a multiplicidade de respostas necessárias à satisfação de suas necessidades.

- Cap. 3: Diretrizes e responsabilidades das várias unidades componentes do atendimento pré-hospitalar fixo;

O Atendimento Pré-Hospitalar fixo é aquela assistência prestada, num primeiro nível de atenção, aos pacientes portadores de quadros agudos, de natureza clínica, traumática ou ainda psiquiátrica, que possa levar ao sofrimento, sequelas ou mesmo à morte, provendo um atendimento e/ou transporte adequado a um serviço de saúde hierarquizado, regulado e integrante ao Sistema Estadual de Urgência e Emergência. Este atendimento é prestado por um conjunto de Unidades Básicas de Saúde (UBS), unidades do Programa Saúde da Família (PSF), Programa de Agentes Comunitários de Saúde (PACS), ambulatórios especializados, serviços de diagnóstico e terapia, unidades não hospitalares de atendimento às urgências e emergências e pelos serviços de atendimento pré-hospitalar móvel.

- Cap. 4: Diretrizes do Atendimento Pré-Hospitalar Móvel;

Considera-se como nível pré-hospitalar móvel na área de urgência, o atendimento que procura chegar precocemente à vítima, após ter ocorrido um agravo a sua saúde (de natureza clínica, cirúrgica, traumática, e inclusive as psiquiátricas), que possa levar ao sofrimento, sequelas ou mesmo à morte, sendo 
necessário, portanto, prestar-lhe atendimento e/ou transporte adequado a um serviço de saúde, devidamente hierarquizado e integrado ao Sistema Único de Saúde.

- Cap.5: Diretrizes do componente hospitalar de atendimento às urgências;

Busca uma nova nomenclatura e classificação para a área de assistência hospitalar de urgência e emergência. Estabelece-se a classificação/estruturação, partindo da premissa que nenhum pronto-socorro hospitalar poderá apresentar infraestrutura inferior à de uma unidade não hospitalar de atendimento às urgências e emergências contido nesta mesma portaria.

Classificação:

As Unidades Hospitalares de Atendimento em Urgência e Emergência serão classificadas da seguinte forma:

A - Unidades Gerais

a) Unidades Hospitalares Gerais de Atendimento às Urgências e Emergências do tipo I;

b) Unidades Hospitalares Gerais de Atendimento às Urgências e Emergências do tipo II.

B - Unidades de Referência:

a) Unidades Hospitalares de Referência em Atendimento às Urgências e Emergências de tipo I;

b) Unidades Hospitalares de Referência em Atendimento às Urgências e Emergências de tipo II;

c) Unidades Hospitalares de Referência em Atendimento às Urgências e Emergências de tipo III.

As Unidades de Referência correspondem, respectivamente, aos Hospitais tipo I,II e III definidos segundo os critérios de classificação estabelecidos pela Portaria GM/MS no 479 de 15/04/1999, que cria mecanismos para a implantação dos Sistemas Estaduais de Referência Hospitalar em Atendimento de Urgências e Emergências.

As Unidades Hospitalares Gerais de Atendimento às Urgências e Emergências do tipo I são aquelas instaladas em hospitais gerais de pequeno porte, aptos a prestarem assistência de urgência e emergência correspondente ao primeiro nível de assistência de média complexidade (M1). 
As Unidades Hospitalares Gerais de Atendimento às Urgências e Emergências do tipo II são aquelas instaladas em hospitais gerais de médio porte, aptos a prestarem assistência de urgência e emergência correspondente ao segundo nível de assistência hospitalar de média complexidade (M2).

As Unidades Hospitalares de Referência em Atendimento às Urgências e Emergências do tipo I são aquelas instaladas em hospitais especializados e que contam com recursos tecnológicos e humanos adequados para o atendimento das urgências/ emergências de natureza clínica e cirúrgica, nas áreas de pediatria ou tráumato-ortopedia ou cardiologia.

As Unidades de Referência do tipo II são aquelas instaladas em hospitais gerais e que contam com recursos tecnológicos e humanos adequados para o atendimento de urgências/ emergências de natureza clínica e cirúrgica.

As Unidades de Referência de tipo III são aquelas instaladas em hospitais gerais e que contam com recursos tecnológicos e humanos adequados para o atendimento das urgências/ emergências de natureza clínica, cirúrgica e traumatológica. Estes hospitais devem, ainda, desempenhar atribuições de capacitação aprimoramento e atualização dos recursos humanos envolvidos com as atividades meio e fim de atenção às urgências / emergências.

- Cap. 6: Transferência e transporte inter-hospitalar;

Dentro da perspectiva de estruturação de Sistemas Estaduais de Urgência e Emergência, com universalidade, atenção integral e equidade de acesso, de caráter regionalizado e hierarquizado, de acordo com as diretrizes do SUS, os serviços especializados e de maior complexidade deverão ser referência para um ou mais municípios de menor porte.

Assim, estes municípios menores devem se estruturar para acolher os pacientes acometidos por agravos de urgência, de caráter clínico, tráumato-cirúrgico, gineco-obstétrico e psiquiátrico, sejam estes adultos, crianças ou recém-nascidos, realizar a avaliação e estabilização inicial destes e providenciar sua transferência para os serviços de referência loco-regionais, seja para elucidação diagnóstica por meio de exames especializados, avaliação médica especializada ou internação. 
As grades de referência loco-regionais devem ser previamente pactuadas e as transferências deverão ser solicitadas ao médico regulador da Central de Regulação de Urgências.

- Cap. 7: Diretrizes dos Núcleos de Educação em Urgências com respectivas grades de temas, conteúdos, habilidades e cargas horárias.

Os Núcleos de Educação em Urgências devem se organizar como espaços de saber interinstitucional de formação, capacitação, habilitação e educação continuada de recursos humanos para as urgências, sob a administração de um conselho diretivo, coordenado pelo gestor público do SUS, tendo como integrantes as secretarias estaduais e municipais de saúde, hospitais e serviços de referência na área de urgência, escolas de bombeiros e polícias, instituições de ensino superior, de formação e capacitação de pessoal na área da saúde, escolas técnicas e outros setores que prestam socorro à população, de caráter público ou privado, de abrangência municipal, regional ou estadual.

- Portaria GM/MS n ${ }^{1863}$ - 29 de setembro de 2003 .

Institui a Política Nacional de Atenção às Urgências a ser implantada em todas as unidades federadas, respeitadas as competências das três esferas de gestão.

- Portaria GM/MS no 1864 - 29 de setembro de 2003.

Institui o componente pré-hospitalar móvel da Política Nacional de Atenção às Urgências, por intermédio da implantação de Serviços de Atendimento Móvel de Urgência em municípios e regiões de todo o território brasileiro: SAMU 192.

- Portaria GM/MS no 2072 - 30 de outubro de 2003.

Instituiu o Comitê Gestor Nacional de Atenção às Urgências.

- Portaria GM/MS no 1828 - 02 de setembro de 2004 .

Institui o incentivo financeiro para adequação da área física das Centrais de Regulação Médica de Urgências em estados, municípios e regiões em todo o território nacional. 
- Portaria GM/MS no 2420 - 09 de novembro de 2004.

Constitui Grupo Técnico (GT) visando avaliar e recomendar estratégias de intervenção do Sistema Único de Saúde (SUS), para abordagem dos episódios de morte súbita.

- Portaria GM/MS no 2657 - 16 de dezembro de 2004.

Estabelece as atribuições das Centrais de Regulação Médica de Urgências e o dimensionamento técnico para a estruturação e operacionalização das Centrais SAMU - 192.

- Portaria GM/MS no 399 - 22 de fevereiro de 2006.

Divulga o Pacto pela Saúde - 2006 - Consolidação do SUS e aprova as Diretrizes Operacionais do Referido Pacto.

- Portaria GM/MS no 3125 - 07 de dezembro de 2006.

Institui o Programa de Qualificação de Atenção às Urgências (QualiSUS) no Sistema Único de Saúde (SUS), em consonância com as diretrizes das organizações de redes loco-regionais de atenção integral às urgências.

- Portaria GM/MS no 2922 - 02 de dezembro de 2008.

Estabelece diretrizes para o fortalecimento e implementação do componente de "organização de redes loco-regionais de atenção integral às urgências" de Política Nacional de Atenção às Urgências.

Apoiar/fortalecer por meio de implementação de Redes de Atenção Integral às Urgências, por meio de implantação/ adequação de Unidades de Pronto-Atendimento (UPA) e Salas de Estabilização (SE), em locais/unidades estratégicas para a configuração dessas redes, em conformidade com as Diretrizes da Política Nacional de Atenção às Urgências, em municípios/ regiões de todo o território brasileiro vinculadas ao SAMU - 192 implantado e habilitado e em consonância com as orientações gerais, diretrizes e parâmetros previstos nesta portaria e de acordo com o caderno de orientações Técnicas da Urgência e Emergência.

As UPAs são estruturas de complexidade intermediárias entre as Unidades Básicas de Saúde (UBS), Unidades da Saúde de Família e a Rede Hospitalar, e com estas devem compor uma 
rede organizada de atenção às urgências, com pactos e fluxos previamente definidos, com o objetivo de garantir o acolhimento aos pacientes que a elas acorram, intervir em sua condição clínica e contra-referenciá-los para a rede de atenção à saúde, para a rede especializada ou para internações, proporcionando uma continuidade do tratamento com impacto positivo no quadro de saúde individual e coletivo da população.

As Salas de Estabilização (SE) devem ser localizadas em unidades/serviços da rede de atenção ou posição estratégica em relação à rede de suporte ao SAMU e/ou à Cadeia de Manutenção da Vida e destinando-se a configurar postos de apoio ao atendimento, transporte e/ou transferência de pacientes críticos/graves nas localidades onde o SAMU tem caráter regional, em locais/municípios com grande extensão territorial de característica rural ou municípios com isolamento geográfico de comunidades.

- Portaria GM/MS no 2970 - o8 de dezembro de 2008.

Institui diretrizes técnicas e financeiras de fomento à regionalização da Rede Nacional SAMU - 192.

- Portaria GM/MS no 2972 - 09 de dezembro de 2008.

Orienta a continuidade do Programa de Qualificação de Atenção Hospitalar de Urgência do Sistema Único de Saúde (SUS) - Programa QualiSUS, priorizando a organização e a qualificação de redes loco-regionais de atenção integral às urgências.

\subsection{Atual perfil do serviço de emergência}

A superlotação dos serviços de emergência é problema sério e de grande relevância no sistema de saúde. O que se vivencia nos últimos anos são unidades de emergências lotadas devido ao deslocamento da população em direção a estes serviços, configurando-se como prestadores de atenção primária de assistência à saúde, e não de fato destinados ao atendimento de emergências.

Mediante a leitura sobre o sistema hierarquizado de saúde, as unidades de urgência e emergência têm seu papel claramente 
definido como atendimento terciário, pelo menos teoricamente, porém na prática constata-se total distorção no serviço prestado.

Para corrigir tal distorção, o atendimento primário do sistema (Unidades Básicas de Saúde - UBS) deveria estar bem estruturado no município, com ampla distribuição no contexto urbano e distritos rurais e ainda com a definição dos territórios de abrangência, cobertura populacional bem caracterizada e principalmente possuindo a referência clara e disponível do sistema secundário de saúde (pronto-atendimento/hospitais secundários) em média complexidade.

No entanto, algumas razões ainda não proporcionam a este sistema a credibilidade necessária para sua eficácia. Isto é: a maioria dos municípios brasileiros não possui as unidades básicas de saúde totalmente implantadas, tanto no que se refere ao número, como também na qualidade ofertada do serviço prestado.

A população em geral busca a credibilidade e confiança nas instituições de maior porte. Serão nestas instituições que a população encontrará a resolução do seu problema de saúde, não somente pela facilidade de acesso a este serviço, mas também pela certeza de obter resposta ao diagnóstico mais rápido da sua enfermidade.

Não há dúvida de que estas distorções proporcionam consequências graves ao serviço de emergência em alta complexidade. Primeiramente ao número de atendimento em uma escalada cada vez mais crescente; segundo e facilmente compreensível é a queda da qualidade do atendimento pela sobrecarga do serviço, carência no suporte de recursos humanos, financeiros e tecnológicos.

Segundo Barakat (2005, p. 1), por meio de pesquisa sobre o total de demanda espontânea pela população na busca do serviço de urgência e emergência, 56,2\% procuraram diretamente a unidade de emergência, isto é: foram à busca do serviço de emergência sem passar por qualquer avaliação em primeiro ou segundo nível de atenção. Quanto ao acesso aos serviços de saúde, 72,5\% residiam próximo a serviços de saúde de atenção primária. Do mesmo total de pessoas pesquisadas, $87,5 \%$ foram dispensadas após a consulta médica, ou seja, houve apenas atendimento ambulatorial e/ou urgência de baixa complexidade, configurando assim uma leitura imediata de que apenas $12,5 \%$ 
da população atendida eram efetivamente casos de emergência constatada.

Outras razões, ligadas aos primeiros níveis de saúde (primário e secundário), ocorrem para alimentar tais distorções. Algumas delas apresentadas abaixo.

a) Aspectos ligados à estrutura física e tecnológica.

- Carência de espaço físico para serviços de diagnóstico de média complexidade. (Raio x, ultrassom, ECG, EEG etc.).

- Indisponibilidade na oferta de serviços e consequente peregrinação às outras unidades pelo paciente.

- Áreas de espera inadequadas (pouco arejadas e mal dimensionadas).

- Indisponibilidade do serviço informatizado do prontuário do paciente.

- Indisponibilidade do serviço on-line de referência entre serviços.

- Indisponibilidade de infraestrutura urbana adequada ao bom funcionamento do serviço (transporte coletivo, pavimentação telefonia etc.).

- Indisponibilidade de salas de estabilização devidamente equipadas.

b) Aspectos ligados ao atendimento.

- Pouca agilidade na marcação de consultas e o seu retorno.

- Insuficiência de médicos para o atendimento não somente nas clínicas básicas (médica / cirúrgica, obstétrica e pediátrica) mas também em outras especialidades (oftalmo, otorrino, neuro etc.).

- Carência de recursos humanos treinados e qualificados.

- Horários inadequados de funcionamento, normalmente coincidente com o horário normal de trabalho da população.

- Falta de serviços disponíveis 24 horas.

- Geração de filas intermináveis para o atendimento, colocando à prova o grau de paciência do paciente em busca de soluções para sua enfermidade.

c) Aspectos ligados à política de saúde.

- Descontrole sobre o acompanhamento pré-natal às parturientes, principalmente àquelas de alto risco. 
- Descumprimento dos calendários vacinais e o acompanhamento do desenvolvimento das crianças.

- Descumprimento de medidas de prevenção e detecção precoce dos cânceres mais frequentes.

- Descontrole sobre as doenças crônicas e degenerativas.

- Descuido com o meio ambiente que inclui tratamento da água, esgoto e resíduos.

- Descuido ao combate de vetores de doenças.

- Ineficiência de leis para a redução da violência urbana e no transito.

- Ineficiência sobre a informação/educação nutricional, física e qualidade de vida.

- Ineficiência sobre a informação/educação sexual a adolescentes.

- Ineficiência sobre a informação/educação sobre o uso de drogas.

- Ineficiência sobre a informação/violência doméstica e abuso sexual.

$\mathrm{O}$ atendimento no serviço de urgência e emergência recebe ainda outras influências sobre fatores socioeconômicos, tais como emprego, renda e grau de instrução, os quais estão diretamente relacionados com as condições de vida e cuidados à saúde. As baixas condições econômicas e sociais contribuem para a precarização das condições de vida e piora dos cuidados à saúde.

O tempo transcorrido entre o início dos sintomas e a percepção da severidade do caso pelo paciente é um outro fator relacionado à demanda por atendimento na unidade de emergência hospitalar, uma vez que se fosse procurado tratamento na fase inicial, a possibilidade de agravamento do quadro clínico deste poderia ser minimizada.

A formação de polos geradores de tráfego resulta na elevação do número de acidentes automobilísticos e de atropelamentos, o que contribui para elevar a procura por atendimento de emergência. No mesmo sentido, o crescimento da violência urbana contribui para aumentar o número de agressões e homicídios.

Para melhorar este panorama atual, serão necessárias medidas que venham a organizar e disciplinar o sistema de saúde, que na teoria parece ser eficaz, porém, na prática chega a níveis bastante caóticos. Portanto, a necessidade de um sistema hierarquizado, 
com fluxo estabelecido e acesso à informação amplamente conhecida pela população é de fundamental importância.

Algumas medidas podem ser tomadas, e acredita-se contribuir para a melhoria da qualidade do serviço de emergência em alta complexidade. Tais como:

- necessidade de investimentos pesados na estruturação do sistema proposto, com políticas governamentais, nos três níveis, bem claras e objetivas na efetiva resolução do problema;

- aplicação de recursos em programas assistenciais e na melhoria das condições de trabalho de médicos e paramédicos;

- implantação da Central Única de Regulação Médica em Emergência, que discipline o fluxo de encaminhamento dos pacientes aos hospitais disponíveis pela rede de serviços em alta complexidade e gerenciamento do atendimento préhospitalar;

- encaminhamento do paciente pela Central de Regulação, mediante a avaliação da gravidade, oferecendo disponibilidade de recursos (humanos físicos e tecnológicos). A equipe técnica passa a racionalizar a utilização dos recursos hospitalares, preservando espaços aptos para atender a alta complexidade, garantindo o atendimento imediato às situações de risco de vida. Assim, pacientes que não demandam investigação e procedimentos especializados não serão encaminhados aos serviços de emergência em alta complexidade, e sim a outros serviços de baixa ou média complexidade e mais compatível com a sua necessidade.

Esta disciplina e organização da assistência deverão provocar redução do número de atendimentos, o que permitirá a melhora na qualidade do serviço, redução do estresse da equipe operacional, pacientes e familiares atendidos.

Com este perfil de atendimento, a unidade de emergência deverá ter taxas de ocupação mais compatíveis com a sua capacidade de oferta de leitos para observação. Isto provocará também a redução de pacientes distribuídos em macas e/ou cadeiras de rodas nos corredores de atendimento e/ou salas de espera.

O tempo de permanência do paciente junto à unidade de emergência em regime de repouso e observação deverá ser articulado com a disponibilidade de leitos ofertados nas 
Unidades de Terapia Intensiva e Unidades de Internação do hospital de referência e ainda confrontado com o tempo médio da permanência dos pacientes nas respectivas unidades.

Segundo Toledo (2004, p.91)

A redução de leitos na unidade também ainda promoverá uma melhor racionalização no uso dos espaços, principalmente salas de espera e observação, que não terão mais o papel da superlotação e como conseqüência poderá contribuir para a propagação de infecções hospitalares, além de dificultar a circulação da equipe de saúde e dos próprios pacientes, pelos corredores, condição indispensável numa unidade de emergência.

De qualquer forma, ainda há necessidade também de organizar um programa físico-funcional bastante compatível com a realidade do serviço de emergência em estudo. Isto se faz necessário para atingir o equilíbrio entre o operacional e a obsolescência física e tecnológica que ocorre a uma velocidade cada vez mais vertiginosa.

Com a redução do número de atendimentos e consequente redução do estresse junto à unidade de emergência, poderão tais ajustes contribuir para o início do processo de humanização no atendimento de emergência. Esta medida permitirá ainda a organização do espaço para o acolhimento dos dramas social e psicológico de pacientes e familiares que se deparam com os agravos agudos da saúde. 



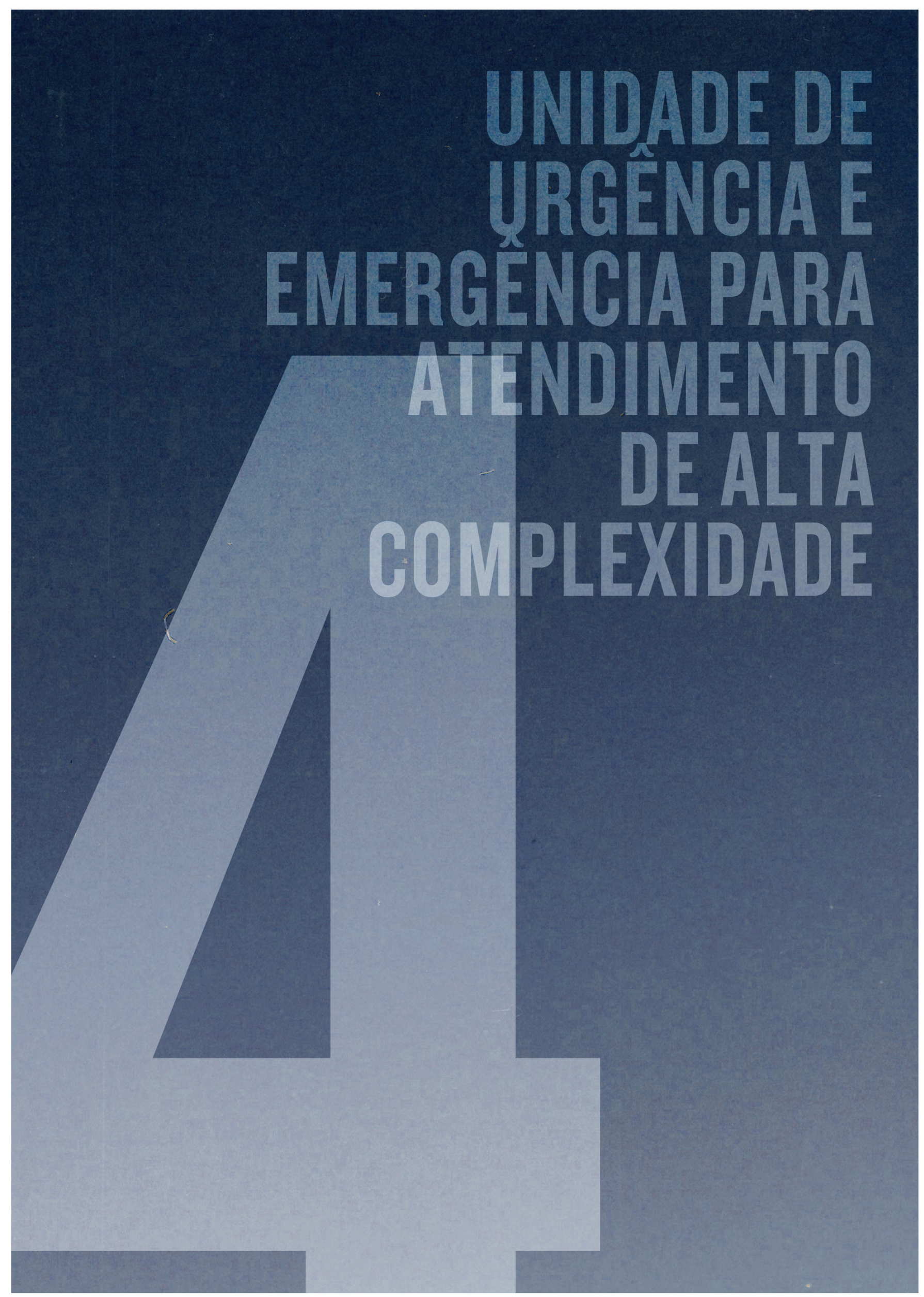





\section{I Conceituação}

As Unidades de Urgência e Emergência são locais apropriados para o atendimento de pacientes com afecções agudas específicas, onde existe um trabalho de equipe especializado, propiciando recursos eficazes para que as suas necessidades sejam atendidas.

O Ministério da Saúde as define como sendo unidades destinadas à assistência de doentes, com ou sem risco de vida, cujos agravos à saúde necessitam de atendimento imediato. Em se tratando de unidades de atenção de alta complexidade, devese prover ainda de atendimento 24 horas ao dia, que disponha de leitos de observação e possua toda a retaguarda diagnóstica (imagenologia, traçados gráficos, análises clínicas e citológicas), tratamento (centro cirúrgico, obstétrico, terapia intensiva e internação), apoio logístico hospitalar (farmácia, esterilização de material, nutrição e dietética, almoxarifado etc.).

O referido atendimento dá-se em duas instâncias: primeiramente, o imediato, em que a eficiência e a eficácia do serviço devem ser as prioridades para atender ao paciente no momento da sua chegada à unidade de emergência. Em seguida, $\mathrm{e}$ após a estabilização dos sinais vitais do paciente, a equipe médica 
e enfermagem passa a ofertar ao ambiente terapêutico as vivências e relações sociais aos pacientes e seus familiares.

Segundo Gomes (1994, p.4)

O atendimento de emergência é o conjunto de ações empregadas para a recuperação de pacientes, cujos agravos à saúde necessitam de assistência imediata, por apresentarem riscos de vida. Tais agravos à saúde põem em risco determinadas funções vitais que, com o passar do tempo, diminuem temerariamente sua chance de eventual recuperação.

Já para o atendimento de urgência, as condições do paciente também são agudas, mas não há perigo eminente de falência de qualquer de suas funções vitais.

Deve-se considerar a importância do serviço, que quando ineficiente poderá causar incapacitação física permanente ou temporária à pacientes, levando a perdas econômicas, previdenciárias e grandes dispêndios em tratamentos de complicações na saúde destes. Isso pode ser evitado, uma vez que boa parte das complicações ocorre em função de atendimentos realizados de forma inapropriada durante a fase aguda.

Neste contexto, a arquitetura assume um papel importante no processo, como um instrumento intermediador na oferta de melhores condições de uso do espaço físico, primeiramente pelos pacientes e familiares, como também ao serviço médico, enfermagem e demais colaboradores.

Ao longo deste processo de concepção e materialização do projeto arquitetônico, caberá ao arquiteto o papel de depurar e traduzir as solicitações da equipe multiprofissional (médicos, enfermeiros, administradores, engenheiros, economistas, entre outros) que colocará suas expectativas de funcionalidade, sistema operacional, relações de contiguidade, capacidade de atendimento, produtividade e ainda a observação às normas e legislação pertinentes à unidade, ao nível federal (RDC 50/ ANVISA e complementares), estadual (código sanitário e normas específicas) e municipal (código de postura, obras e legislação para o uso e ocupação do solo urbano).

Sendo assim, esta ferramenta de organização do ambiente hospitalar será sempre um meio, não um fim. Pois, para a perfeita operação entre a função e o espaço físico será necessário que o 
referido processo idealizado seja implantado e assegurado quando da conclusão da obra e sua colocação em funcionamento.

É importante ressaltar que a equipe multiprofissional que esteve envolvida no processo e acompanhou toda a discussão na formatação deste produto arquitetônico seja a mesma que irá, não somente colocar a unidade em operação, mas também, e principalmente, acompanhar a consolidação dos objetivos inicialmente propostos.

Logicamente, esta continuidade não será um processo imutável, até porque em alguns casos pequenos ajustes serão necessários, quando da avaliação pós-ocupação (APO) que a unidade irá sofrer e devido às mudanças normativas que periodicamente é revista na legislação em vigor.

Estas adequações ocorrem ainda mais enfaticamente quando entre o início do processo da elaboração dos projetos de arquitetura, engenharia e complementares, e a entrega final da obra haja um período longo de tempo. Por vários motivos, desde a incapacidade financeira, dependência da liberação de recursos financeiros, processo licitatório e morosidade das aprovações dos projetos junto aos órgãos públicos podem provocar a sua rápida obsolescência, tendo em vista a própria dinâmica nos avanços da medicina, na oferta de novas tecnologias em equipamentos médicos-hospitalares, bem como em novos materiais e produtos para a construção civil e na infraestrutura de instalações prediais.

Para as unidades já existentes, o processo não será diferente, porém a leitura da unidade passa pela análise do Plano Diretor de Organização e Expansão Física de todo o complexo hospitalar, previamente elaborado, o qual norteará as decisões para se atingir os objetivos de uma unidade eficiente em seu serviço de atenção à saúde. Sem este diagnóstico prévio é muito provável a geração de uma arquitetura confusa, inoperante e de obsolescência a curtíssimo prazo.

No plano da assistência, o serviço em estudo, para sua real eficácia, deve sempre estar vinculado ao sistema de atendimento pré-hospitalar (SAMU) bem-estruturado, integrado à central de regulação médica de urgências, com pessoal treinado para os primeiros socorros, os quais garantem o perfeito encaminhamento do enfermo ao hospital de referência. 
No âmbito interno, a unidade deve estabelecer padrões operacionais (procedimentos médicos e enfermagem) eficazes, onde estes se estendam às demais áreas de apoio, por meio de recursos e atuações sistematizadas, com equipes devidamente treinadas.

Gomes (1994, p.5) ainda coloca que

[...] não há atendimento bem sucedido sem uma boa administração de recursos materiais, a qualidade do material aliada à sua quantidade, bem como a adequação ao uso, são fatores que contribuem significativamente para a assistência. As funções de previsão, provisão, organização e controle desses recursos passam por diferentes áreas do hospital, que devem ser mantidas em condições seguras e familiarizadas com a forma de administrá-los.

Neste cenário, a Unidade de Urgência e Emergência exerce a função de ser o principal acesso de pacientes ao complexo hospitalar. Devido o grande volume de atendimento, diversidade do perfil do enfermo, grau de educação e escolaridade do pacientee familiar, a equipe de assistência deve, com seu trabalho, transmitir segurança, confiabilidade, conforto e conduzir por meio de um bom relacionamento humano como ferramenta para minimizar conflitos, reduzir ansiedade, angústia e medo.

Com o equilíbrio destas ações, o serviço atinge níveis de estabilidade operacional necessária para a boa resolutividade dos procedimentos e a compreensão dos usuários assistidos às indicações terapêuticas.

Nessa atmosfera estressante, é importante observar o quanto este "clima" contínuo no processo de assistência atinge grande parte dos seus operadores, provocando insatisfação, desinteresse, apatia e irritação. Fatores estes originados muitas vezes pelo número reduzido de funcionários da equipe, carga de trabalho fatigante, necessidade de realização de tarefas em tempo reduzido, descontentamento com o trabalho, falta de comunicação e compreensão por parte da supervisão de serviço, assistência e relacionamento com pacientes e familiares, baixos salários, ambiente físico inadequado da unidade e pouca tecnologia ofertada em equipamentos.

Segundo Pinho (2007, p.330), “O ambiente hospitalar é caracterizado por um tipo de trabalho com forte carga emocional, 
onde a vida e a morte se misturam para compor um cenário desgastante e, não raro, frustrante".

Unidades de Urgência e Emergência com atendimento em alta complexidade são sempre parte integrante de hospitais de médio a grande porte, com o caráter de abrangência populacional significativo de grandes centros urbanos, ou ainda de referência regional. Sua capacidade de leitos ofertados deve ser no mínimo a partir de 150 camas. Esta oferta geral de leitos pode ocorrer nas diversas especialidades médicas, bem como ainda em hospitais especializados nas áreas de: cardiovascular, ortopedia e traumas, obstetrícia, pediatria, saúde mental, entre outros.

\subsection{Tipologia por Característica de Atenção à Saúde}

\subsection{Unidade de Urgência e Emergência geral}

Como o exposto, a unidade em estudo, com característica de atendimento geral se torna na sua organização um desafio para o profissional arquiteto e seus interlocutores. Isto porque a abrangência do serviço no recebimento de pacientes com características distintas como: politraumatismos, feridos por armas brancas e de fogo, paradas cardiovasculares, infarto do miocárdio, queimaduras, pediátricos, obstétricos e ainda pacientes com distúrbios mentais, provocam severa turbulência ao sistema operacional e, sobretudo, quando a arquitetura não estiver minimamente organizada.

Com este nível de complexidade no seu atendimento, a unidade necessita, além de todo o suporte logístico, obrigatoriamente de um centro de diagnósticos por imagem bem equipado, centro cirúrgico e obstétrico com um número de salas cirúrgicas e parto generoso, Unidades de Terapia Intensiva com disponibilidade de leitos para garantia de absorção de casos mais graves e ainda o suporte hoteleiro de internação para os pacientes que necessitam de atendimento de menor gravidade.

A compreensão da sazonalidade, embora não rigidamente, é importante ressaltar que aos finais de semana e períodos noturnos, constata-se um nível mais elevado de ocorrência de pacientes feridos com armas brancas e de fogo. Durante a semana, no período diurno, ocorrem muitos acidentes com motociclistas 
e ainda outros vinculados ao trânsito de veículos e pedestres na área urbana. "Mudança de lua", embora não constatado cientificamente, tem promovido um aumento significativo no atendimento de gestantes em trabalho de parto, sendo que alguns casos quase em processo expulsivo. Nos meses de inverno, elevase em muito o atendimento dos pacientes portadores de afecções broncorrespiratórias, principalmente em crianças e idosos. Já no verão, tem se agravado o atendimento aos pacientes em moléstias infectocontagiosas, como a dengue e meningite, por exemplo.

Um bom sistema de encaminhamento do paciente ao serviço de emergência inicia-se pela Central Única de Regulação Médica (CURM), por meio da ficha de referência preenchida pelo serviço de saúde de origem, sejam eles procedentes das UBS (Unidades Básicas de Saúde) ou demais hospitais locais e/ou da região. Este encaminhamento é realizado pelo SAMU, que oferece ao paciente todo o suporte na assistência, bem como disponibiliza com antecedência ao hospital referenciado todas as informações necessárias para o melhor e mais seguro acolhimento ao referido paciente. Para tanto, a integração e a compatibilização das informações requerem um sistema de comunicação eficiente e confiável.

Neste cenário, a arquitetura deve organizar a setorização e disciplina de fluxos externos e internos, agrupamentos por tipo de pacientes, características de atendimento e sexo, para que se minimizem os problemas conflituosos e intercorrências no processo de atenção à saúde do paciente em estado crítico.

Esta organização passa pelo direcionamento e separação dos fluxos externos, conforme leitura da figura 89 em classificação descrita abaixo.

- Emergência (atendimento imediato independente de sexo, idade e especialidade médica).

- Urgência (separação dos fluxos para pacientes adultos de ambos os sexos, e ainda pediatria, gestantes e saúde mental). 


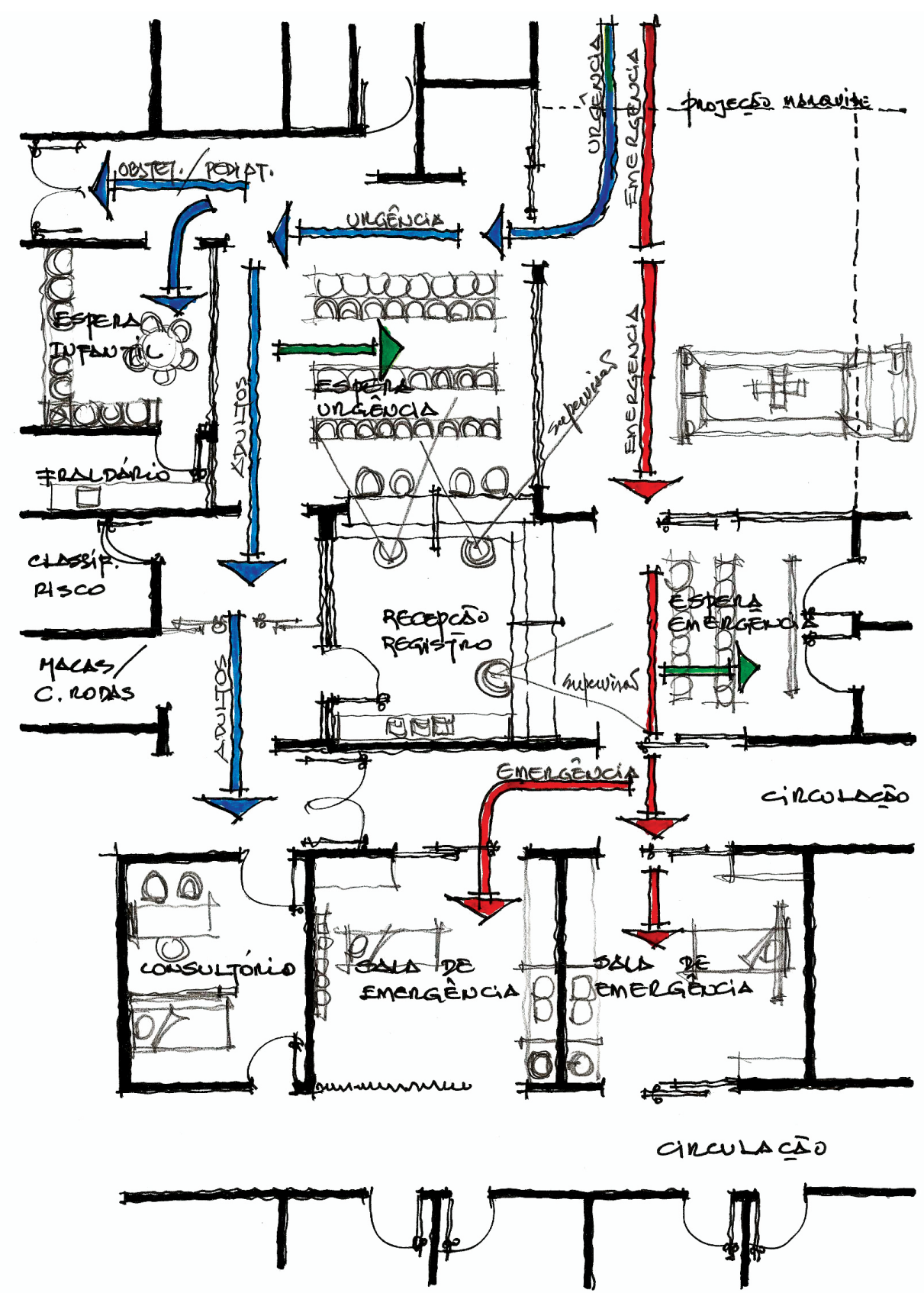

Figura 89 - Croqui esquemático: organização de fluxos de urgência e emergência.

(Fonte: elaborada pelo autor).

\subsubsection{Unidade de Urgência e Emergência Cardiovascular}

Reflexo das grandes transformações ocorridas no último século, em que, de forma significativa, alteraram-se os padrões de vida da sociedade em geral, a industrialização se consolidou 
e, por consequência, ocorrendo o êxodo rural com processo de "inchamento" das grandes cidades.

Ocorreram ainda mudanças no perfil sanitário, em que a interação entre maior expectativa de vida, o controle das doenças infecciosas e as melhores condições de vida promoveram uma mudança progressiva ao perfil do cidadão brasileiro, no qual hoje predominam os óbitos por doenças crônico-degenerativas.

Esta nova realidade epidemiológica fez com que a doença cardiovascular (DCV) emergisse como doença crônica dominante em muitas partes do mundo, sendo uma das principais causas de morte e incapacidade. No Brasil, esta doença já representa a primeira causa de óbitos na população. Porém, quando isto não ocorre, esta leva com frequência à invalidez parcial ou total do paciente, com graves repercussões para a pessoa acometida, sua família e a sociedade.

Pelas razões expostas, pela complexidade do serviço, bem como a necessidade do preparo e qualificação da equipe multiprofissional, ao longo dos últimos 15 anos surgiram no Brasil os serviços especializados em emergência cardiovascular. $\mathrm{O}$ atendimento ocorre mais frequentemente ao infarto agudo do miocárdio (IAM), parada cardiovascular (PCR), parada cardiopulmonar (PCP) e acidente vascular encefálico (AVE). (MATSUMOTO, 2008, p. 2). Com isto, procurou-se, por meio da criação de unidades especializadas, dar um suporte maior ao atendimento e tratamento às doenças para que, por consequência, aumentassem significativamente os resultados positivos na recuperação do paciente.

As Unidades de Urgência e Emergência Cardiovascular ou Unidades de Dor Torácica necessitam de boa organização física dos seus espaços, facilidade de acesso imediato à sala de emergência, bem como contar com o laboratório de intervenção cardiovascular (hemodinâmica) na sua estrutura de atendimento ao paciente. (Fig. 90). 


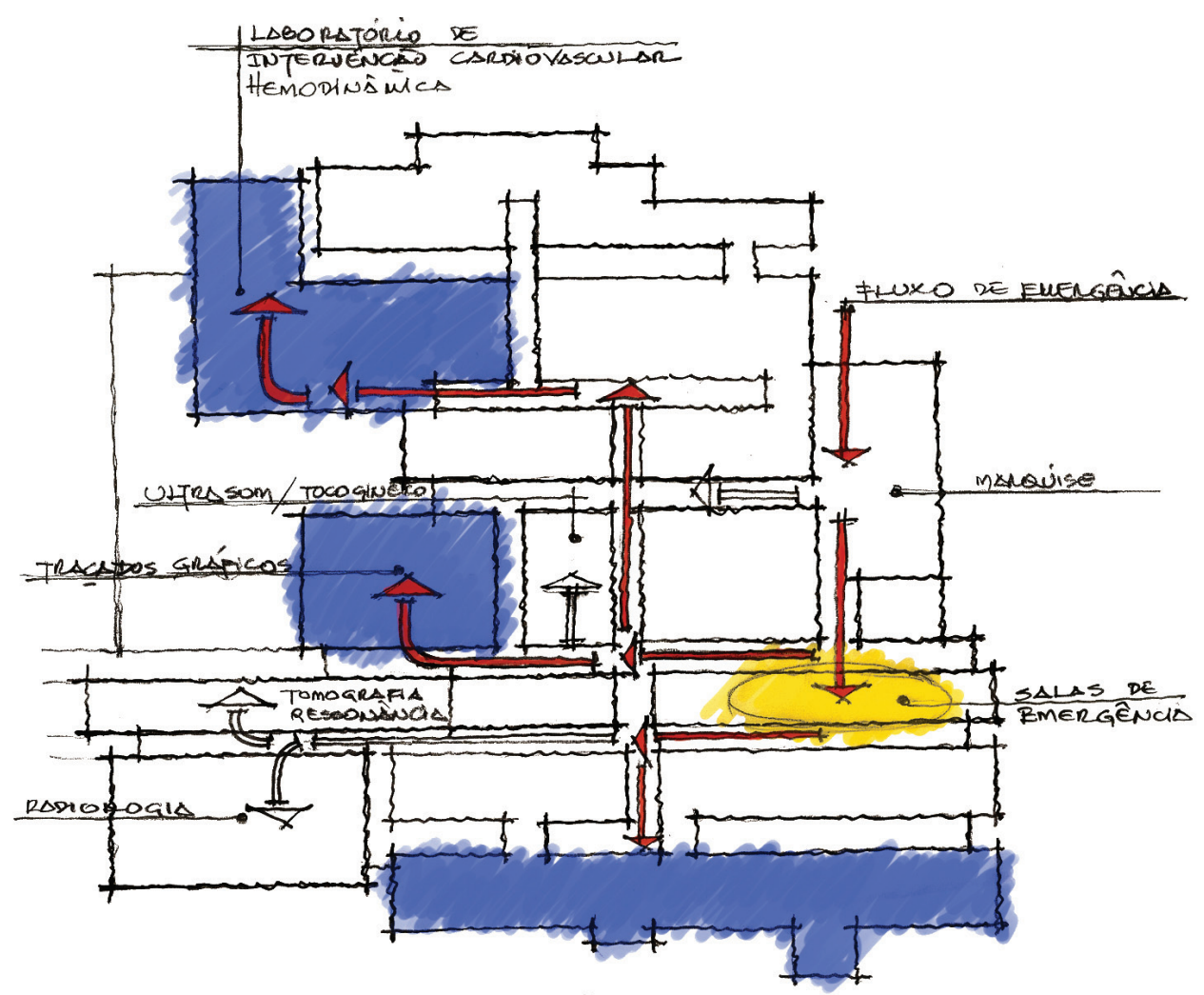

Figura 90 - Croqui esquemático: fluxos de emergência cardiovascular. (Fonte: elaborada pelo autor).

A disciplina e facilidade de fluxos são condicionantes importantes na distribuição física dos espaços, isto porque o tempo é outro fator importantíssimo no processo.

Segundo Matsumoto (2008, p.1),

A equipe multiprofissional deve possuir plena ciência da gravidade da situação, além de ter conhecimento prático e teórico sobre as atitudes que devem ser tomadas prioritariamente a fim de preservar as funções fisiológicas, visto que a gravidade aumenta a cada segundo da demora, podendo causar seqüelas irreversíveis.

Conforme Gomes (2005, p.6), “O SBV (Suporte Básico de Vida) quando fornecido com menos de 4 minutos de PCR e o SBV com menos de 8 minutos há um prognóstico de 36 a $70 \%$ de sobrevida a alta hospitalar, pois o tempo é um forte fator prognóstico sobre os resultados alcançados".

Sobre a Parada Cardiorespiratória Matsumoto (2008, p.2) coloca: 
Outro fator relacionado à PCR é o trauma, sendo principalmentecausadoporacidentesautomobilísticos e ferimentos por arma de fogo. Envolve, na maioria das vezes, o adulto jovem. A parada cardíaca, nesses casos,é conseqüência do trauma direto e de fatores como hipóxia, hipovolemia e hipotermia.

As PCRs constituem hoje um relevante serviço no Brasil, de grande alcance médico-social, podendo representar uma importante estratégia para o melhor manuseio de recursos e de qualidade assistencial.

\subsubsection{Unidade de Urgência e Emergência em Ortopedia e}

Trauma

Os casos de atendimento emergencial em ortopedia e trauma são ocorrências que afligem todo o mundo, não somente pelo número elevado de mortes, mas também pelo número de pacientes sequelados. Nesta situação, as vítimas requerem que seja feita uma avaliação rápida para que as lesões possam ser identificadas e subsequentemente proceder as intervenções necessárias para que não coloque o paciente em risco.

O trauma é a terceira causa de morte da população em geral, ficando atrás apenas do câncer e doenças cardiovasculares. Com este cenário, tal área de atenção à saúde vem trabalhando para modificar este quadro estatístico no sentido de permitir aos pacientes traumatizados menor nível de morbidade e mortalidade.

Uma das primeiras ações nesta direção ocorreu por volta de 1976, nos Estados Unidos, com a criação do programa ATLS (Advanced Trauma Life Support) ou SAVT (Suporte Avançado de Vida ao Trauma), no qual se objetivou estabelecer uma rotina de procedimento de assistência médica-enfermagem, que se inicia já no atendimento pré-hospitalar (SAMU) até o encaminhamento final do paciente assistido.

$\mathrm{O}$ atendimento pré-hospitalar tem sido peça fundamental na eficácia do serviço de emergência em trauma, quando ocorre a imediata avaliação e estabilização das vítimas e em seguida sua transferência para os hospitais referenciados.

Conforme Karstein (1996, p.4) em seus estudos para a cidade de Curitiba, mesmo tomando estes parâmetros como 
amostragem para o que ocorre em cidades de mesmo porte, pode ser estabelecido que as principais ocorrências nesta área de atenção à saúde são:

Quantoà causa, as colisões foram a principal produtora de vítimas (35,22\%). Seguiram-se atropelamentos $(18,24 \%)$, quedas $(11,74 \%)$ e acidentes com motos $(8,07 \%)$. As agressões interpessoais e por arma branca ou de fogo foram causa da $6,8 \%$ dos atendimentos. Os acidentes de trânsito foram a causa de $61,55 \%$ dos atendimentos.

Como consequência, o estudo demonstra ainda que o trauma continua sendo a principal causa de morte durante as primeiras quatro décadas de vida, tornando-se verdadeira doença e responsável pela perda de muitos anos de vida produtiva.

Do ponto de vista estrutural-físico, é importante a garantia de fluxo imediato às salas de emergência (estabilização) para os primeiros socorros, mas também para estes casos será necessário a oferta de serviço de diagnóstico por imagem, por meio de equipamentos como raio $\mathrm{x}$, tomografia e/ou ressonância magnética, entre outros, para proporcionar maior segurança ao diagnóstico. Considera-se ainda que outros serviços de suporte serão necessários, como agência transfusional, laboratórios de urgência em análises clínicas, fluxo facilitado ao centro cirúrgico e Unidades de Terapia Intensiva, para o melhor atendimento do enfermo. (Fig. 91). 


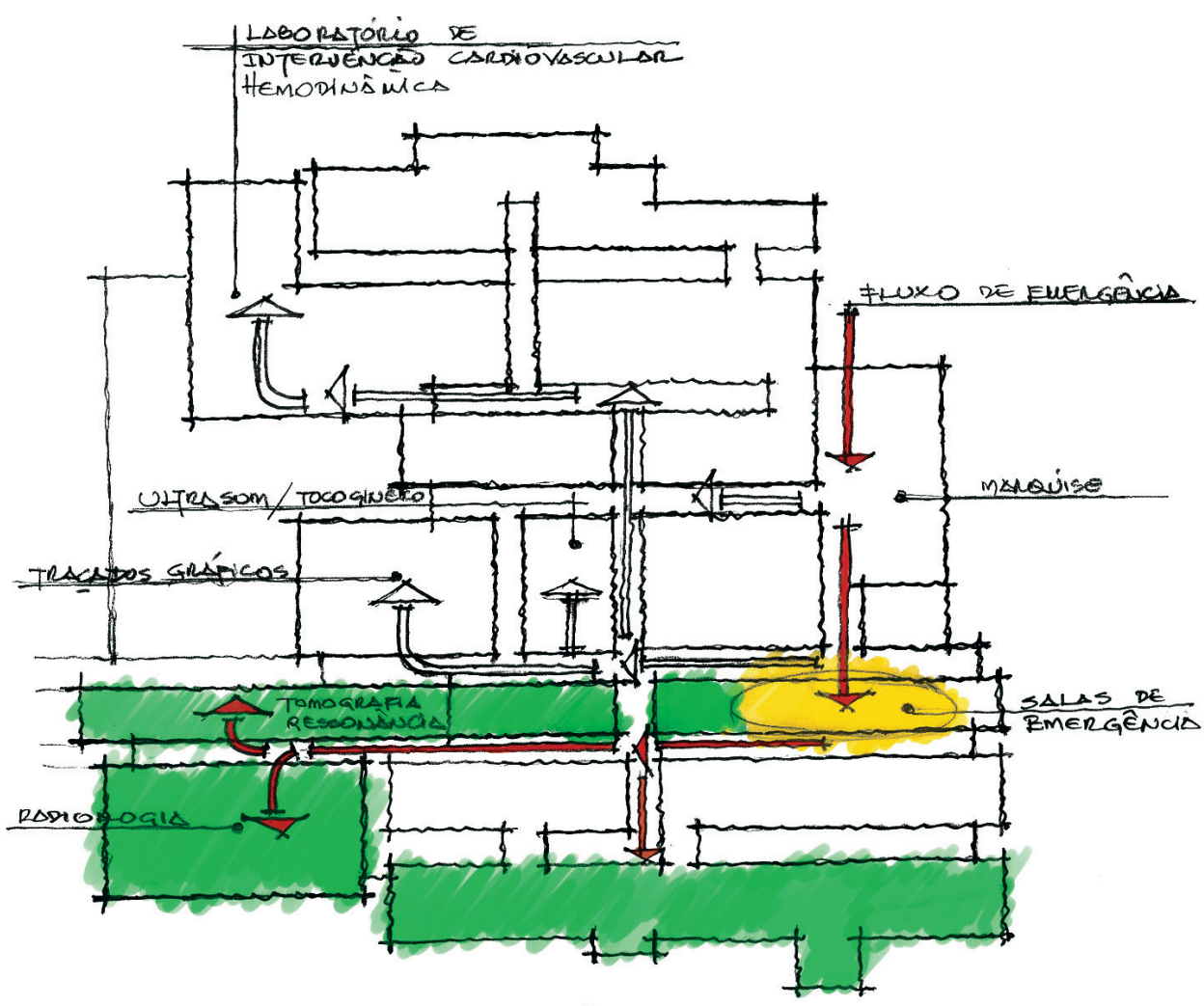

Figura 91 - Croqui esquemático: fluxos de emergência em ortopedia e

trauma.

(Fonte: elaborada pelo autor).

\subsubsection{Unidade de Urgência e Emergência em Obstetrícia}

Embora a gestação seja um fenômeno fisiológico e sua evolução ocorra, na maioria das vezes, sem intercorrências, há um grupo de gestantes que apresenta maiores probabilidades de complicações, como aquelas consideradas de alto risco (para mulheres abaixo de 17 anos e acima de 35), ou ainda por outros tipos de enfermidades, como cardiopatias, hipertensão, diabetes etc., as quais possam comprometer a evolução natural da gestação, tanto para o feto como também para a mãe.

A especialidade médica em obstetrícia é um dos serviços comumente ofertado em Unidades Básicas de Saúde, que tem como finalidade acompanhar a parturiente desde o início do processo de gestação, com programas educacionais, preventivos e terapêuticos, até o momento do seu encaminhamento à maternidade de referência. Com este trabalho ocorrendo de forma sincronizada e contando com equipes multidisciplinares 
de apoio bem treinadas, haverá sempre a segurança na obtenção de resultados positivos.

A importância deste trabalho de base, com acompanhamento contínuo durante todo o período pré-natal, é que possibilita ao serviço de urgência e emergência exercer o seu verdadeiro papel no atendimento às intercorrências mais graves.

Pelas características próprias no seu atendimento, equipe especializada, momento emocional da parturiente e familiares, sempre é interessante que as Unidades de Urgência e Emergência nesta especialidade médica tenham sua individualidade assegurada, principalmente quando colocada em conjunto a outros serviços.

É benéfica a criação de unidades próprias para a retirada desta paciente e familiares de ambientes mais conturbados e à exposição a outros tipos de afecções, possuindo melhores condições na oferta de serviço mais acolhedor e humanizado, e principalmente oferecendo maior segurança e privacidade.

A unidade deve contar como estrutura de apoio, não somente com salas de emergência para o atendimento imediato, mas também suporte de diagnóstico por imagem, laboratorial e ainda um centro obstétrico adequado ao tipo de parto a ser realizado (vaginal ou cesárea). (Fig 92). 


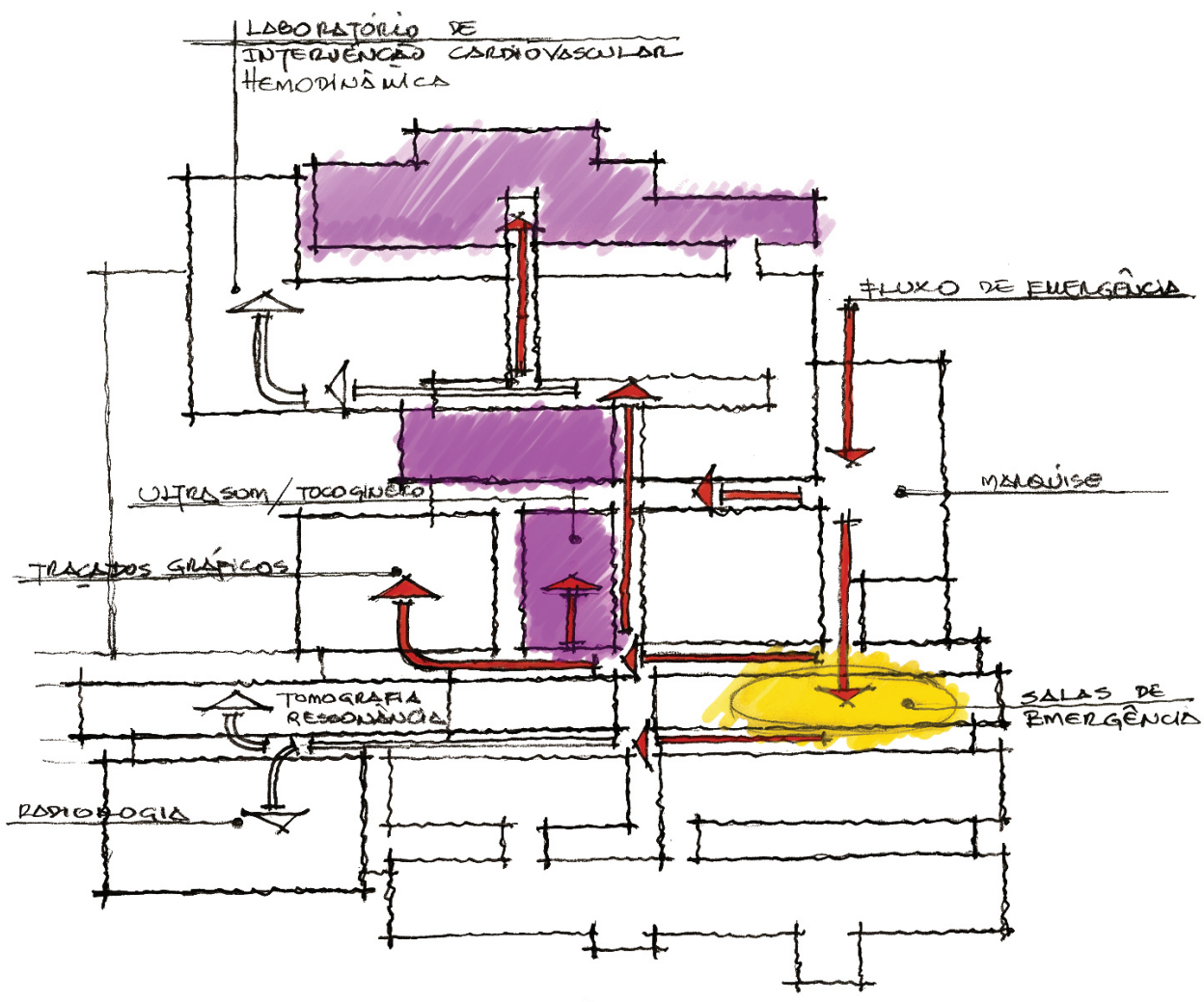

Figura 92 - Croqui esquemático: fluxos de emergência em obstetrícia.

(Fonte: elaborada pelo autor).

A adoção do sistema PPP (pré-parto, parto, pós-parto/ puerpério) por alguns serviços de atendimento à gestante tem ofertado um serviço mais humanizado, individualizado e maior privacidade à parturiente e seus familiares.

Segundo Bitencourt (2008, p.46),

O desenvolvimento de projetos arquitetônicos para novos serviços em obstetrícia determinará uma revisão de conceitos com base em propostas recentes de humanização da assistência ao parto e nascimento, onde o foco das ações deve considerar a construção dos elementos que possam propiciar o devido conforto ambiental para os diferentes atores desse processo, particularmente as parturientes, o recém-nascido e a equipe de saúde. 


\subsubsection{Unidade de Urgência e Emergência em Pediatria}

OSistemaÚnicodeSaúdetraznoseubojotodasasconformações e limitações de um modelo concebido e fundamentado na concepção biologista da saúde, cujos resultados têm sido práticas excessivamente medicocêntricas, com predomínio de hospitalização e da fragmentação do cuidado da saúde.

Aliado à complexidade da reestruturação do sistema de saúde, o Brasil apresenta-se ao longo das últimas décadas com um dos piores desempenhos entre os países do Terceiro Mundo no que diz respeito à pobreza e distribuição de renda.

Segundo estimativas do PNAD (Pesquisa Nacional por Amostra Domiciliar) 53,5\% das crianças e adolescentes brasileiros vivem em famílias cuja renda mensal per capita não ultrapassa a meio salário mínimo

Atualmente, há muitas famílias chefiadas por mulheres, isso acarreta um peso maior para estas que, abandonadas pelo marido, exercem o papel de dona de casa, de mãe, de pai, tendo que sustentar, cuidar dos filhos e da casa ao mesmo tempo, por esta razão, principalmente nas camadas mais desfavorecidas da população, ocorre uma maior precariedade à situação das crianças e adolescentes brasileiros.

Aliado a este quadro, tem-se que nos últimos anos a violência contra as crianças tem aumentado significativamente. Atualmente, a violência infantil tem sido objeto constante de discussões, tanto por organismos governamentais como também dos não governamentais, no que diz respeito aos direitos das crianças.

Os resultados nocivos desta situação de pobreza têm efeito direto sobre a vida das crianças nos seus aspectos mais fundamentais, como na saúde, nutrição e educação.

Neste contexto, é importante que todos os dirigentes e profissionais de saúde, que atuam principalmente no setor público, conheçam este quadro e assumam a tarefa de acompanhar a evolução das condições de vida e saúde das crianças em seus diferentes níveis de atenção e que participem da criação de oportunidades que visem promover a superação desta realidade.

Enxergar o eixo de atenção à criança, por meio dos resultados mínimos esperados na prática da promoção à saúde, prevenção das doenças e tratamento precoce dos agravos que acometem a 
criança, principalmente no período que vai desde o intrauterino até a faixa dos 12 anos, são obtidos pelo atendimento integrado (obstetrícia/gestação e pediatria) junto a estrutura básica de saúde.

Compreende este atendimento ao nível primário de atenção à saúde desde a assistência durante o período pré-natal, de forma sistematizada e multidisciplinar, aleitamento materno, no mínimo até os 6 primeiros meses de vida, acompanhado de um desmame adequado, observação quanto à cobertura vacinal até pelo menos os primeiros 18 meses de vida, implementação do sistema de vigilância alimentar e nutricional e detecção dos casos de maus tratos e abuso às crianças.

As unidades específicas para o atendimento de urgência e emergência em pediatria podem se considerar um fator importante nos resultados e satisfação da clientela, pelo fato de separar os pequenos enfermos das grandes unidades gerais de emergência. A criança é removida dos ambientes de maior tumulto e com a convivência inadequada entre pacientes adultos e, portanto, expostas à outras enfermidades.

Segundo estudos de Tácsi (2004, p.2),

À cada ano morrem cerca de 12 milhões de crianças, antes de chegar aos cinco anos de idade, muitas delas, durante o primeiro ano de vida, sobretudo nos países em desenvolvimento. Sete, de cada dez, dessas mortes devem-se a infecções respiratórias agudas como a pneumonia, diarréia, sarampo, malária ou desnutrição, frequentemente, a uma combinação dessas afecções.

Complementa ainda que, entre as doenças de maior demanda aos serviços de emergência pediátrica, estão as doenças respiratórias, os estados convulsivos, as intoxicações, os acidentes e traumas, provocando, muitas vezes, a parada cardiorrespiratória, que constitui a emergência médica de maior importância na área pediátrica. Os processosinfecciosos, parasitológicos e traumáticos, na maioria das vezes, constituem as principais causas de ingresso a essas unidades.

Nestes casos, no momento da chegada do paciente pediátrico em estado crítico é de fundamental importância o acolhimento por parte da equipe médica e enfermagem e que esta seja bastante preparada, contando ainda com uma estrutura física que facilite 
o seu ingresso de forma rápida e direcionada aos primeiros socorros. (Fig 93).

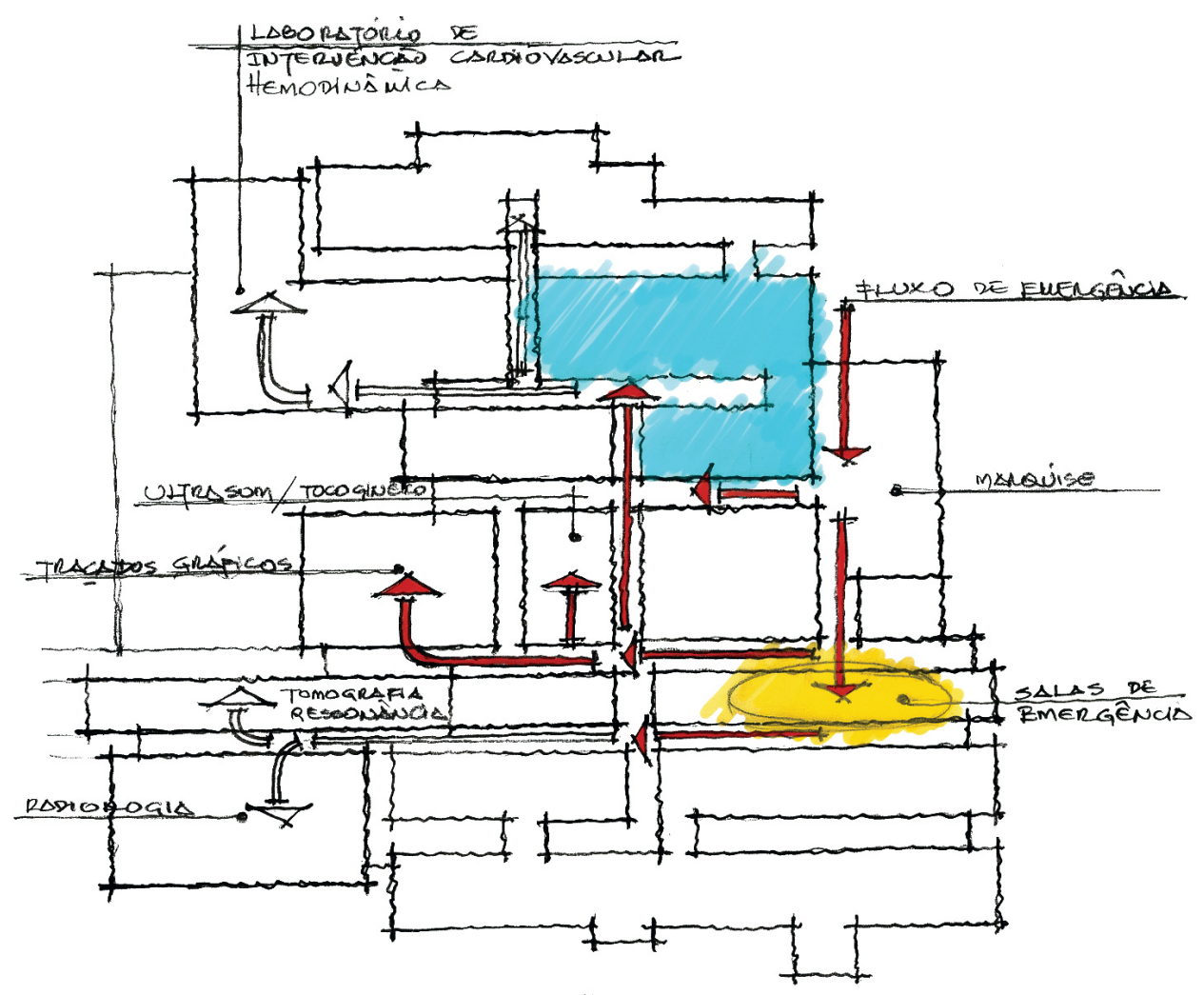

Figura 93 - Croqui esquemático: fluxos de emergência em pediatria.

(Fonte: elaborada pelo autor).

Nos municípios que possuem uma boa estrutura básica em saúde, distribuída de forma equilibrada, conforme demanda de seu território de abrangência, as UBS’s (Unidades Básicas de Saúde) devem desempenhar o papel de absorver o atendimento às crianças com afecções de menor gravidade, como também atender aos programas vacinais e preventivos. Isto significa uma redução substancial nos atendimentos de emergência nos hospitais terciários, com serviço de alta complexidade. Porém, esta não é a realidade da grande maioria das cidades brasileiras.

A oportunidade de se trabalhar arquitetonicamente os espaços para este público, permite ao arquiteto reconstituir, recriar a ambiência necessária para a oferta de conforto, acolhimento e segurança dos pequenos e seus familiares. (Fig. 94 e 95). 


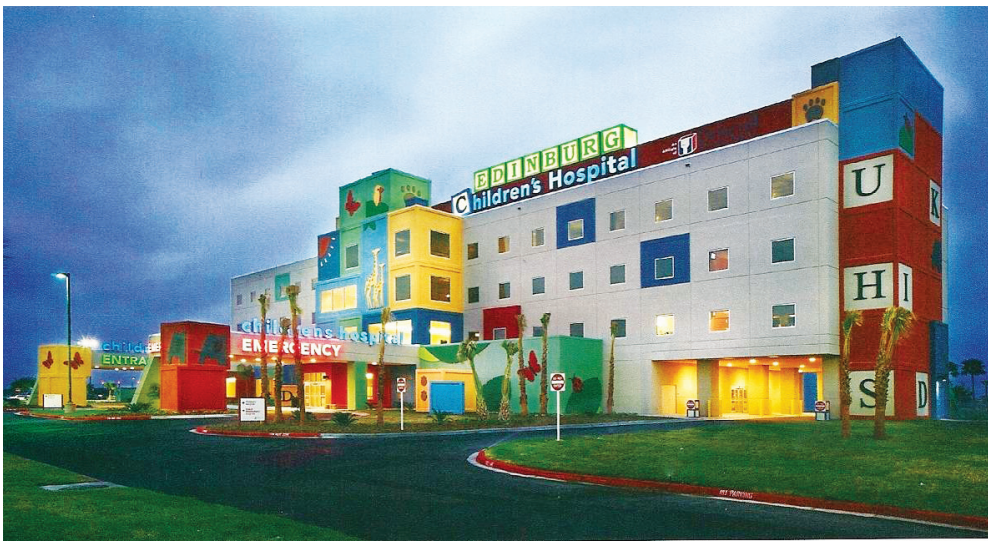

Figura 94 - Edinburg Children's Hospital, Texas, USA.

(Fonte: Architecture for Healthcare - The Images Publishing Group, Hong Kong China, 2008).

Ainda em processo de discussão, porém já com muita força de reivindicação da classe médica e enfermagem, há necessidade de se caracterizar uma área específica para o atendimento em herbiatria. Pelo padrão e classificação de hoje, o atendimento ao paciente com 12 anos será realizado na unidade de adultos, o que demonstra total incompatibilidade de assistência adequada à sua faixa etária. Portanto, criar o espaço adequado ao adolescente de 12 a 19 anos, compreendido e enquadrado na categoria de herbiatria é necessário e de fundamental importância para organização geral da unidade. Com isto deve-se garantir maior privacidade e individualidade ao paciente assistido.

Para efetivamente criar uma proposta como esta, o profissional arquiteto, mediante a sua sensibilidade, pode se apropriar de elementos arquitetônicos, como utilizações de diferentes materiais de acabamentos, espaços abertos, rampas, espelho d'água, como também por meio da incorporação de elementos lúdicos associados ao mundo da criança, som, além da permeabilidade visual, continuidade e proporcionalidade espacial.

\subsubsection{Unidade de Urgência e Emergência em Saúde Mental}

O serviço em saúde mental teve seu grande momento deruptura do modelo de atenção implantado por meio da Lei n ${ }^{\circ} 10.206$ Paulo

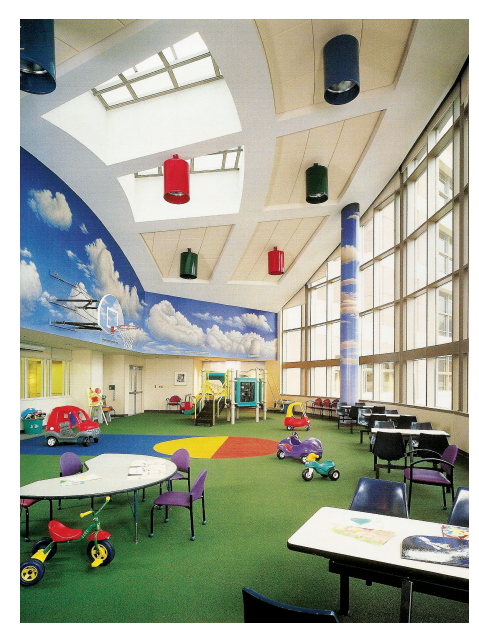

Figura 95-MD Anderson

Cancer Center, Houston, Texas, USA.

(Fonte: Health Spaces Vol. 01 The Images Publishing Group, Melbourne, Australia, 2000). 
Delgado em abril de 2001, a qual modifica substancialmente a forma e o processo de atendimento esta especialidade médica. Isto é: propôs a alteração no modelo de atenção, onde os hospitais até àquele momento eram vistos apenas como um alojamento de pacientes rejeitados pela família e a sociedade, passando a uma assistência mais classificatória, de acordo com a natureza e especificidade do problema.

Sendo assim, muitos casos passaram a um atendimento meramente ambulatorial, ficando a assistência dos casos mais graves ao serviço de emergência.

Segundo Estelmhsts (2008, p.400),

Emergência em saúde mental se refere a uma condição em que a pessoa manifesta alteração do pensamento (delírio) ou nas atitudes (agitação motora, atos agressivos físicos e/ou verbais), o que requer atendimento rápido. Essas alterações estão associadas a risco de vida para a própria pessoa e/ ou para terceiros, pois, nas síndromes ou sintomas psiquiátricos mais freqüentes, estão presentes agressividade, comportamento suicida e delírio com o juízo crítico comprometido.

Nos serviços especializados de emergência em Saúde mental, estima-se que em torno de $20 \%$ dos pacientes atendidos são suicidas e 10\% apresentam comportamento agressivo. Os diagnósticos mais comuns envolvem a depressão, mania, esquizofrenia e dependência de álcool. Cerca de $40 \%$ dos pacientes atendidos são encaminhados para internação.

Como já abordado, nos avanços da medicina e na oferta cada vez maior de tecnologia na área médica-hospitalar, há como resultado um progressivo aumento na expectativa de vida da população e, como consequência, aumentado significativamente o percentual dos idosos na composição demográfica do mundo em geral.

No Brasil, isto não é diferente, segundo o censo/2008, conta-se com aproximadamente 14 milhões de habitantes com mais de 60 anos de idade. Esse grupo etário, que neste momento representa $8,6 \%$ do total da população brasileira, é aquele que mais rapidamente vem crescendo no país. De fato, estima-se que nos próximos 25 anos o número de idosos vivendo no Brasil deverá praticamente duplicar estabelecendo de forma definitiva uma 
verdadeira revolução demográfica em um país que, até pouco tempo, era considerado jovem.

Segundo Almeida (1999, p.13)

O envelhecimento da população traz, como uma das conseqüências, um aumento na prevalência dos problemas de saúde característicos do idoso: doenças cardiovasculares, neoplasias, diabetes, doenças reumatológicas e alguns transtornos mentais. A demência, por exemplo, afeta aproximadamente 5\% dos idosos aos 65 anos de idade e $20 \%$ daqueles com 80 anos ou mais. Depressão é outro transtorno mental freqüente entre idosos, com taxas de prevalência variando entre $5 \%$ e $35 \%$, de acordo com o nível de gravidade da depressão. Além disso, os distúrbios psiquiátricos dos idosos interferem de forma negativa na vida daqueles envolvidos com seus cuidados, e já representam uma das principais áreas de gastos com a saúde da população em países desenvolvidos.

Com este cenário, o nível de preocupação aumentou, como registrado na recente conferência sobre "Pacto Europeu para a Saúde Mental e Bem-Estar", realizada em Bruxelas em Julho/2008. A principal abordagem foi desvendar o que vem ocorrendo, principalmente junto aos países da Comunidade Europeia, no qual foi constatado nos últimos anos um aumento significativo de pacientes com depressão e o suicídio como uma das principais causas de morte, com números expressivos junto aos países membros.

A leitura é clara de que as doenças mentais e o suicídio causam um enorme sofrimento para os indivíduos, familiares e comunidades, e as doenças mentais são a maior causa de incapacidade, originando assim pressão nos sistemas de saúde, educacionais, econômicos, trabalhistas e sociais.

Os transtornos relacionados a ansiedade, mania, alcoolismo são outros problemas que afetam a vida do idoso. Outro ainda, relacionado ao abuso ou dependência de sedativos, a qual está associada a maior risco de quedas e fraturas, especialmente quando a dose utilizada for elevada. É relevante observar que os transtornos mentais tem sido mais frequentes quanto ao sexo feminino, que segundo Halbreich e Sherwin (1997, p.16), 
outros fatores que possivelmente contribuem para que as mulheres sejam mais vulneráveis ao desenvolvimento de transtornos mentais na velhice incluem a alta taxa de viuvez e de isolamento social entre aquelas com mais de 60 anos, e a privação de estrogênio (reposição hormonal).

Dentro desta realidade no atendimento emergencial de pacientes com algum distúrbio mental, principalmente em unidades de emergência acopladas aos hospitais gerais, sempre há um desafio para a sua organização espacial.

Muitos dos atendimentos a pacientes com este perfil vêm associados a outros tipos de lesões e/ou ferimentos como cortes, perfurações, fraturas etc. A associação entre a equipe multidisciplinar e o espaço deve manter o ambiente de trabalho com alto nível de segurança e ao mesmo tempo um clima de harmonia, e deve-se remover objetos que possam ser usados como instrumentos de agressão. Além disso, o espaço deve refletir um sentido de proteção e acolhimento.

É importante que a arquitetura esteja organizada para receber pacientes com estas características, de forma que o seu atendimento seja rápido e direto às áreas de estabilização. Considera-se com isto, que haverá maior agilidade no serviço, proporcionando ainda maior tranquilidade aos demais pacientes e profissionais envolvidos na unidade de emergência. 



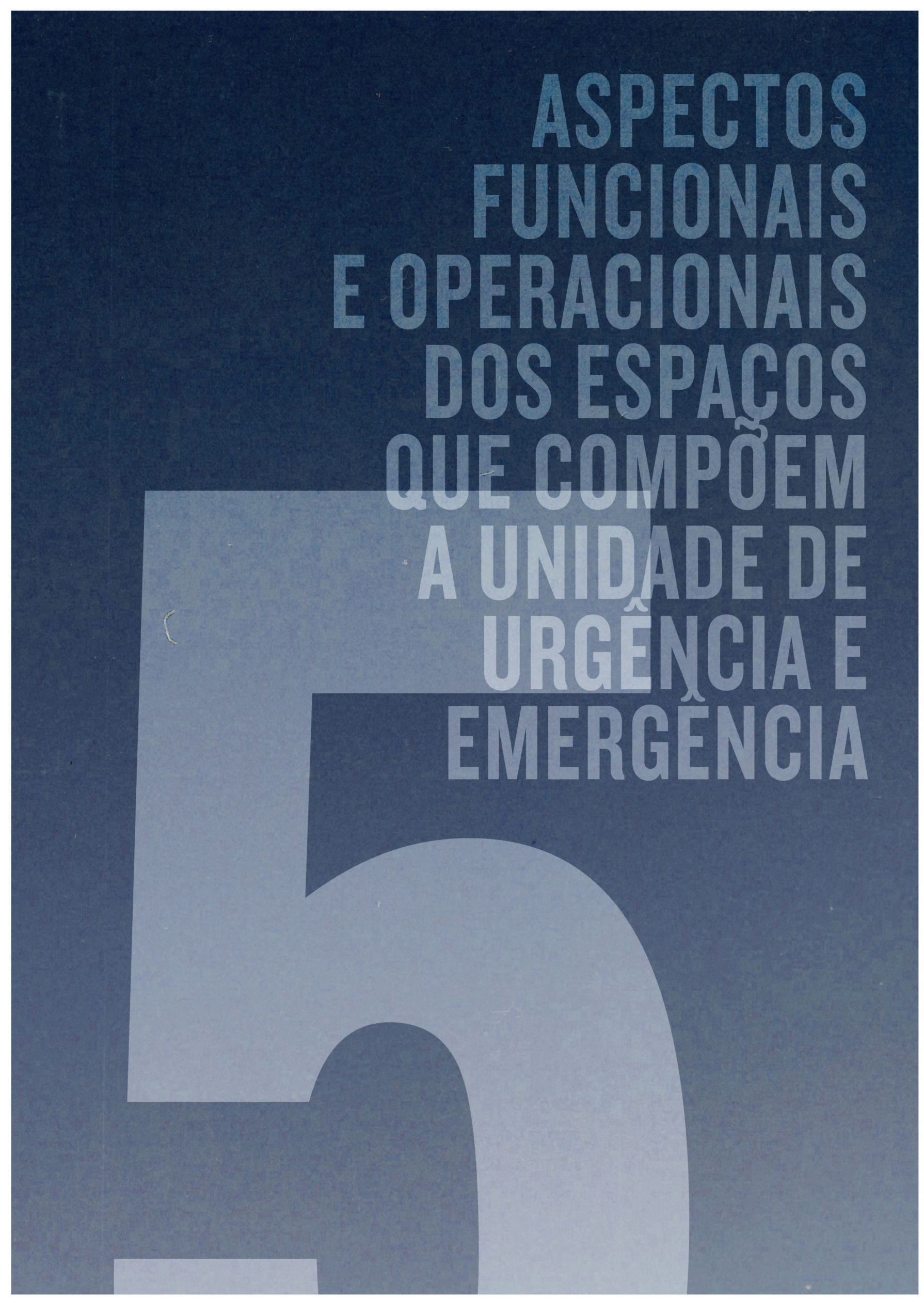



Ao longo dos últimos 45 anos, os órgãos de saúde vinculados diretamente ao Ministério da Saúde vêm desenvolvendo um projeto de normatização iniciado em 1965, por meio do "Projeto de Normas Disciplinares das Construções Hospitalares".

Neste período ocorreram as publicações da Portaria 400/1977, Portaria 1884/1994 e finalmente a Resolução n50 / 2002, que se encontra em vigor até os dias de hoje. Com as revisões e mudanças necessárias para sua adequação ao seu momento histórico, a atual resolução "Regulamento Técnico para Planejamento, Programação, Elaboração e Avaliação de Projetos Físicos de Estabelecimentos Assistenciais de Saúde" procura estabelecer de forma orientativa a relação de atividades, procedimentos e resultados, para todas as unidades que compõem o edifício hospitalar. Alem disso, estabelece ainda um conjunto de espaços necessário para cada unidade hospitalar, considerado como um programa físico mínimo para atender as expectativas funcionais e operacionais.

Objetiva-se ainda, estabelecer mediante deste documento, a leitura única pelos meios fiscalizadores do Departamento de Vigilância Sanitária, nas três esferas de governo, bem como todos os profissionais envolvidos na organização, adequação e transformação dos espaços físicos dos edifícios de saúde. 
Com este eixo direcionador de conduta, a RDC 50 / ANVISA estabelece um norte, porém com uma abrangência imensurável, isto porque trata o assunto sem particularidades e especificidades de cada Estado, região e/ou local de sua aplicação.

Esta aridez é compreensível na medida que é observada como mais um instrumento de trabalho, porém é necessário que o grupo gestor envolvido tenha total clareza e discernimento dos reais objetivos a serem atingidos para o empreendimento hospitalar e assim possa obter resultados positivos e a resolutividade esperada.

A RDC n 50 / ANVISA, estabelece atribuições e atividades para as Unidades de Urgência e Emergência em seus três níveis de atenção (baixa, media e alta complexidade), como segue:

\section{ATRIBUIÇÃO: PRESTAÇÃO DE ATENDIMENTO IMEDIATO DE ASSISTÊNCIA À SAÚDE}

ATIVIDADES: Nos casos sem risco de vida (urgência de baixa e média complexidade):

- fazer triagem para os atendimentos;

- prestar atendimento social ao paciente e/ou acompanhante;

- fazer higienização do paciente;

- realizar procedimentos de enfermagem;

- realizar atendimentos e procedimentos de urgência;

- prestar apoio diagnóstico e terapêutico por 24 hs;

- manter em observação o paciente por período de até $24 \mathrm{hs;e}$

- fornecer refeição para o paciente.

Nos casos com risco de vida (emergência) e nos casos sem risco de vida (urgências de alta complexidade):

- prestar o primeiro atendimento ao paciente;

- prestar atendimento social ao paciente e/ou acompanhante;

- fazer higienização do paciente;

- realizar procedimentos de enfermagem;

- realizar atendimentos e procedimentos de emergência e urgência de alta

- complexidade;

- prestar apoio diagnóstico e terapia por 24 hs;

- manter em observação o paciente por período de até 24 hs;e

- fornecer refeição para o paciente. 
Como programa físico, estabelece para os três níveis de atenção o relacionado abaixo.

- Atendimento de Urgência e Emergência (baixa e media complexidade)

| Área externa para desembarque de ambulância

| Sala de triagem médica e/ou de enfermagem

| Sala de Serviço Social

| Sala de higienização

| Sala de suturas / curativos

| Sala de reidratação

Sala de inalação

| Sala de aplicação de medicamentos

| Sala de gesso e redução de fraturas

| Sala para exames diferenciados (oftalmo, otorrino etc.)

| Sala de observação

- Atendimento de Urgência e Emergência (alta complexidade)

| Posto de enfermagem / prescrição medica

Sala de serviços

| Sala de isolamento

| Sala coletiva de observação de pediatria

| Sala coletiva de observação de adultos (masculino/ feminino)

| Sala de procedimentos especiais (invasivos)

| Área de escovação

| Sala de Emergência (politraumatismo, parada cardíaca etc.).

\section{- Estrutura de apoio logístico}

| Área para notificação médica

| Área de recepção de pacientes

| Sanitários para pacientes

Sala de atividades

| Sala de espera para pacientes e acompanhantes

| Depósito de material de limpeza

Área para guarda de macas e cadeira de rodas

Sala administrativa

Copa

| Área para guarda de pertences dos pacientes 


\author{
| Sanitários para funcionários \\ Banheiro para funcionários (plantão) \\ Quarto de plantão \\ Depósito de equipamentos
}

A abordagem aqui tratada visa não somente uma análise dos ambientes que compõem a estrutura espacial das Unidades de Urgência e Emergência como apenas condicionantes funcionais, mas também como um processo interativo, participativo das pessoas com o meio ambiente.

Como já observado, a geração de um programa físicofuncional ou programa de necessidades é fruto de um processo de discussão entre os profissionais de arquitetura e a equipe de saúde, em que se obtém como resultado não apenas uma lista de ambientes que deverá estar contemplada no projeto arquitetônico, mas principalmente a inserção das aspirações e desejos da equipe multidisciplinar, sempre pautada sobre a ótica do modelo assistencial do serviço a ser implantado.

Ao profissional arquiteto cabe a tradução e transformação destas aspirações na materialização da unidade hospitalar, no qual será norteado por meio da ampla lista de normas, resoluções, códigos e legislações técnicas, porém com a sensibilidade projetual para se atingir o equilíbrio esperado.

Quando não ocorre o equilíbrio, segundo Silva (1999, p.6),

A qualidade dos serviços prestados está, diretamente relacionada com a funcionalidade da estrutura arquitetônica e organizacional de uma instituição de saúde. A alta tecnologia, o profundo conhecimento científico e a excelência na habilidade técnica da equipe, ficam severamente prejudicadas quando os elementos arquitetônicos e administrativos não estão em harmonia com as reais necessidades do serviço. Nas unidades de atendimento de emergência, estes elementos são de fundamental importância, pois a precisão na assistência prestada, aliada ao conhecimento técnico-científico e o desenvolvimento tecnológico, determinam a eficiência e eficácia do serviço, o que implica em muitos casos, na vida, na morte ou em danos irreparáveis ao cliente e família.

A estrutura física deverá conter espaços básicos de atendimento (recepção, espera, salas de emergência, consultórios etc.), amplos eixos de circulação e estar localizada de modo a permitir fácil 
acesso ao público. Isto significa implantá-la na área periférica do edifício, a qual será a garantia do seu isolamento das áreas de passagem e fluxos para outras unidades hospitalares. Porém, não se poderá abrir mão da proximidade de unidades de apoio (centro cirúrgico, imagenologia, centro obstétrico, UTI`s etc.) as quais são inerentes e fundamentais para o bom desempenho do serviço de urgência e emergência.

Segundo o modelo atual de assistência à emergência, a ótica neste momento, pauta-se sobre o acolhimento com a avaliação e classificação de risco e de acordo com a Política Nacional de Humanização. (PNH/2004).

Esta proposta de assistência procura estabelecer novos critérios para disciplinar o atendimento de urgência e emergência aos pacientes que procuram o serviço, onde anteriormente era realizado por ordem de chegada.

Os resultados obtidos têm sido melhores a partir da classificação de pacientes por gravidade, como também a assistência prestada ao enfermo. Constata-se a melhora ainda nas demandas espontâneas não graves, por meio do programa de acolhimento e redirecionamento ao serviço de competência e de acordo com nível de atendimento necessário para cada caso.

De acordo com Abbês e Massaro (2004, p.2),

O acolhimento não é um espaço ou um local, mas uma postura ética, não pressupõe hora ou profissional específico para fazê-lo, implica compartilhamento de saberes, necessidades, possibilidades, angústias e invenções. Desse modo é que o diferenciamos da triagem, pois ele não se constitui como uma etapa do processo, mas como ação que deve ocorrer em todos os locais e momentos do serviço de saúde.

Este programa consiste na implantação do sistema de classificação de risco por gravidade, por meio das cores, como: vermelho, amarelo, verde e azul e excluindo definitivamente a forma burocrática de entrada por filas e ordem de chegada, mudança do foco, não mais sobre a doença, mas para o cliente.

Consiste ainda na procura da humanização das relações entre os profissionais de saúde e usuários no que se refere à forma de escutar este usuário em seus problemas e demandas, com abordagem integral a partir de parâmetros humanitários de solidariedade e cidadania. 
Visa também a implantação de protocolos de rotinas para as patologias de maior prevalência e mortalidade, obtendo-se assim melhores índices na resolutividade, qualidade de desempenho e assistenciais no serviço prestado.

Para disciplinar e organizar o fluxo e ampliar a humanização no atendimento, todo o encaminhamento à unidade de urgência $\mathrm{e}$ emergência é feito pelo contato telefônico (linha específica), pelos sistemas de resgate, pela central reguladora de vagas, hospitais de referência e contrarreferência e ainda a secretaria municipal ou como também da região de abrangência.

O sistema de avaliação e classificação de risco por cores está assim distribuído:

Vermelho: prioridade zero - emergência, necessidade de atendimento imediato.

Amarelo: prioridade 1: urgência, atendimento o mais rápido possível.

Verde: prioridade 2: prioridade não urgente.

Azul: consultas de baixa complexidade.

Por tratar a Unidade de Urgência e Emergência como um sistema e parte integrante do complexo hospitalar, a sua estrutura física pode ser dividida para sua melhor compreensão, em termos de hierarquia de fluxo e serviços, em cinco subsistemas. (Fig. 96):

5.1) Subsistema de recepção, acolhimento e registro do paciente.

5.2) Subsistema de atendimento ao enfermo e familiares.

5.3) Subsistema de apoio ao diagnóstico e tratamento.

5.4) Subsistema de observação e repouso

5.5) Subsistema de apoio logístico e operacional. 


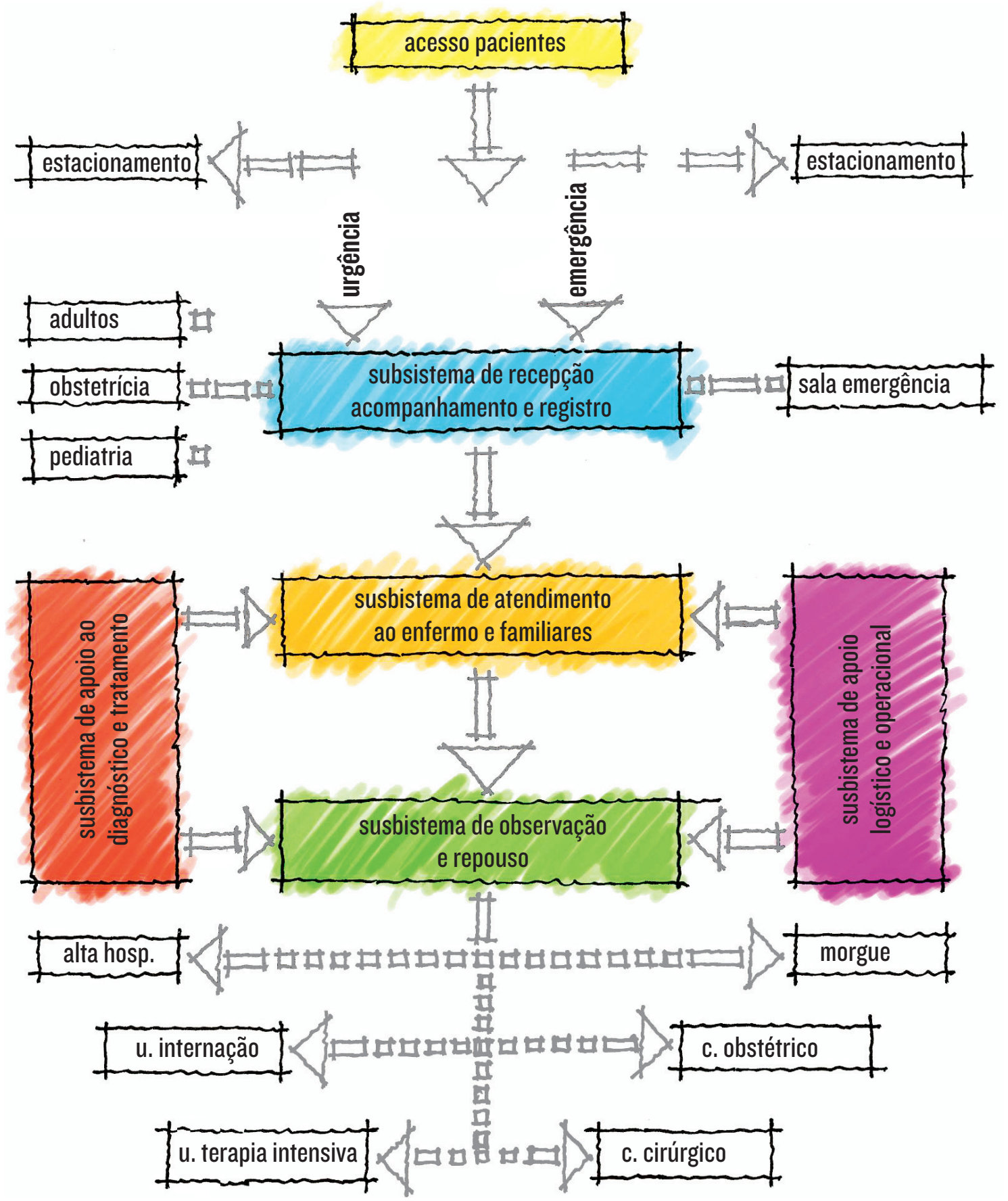

Figura 96 - Croqui esquemático: organização do sistema de urgência e emergência e fluxos operacionais.

(Fonte: elaborada pelo autor).

Como reflexão e aprofundamento sobre as necessidades funcionais dos ambientes que compõem a unidade em estudo, objetiva-se fazer a análise sobre cada um destes espaços, dentro da ótica operacional e arquitetônica, em que os dados relativos 
às suas dimensões mínimas e necessidade de equipamentos $\mathrm{e}$ mobiliário, são facilmente encontrados na RDC 50/ANVISA e Programa Somasus (Sistema de Apoio à Organização e Elaboração de Projetos de Investimentos em Saúde)/MS.

Por outro lado, passa que este programa de necessidades não assume o papel de um roteiro ou lista "fechada" de ambientes como se fosse uma "receita de bolo" que irá compor a unidade em estudo. O real objetivo aqui apresentado visa enxergar o verdadeiro papel a ser desempenhado pelos operadores do sistema junto aos ambientes, onde os quais deverão ofertar a qualidade esperada.

\section{I Subsistema de recepção, acolhimento e registro do paciente}

\section{I.I Entrada de veículos e pedestres/ estacionamento para veículos, motos e ambulâncias}

O acesso à unidade de urgência e emergência é feita por pedestres, veículos (ambulâncias, táxis e particulares) e motos. $\mathrm{Na}$ entrada deste acesso deverá possuir uma boa sinalização e identificação pelos usuários, pois nem todas as pessoas estão familiarizadas com o local e o serviço hospitalar.

Devem ser disponibilizadas vagas em geral de estacionamento para todos os tipos de veículos e motos que acessam a unidade. Recomenda-se, se possível, que seja próximo à unidade e disponha também de vagas específicas para portadores de necessidades especiais (conforme NBR 9050), e ambulâncias a serviço da própria unidade.

Os serviços de urgência e emergência de alta complexidade e de referência local e/ou regional podem dispor do espaço para pouso e decolagem de helicópteros (heliponto). Apesar do ruído provocado por este equipamento de transporte, é recomendável que o local seja próximo à unidade, em uma área aberta e adjacente ao complexo hospitalar, ou ainda na cobertura do edifício, porém qualquer solução adotada deverá obedecer a legislação específica Portaria 1141/GM5/1987 e sua aprovação junto aos órgãos competentes. 
O fluxo de pedestres, na maioria dos casos, é procedente de transporte coletivo. $\mathrm{O}$ acesso deve ter a garantia de que seja de forma independente do fluxo de veículos e motos, possibilitando assim maior segurança aos usuários.

\section{I.2 Área de embarque e desembarque de pacientes}

Esta área deve ser disponibilizada junto a área de entrada dos serviços de urgência e emergência. Deve-se ainda ser um espaço amplo, para acomodação de 02 a 03 veículos, coberto para proteção em dias chuvosos, possibilitando total conforto ao paciente e operadores do serviço.

$\mathrm{O}$ acesso à área de emergência deve possuir fluxo específico e separado do acesso às urgências. Considera-se ainda que o espaço disponha de dimensões que garantam a manobra dos veículos, principalmente para as ambulâncias, nas quais o paciente deve desembarcar pela porta traseira do referido veículo. É aconselhável observar a altura do pé-direito nestes locais, tendo em vista que ambulâncias possuem dimensão bastante significativa na sua altura, e com isto proporciona problemas com o forro, laje ou até mesmo com luminárias expostas no teto da referida área.

A acessibilidade nestas áreas de embarque e desembarque é necessária, tendo em vista que os pacientes são transportados por macas ou cadeiras de rodas. Isto deve ser garantido com a utilização de rampas, com inclinação máxima de 8,33\%, conforme norma (NBR 9050), e ainda com aplicação de piso antiderrapante incombustível, de fácil limpeza e manutenção.

\section{I.3 Saguão/Salas de Espera para pacientes, familiares e acompanhantes}

Tais espaços quase que se confundem, tendo em vista que praticamente um está contíguo ao outro e não há qualquer necessidade de delimitação entre eles. Porém, suas funções são claras, o saguão tem o papel de distribuição e direcionamento de pessoas que se utilizam do serviço de urgência e emergência e as salas esperas constituem os espaços do aguardo dos pacientes, familiares e/ou acompanhantes, a partir da definição do serviço pelo qual o enfermo será assistido. 
Este direcionamento é necessário para disciplinar os fluxos de pacientes graves em caráter de emergência, dos atendimentos de urgências; para este segundo caso, é também necessário disciplinar os fluxos de pacientes adultos, gestantes, crianças e idosos, direcionando-os para salas de espera específicas, adequadas à faixa etária do usuário.

Se houver a intenção de ofertar um balcão de informação, este deve estar disponível junto ao saguão, porém cabe avaliar pela equipe coordenadora do projeto, neste caso, que uma boa comunicação visual poderá substituí-lo, minimizando espaço físico, custo operacional e recursos humanos.

Como já observado, o fluxo à assistência aos pacientes graves, transportados por ambulâncias e veículos, deve ter seu acesso imediato ao serviço, livre de qualquer elemento que possa obstruir o seu fluxo. Considera-se importante, já na entrada ao serviço, a oferta de área para espera de familiares e/ou acompanhantes onde aguardarão neste local, enquanto o paciente será levado para ambientes específicos para o atendimento aos primeiros socorros.

O posicionamento da área de recepção e registro de pacientes junto ao serviço de urgência e emergência deve ser sempre estratégico. Isto porque, dependendo da solução adotada no projeto arquitetônico, este pode ser o elemento divisor entre os fluxos de urgência e emergência. Isto, na maioria dos casos, permite redução de custos operacionais, facilidade na disciplina dos fluxos dos usuários e ainda permite aos funcionários visualização e controle sobre a movimentação das pessoas que estão aguardando nas salas de espera.

Recomenda-se que o balcão, que define o espaço da recepção e registro de pacientes, proporcione com o seu "design" condições de atendimento para aqueles que permanecem em pé (atendimento rápido), sentados, ou ainda para aqueles em cadeiras de rodas. Nesta segunda situação, mais confortável e humana, o paciente e/ou familiar se posiciona frente a frente com o seu interlocutor, com visão ampla e sem qualquer tipo de barreira que seja agressiva e ostensiva. Este diálogo deve ocorrer em condições de privacidade, possibilitando assim, desde a chegada do paciente, estabelecer um atendimento menos vulnerável e mais acolhedor.

Os espaços do saguão e esperas são para os arquitetos talvez um dos poucos ambientes hospitalares que lhes permitem maior 
flexibilidade na sua organização, como também liberdade de criação. Isto significa para o profissional arquiteto a apropriação de diversos recursos visuais e sonoros que proporcionam a ambiência necessária para o reforço ao acolhimento e a boa qualidade espacial.

Esta tarefa, em princípio aparentemente simples, é sem dúvida um desafio. A dosagem certa com equilíbrio na utilização destes recursos está intimamente ligada à sensibilidade e bom-senso do arquiteto. Em muitos exemplos espalhados pelo mundo, sempre observa-se que pecar por excesso tem quase que sempre provocado a "overdose" ao ambiente constituído. Por outro lado, pecar por falta, pode-se provocar a "inanição" ao espaço hospitalar.

Os recursos para se obter esta ambiência desejada têm sido em recorrer na utilização de cores, boa luminosidade natural e/ou artificial, som de queda d’água, aquários, boa aeração dos espaços, permeabilidade visual, maior integração do espaço interior com o exterior e áreas verdes. Estes e outros elementos arquitetônicos podem possibilitar a obtenção dos projetos propostos. Sobre a iluminação artificial, aconselha-se a utilização de luminárias providas de lâmpadas do tipo "PL" eletrônica/compacta (3000k), as quais têm a predominância da cor amarela que promovem uma sensação mais "quente" ao espaço.

O mobiliário também é um grande contribuidor para a boa qualidade espacial pretendida, em que por meio do uso de televisores, que se utilizado para transmitir uma programação amena, informes educacionais e orientadores no campo da saúde, possibilitam diminuir a ansiedade e o estresse durante o período de espera. Disponibilizar telefones públicos e bebedouros sempre é recomendável ao conforto dos usuários. Por outro lado, deve-se evitar o uso de relógios de parede, pois este desempenha o papel do objeto estressor.

Pelo motivo de que em alguns casos os pacientes e familiares permanecem por muito tempo no aguardo do seu atendimento, as cadeiras nas salas de espera devem ser confortáveis e anatômicas. Disponibilizar alguns lugares para pessoas obesas e ainda espaços na área de espera para acomodação de pacientes em cadeiras de rodas, é sempre recomendável.

As cadeiras devem dispor de braços de apoio para que inicialmente se estabeleça o "espaço psicológico do indivíduo" ou o "domínio sobre o espaço", não permitindo que pessoas 
(debilitadas ou não) se deitem, comprometendo o uso das demais cadeiras e consequentemente proporcionando uma "atmosfera" de abandono ao espaço.

Pacientes nestas condições, se debilitados, devem ser encaminhados para o atendimento, para que se sinta mais confortável.

As cadeiras também podem ter uma variação de cores para se estabelecer em que fase do processo de atendimento o paciente se encontra. A visualização por parte da equipe de saúde, principalmente para os grupos de atendimento de maior urgência, pode contribuir para a agilização do serviço e satisfação do cliente.

O uso de equipamento visual e sonoro para a chamada do paciente pode também disciplinar o fluxo de atendimento e transferir ao paciente uma noção de tempo de aguardo que lhe cabe.

Com a implantação do modelo de atenção com avaliação, classificação e gerenciamento de risco, a assistência ao enfermo pode também proporcionar a diminuição do estresse, pois com o primeiro atendimento, anamnese e coleta dos dados iniciais do paciente, ele se sente engajado ao processo, reduzindo assim a ansiedade, angústia e impaciência.

As esperas para crianças, gestantes e idosos devem ser trabalhadas de forma que lhes ofertem conforto, acolhimento e a ambiência necessária para cada público específico. Em particular, o espaço para as crianças deve propiciar o brincar, ler, ver e ouvir. O mobiliário deve ser na escala adequada aos pequenos enfermos, e que se possa introduzir ao espaço os personagens que façam parte do seu repertório imaginário, um ambiente que lhes remeta aos espaços do cotidiano residencial, escolar e lazer. A figura dos pais, neste caso, é de apenas observação e acompanhamento. (Fig. 97). 


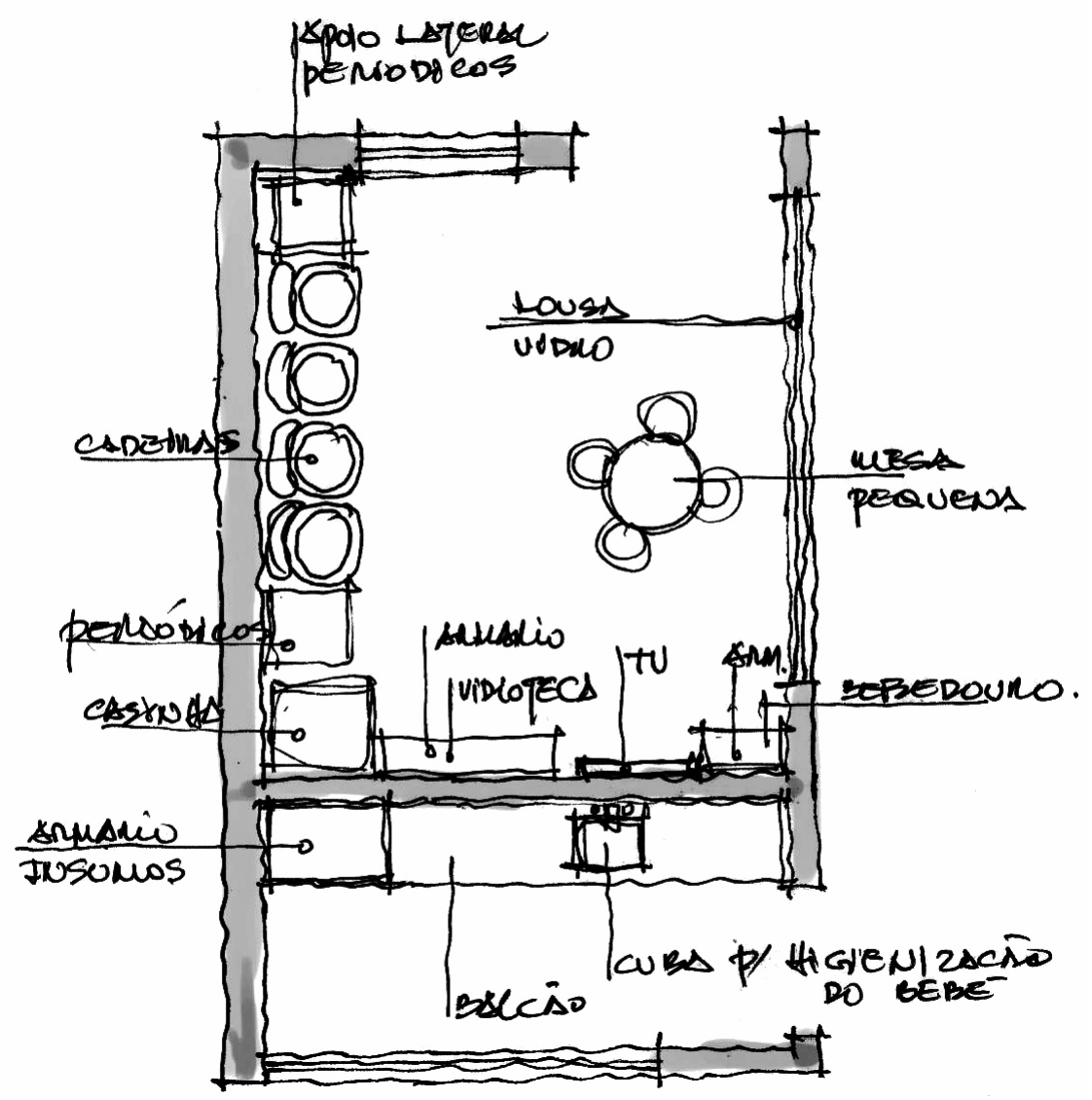

Figura 97 - Croqui esquemático: sala de espera infantil e fraldário.

(Fonte: elaborada pelo autor).

Anexo a este espaço, deve-se dispor uma área do fraldário que garanta o conforto das mães na troca de fraldas e higienização dos bebês. Pode-se ainda, utilizando-se da contiguidade deste espaço, prover área para amamentação, a qual pode ser concebida no sentido de ofertar privacidade, higiene e ambientação mais tranquila para a mãe e o bebê.

\section{I.4 Sanitários de público}

Os sanitários de público devem ser dimensionados a partir de uma clara visão de demanda do serviço de urgência e emergência, no que se refere principalmente aos números de lavatórios, bacias sanitárias e mictórios.

Para os grandes serviços de urgência e emergência é aconselhável que os sanitários estejam voltados para as áreas externas do ambiente de espera, porém, este acesso deve ser 
coberto para garantir a passagem com proteção em dias chuvosos. Esta medida pode contribuir na eliminação de um fluxo interno (acesso aos sanitários) junto às esperas, o que proporciona um melhor aproveitamento do espaço e o aumento do número de cadeiras. Considera-se ainda que com esta solução de projeto seja removido o som (válvula de descarga) e o odor produzidos pelo intenso uso destes ambientes.

Não somente para os portadores de necessidades especiais, mas também para um público que, em muitos casos está debilitado ou utilizando cadeiras de rodas, ou ainda com o auxílio de acompanhantes, os sanitários devem garantir a acessibilidade (NBR 9050), bem como os acessórios como barras de apoio, espelhos com inclinação adequada, cabides para suporte de pertences etc., adequados para o conforto e bem-estar do usuário.

\section{I.5 Estacionamento de macas e cadeiras de rodas}

É recomendável que sua localização seja junto aos acessos de urgência e emergência, disponibilizando de pelo menos 02 macas e 02 cadeiras de rodas.

Deve-se, nesse caso, considerar a facilidade de remoção deste instrumento de transporte do paciente, quando da sua chegada e o seu acesso imediato ao serviço.

\subsection{Subsistema de atendimento ao enfermo e familiares}

\subsection{Sala de acolhimento com avaliação e classificação de} risco

Recomenda-se que este ambiente que esteja próximo ao acesso às urgências, para o imediato acolhimento do enfermo. Isto porque neste local será definido o encaminhamento do paciente, de acordo com a gravidade do caso, constatada pela anamnese inicial, por meio do relato de suas queixas, breve histórico, exame físico, uso de medicações, verificação de sinais vitais e oximetria de pulso, glicemia, entre outros. 
Estabelecido o grau de gravidade do caso, o paciente pode ser encaminhado para o atendimento imediato (classificação vermelha ou amarela), como também pode retornar à sala de espera para o aguardo do seu atendimento quando enquadrado na classificação verde ou azul.

Aconselha-se para este espaço, dimensões generosas para o acesso de pacientes em cadeiras de rodas (muitas vezes debilitado), o acompanhamento de familiares, a disponibilidade de poltrona e/ou maca para um exame clínico mais minucioso, como também balança antropométrica e esfigmomanômetro.

\subsubsection{Sala de emergência}

Imediatamente disponibilizada junto ao acesso de emergência, a sala tem o papel de acolher os pacientes em estado grave e processar o seu pronto restabelecimento. Após os primeiros socorros e a estabilização dos sinais vitais do paciente, este pode ser encaminhado para o centro cirúrgico, obstétrico, UTI's, e centro de diagnóstico por imagem, para a continuidade na sua assistência. Quando o paciente for a óbito será encaminhado ao morgue.

Por suas características, é aconselhável que a referida sala seja posicionada no fluxo imediato à entrada da emergência, provida de portas largas, dimensões generosas para movimentações de macas, circulação da equipe de profissionais e disponha de boa infraestrutura física, como lavatórios, bancadas com cubas, armários para materiais de consumo e esterilizado, gases medicinais, pontos de lógica e elétrica para acoplar equipamentos e raio-x móvel. A sala ainda deve disponibilizar carros de emergência, anestesia e ressuscitação. (Fig. 98). 


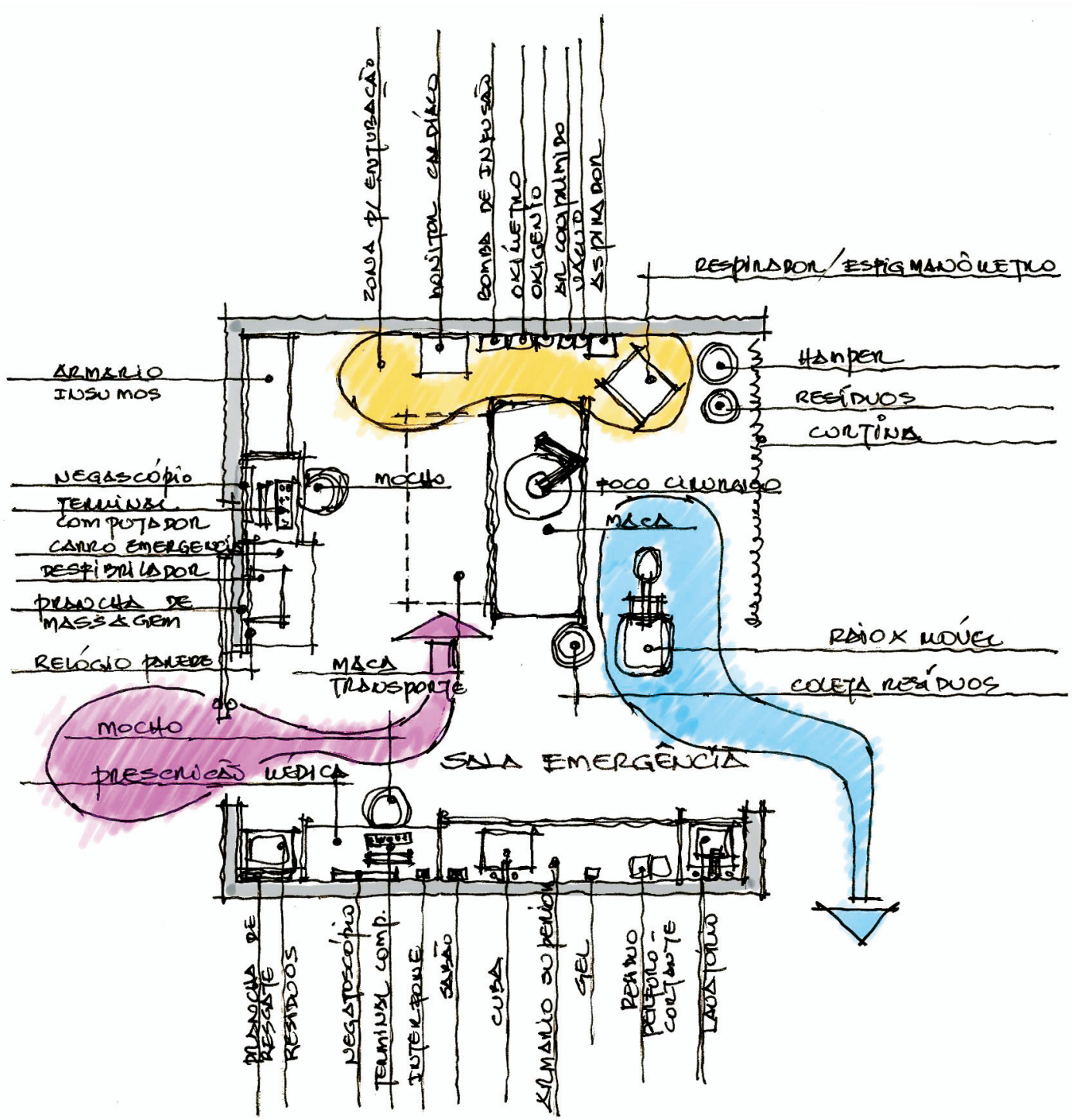

Figura 98 - Croqui esquemático: fluxo, mobiliário e equipamentos sala de emergência.

(Fonte: elaborada pelo autor, baseada em Gomes, 1994).

Segundo Gomes (1994, p.23),

Sua utilização fica limitada àquelas situações realmente emergenciais durante o tempo necessário e suficiente, para que os ciclos de desequilíbrios funcionais que levam à morte sejam interrompidas. É mantida em condição de uso, com reposição sistemática de seus componentes e limpeza terminal a cada utilização.

O dimensionamento adequado, como também o número de boxes, para o atendimento de emergência devem estar de acordo com a demanda do serviço analisado a partir do seu caráter de 
abrangência (local e/ou regional), referência em alta complexidade e por especialidades médicas disponíveis.

Independentemente da organização espacial do serviço de atendimento de emergência, sendo por salas individualizadas ou boxes, é importante ressaltar que sempre se deve garantir a privacidade ao paciente e disponibilizar de dois ou mais leitos de atendimento.

Considera-se ainda importante observar o afastamento de pelo menos $60 \mathrm{~cm}$ da cabeceira do leito/maca para com qualquer obstáculo (parede ou equipamento), para que o profissional possa proceder a entubação orotraqueal ao paciente na posição correta, de forma segura e confortável. (Fig. 99).

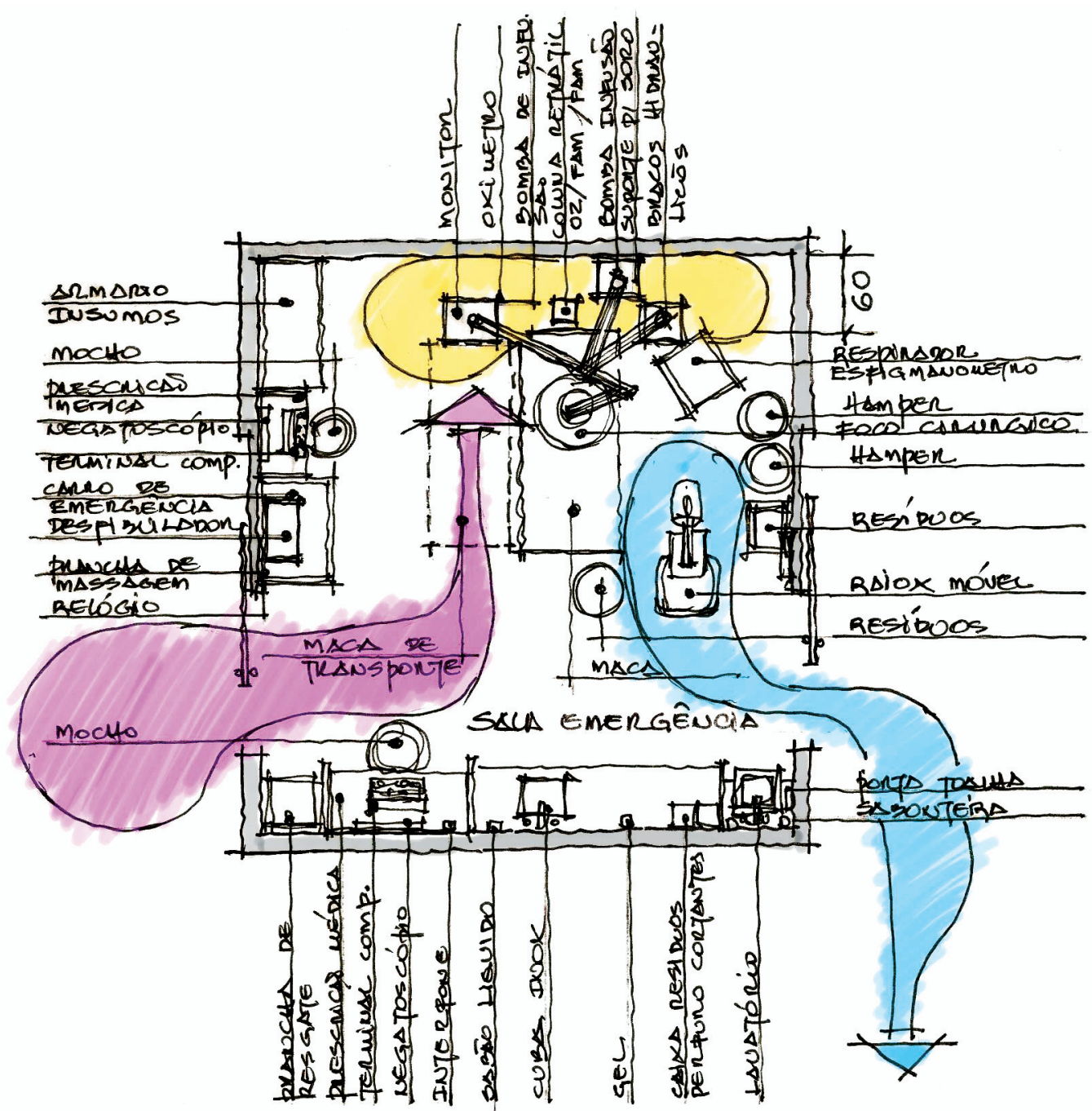

Figura 99 - Croqui esquemático: fluxo, mobiliário e equipamentos sala de emergência.

(Fonte: elaborada pelo autor). 


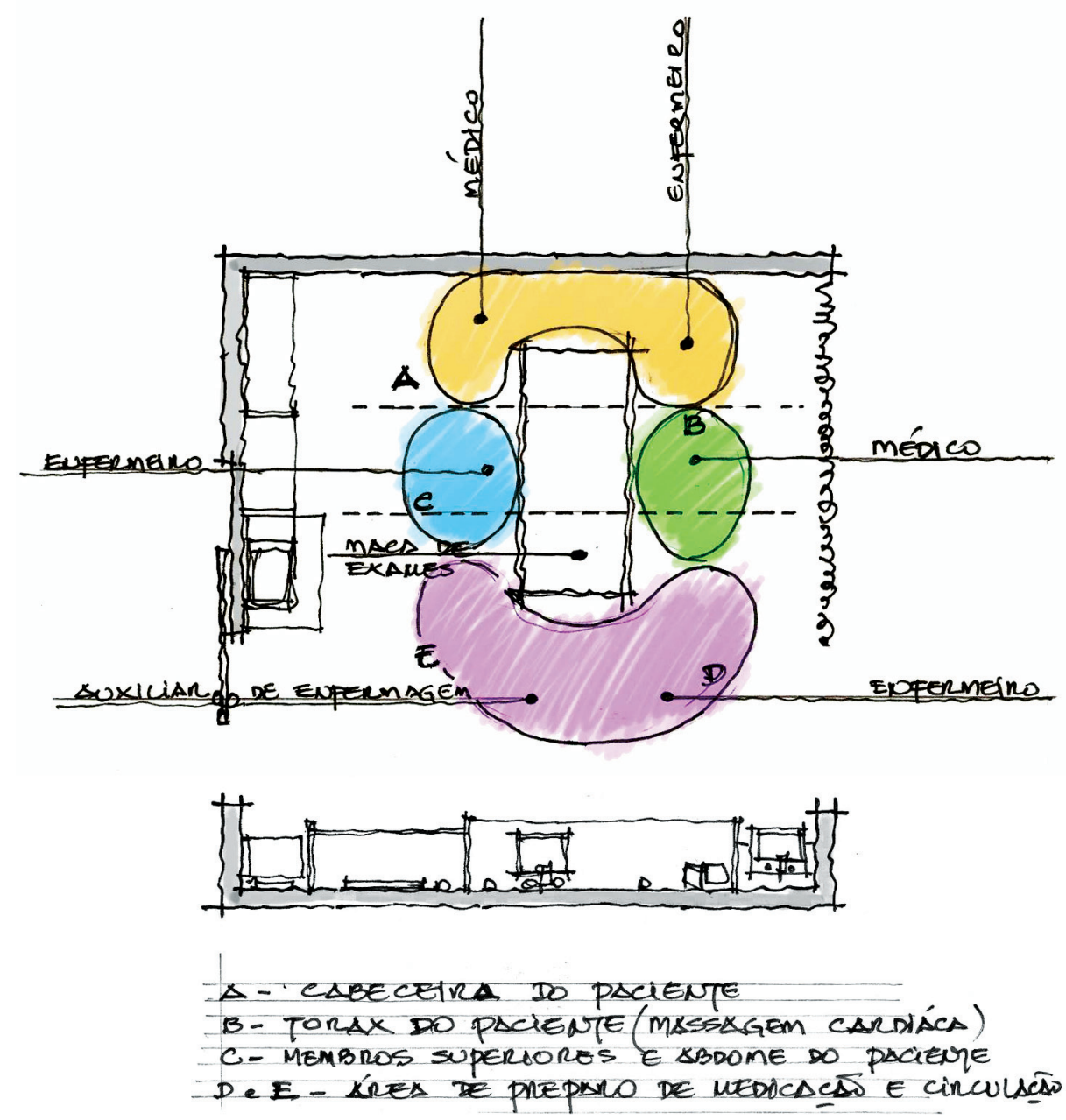

Figura 100 - Croqui esquemático: zonas de atuação da equipe de assistência.

(Fonte: elaborada pelo autor).

É fato que, em muitos serviços de emergência, os espaços (boxes ou salas individualizadas) destinados ao atendimento imediato, muitas vezes, são ocupados por pacientes em observação, internados ou ainda em estado grave, o qual deveria ser encaminhado para as unidades adequadas. Nestes casos não há sincronia na liberação de leitos nas unidades de internação, ou UTI's para receber estes pacientes, e assim estes permanecem por tempo indeterminado na sala ou boxes de emergência a espera de um leito vago, reduzindo assim o número de leitos disponíveis ao atendimento de emergência e consequentemente comprometendo a qualidade, resolutividade e eficácia do serviço.

As unidades de alta complexidade, em alguns casos, dispõem de centros de atendimento específicos para determinadas 
especialidades médicas, como os Centros de Traumas e como também de Dor Torácica.

A disponibilidade de equipamentos, como tomógrafos, ressonância magnética, raio x computadorizado e serviço de hemodinâmica, é necessária para se obter a eficiência, boa resolutividade e resultados satisfatórios dos serviços mencionados acima.

Observa-se a importância de garantir dois fluxos às salas de emergência, sendo o primeiro já apresentado como de entrada do paciente e outro de saída, este se possível interligado à circulação de serviço da unidade, por onde o paciente atendido será conduzido para outras unidades de apoio, diagnóstico e tratamento. Desta forma permite a separação e a disciplina de fluxos no setor.

\subsubsection{Sala de higienização do paciente}

Pacientes politraumatizados, acidentados, feridos de arma de fogo, entre outros casos, após o seu atendimento na sala de emergência e conquistado o grau de estabilização dos sinais vitais, este segue para a sala de higienização, na maioria dos casos em macas ou cadeiras de rodas para efetuar a limpeza do corpo, retirada de tecidos sujos e contaminados.

Por estas características, é importante ressaltar que a localização do referido ambiente deve se posicionar próximo a sala de emergência. Suas dimensões devem não somente atender às exigências de normas e/ou resoluções, mas também e principalmente que o espaço ofereça condições de tráfego, giro da maca, e a movimentação da equipe de enfermagem.

A ducha de banho deve possuir o dispositivo manual para melhor direcionamento e controle do fluxo de água sobre o paciente.

Considera-se ainda importante que os volantes (registros) da ducha estejam do lado oposto deste, para que o profissional de enfermagem tenha maior conforto para o momento do seu acionamento e que não venha a se molhar.

É recomendável também disponibilizar neste espaço, lavatório, bacia sanitária, hampers cadeiras para banho, barras de apoio e cuba para o despejo de secreções. 


\subsubsection{Consultórios/salas de exames}

Para o serviço de urgência, recomenda-se disponibilizar salas de exames, onde possa permitir a realização de consulta médica, (entrevista e anamnese mais detalhada) e proceder o exame clínico.

$\mathrm{O}$ número de salas para consultórios indiferenciados (sem necessidade de mobiliário, equipamento e dimensões específicas), como também os diferenciados (para clínicas médicas especializadas), deve ser dimensionado a partir da análise e oferta de demanda ao serviço de urgência e emergência.

Algumas especialidades médicas, como gineco-obstetrícia, urologia e proctologia necessitam que seja disponibilizado um sanitário anexo.

Para a área de exames sempre é recomendável a instalação de lavatório para lavagens das mãos do médico, antes e após o contato com o paciente.

Outros consultórios se diferenciam pelo uso de equipamentos específicos como para as áreas de oftalmologia, ortopedia, otorrinolaringologia, entre outros.

A localização dos referidos espaços deve ser próxima a entrada de urgência e estejam interligados à circulação de serviço para o encaminhamento do paciente após a consulta, às áreas de apoio para medicação, exames laboratoriais, exames por imagens, entre outros.

O consultório para o atendimento pediátrico e obstétrico são recomendáveis que fossem separados dos demais pacientes, com fluxo próprio, ambientação por faixa etária e com tratamento adequado ao perfil do paciente a ser atendido.

\subsubsection{Salas de esperas intermediárias}

Com o momento de aguardar subdividido em duas instâncias, a oferta de áreas de esperas internas à unidade de urgência é sempre interessante. Primeiramente, promove o deslocamento do paciente da sala de espera geral para o espaço mais interno, provocando no paciente a sensação de que seu atendimento esta em processo de assistência e que deve ocorrer em breve. $\mathrm{O}$ 


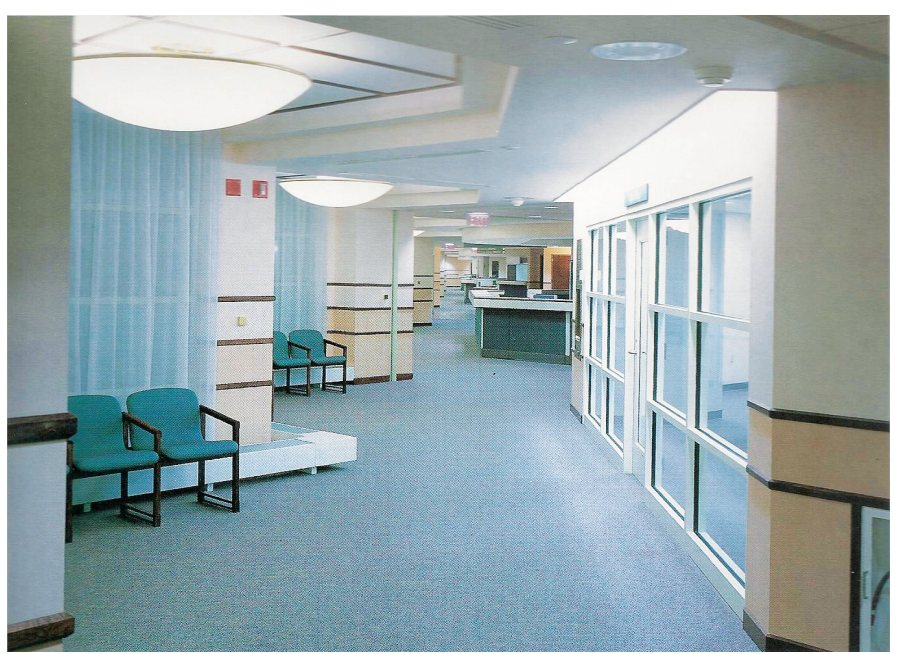

paciente se sente prestes a ser atendido, e com isto diminui sua ansiedade e impaciência. (Fig. 101).

Para um segundo momento do atendimento, e após a realização da consulta médica, o paciente deve aguardar o seu encaminhamento aos serviços de apoio diagnóstico, ou ainda esperar pelos resultados dos exames para que possa ser chamado pelo médico para a conclusão da sua consulta.

Figura 101 - Ambulatory Care Center - University of North Carolina, Chapel Hill, North Carolina, USA.

(Fonte: Health Care Architecture - Designs for the Future, Rockport Publishers, Massachusetts, USA, 1995).
A importância da oferta do referido espaço é o acolhimento dos pacientes que normalmente ficam perambulando pelos corredores internos da unidade. Quando isto ocorre, surgem soluções como a colocação de cadeiras ao longo do eixo de circulação, as quais comprometem o fluxo das pessoas, deslocamento de macas, carros de transportes e equipamentos.

As características espaciais destas salas de esperas intermediárias devem seguir as recomendações já mencionadas para a área de espera geral, proporcionando o máximo conforto e bem-estar ao paciente e familiares.

\subsection{Sala do serviço social}

A assistente social tem como função a coleta de dados do paciente, a orientação aos familiares e levantamento das condições sociais do paciente. Por se tratar de informações pessoais, o espaço deve possuir a garantia do isolamento acústico, e a privacidade ao paciente. Geralmente localizada junto às áreas de espera da unidade de urgência para facilitar o fluxo de entrada ou de saída do paciente.

\subsubsection{Salas de procedimentos sépticos}

A oferta de sala para procedimentos sépticos ou contaminados possibilita o tratamento em pequenos curativos e abcesos, sem a necessidade do uso de sala cirúrgica de maior complexidade. 
Porém, é necessário que, após a realização de cada procedimento, a equipe operacional proceda a desinfecções do local, materiais e equipamentos para evitar infecções cruzadas.

Suas dimensões devem garantir a circulação no entorno do leito, para que se obtenha total flexibilidade de contato com o corpo do paciente. Deve-se disponibilizar equipamento e materiais cirúrgicos, foco auxiliar, instalações de gases medicinais, elétrica e lógica, como auxílio na coleta de bons resultados.

Recomenda-se para este espaço o uso de ar condicionado com pressão negativa, para que se tenha sob controle os índices de infecção hospitalar.

A localização deste ambiente deve ser próxima à sala de emergência para facilidade de deslocamento do paciente, porém sempre pela circulação de serviço da unidade.

\subsubsection{Sala de procedimentos assépticos/suturas}

Com as mesmas características físicas das salas de procedimentos contaminados, as salas assépticas vêm a cumprir o papel na realização de pequenos procedimentos cirúrgicos considerados "limpos", como suturas por exemplo.

A sua localização deve estar próxima às áreas de atendimento de emergência, conectada pelo corredor de serviço interno à unidade, evitando-se assim o contato com outros pacientes que aguardam $o$ atendimento.

Deve-se disponibilizar acesso fácil, como também portas amplas para passagem de macas e cadeiras de rodas. É recomendável que disponha ainda de toda a estrutura física de instalações, equipamentos e mobiliário para a realização das tarefas ali programadas. (Fig. 102). 


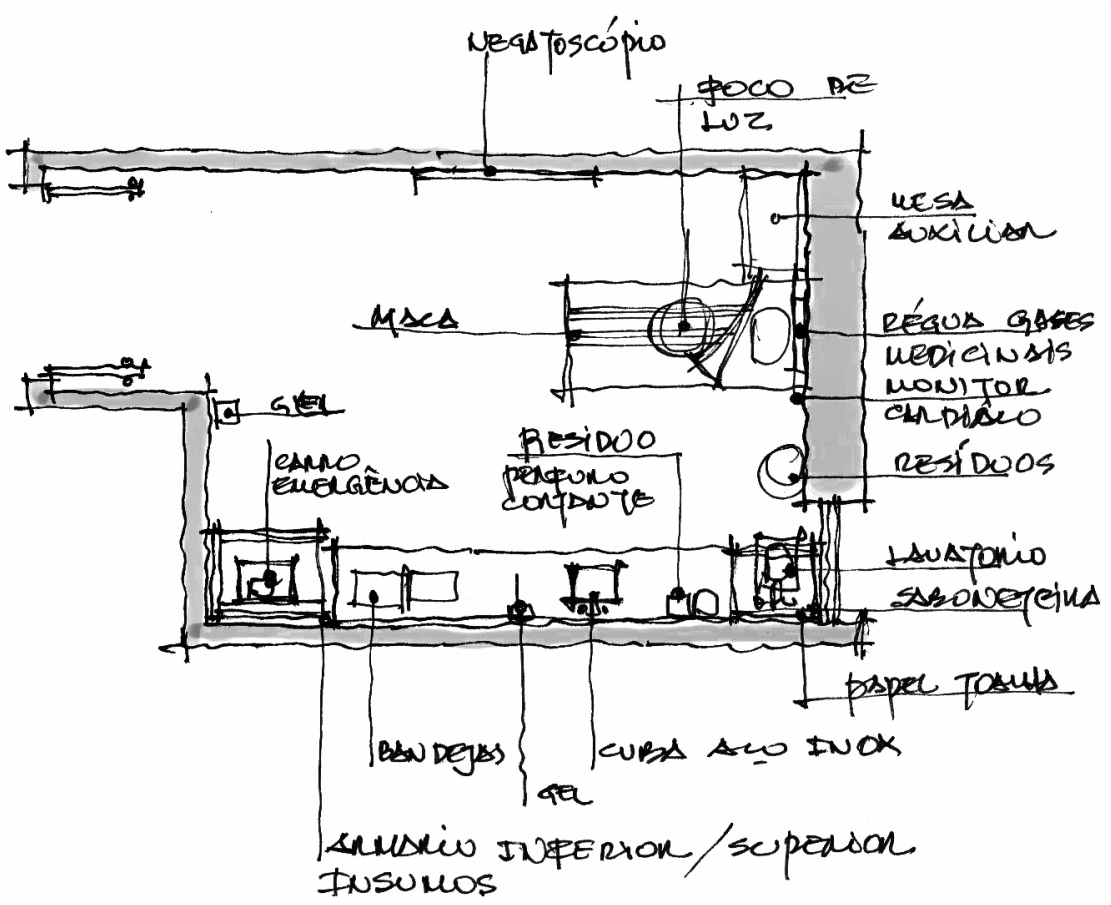

Figura 102 - Croqui esquemático: sala de procedimentos assépticos/ suturas.

(Fonte: elaborada pelo autor).

Em algumas unidades de alta complexidade, as salas de suturas são incorporadas pelo serviço realizado em salas de pequenas cirurgias, com melhores condições de assepsia e controle de acesso.

\subsubsection{Salas de pequenas cirurgias/procedimentos invasivos}

A finalidade de uso das salas de procedimentos invasivos é na realização de procedimentos endoscópicos, aplicação de sondas e também como procedimentos cirúrgicos de pequeno porte.

Sua localização é recomendada junto ou próxima às salas de emergência, o que vem a facilitar a tarefa pela menor distância para o grupo operacional.

Suas características construtivas são as mesmas empregadas nas salas cirúrgicas convencionais, com todo o aparato de instalações de gases medicinais, pontos elétricos e lógica, disponibilidade de carro de anestesia e emergência, bem como a oferta de sistema de ar condicionado com renovação e pressão positiva. 
Vale lembrar o cuidado com as dimensões das portas, as quais deverão ser amplas para a passagem do paciente em maca e acoplado a ele uma série de equipamentos (bomba de infusão, respirador, monitor cardíaco, cilindro de oxigênio etc.) e ainda a passagem de pessoas que transportam o enfermo.

O fluxo do grupo operacional à sala de pequenas cirurgias/ procedimentos invasivos deve ser outro, passando por vestiários de barreira, paramentação e higienização (lavabo cirúrgico/ escovação das mãos da equipe profissional).

Ainda anexo às salas de pequenas cirurgias/procedimentos invasivos é importante ofertar uma sala de apoio que tem o papel de realizar a limpeza e o acondicionamento de todo o material e equipamentos utilizados durante o procedimento cirúrgico, anterior ao seu encaminhamento para o centro de esterilização de materiais.

Nesta sala, deve-se também armazenar as roupas utilizadas no serviço, bem como os resíduos produzidos, onde permanecem até o seu recolhimento e transporte ao destino final. Todo o material, instrumental, equipamentos, roupas sujas e resíduos devem ser sempre separados e classificados na origem, acondicionados em recipientes adequados e lacrados, até o seu destino final.

A total viabilidade da oferta de uma ou mais salas para pequenas cirurgias/procedimentos invasivos, passa pela análise do grupo gestor, quando da montagem do perfil de atendimento esperado pelo serviço de Urgência e Emergência. Isto porque, deve-se sempre observar a projeção de demanda esperada ao serviço, como também a constatação na oferta de outros serviços semelhantes à população. Esta analise passa também pela disponibilidade de equipe profissional capacitada e ainda a oferta de material de consumo, instrumental e equipamentos para uso exclusivo no setor.

Para hospitais de grande porte, a oferta de salas de pequenas cirurgias/procedimentos invasivos, junto à Unidade de Urgência e Emergência, pode-se considerar benéfico para a resolutividade do complexo hospitalar, se foi considerado que para o Centro Cirúrgico deve-se encaminhar apenas pacientes para procedimentos de média e alta complexidade. Isto significa, como consequência, maior liberação das salas cirúrgicas, menor custo operacional e maior agilidade do sistema de atendimento. 


\subsubsection{Sala de gesso, imobilização e redução de fraturas}

Para a localização desta sala, no serviço de Urgência e Emergência, recomenda-se proximidade com as salas de emergência, pequenas cirurgias e consultórios de ortopedia. Este conjunto de atividades, com respectiva estrutura de apoio, faz parte, em alguns casos, da implantação de Centros de Traumas de referência local e/ou regional.

Os cuidados com as dimensões de salas e acessos são sempre recomendáveis, bem como interligadas a largos eixos de circulação para o transporte de pacientes ao centro de imagens, centro cirúrgicos, UTI`s, unidades de internação, entre outros. (Fig. 103).

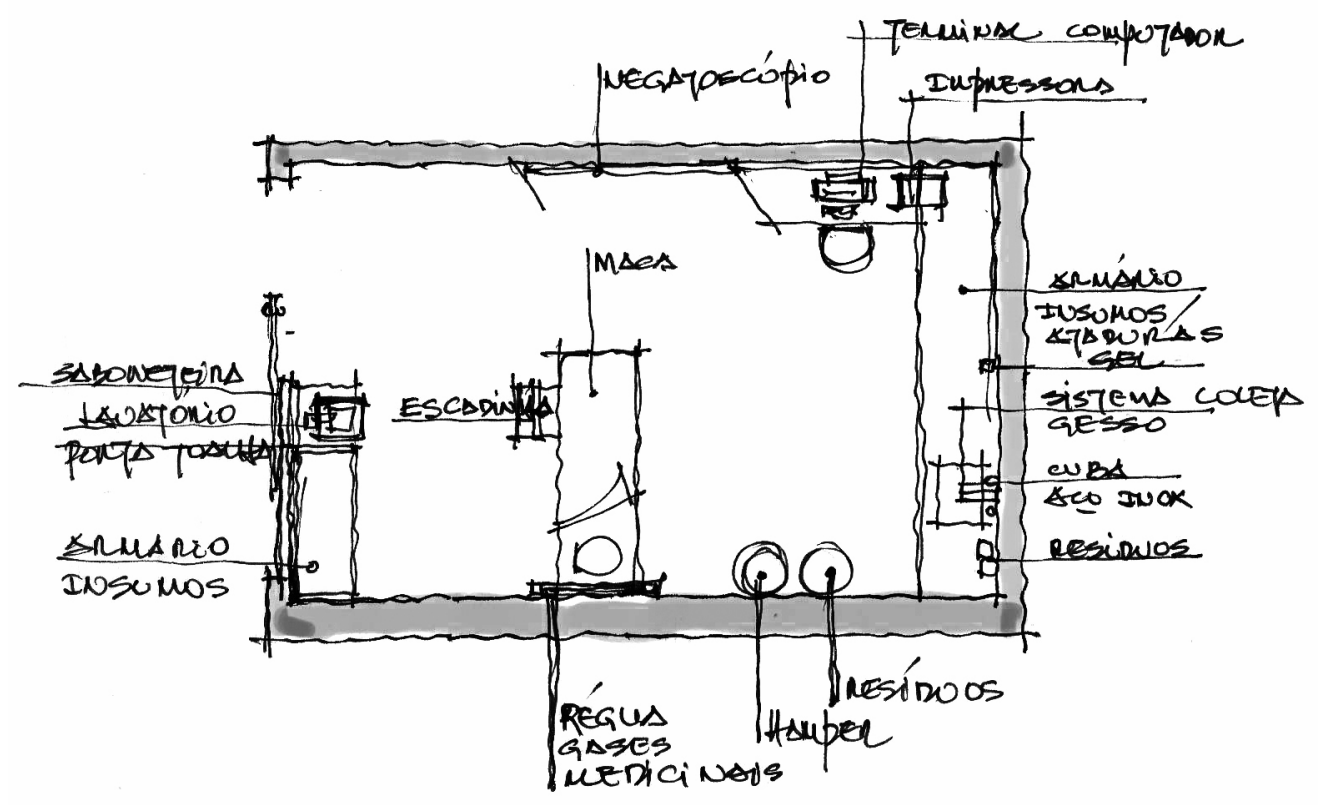

Figura 103 - Croqui esquemático: sala de gesso, imobilização e redução de fraturas.

(Fonte: elaborada pelo autor).

Uma das particularidades desta sala é quanto a cuba, onde se deve ofertar o sistema de decantação do gesso antes do seu lançamento à rede de esgoto. A disponibilidade de equipamentos como negatoscópios, raio x móvel, mesa ortopédica, entre outros, sempre é aconselhável. 


\subsection{Sala de medicação/reidratação}

A atividade destinada ao espaço é em ministrar medicamentos por via oral e venosa aos pacientes que, após avaliados e liberadas as prescrições pela equipe médica, recebem estes cuidados pelo grupo de enfermagem.

Os medicamentos prescritos são preparados na sala de serviço, contíguo ao posto de enfermagem. Sendo assim, é importante considerar na localização da sala de medicação alguma proximidade com o serviço de enfermagem não somente pelo preparo dos medicamentos, mas também pela sua supervisão ao serviço. Deve-se ainda considerar a facilidade de acesso da equipe médica quando acionada, em casos de alguma intercorrência. (Fig. 104).

Disponibilizar macas ou poltronas ao paciente, dependendo do grau de instabilidade de seu estado de saúde, e cadeiras para o acompanhante é sempre recomendável. A divisão em boxes pode ofertar uma maior privacidade ao enfermo.

O dimensionamento da sala e número de pacientes a serem
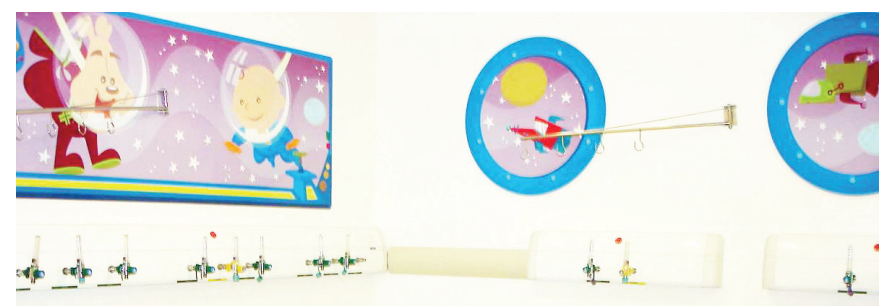
atendidos passa pela análise do grupo gestor sobre a demanda ao serviço.

Salas de medicações para crianças e gestantes são sempre recomendáveis que sejam separadas dos demais pacientes com fluxo próprio, ambientação por faixa etária e com tratamento adequado ao perfil do paciente atendido.

\subsubsection{Sala de inalação/nebulização}

Nos períodos de inverno, os problemas respiratórios se agravam principalmente para crianças e idosos. Nestes momentos de grande afluxo de pacientes, em acesso de urgência, passando pelo serviço de pediatria e clínica na especialidade em pneumologia, a sala de inalação deve ser projetada no escopo desta compreensão de atendimento.

Figura 104 - Hospital São Luiz / Anália Franco - sala de medicação.

(Fonte: foto do autor). 
Salas para o atendimento do público infantil e adulto são sempre recomendáveis que sejam separadas dos demais pacientes, com fluxo próprio, ambientação por faixa etária e em tratamento adequado ao perfil do paciente atendido.

Disponibilizar instalações adequadas de gases medicinais (ar comprimido/oxigênio), pontos elétricos e lógica, lavatório, bancada com pia para lavagem e apoio do material em uso é também recomendável.

Cadeiras para acompanhantes e poltronas para mães com crianças enfermas que permanecem em seu colo, enquanto é realizado o procedimento inalatório é imprescindível para o conforto e bem-estar dos usuários.

A localização da sala junto ao serviço de enfermagem é aconselhável não somente pelo preparo do procedimento, mas também pela sua supervisão.

\subsubsection{3 Área de conforto dos pais e acompanhantes}

A geração da necessidade de contemplar a área de conforto aos pais e/ou acompanhantes ocorre muito mais por consequência das distorções de funcionamento que o sistema operacional administrativo do hospital apresenta, isto porque os pacientes da pediatria permanecem por mais tempo do que deveriam na Unidade de Urgência e Emergência.

Como já abordado anteriormente, este problema ocorre não somente na especialidade médica pediátrica, mas também em obstetrícia e geriatria.

A causa mais significativa do problema se identifica pela indisponibilidade de oferta de leitos nas referidas especialidades médica em outras unidades (UTI's e internação), as quais teriam o papel de absorver este paciente e consequentemente garantir a dinâmica e rotatividade dos leitos na Unidade de Emergência. Sendo assim, para atender as necessidades de familiares e/ ou acompanhantes que permanecem na unidade urgência e emergência, é recomendável ofertar uma estrutura física de apoio, para seu maior conforto e bem-estar.

Em muitos casos, a permanência destas pessoas, que em um primeiro momento deveria ser de algumas horas é por alguns dias. Sendo assim, para estes casos, é aconselhável a oferta de vestiários 
com sanitários para ambos os sexos, bem como uma copa de apoio para o café, água e eventualmente um lanche rápido.

Este espaço deve se localizar próximo às áreas de observação específicas, por grupos de atenção, e junto ao eixo de serviço da unidade, sempre sob a supervisão do grupo operacional e enfermagem.

O deslocamento de familiares e/ou acompanhantes a este local, mesmo que seja por alguns momentos, pode contribuir na redução de seu estresse e cansaço, produzido pelo "clima tenso" da unidade.

É aconselhável que os vestiários com sanitários possuam a infraestrutura de armários para guarda de seus pertences e ainda ofereçam duchas para banho, tendo em vista que a permanência destas pessoas junto ao enfermo é, em muitos casos, bastante longa. (Fig. 105).

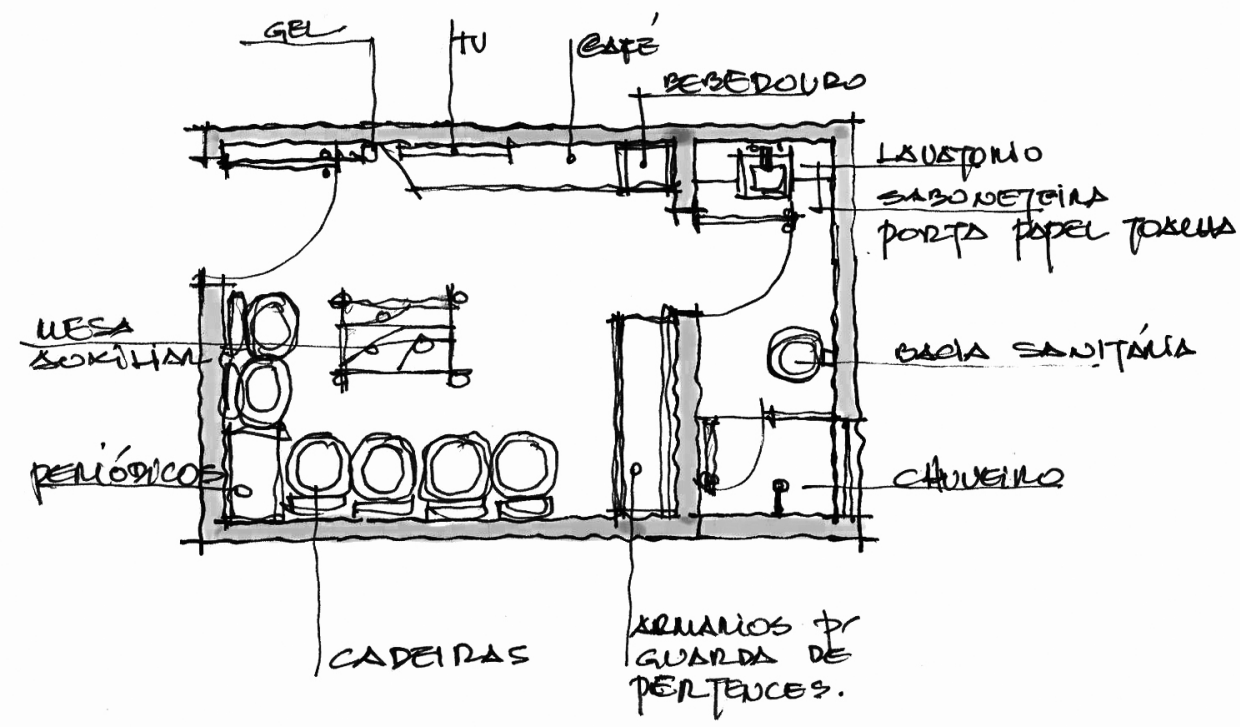

Figura 105 - Croqui esquemático: sala de conforto dos pais e acompanhantes.

(Fonte: elaborada pelo autor).

\subsubsection{Sala de atendimento a familiares}

Este espaço tem uma função importante dentro da estrutura da unidade, isto porque é neste ambiente que se recebe a família para notificá-la da real situação em que se encontra o paciente, ou ainda comunicar o seu falecimento. 
A importância na oferta deste espaço específico ocorre pelo fato de que em muitos casos esta notícia para a família é dada nos corredores ou espaços inadequados. Com níveis elevados de estresse, tensão e angustia, é aconselhável que se oferte um local onde a família possa permanecer por algum tempo, até se recompor, que tenha a privacidade e o respeito neste momento tão difícil e delicado da sua vida. (Fig. 106).

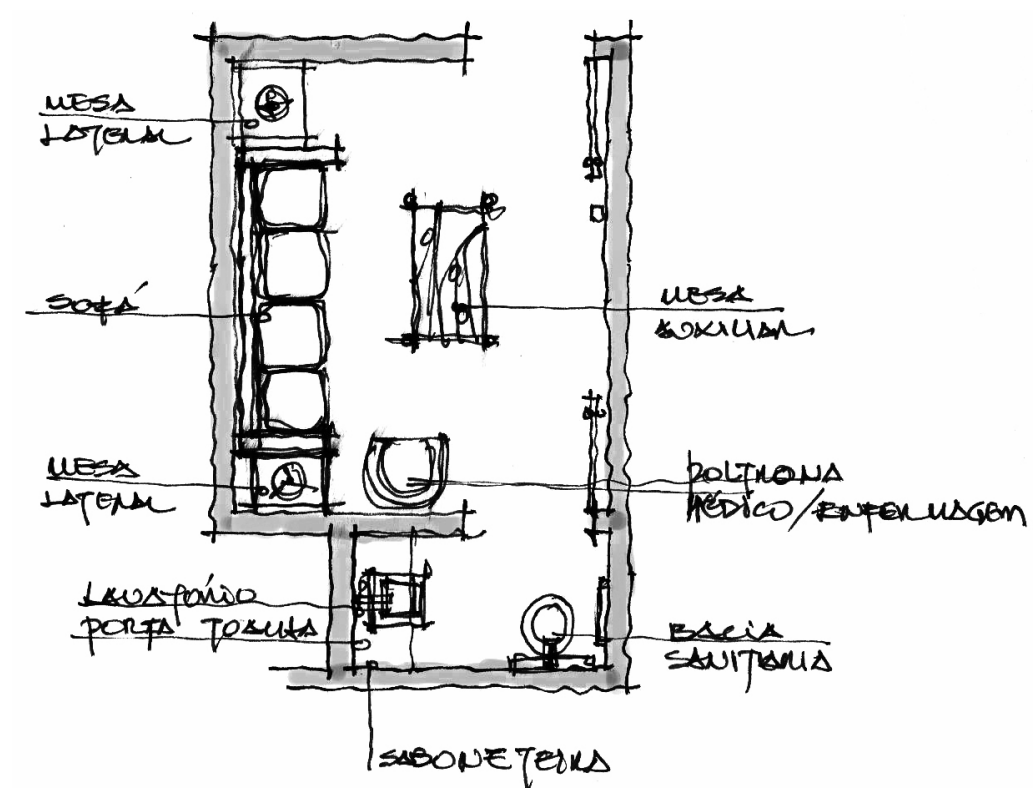

Figura 106 - Croqui esquemático: sala de atendimento aos familiares.

(Fonte: própria, 2010).

É interessante observar que neste mesmo local se desenvolvem duas situações, onde para a família possa parecer até conflitantes, mas ao mesmo tempo de extrema necessidade. Constatada a morte cerebral do paciente, cabe ao grupo médico e/ou enfermagem abordar a família sobre a concordância na doação dos órgãos do paciente em óbito, dentro do que se preconiza o Programa de Captação de Órgãos para transplantes. Novamente, para esta situação, o caráter de privacidade e respeito aos familiares é de fundamental importância.

A oferta de lavabo anexo à sala é sempre aconselhável. 


\subsection{Subsistema de apoio ao diagnóstico e tratamento}

A infraestrutura de diagnóstico por imagem e traçados gráficos para atender a Unidade de Urgência e Emergência, na maioria dos casos, está acoplada ao Centro de Diagnóstico por Imagem, e que recomendávelmente deve estar próximo à unidade em estudo. Porém, por fatores de demanda, distância ou ainda horários de funcionamento, alguns hospitais de alta complexidade, oferecem na sua estrutura física-operacional da Unidade de Urgência e Emergência alguns serviços de apoio para maior agilidade e resolutividade ao modelo de atenção. Isto significa a inserção no pensamento do projeto arquitetônico, após ampla discussão e definição pelo grupo gestor, na oferta dos serviços como: raio-x, eletrocardiograma, ecocardiotoco, ultrassom e laboratório de urgência em análises clínicas, por exemplo.

Os equipamentos instalados no interior da unidade têm o papel de atender às diversas especialidades de forma mais abrangente possível.

\subsection{Sala de Exames Radiológicos}

Esta sala deve possuir dimensões generosas para a entrada e o deslocamento do paciente acamado ou em cadeira de rodas, e permitir ainda a fácil circulação do técnico no preparo do exame.

Sua localização próxima aos consultórios de ortopedia, sala de gesso e redução de fraturas é recomendável pela facilidade de deslocamento do paciente e da equipe médica e enfermagem.

Deve-se sempre, a partir do modelo do equipamento a ser utilizado, desenvolver o projeto de radioproteção que estabelece toda a especificação do material que irá proceder o isolamento dos raios ionizantes gerados pelo aparelho de raio-x $\mathrm{e}$ consequentemente se obter a blindagem do espaço para todos os ambientes contíguos.

Para algumas especialidades médicas e para exame de constrastes é aconselhável que anexo à sala de exames do raio-x seja disponibilizado um sanitário, com dimensões para pacientes 
em cadeira de rodas, objetivando maior conforto, privacidade ao paciente, como também maior agilidade na realização do referido exame.

A área de controle e comando do aparelho de raio-x deve ser também protegida contra raios ionizantes, e utilizada de vidro plumbífero como visor no acompanhamento e orientação do paciente durante a realização do exame.

Ainda anexo a este serviço de radiologia, deve-se disponibilizar o espaço para a câmara escura utilizada para revelação das chapas radiográticas onde este processamento pode ser (dependendo do modelo do equipamento do raio-x) do tipo convencional, por processadora automática ou ainda por processamento digitalizado.

A verificação do resultado quanto à qualidade visual e leitura para o diagnóstico é feita junto ao espaço da câmara clara, onde se disponibiliza uma quantidade de negatoscópios suficiente para a demanda do serviço.

\subsubsection{Sala de Exames de ultrassom}

Esta sala deve possuir dimensões adequadas para a entrada e deslocamento do paciente acamado, cadeira de rodas ou ambulante e ainda permitir a fácil circulação do técnico e médico no preparo e realização do exame.

Recomenda-se o uso de monitor de parede posicionado de forma adequada à visualização do paciente para que ele acompanhe as observações feitas pelo médico, durante a realização do exame.

Para se obter a melhor visualização do exame no monitor instalado, bem como atingir uma ambientação tranquila e repousante para o espaço, é aconselhável a utilização de dimmers para controle de intensidade luminosa na sala de exames, deixando em um nível de iluminamento bastante baixo, para que se obtenha os resultados esperados.

Para as especialidades médicas como gineco-obstetrícia, urologia, proctologia, entre outras, é necessário que para a realização do exame de ultrassom seja disponibilizado um sanitário (lavabo) anexo à sala de exames para ofertar mais conforto e privacidade ao paciente. 
Recomenda-se a sua localização junto aos consultórios das especialidades médicas citadas acima, para se obter facilidade de deslocamento e maior conforto do paciente e equipe profissional.

\subsubsection{Sala de Eletrocardiografia contínua (Holter)}

Esta sala deve possuir dimensões adequadas para a entrada e deslocamento do paciente acamado, cadeira de rodas ou ambulante e ainda permitir a fácil circulação do técnico no preparo e realização do exame.

Recomenda-se a sua localização junto aos consultórios de cardiologia, ou ainda integrada ao Centro de Dor Torácica, se houver como proposta do serviço.

\subsubsection{Sala de endoscopia alta}

Esta sala deve possuir dimensões adequadas para a entrada e deslocamento do paciente acamado, cadeira de rodas ou ambulante e ainda permitir a fácil circulação dos técnicos e médicos no preparo e realização do exame.

Anterior a realização do procedimento, é necessário uma área de preparo e sedação do paciente, colocado em cadeira ou poltrona confortável e que, após observado e definitivamente preparado pela equipe de apoio médico, seja encaminhado para a sala de exames.

Após a realização do referido exame, o paciente é encaminhado para a área de pós-exames, onde permanece até a sua recuperação plena dos sentidos, com a passagem do efeito da sedação, para que possa ser liberado pela equipe profissional.

\subsubsection{Laboratório de Urgência em Análises Clínicas}

As Unidades de Urgência e Emergência de alta complexidade, que possuem grande demanda de pacientes são referências locais ou regionais e ainda acopladas em estruturas hospitalares de grande porte. Em muitos casos, os serviços de urgência e emergência possuem laboratórios de análises clínicas próprios 
para maior agilidade e resolutividade na obtenção dos resultados dos exames solicitados.

Considerado como estrutura de apoio ao diagnóstico, os materiais e/ou secreções são colhidos junto ao leito, maca ou poltrona na qual o paciente se encontra em observação. Em casos de pacientes ambulantes, este deve ser encaminhado para a sala de coleta de material para exames, onde anexa a esta deve ser disponibilizado lavado para coleta de urina ou fezes. (Fig. 107).

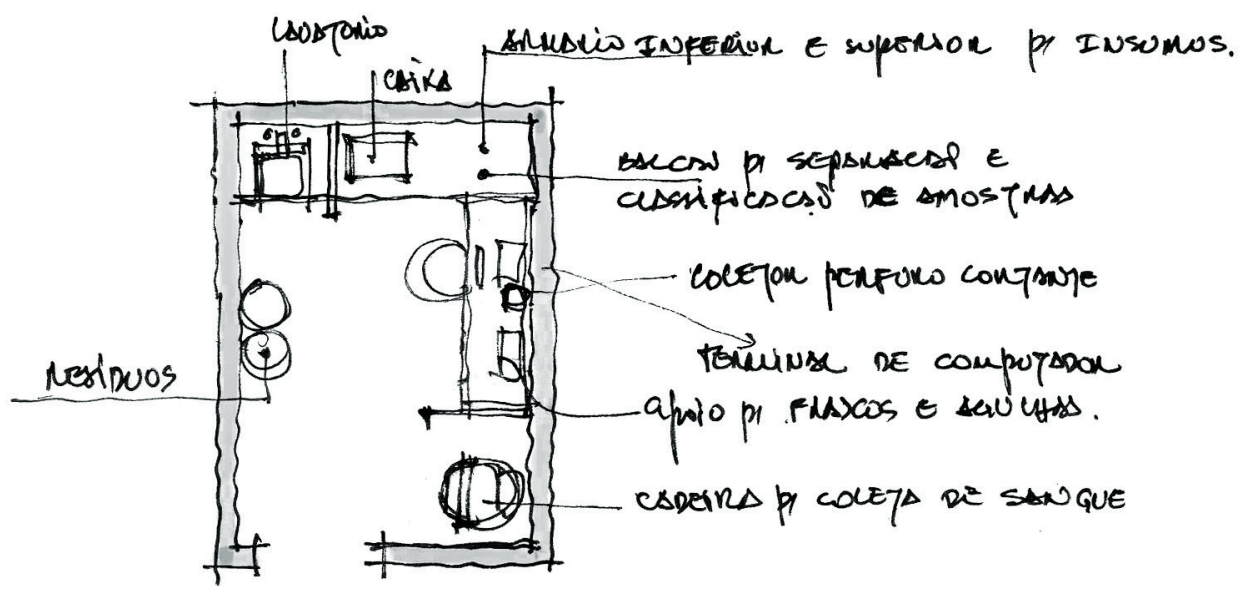

Figura 107 - Croqui esquemático: sala de coleta laboratorial.

(Fonte: elaborada pelo autor).

As amostras coletadas são encaminhadas ao laboratório de urgência em análises clínicas, que funciona por 24 horas, e tem o papel de obter os resultados e encaminhá-los aos médicos em processo de atendimento ao paciente.

Pelo caráter do serviço, os exames realizados na unidade laboratorial são exames mais simples, tipo gasometria, exames de rotina, entre outros. Para os exames mais sofisticados, com a necessidade de maior tempo para sua realização, o paciente poderá ficar em observação ou liberado a partir da análise e decisão tomada pela equipe multiprofissional.

\subsection{Subsistema de observação e repouso}

As áreas de observação e repouso devem ser ofertadas para pacientes adultos com a separação por sexo, e ainda áreas específicas para pediatria e gestantes. 
A localização destas áreas deve ser separada do fluxo geral da unidade de urgência e emergência, próximo ao posto central de enfermagem e com facilidade de acesso pela equipe médica.

O objetivo no atendimento do paciente é a sua permanência em até, no máximo, 24 horas, em que, a partir disto, ele será encaminhado para a respectiva unidade de internação, ou liberado após a completa avaliação sobre seu estado geral.

É interessante observar que em um número expressivo de hospitais pesquisados, ou por meio de relatos de serviços de urgência e emergência espalhados por este país afora, há um problema crônico na oferta de leitos em UTI's e unidades de Internação, provocando a demanda reprimida na unidade de emergência, o que proporciona o total descontrole na acomodação de pacientes "internados" por 48 ou até 72 horas em consultórios, sala de medicação, corredores e ainda pacientes graves nas salas de atendimento de emergência.

$\mathrm{Na}$ maioria das vezes, a concepção do projeto arquitetônico parte pela absorção do efeito e não na resolução da causa, que em muitos casos esbarra na indisponibilidade de recursos financeiros, falta de pessoal qualificado, indisponibilidade de espaço físico para ampliação, ou ainda na falta de vontade política na solução da saúde pública em aumentar a oferta do número de leitos hospitalares.

As áreas de observação e repouso para adultos devem acomodar até no máximo 12 leitos, posicionados de forma com que estejam sob a supervisão do grupo de enfermagem.

O posicionamento do leito deve garantir o conforto do paciente, separados por divisórias ou cortinas para proporcionar a privacidade $\mathrm{e}$ bem-estar, possibilitar a entrada de maca ao lado dos leitos, no momento de transferência do paciente, acesso e circulação da equipe de trabalho na realização dos procedimentos e ainda garantir o espaço para acomodação de equipamentos necessários para mensuração dos sinais vitais do paciente. (Fig. 108).

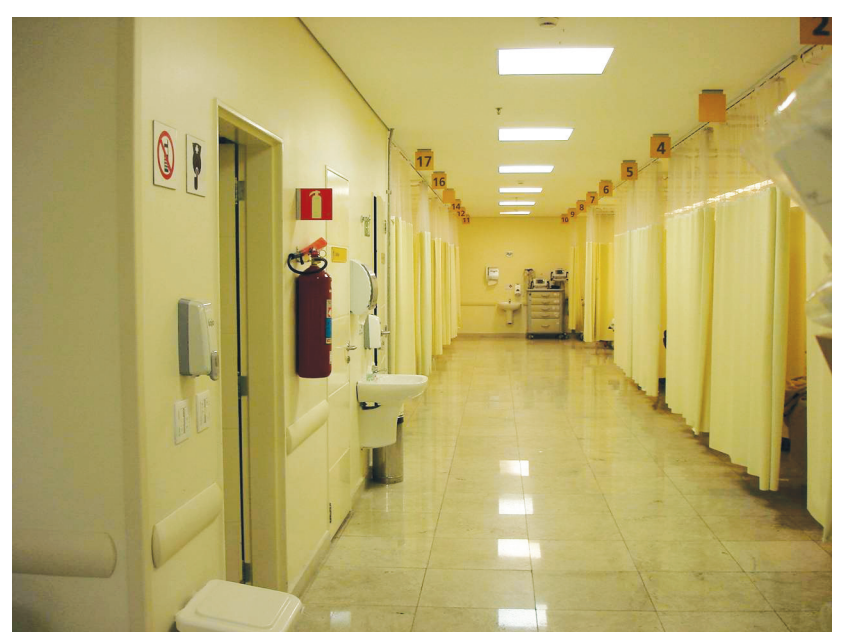

Figura 108 - Hospital São Luiz / Anália Franco - área de observação e repouso adultos.

(Fonte: foto do autor). 
Torna-se necessário ainda, junto às áreas de observação e repouso, a oferta de locais para isolamento de pacientes, portadores de doença infectocontagiosa, agravada por problemas que exijam cuidados de emergência, ou ainda a pacientes agressivos, psicopatas ou criminosos. $\mathrm{O}$ acesso a este espaço deve ser com antecâmara, com lavatório (lavagem de mãos pela equipe profissional) e armários onde estarão estocados jalecos ou aventais para paramentação da equipe de atendimento ao paciente.

Para o bom isolamento do paciente é indispensável a existência de sanitários completos e anexos aos referidos quartos.

Para as áreas de observação pediátrica é importante que o arquiteto responsável pelo projeto tenha a sensibilidade necessária para criar o espaço de forma com que este ofereça a ambientação

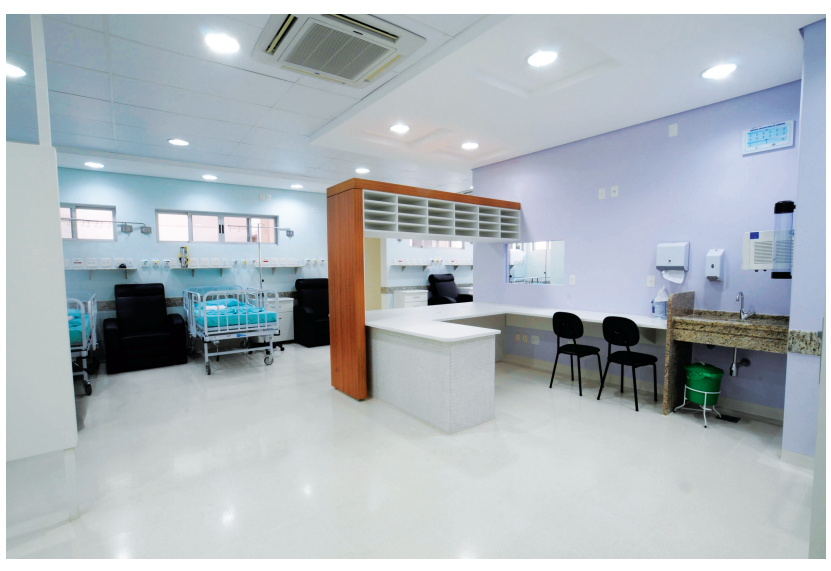
de acolhimento e aconchego aos pequenos enfermos.

Os espaços disponíveis para cada leito pediátrico devem acomodar uma cadeira ou poltrona para que o acompanhante (pais) possa permanecer no local, com razoável nível de conforto durante o período em que a criança estiver em observação. (Fig. 109).

Para atender às crianças menores e ao

Figura 109 - Hospital Universitário, Londrina, PR área de observação e repouso pediatria.

(Fonte: foto do autor). grupo operacional, recomenda-se a disponibilidade de sanitários e área para higienização, com bancadas de apoio.

Para todos os grupos de leitos, devem ser ofertados sanitários com número suficiente de bacias, lavatórios, duchas higiênicas e chuveiros. Recomenda-se para estes espaços dimensões adequadas para transporte de pacientes em cadeira de rodas e ainda a colocação de cadeiras de banho, acopladas às barras de apoio junto ao Box do chuveiro/ducha. Aconselha-se também que os volantes do chuveiro/ducha estejam do lado oposto ao chuveiro, para que o acesso a eles pela enfermagem seja mais confortável tanto em termos de distância, como também fora da queda d’água.

Pelo número de pacientes que permanecem nas áreas de observação e repouso, pela diversidade de patologias apresentadas, pelo sentimento de angústia, ansiedade e insegurança, pela dor e desconforto, é importante que estes espaços ofereçam os cuidados projetuais de boa luminosidade, aeração e relação visual 
com os espaços externos. É importante permitir ao paciente e ao acompanhante que através das aberturas visuais possam ter a noção clara de tempo e clima.

\subsection{Subsistema de apoio logístico e operacional}

\subsection{Posto de enfermagem, serviço e prescrição médica}

Para grandes Unidades de Urgência e Emergência principalmente para atendimento em alta complexidade, o posto de enfermagem tem o papel de gerenciar todos os fluxos de pessoas, serviços, deslocamentos de pacientes e equipamentos. Além disto, supervisionar os procedimentos realizados na unidade, desde o primeiro contato com o paciente até o seu encaminhamento para outras unidades de atenção ou a sua simples liberação, ao retorno do seu lar.

Com todas estas tarefas e exercendo como ponto focal de referência para toda equipe multidisciplinar envolvida no atendimento ao paciente em estado crítico, é importante considerar, já na concepção do projeto arquitetônico, a localização do referido espaço, no contexto de unidade, principalmente pela sua função estratégica de gestão e controle.

Para a obtenção de melhores resultados e eficácia no atendimento ao paciente, deve-se gerar para os serviços de observação e repouso, salas de emergência, medicação e apoio diagnóstico, subpostos de enfermagem, com o caráter de atendimento mais próximo ao serviço, tendo em vista que as estruturas das unidades de urgência e emergência são bastante grandes e que proporcionam grandes distâncias e uma infinidade de deslocamento pela equipe profissional.

$\mathrm{O}$ espaço do posto de enfermagem é dividido em quatro funções que se interagem entre si e estão abaixo relacionadas. (Fig. 110). 


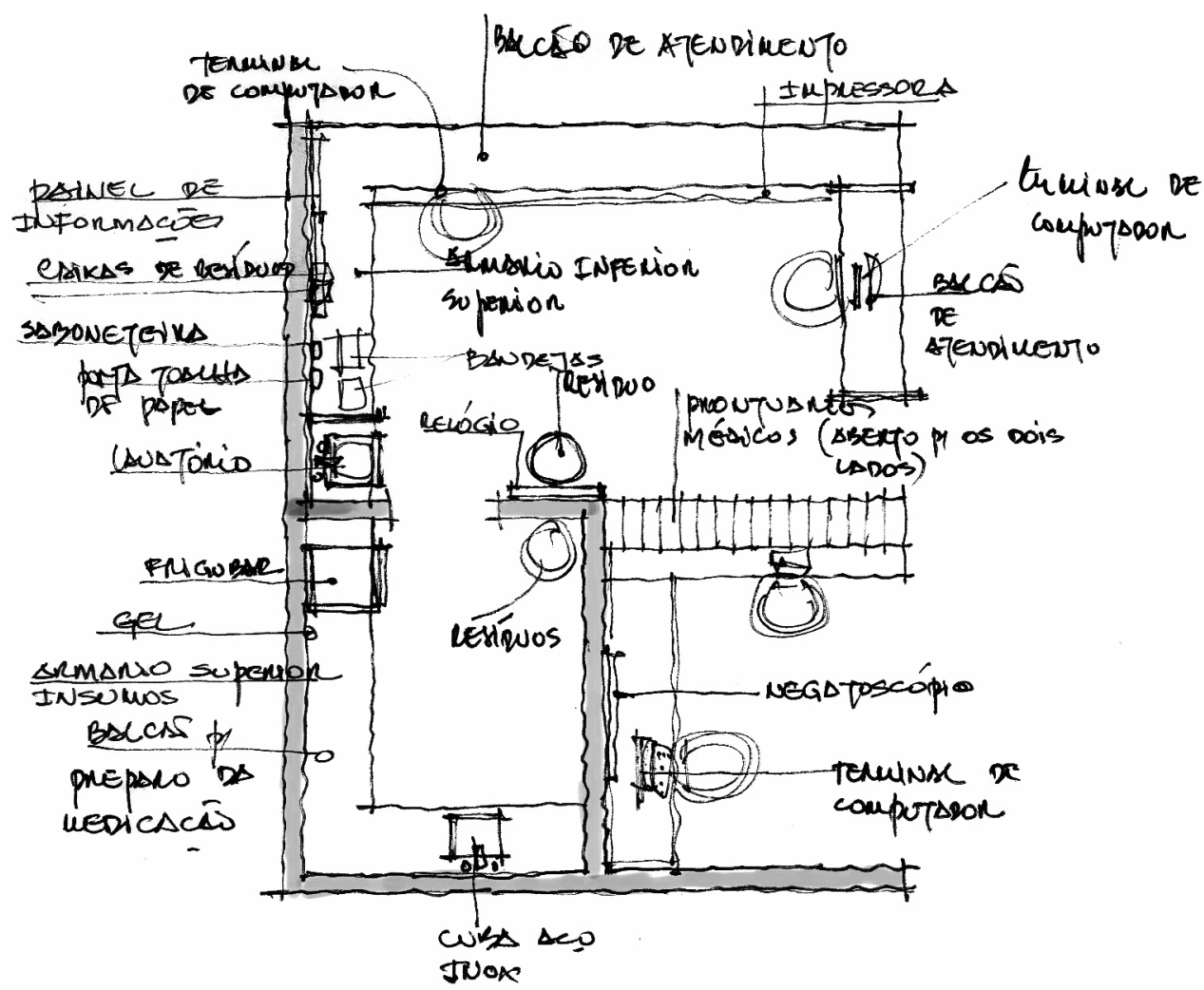

Figura 110 - Croqui esquemático: posto de enfermagem, serviço e prescrição médica.

(Fonte: elaborada pelo autor).

- Balcão de atendimento, espaço de relatório e acompanhamento de prontuários pela equipe de enfermagem.

- A área de serviço, interno ao posto de enfermagem, é o local para o preparo da medicação a ser ministrada ao paciente. É necessário dispor para o espaço bancada com cuba, armários de estoque de insumos e frigobar para conservação de alguns medicamentos específicos que exijam controle de temperatura. Pela responsabilidade no preparo da medicação é importante que o espaço esteja fora da circulação geral da unidade e mais internamente ao posto de enfermagem.

- A área para escrituração tem o papel de atender todo o serviço administrativo e burocrático da unidade de urgência e emergência. Por este setor passam registros de todos os documentos, prontuários, exames, pedidos de materiais e de consertos de equipamentos. Sua localização deve ser contígua ao posto de enfermagem, com a função de atendimento de pessoas na entrega de documentos ou materiais e ainda 
como referência no atendimento e transferência das ligações telefônicas.

- A área destinada à prescrição médica deve ser externa ao posto de enfermagem, porém garantida a contiguidade, comunicação visual e passagem de documentos. A separação entre os dois espaços pode ocorrer por meio de balcão de trabalho, visor e guichê. A separação dos serviços é importante para evitar que se tenha um grupo grande de pessoas internamente ao posto de enfermagem, o que na maioria dos casos provoca congestionamento e conflitos. O espaço da prescrição médica, com disponibilidade de negatoscópios para análise de chapas radiográficas, o acompanhamento por parte de familiares, discussões com a equipe multidisciplinar ou ainda orientações e discussões dos casos com alunos, provocando a aglomeração de pessoas alheias ao serviço de enfermagem, por estas razões que é aconselhável a delimitação dos espaços de trabalho pelas equipes médica e enfermagem.

\subsubsection{Estar médicos/quarto plantonistas}

O espaço para descanso da equipe médica deve ser separado por sexo (quando houver um número maior de plantonistas), e necessita de sanitário anexo com chuveiro para o maior conforto e privacidade dos profissionais.

Deve-se disponibilizar qualquer forma de comunicação de urgência entre o posto de enfermagem central e local de repouso médico, como também o espaço dos plantonistas deve ser localizado próxima às áreas de observação, repouso e sala de emergência.

A área de estar, contígua aos quartos de plantonistas, deve disponibilizar mobiliário adequado ao relaxamento da equipe, como sofás ou poltronas, equipamentos como computadores para consultas às informações e ainda televisão, revistas e periódicos.

Esta área tem o papel importante de ser a referência da equipe médica para discussões mais amenas e troca de informações. 


\subsubsection{Conforto de enfermagem e equipe de colaboradores}

A área de estar e referência de descanso para a equipe operacional deve ser localizada próxima ao posto de enfermagem central, porém deslocada do eixo principal de circulação.

Embora esta área não esteja contemplada como obrigatória no programa físico-funcional da RDC 50/Anvisa, ela se torna importante para aliviar o estresse da equipe, nos pelo menos 15 minutos de intervalo durante seu turno de trabalho. Agrega-se a isto a importância em dispor uma pequena copa, para o café, água e/ou suco.

Junto a estes espaços de apoio é aconselhável a oferta de sanitários, dimensionados adequadamente ao número de colaboradores por turno de trabalho, para garantir maior conforto e privacidade à equipe profissional. A disponibilidade de chuveiros é também aconselhável, tendo em vista que em alguns procedimentos há o contato com sangue, vômitos ou outros tipos de secreções, o funcionário necessita remover a roupa e proceder a sua higiene.

\subsubsection{Salas de chefia médica e enfermagem}

A função das salas aqui mencionadas é de ordem burocrática e importante para a organização dos respectivos serviços. A conversa com os colaboradores, enfermagem e médicos ocorre nestes locais, como garantia das discussões em ambiente adequado e privativo.

Preparar escalas de plantão, processar as comunicações internas, encaminhar ordem de serviços, atender público externo e imprensa são algumas tarefas desenvolvidas pelas chefias de enfermagem e médica, respectivamente ao seu nível de gestão.

\subsubsection{Salas de discussão de casos}

O caráter de uso destas salas pode ser até multifuncional, isto porque embora o espaço não esteja contemplado no programa físico-funcional da RDC 50/Anvisa, é de importância significativa para toda a equipe profissional para as discussões 
sobre determinados casos de patologias, que necessitam de uma tomada de decisão de forma interdisciplinarmente conjunta.

Principalmente para os Estabelecimentos Assistenciais de Saúde que possuem o caráter de ensino, estas salas passam também a exercer a atividade de discussão com acadêmicos e residentes, como desenvolvimento complementar à aprendizagem.

Com o mobiliário adequado para a atividade, compreendendo cadeiras e mesa para reuniões, computadores, projetor e televisão para transmissão de vídeo conferência, sempre será uma oferta saudável e benéfica para a complementação dos estudos e discussões científicas, inerentes aos serviços de urgência e emergência de alta complexidade.

\subsubsection{Depósito de materiais/arsenal}

Local destinado à guarda de todo o material de consumo na Unidade de Urgência e Emergência, com estoque mínimo para pelo menos 24 horas.

Este material estocado compreende insumos (médicohospitalar), esterilizados (procedentes da central de esterilização de materiais) e medicamentos. (Fig. 111).

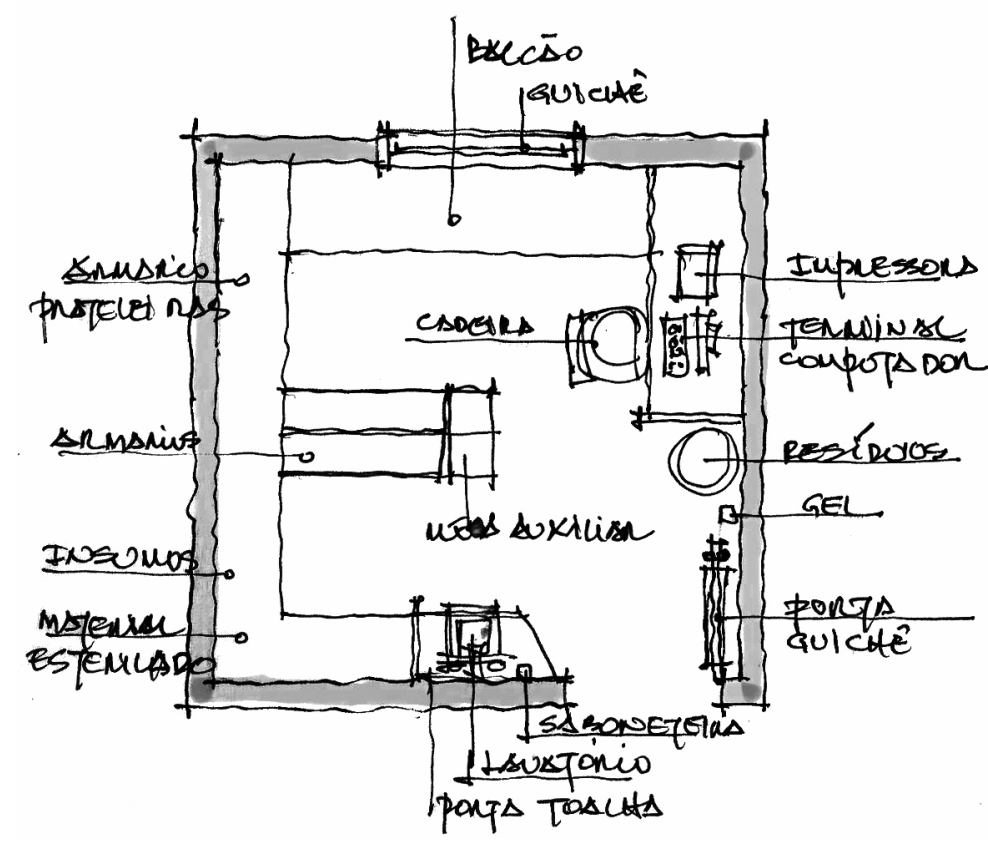

Figura 111 - Croquiesquemático: depósito de materiais, medicamentos e arsenal.

(Fonte: elaborada pelo autor). 
O dimensionamento da sua área está diretamente vinculado ao porte do serviço de Urgência e Emergência ofertado. Conter armários fechados para estocar produtos de maior controle, prateleiras abertas para produtos que necessitam de rápida visualização e distribuição de mesas de apoio para separação, registro e entrega do material, lavatório para higiene das mãos, são alguns itens imprescindíveis para a obtenção da qualidade desejada ao serviço.

É importante observar que na organização e armazenagem dos produtos, as prateleiras devem possuir a identificação clara e necessária para evitar erros na coleta de determinados materiais, bem como cuidar para que haja a perfeita classificação destes.

Aconselha-se, ainda, a utilização de barreira física, por meio de portas guichês ou sistema monitorado de acesso ao espaço. Isto se torna indispensável tanto para a manutenção da qualidade dos produtos estocados, como também para o controle sobre a evasão de produtos estocados. Sua localização, pela característica de atendimento a toda unidade, é recomendável que esteja numa posição mais centralizada, próxima aos serviços de enfermagem e conectada pelos eixos de circulação de serviço.

\subsubsection{Sala para guarda de equipamentos}

Espaço destinado ao armazenamento de todos os equipamentos de possível utilização no serviço de urgência e emergência, e de uso transitório.

Neste local estocam-se equipamentos como: bombas de infusão, monitores cardíacos, raio-x transportável, como também cadeiras para banho, banquinhos, escadas pequenas, suporte para soro etc.

O dimensionamento do espaço deve considerar a mobilidade dos próprios equipamentos tendo em vista que alguns deles ocupam espaço de piso necessitando serem removidos com facilidade e rapidez. Outro fator a considerar é a disponibilidade de bancadas de apoio de equipamentos menores, para facilitar na sua organização e visualização. É indispensável ainda uma boa oferta de tomadas elétricas de 110 ou 220 watts para conectar aparelhos movidos a bateria, que necessitam de carregamento. 
Sua localização nas proximidades dos serviços de enfermagem é sempre aconselhável, bem como conectado pelo eixo de circulação de serviço da unidade.

\subsubsection{Expurgo ou sala de utilidades}

Espaço destinado a limpeza de materiais como: cuba rim, instrumental, comadres, papagaios, escarradeiras, baldes, entre outros produtos que receberão a higienização necessária para depositá-los de volta ao processo de assistência ao paciente.

Os produtos que necessitam ser esterelizados passam por este local para a pré-lavagem e acondicionamento em embalagens adequadas para seu correto encaminhamento à Central de Esterilização de Material.

Disponibilizar cuba em aço inoxidável para despejo de urina, fezes, sangue ou qualquer outro tipo de secreção é indispensável para se atingir a boa qualidade operacional.

É importante ofertar na sequência da operação de despejo cuba (área suja) de higienização dos produtos/materiais para se processar a primeira lavagem. É recomendável ainda que disponha outra cuba (área limpa) de higienização dos referidos produtos para a segunda e mais refinada lavagem. Recomenda-se que seu dimensionamento preveja as condições de movimento dos carros de transporte para os diversos tipos de produtos.

Para muitas unidades de urgência e emergência, é neste espaço que se destina também a armazenagem temporária de roupas sujas e resíduos. Porém, considera-se que para as unidades de grande porte, com a produção de grandes volumes de roupa suja e resíduos, justifica-se a oferta de área específica para este fim.

Sua localização nas proximidades dos serviços de enfermagem é sempre aconselhável, bem como conectada pelo eixo de circulação de serviço da unidade.

\subsubsection{Depósito de roupa suja e resíduos}

Como exposto anteriormente, este espaço é necessário, principalmente para unidades de grande porte e de movimento intenso na sua assistência, isto significa a geração de grande volume de roupa suja e resíduos. 
Para o seu dimensionamento, é necessário ter clareza sobre todos os tipos de resíduos gerados, correspondência em volume de produção e respectivos volumes de produção e tempo de permanência no local.

Recomenda-se que para a armazenagem dos resíduos neste local, disponibilize recipientes grandes com identificação própria para a perfeita separação e classificação dos resíduos (comum/ reciclável/infectante/químico), segundo a RDC 306/Dez 2004/ ANVISA/MS.

Conectar com o eixo de circulação de serviço é aconselhável para evitar o trânsito de carros de transporte pelo interior da unidade.

Sua localização, considerando a finalidade do espaço e fluxo de atividade, é recomendável que esteja implantada na área mais periférica da unidade, para fácil acesso dos funcionários de lavanderia (recolhimento de roupa suja) e da limpeza (recolhimento dos resíduos).

Aconselha-se ainda o dimensionamento do espaço que seja suficiente e possibilite a movimentação de carros de transporte, guarda de hampers e recipientes estacionários para os resíduos.

\subsubsection{Rouparia}

Espaço destinado à recepção, guarda e distribuição da roupa limpa da unidade.

O dimensionamento do espaço está vinculado ao volume de uso e porte da unidade em estudo. Para melhor segurança e higiene, é recomendável que esteja colocada em armários com portas e de acesso restrito ao grupo operacional. Por esta razão, aconselha-se que sua localização esteja próxima ao serviço de enfermagem e conectada ao eixo de circulação de serviço da unidade.

\subsection{Sala de guarda de Hemocomponentes}

Área de referência para guarda de bolsas de sangue e hemocomponentes, armazenados em freezers ou refrigeradores específicos com controle de temperatura. 
Sua localização é recomendada próximo ao posto de enfermagem central e o material a ser distribuído principalmente para as salas de pequenas cirurgias, procedimentos invasivos e sala de emergência.

\subsubsection{Depósito de material de limpeza}

Espaço destinado ao armazenamento de todos os materiais (vassouras, rodos, baldes, produtos de limpeza etc.) de uso na limpeza e higiene da unidade de urgência e emergência, com a instalação de tanques para a lavagem dos materiais utilizados e despejo de água suja após o serviço realizado.

Esta área é referência para a zeladoria da unidade e seus produtos são repostos pelo almoxarifado, para se estabelecer a periodicidade necessária para que não haja a falta do produto e se obtenha um trabalho eficiente e de boa qualidade.

Por se tratar de uma unidade que atende pacientes debilitados, é muito comum ocorrerem situação com vômitos, sangue e secreções em geral. Nesses casos, é necessário o trabalho rápido do serviço de zeladoria, no que se refere a higiene do local afetado.

Sua localização poderá ser mais periférica à unidade em estudo, pois este serviço não depende da equipe operacional de atendimento ao paciente e sim da zeladoria.

\subsubsection{Copa para pacientes}

Este espaço possui a finalidade de receber e distribuir as dietas dos pacientes, as quais já vêm preparadas do Serviço de Nutrição e Dietética (SND), e são transportadas em carros térmicos para garantir a manutenção da temperatura do alimento.

Neste local, faz-se a retirada das bandejas e distribuição efetiva aos pacientes, ficando ainda como referência para a guarda de utensílios e a pré-lavagem de talheres e louças, antes do seu retorno às SND.

Em princípio, neste local não haverá qualquer tipo de preparo de alimentos. No entanto, é sempre recomendável a oferta de frigobar, para armazenagem de suco, água ou leite, e micro-ondas para aquecer algum alimento em poucos segundos. 
O dimensionamento desta área não deve ser grande, porém cabe ao grupo gestor de discussão do projeto o dimensionamento adequado à demanda do serviço. Teoricamente, os pacientes em observação não permanecem por muito tempo na unidade de emergência, e com isto a rotatividade da assistência requer apenas de pequenas refeições, como também deve-se considerar que pacientes em condições críticas não se alimentam nas primeiras horas.

Porém, na prática da grande maioria dos hospitais de grande porte, em especial os hospitais públicos, o tempo de permanência do paciente na Unidade de Emergência é bastante longo. Sendo assim, o grupo gestor deve analisar também por esta ótica para que o serviço não se torne ineficiente.

Sua localização poderá ser mais periférica à Unidade de Urgência e Emergência, pois este serviço não depende da equipe operacional de atendimento ao paciente, sendo que ele será realizado pela equipe de transporte e /ou do SND.

\subsubsection{4 Área de guarda de pertences dos pacientes}

Espaço destinado à colocação de armários, com a finalidade de guarda de pertences dos pacientes durante o período de permanência na unidade.

É interessante observar a oferta deste espaço próximo à sala de emergência, como também junto aos leitos de observação e repouso.

O dimensionamento dos pequenos armários deve comportar roupas, pequenos objetos e capacete utilizado pelos motociclistas.

\subsubsection{Sala de estar para motoristas de ambulâncias}

Espaço destinado ao pessoal de transporte e resgate de pacientes em ambulâncias. Recomenda-se que a sua localização seja na área externa ao serviço de Urgência e Emergência e próximo a área de estacionamento dos referidos veículos.

O espaço deve dispor de sistema conectado 24 horas com serviço pré-hospitalar (SAMU), permanecer disponível e com 
facilidade de saída para realizar o resgate ao paciente em estado grave e que necessita de atendimento imediato.

Aconselha-se ainda disponibilizar, anexo ao serviço, sanitário para o grupo operacional como garantia de conforto e privacidade, como também a permanência destes no local, sem que haja o comprometimento pela ausência do funcionário de plantão. 


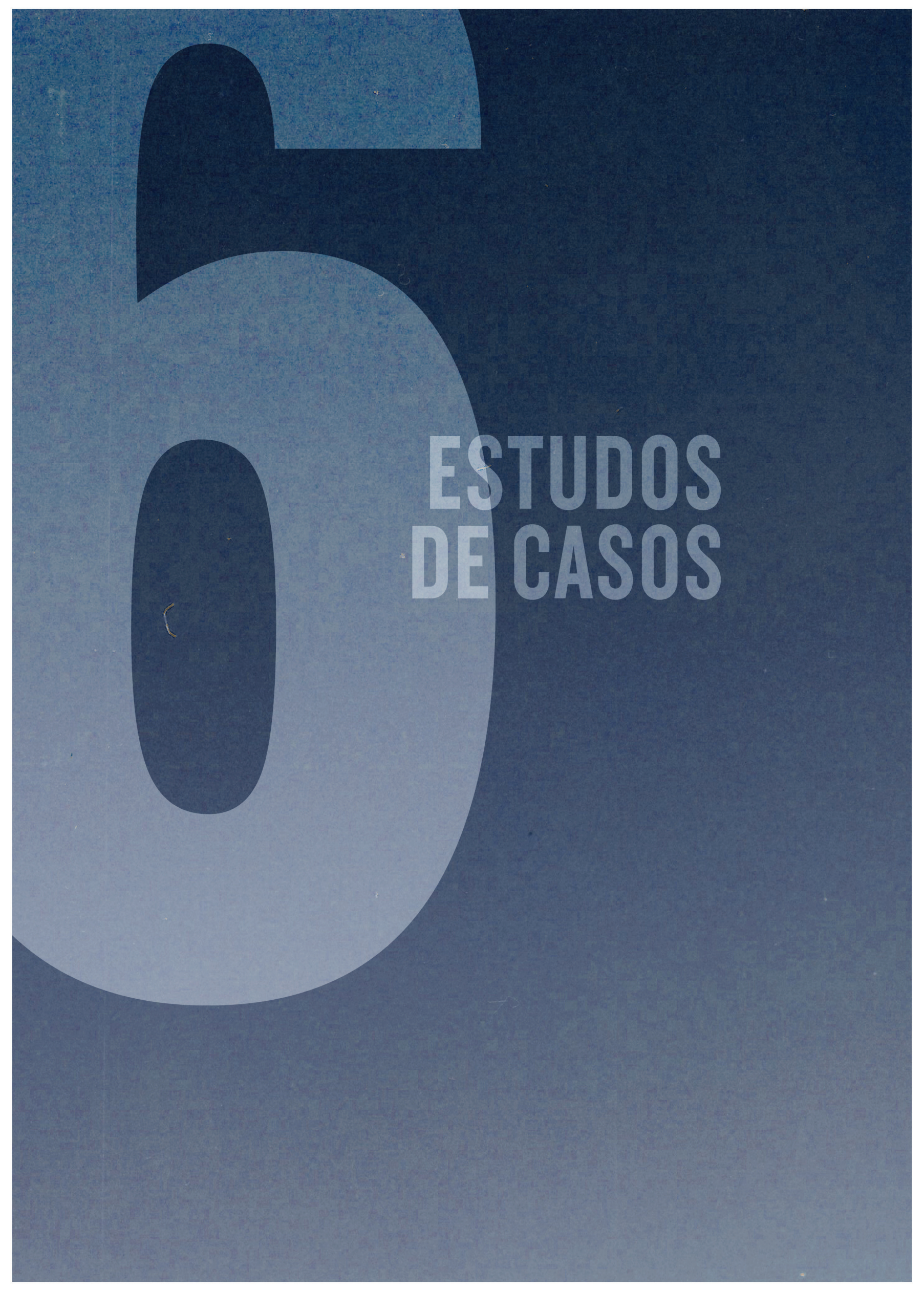





\section{I Hospital Universitário Regional Norte do Paraná (UEL) Londrina - PR}

\section{I.I Introdução}

A unidade em estudo está agregada a um complexo hospitalar de atendimento geral, que inclui pediatria, obstetrícia caracterizado como hospital público, com capacidade para aproximadamente 270 leitos. Possui ainda a característica de hospital escola, vinculado à UEL (Universidade Estadual de Londrina) e parte integrante do Sistema de Saúde da Cidade de Londrina - PR.

Esta cidade possui hoje aproximadamente 500.000 habitantes, sendo com este indicador a segunda cidade do estado do Paraná e a quarta (censo 2010) na região sul do Brasil. (Figura 112).

A estrutura da saúde municipal está delineada na proposta de hierarquização do sistema de atendimento ao paciente, nos três níveis de atenção. Isto é: primário, secundário e terciário. Pela figura 113 é possível visualizar a distribuição dos serviços ao nível primário no contexto da cidade e ainda enxergar a definição dos territórios de abrangência dos serviços das Unidades Básicas de Saúde (UBS). 
Segundo o Plano Municipal de Saúde 2008/2011, as UBSs instaladas (em aproximadamente 54 unidades) procuram cobrir os "territórios" de abrangência, compreendendo aproximadamente 8000 habitantes, devendo exercer o papel de "porta de entrada" ao sistema de saúde. Porém, por inúmeras razões, entre elas a precariedade das suas instalações físicas, indisponibilidade de pessoal técnico qualificado, pouca flexibilidade de horário ao atendimento à população, baixa resolutividade do serviço, pequena oferta de equipamentos de diagnóstico básico e tecnologia em geral, entre outras, isto não ocorre. Este panorama condiciona a população a transpor esta etapa inicial no processo de atendimento, a qual procura diretamente os serviços secundários e/ou até terciários, provocando a desarticulação do sistema proposto. Este perfil do serviço pode ser colocado quase como um padrão de ocorrência na grande maioria das cidades brasileiras.

Ao nível terciário, a cidade de Londrina, ao longo dos seus 75 anos de existência, possui três grandes hospitais, sendo que um deles faz parte deste estudo mais detalhado. (Figura 114). 






Pelas suas características no que se refere ao porte, ao atendimento eminentemente SUS, à capacidade de leitos ofertada, à capacitação elevada de sua equipe técnica, o tratamento em todas as especialidades médicas, entre outras especificidades, o referido hospital exerce o seu papel como hospital regional que abrange o norte do Paraná, sul de São Paulo, Mato Grosso do Sul etc. (Fig. 115).

Figura 115 - Hospital Universitário Regional Norte do Paraná, HU - vista aérea.

(Fonte: Google Earth, 2010)

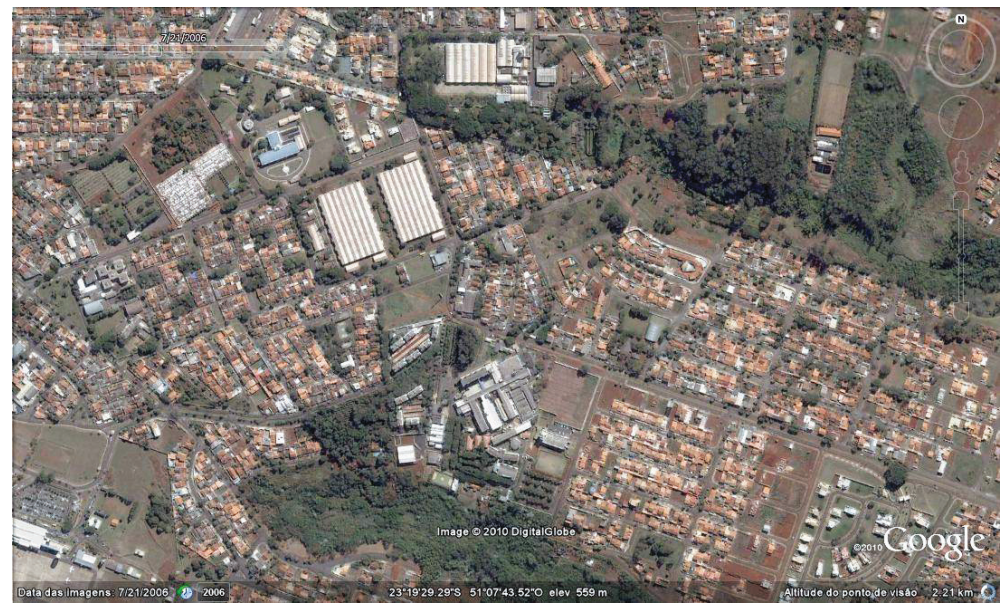

Com as características abordadas acima, o hospital em estudo faz parte do sistema hierarquizado de saúde ao nível terciário e com atendimento em média e alta complexidade.

As análises sobre o município de Londrina, pode se colocar que esta unidade hospitalar, pelas deficiências do sistema básico de atendimento à saúde, absorve grande parte dos serviços de menor complexidade, o que lhe acarreta a superlotação no serviço, descontrole funcional e operacional, geração do estresse de todos os usuários etc.

Esta unidade hospitalar possui hoje aproximadamente $32.500,00 \mathrm{~m}^{2}$ de área construída, cuja capacidade de leitos está assim distribuída:

- unidade de Internação adulto feminina com 47 leitos;

- unidade de Internação adulto masculina com 68 leitos;

- pediatria com 34 leitos;

- gineco-obstetrícia com 19 leitos;

- moléstias infectocontagiosas com 30 leitos;

- unidade de Queimados com 16 leitos;

- unidade de Tisiologia com 23 leitos

- total 226 leitos. 
Possui ainda Unidades de Terapia Intensiva com o total de 39 leitos, assim distribuídas:

- UTI geral com 10 leitos;

- UTI geral com o7 leitos (pacientes potencialmente contaminados);

- UTI Pediátrica com 05 leitos;

- UTI Neonatológica com 17 leitos.

A Universidade Estadual de Londrina criou o curso de medicina a partir de 1967, fato que precipitou a necessidade de possuir um hospital escola de porte, o que nos primeiros anos foi suprida por convênios com entidades locais. A partir de 1975, a UEL por meio do governo do Estado do Paraná, obteve a condição de ocupar o antigo Sanatório Noel Nutels de Tuberculosos, implantado na região leste da cidade.

Este edifício, construído em meados dos anos 1950, além da sua estrutura física já sucateada, possuía ainda uma distribuição funcional bastante inadequada para atender as necessidades de um hospital escola.

Com esta realidade dos fatos, o hospital sofreu ao longo destes 35 anos, uma série de adequações, transformações e ampliações para torná-lo viável ao desenvolvimento das suas atividades assistenciais, acadêmicas e de investigações científicas.

Unidade de Urgência e Emergência, desde seu início de implantação junto ao complexo hospitalar, foi colocada em um dos extremos do edifício para que houvesse a condição de um acesso independente ao

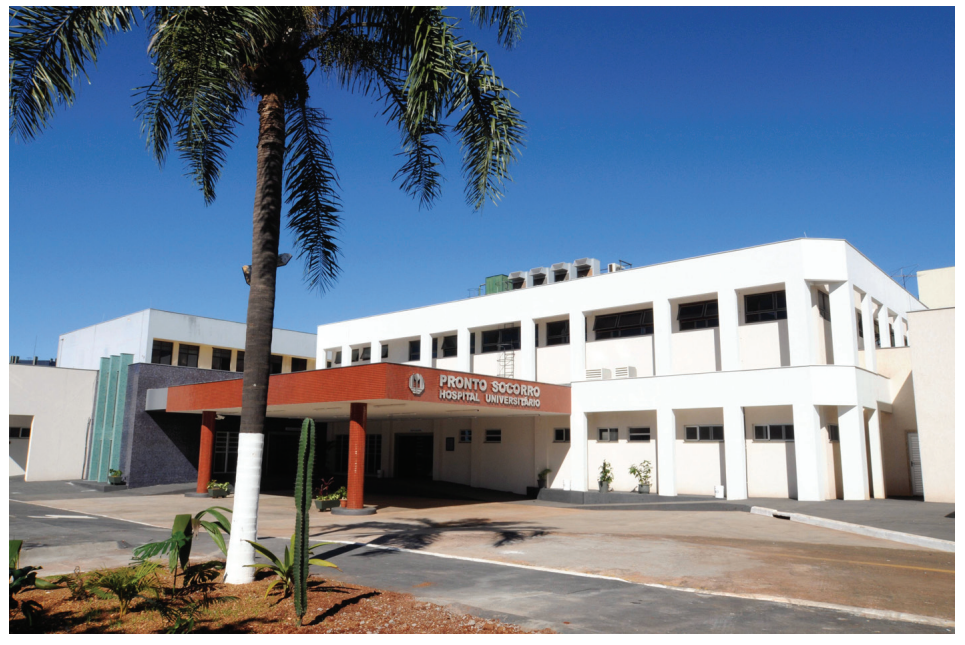
seu serviço. (Fig. 116). Esta unidade foi recentemente reformada e ampliada e hoje possui uma área total de aproximadamente Figura 117 - Hospital Universitário Regional Norte do $2.460,00 \mathrm{~m}^{2}$. (Fig. 117). Paraná, HU - vista externa.

Fonte: foto do autor, 2010 
6.I.2 A unidade hospitalar no contexto urbano e sua inserção no sistema de saúde

Como já apresentado, o Hospital Universitário teve sua implantação a partir de 1975, na região leste da cidade de Londrina, região esta que naquele momento possuía baixa densidade populacional.

Com a mudança do perfil do atendimento e com confluência de inúmeros profissionais e estudantes ao hospital, as características do lugar transformaram-se ao longo deste período. Hoje a densidade demográfica na região é bastante elevada, onde vários tipos de comércio e serviços se instalaram no seu entorno. Além disso, inúmeros projetos imobiliários surgiram para a região, o que fez com que se tornasse referência urbana.

Com a necessidade de crescimento dos serviços a serem ofertados, avanços tecnológicos, adequação a legislação vigente, maior oferta de leitos para atender à demanda pelo crescimento populacional da cidade e região, novas necessidades acadêmicas e laboratórios de pesquisa, o referido hospital teve, ao longo de sua historia, os seus momentos de crescimento físico. (Fig. 118).

\section{I.3 Implantação e fluxo externos}

Mesmo com as constantes transformações ao longo dos seus 35 anos de existência, a unidade hospitalar mostra, com sua implantação geral, uma organização racionalizada dos seus fluxos de acessos externos que, gradativamente, foram se consolidando. (Fig. 119). 







Neste período, quatro momentos importantes e de grande impacto sobre o planejamento físico do hospital ocorreram: construção e transferência das instalações acadêmicas que anteriormente ocupavam as dependências do próprio hospital e a consolidação do CCS (Centro de Ciências de Saúde), como estrutura acadêmica e de pesquisa; aquisição, em 1996, do terreno ao lado do hospital com área de aproximadamente $35000,00 \mathrm{~m}^{2}$; implantação do novo sistema viário e a conclusão da avenida frontal ao edifício; e cessão de uso dos barracões (2009) do antigo IBC (Instituto Brasileiro do Café), localizado a menos de 100 metros do hospital, com área de aproximadamente 12.000,00 $\mathrm{m}^{2}$, o que possibilitará, em grande parte, a transferência do setor de apoio logístico (almoxarifado, serviços gerais de marcenaria, serralheria, oficinas, manutenção, lavanderia etc.) para o local.

O terreno do hospital é abastecido por uma avenida de fluxo rápido e interligado à malha viária principal do município. As duas laterais do terreno são atendidas por vias locais e parte integrante do sistema viário urbano ao nível do bairro. Na parte posterior à sua entrada principal, a unidade hospitalar possui uma região de APP (Área de Preservação Permanente) de fundo de vale, onde passa o córrego Limoeiro.

Com a configuração do sistema viário, pode-se visualizar mais claramente (Figura 119) a disciplina dos acessos externos, estabelecidos como:

- acesso principal / público em geral;

- acesso à Unidade Urgência / Emergência;

- acesso às Unidades de serviço e apoio logístico;

- acesso às instalações acadêmicas.

A implantação do complexo hospitalar baseia-se também nos afastamentos obrigatórios pela legislação municipal.

Com o impacto e a retirada de área frontal ao terreno para a implantação da avenida, há a preocupação em preservar o recuo frontal da edificação em relação a ela, para que a arquitetura seja melhor absorvida e observada e, com esta medida, há a possibilidade de criar um espaço de transição entre a área efetivamente pública (vias e calçadas) e a área edificada, com áreas de jardins, tornando este percurso mais agradável e acolhedor. Além disso, esta condição estabelece maior identidade ao edifício. 
As áreas de apoio logístico ainda estão em fase de transferência para os antigos barracões do IBC, o que acarretará liberação de novas áreas de terreno e novas possibilidades de ocupação dentro do que foi estabelecido no Plano Diretor de Organização e Expansão Física para o complexo hospitalar.

Atualmente a estrutura física hospitalar está constituída em três níveis de construção e melhor visualizada a partir das figuras 120, 121 e 122. Constam ainda outras construções de menor porte espalhadas no terreno. 








\section{I.4 A Unidade de Urgência e Emergência no contexto do complexo hospitalar.}

A Unidade de Urgência e Emergência posiciona-se na estrutura física hospitalar com acesso independente, através da avenida frontal. Somente junto à unidade é que os fluxos à Urgência e à Emergência se diferenciam para permitir melhor disciplina e organização funcional.

O serviço está integrado ao Centro de Regulação Médica para o correto encaminhamento do paciente, contando com o apoio do SIATE (Serviço Integrado de Atendimento ao Trauma e Emergência) e pelo SAMU (Serviço de Atendimento Médico à Urgência).

A separação do fluxo de atendimento às urgências permite o acesso não somente dos pacientes adultos ambulantes, mas também ao atendimento às parturientes de alto risco, bem como a especialidade pediátrica.

O fluxo/acesso aos pacientes em emergência é para atender pessoas que precisam de atendimento imediato, as quais são vítimas de agressões com armas, acidentes de trânsito, acidentes domésticos e ou naturais, queimaduras, enfartes e AVE (Acidente Vascular Encefálico) entre outros casos que colocam em risco a vida do paciente.

A estrutura organizacional da unidade (macrozoneamento) procura estabelecer a melhor definição dos territórios de ação entre os serviços de urgência e emergência, objetivando atingir melhor atenção dos profissionais envolvidos, correta disciplina de fluxos internos e relações de contiguidade espacial mais adequadas.

Por meio da figura 123, pode-se melhor observar a configuração das áreas de atuação entre, serviço de pediatria; serviço de ginecoobstetrícia; serviço de clínica médica; serviço de clínica cirúrgica; e serviço de trauma/ortopedia.

As áreas de apoio logístico servem aos serviços de forma compartilhada, o que lhes permitem uma utilização de forma mais racionalizada no que se refere à duplicação de área física, equipamentos e aumento do número de colaboradores técnicoadministrativos. 
Contígua à Unidade de Urgência e Emergência, a estrutura hospitalar contempla o Centro de Diagnóstico por Imagem, o qual oferece maior rapidez no transporte do paciente, agilidade nos resultados dos exames e resolutividade ao sistema. Esta unidade contempla:

- Radiologia

- Tomografia

- Ultrassonografia

- Registros fisiopatológicos (métodos gráficos)

| Eletrocardiografia

| Eletroencefalografia

| Eletromiografia

- Serviço de hemodinâmica (emergência em dor torácica)

- Serviço de litotripsia.

As três outras unidades localizadas no pavimento superior e de grande importância na relação direta ao serviço de Urgência e Emergência são o Centro Cirúrgico, Centro Obstétrico e Unidades de Terapia Intensiva, onde estas se integram à estrutura física através das circulações horizontais e verticais (corredores, rampa, escadas e elevadores para transporte de leitos).

Com a configuração e a predominância horizontal na organização física, a estrutura de apoio logístico distancia-se da unidade em estudo. Este abastecimento é realizado através de longo corredor de serviço que serve de eixo estruturador do complexo hospitalar, promovendo a independência de fluxo necessária para a razoável funcionalidade exigida. 




\section{I.5 Estrutura física instalada.}

A Unidade de Urgência e Emergência procura cumprir seu papel dentro do sistema hierarquizado de saúde municipal e/ ou regional, como, por exemplo, o atendimento efetivamente de Urgência e Emergência para casos de alta complexidade.

A composição física atual, com área de aproximadamente $2.460,00 \mathrm{~m}^{2}$, é resultante da última intervenção de reforma e ampliação das áreas, ocorrida há aproximadamente dois anos atrás, sob a vigência da RDC50 - ANVISA / Ministério da Saúde.

Em termos de área física, esta unidade representa 7,57\% da área total construída. Esta composição física está assim distribuída:

I) Atendimento de Emergência:

- marquise (embarque e desembarque de pacientes);

- recepção;

- espera com sanitários/PNE;

- sala para guarda de macas e cadeiras de rodas;

- sala de emergência com 03 boxes (Figura 124);

- sala de medicação;

- sala de curativos (procedimento contaminado);

- sala gesso/consultório ortopedia e trauma;

- posto de enfermagem/serviço e prescrição médica.

Figura 124 - Sala de emergência (Fonte: foto do autor)

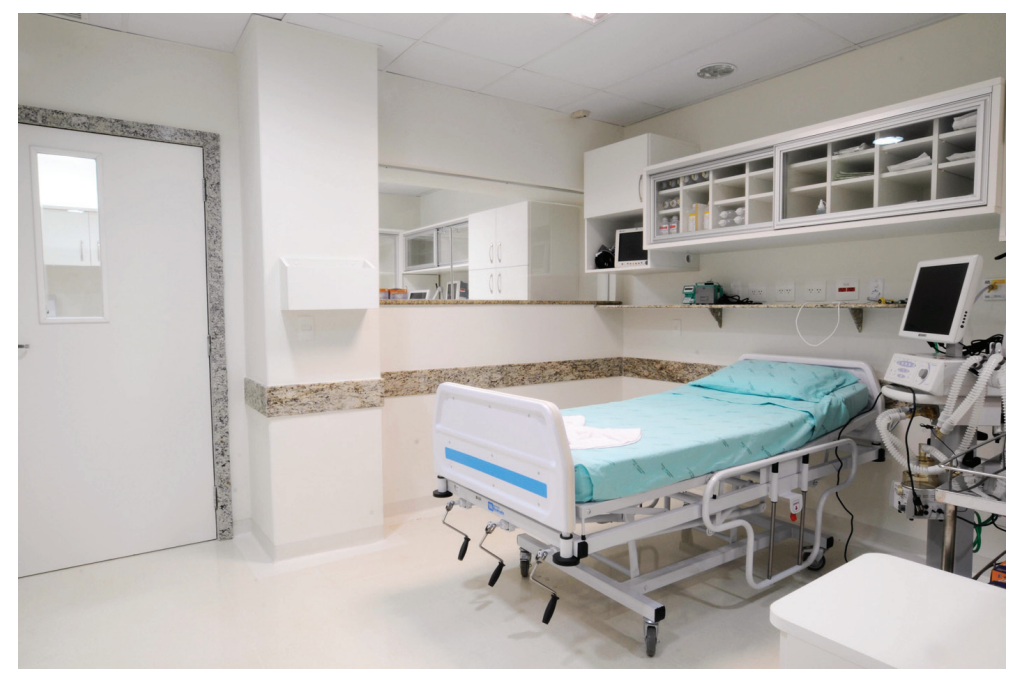


II) Atendimento de Urgência:

- marquise (embarque e desembarque de pacientes);

- recepção (Figura 125);

- espera adulto com sanitários/PNE (Figura 125);

- sala de espera pediatria;

- sala de triagem (gerenciamento de risco);

- sala de guarda de macas e cadeiras de rodas;

- fraldário.

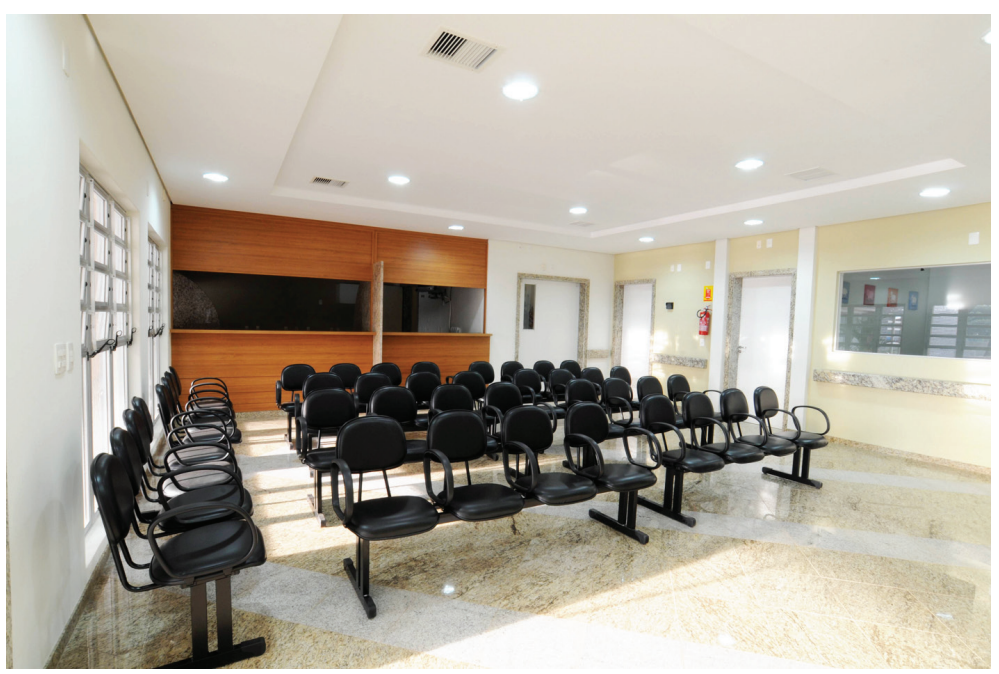

Figura 125 - Recepção e espera adultos

(Fonte: foto do autor)

- Área de atendimento pediátrico:

| consultórios;

| sala para tratamento e reidratação oral;

| sala de emergência pediátrica;

| sala de procedimentos em pediatria;

| sala de higienização dos pacientes;

| posto de enfermagem / serviço e prescrição médica (Figura 126);

| sala de nebulização pediátrica;

| vestiário para os pais;

| estar e copa para os pais. 
Figura 126 - Posto de enfermagem (observação e repouso)

(Fonte: foto do autor)

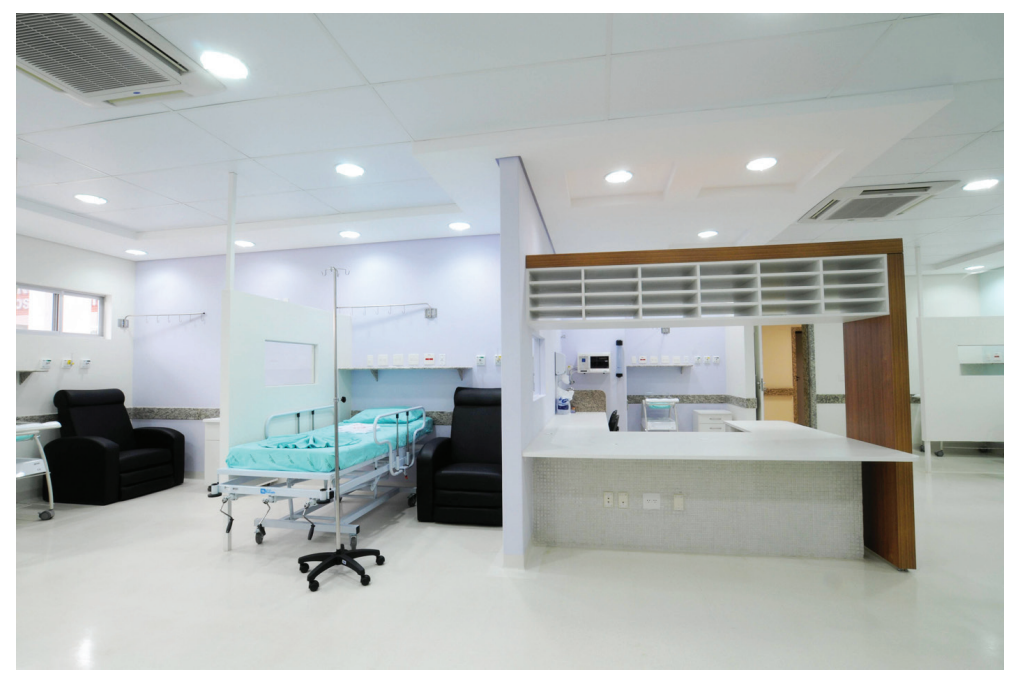

- Área de atendimento gineco-obstetrícia:

| consultórios;

| posto de enfermagem / serviço e prescrição médica;

| sala de exames ultrassonografia;

| sala para higienização das parturientes.

- Área de ortopedia e trauma (clínica médica e cirúrgica);

| consultórios;

| esperas intermediárias;

| posto de enfermagem / serviço e prescrição médica.

III) Área de observação e repouso:

- enfermaria para observação pediátrica com 12 leitos (Fig. 127);

- enfermaria para Gineco-obstetrícia com 6 leitos (Fig. 128);

- enfermaria para observação adulto masculino com 16 leitos e o1 leito de isolamento (Fig. 129);

- enfermaria para observação adulto feminina com 10 leitos e o1 leito de isolamento. 

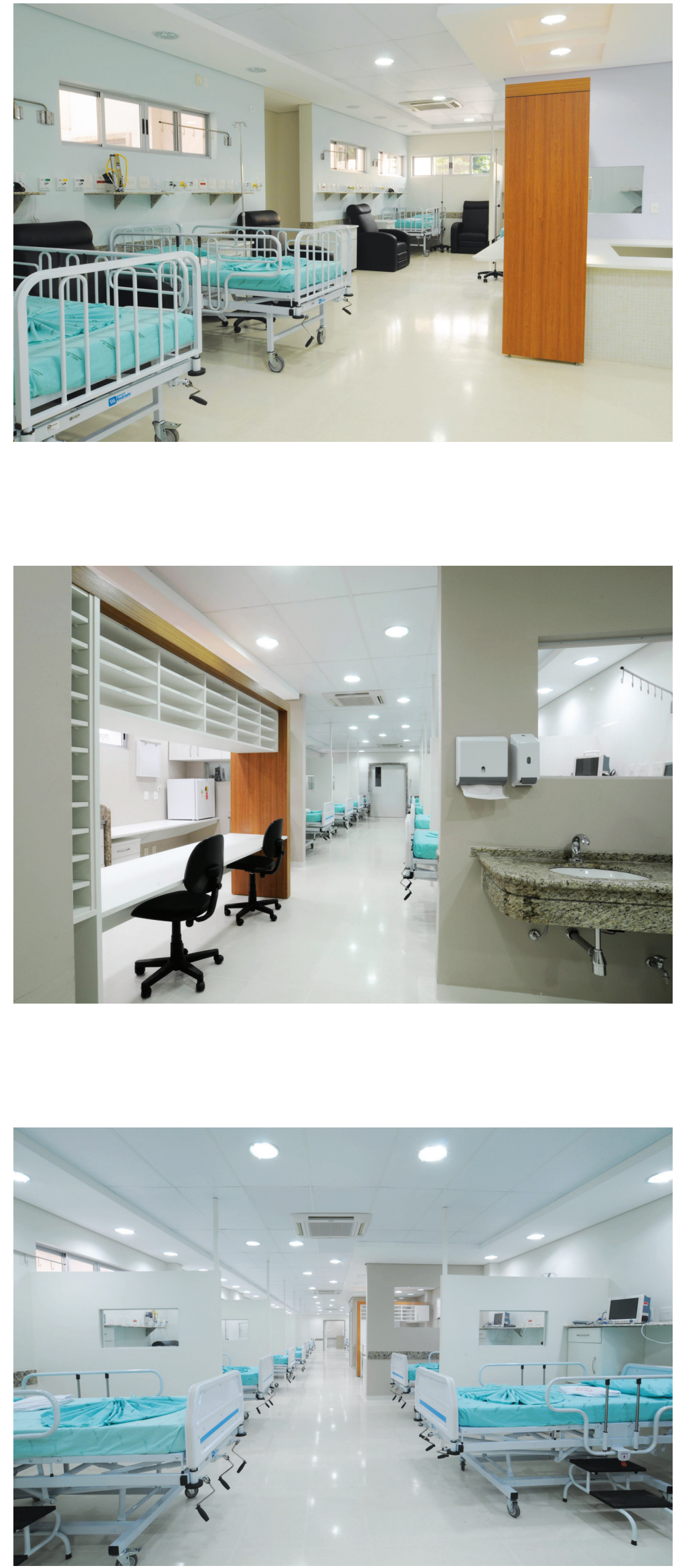

Figura 127 - Sala de observação e repouso pediatria

(Fonte: foto do autor)

Figura 128 - Sala de observação e repouso gineco-obstetrícia

(Fonte: foto do autor)
Figura 129 - Sala de observação e repouso adultos

(Fonte: foto do autor) 
IV) Área de uso comum e compartilhado:

- salas administrativas;

- farmácia satélite;

- DMMH - Depósito de Material Médico - Hospitalar;

- copa para pacientes;

- copa pessoal técnico-administrativo;

- sala equipamentos;

- rouparia (limpa);

- sala para guarda de roupa suja e resíduos;

- expurgo / sala de utilidades;

- DML - Depósito de Material de Limpeza;

- sanitários para funcionários;

- estar para funcionários;

- quartos para plantonistas (pavimento superior).

V) Área de apoio acadêmico:

- salas de discussão de casos.

VI) Área de apoio diagnóstico:

- laboratório de urgência.

\subsubsection{Conformidade}

Ao analisar a Unidade de Urgência e Emergência é simples observar que quanto às questões relacionadas à legislação urbana e segurança do edifício, esta atende a forma satisfatória.

Quanto às questões relacionadas à Vigilância Sanitária, a unidade atende às normas quanto a sua organização funcional. Porém, em função do seu volume de atendimento, grupo operacional em número elevado, atividades relacionadas à academia, residência médica, entre outras atividades, os espaços necessitam, em alguns casos, de maiores dimensões e serem em maior número. Em consequência disto, alguns espaços tornamse insuficientes para o desenvolvimento da atividade que lhe é pertinente. Na maioria dos casos, os espaços mais prejudicados por esta questão são os ambientes de apoio logístico.

Ao longo destes 35 anos de ocupação, a Unidade de Urgência e Emergência sofreu três intervenções mais significativas de 
reforma e ampliação, sendo que a última, a cerca de dois anos, foi de maior expressividade.

Estas intervenções procuraram adequar-se às normas da ANVISA / MS, sendo que a primeira delas, em 1979, fora para atender à Portaria 400 / MS. Passou ainda pelas exigências da Portaria 1884 / 94, quando a unidade sofreu sua segunda grande reforma interna.

Em sua última intervenção de reforma e ampliação, na análise de conformidade, passou pelo olhar da RDC 50/ANVISA. Esta proposta de modificações dos espaços bem como de aumento de área física gerou, inicialmente, um projeto para a unidade, de aproximadamente $3500,00 \mathrm{~m}^{2}$, o qual se delineava nas condições ideais para a unidade. Porém, em função da carência de recursos financeiros naquele momento, decidiu-se por equacionar o projeto em duas fases para sua implantação, ficando, assim, como primeira fase um total de área de aproximadamente $2500,00 \mathrm{~m}^{2}$.

\section{I.7 Relação de Contiguidade e Fluxos Internos}

A contiguidade entre espaços se dá em dois níveis diferentes, sendo o primeiro ao nível macro, isto é: na abrangência da unidade em foco e sua relação com as demais unidades que compõem o complexo hospitalar.

O segundo nível se estabelece apenas na linha limítrofe da própria Unidade de Urgência e Emergência. Suas relações de proximidade se estabelecem entre os espaços que compõem a própria unidade.

Pode-se analisar o objeto de estudo ao seu primeiro nível de contiguidade (Figura 130) por meio da proximidade com outras unidades de apoio ao diagnóstico e tratamento, como garantia de suporte e bom desempenho das atividades profissionais. Esta relação se estabelece com as unidades do Centro Cirúrgico, Obstétrico, Centro de Diagnóstico por Imagem, Unidades de Terapia Intensiva, entre outras.

A estrutura do Centro de Diagnóstico por Imagem é composta pela oferta de exames em Radiologia, Tomografia, 


Métodos Gráficos (EEG, ECG, Ecocardiografia, Holter, Mapa, Eletromiografia etc.) e ainda hemodinâmica.

O laboratório de urgência em patologia clínica opera por 24 horas e é parte integrante do corpo da unidade que lhe confere a agilidade, segurança e resolutividade na liberação dos resultados dos exames.

A Unidade de Urgência e Emergência se interliga com as Unidades de Terapia Intensiva, Centro Cirúrgico, Centro Obstétrico e Unidades de Internação, na sua maioria instalada no segundo pavimento, com rampas e elevadores em dimensões para transporte de leitos e macas.

O apoio logístico comunica-se com a unidade através do grande eixo horizontal de serviço, que a abastece com produtos e serviços (almoxarifado, farmácia, lavanderia e nutrição), bem como o acesso do grupo de pessoal interno, saída de resíduos e, ainda, pacientes em óbito encaminhados ao morgue.

No âmbito da Unidade de Urgência e Emergência suas relações de contiguidade se estabelecem a partir da compreensão de como ela se organiza. A sua estrutura física está composta em sete núcleos, conforme distribuição abaixo:

- atendimento em gineco-obstetrícia;

- atendimento em pediatria;

- atendimento clínica médica;

- atendimento clínica cirúrgica;

- atendimento ortopedia e traumatologia;

- estrutura de apoio logístico e enfermagem;

- áreas de observação e repouso.

Percebe-se que a tomada de decisão no lançamento da proposta projetual teve como objetivo a melhor definição dos territórios de ocupação, não somente pela separação e características dos pacientes, mas também pela definição dos grupos de trabalho.

Os núcleos se compõem de forma quase que autônomas, compreendendo os serviços imediatos, os quais são de fundamental importância para o bom desempenho operacional. Estes serviços são: posto de enfermagem, serviço, de prescrição médica, higienização e alguns procedimentos mais específicos. Por outro lado, toda a estrutura de apoio logístico como: depósitos, rouparia, copas, vestiários, sanitários, entre outros ambientes são de uso compartilhado. 
A área destinada às enfermarias para observação e repouso dos pacientes de clínica médica-cirúrgica, ortopedia e traumatologia está posicionada mais na retaguarda da unidade, para que no último estágio do atendimento seja tomada a decisão sobre o encaminhamento do paciente para as Unidades de Internação, Centro Cirúrgico, Unidade de Terapia Intensiva, morgue, ou simplesmente ao seu retorno para casa.

As áreas de observação dos médicos de pediatria e ginecoobstetrícia estão acopladas ao próprio serviço de atendimento.

O tempo de permanência destes pacientes nas enfermarias está previsto para até 24 horas. Porém, este tempo em muitos casos, é dilatado pelo fato de não haver a disponibilidade de leitos, tanto nas Unidades de Internação, como nas Unidades de Terapia Intensiva.

Outro fator importante que intervém neste processo é que, por se tratar de um hospital-escola, em alguns casos há a importância acadêmica na sua análise e discussão sobre o caso, provocando o retardamento de transferência deste paciente, tendo em vista a compatibilização com os horários de docentes, internos e residentes.

Neste quadro ainda se incorpora à interdisciplinaridade que envolve outros profissionais, como enfermeiros, psicólogos, assistente social, farmacêutico, nutricionistas etc., o que provoca também o retardamento ainda maior.

O conjunto de espaços destinado ao repouso dos plantonistas (docentes, internos e residentes) está locado no pavimento superior às enfermarias de observação e repouso dos pacientes adultos, o que vem a facilitar o seu deslocamento para a realização e supervisão dos procedimentos junto aos pacientes.

\subsubsection{Acessibilidade}

A Unidade de Urgência e Emergência está implantada em apenas um nível, no pavimento térreo, o que facilita em muito o deslocamento e acesso de pacientes portadores de necessidades especiais, idosos, gestantes e ainda aqueles que são transportados em macas ou cadeiras de rodas.

Não somente para atender as exigências da NBR 9050, que trata sobre a acessibilidade, mas e, principalmente, para garantir 
o conforto e segurança aos pacientes que nesta unidade de estudo, na maioria das vezes, estão debilitados fisicamente. Para isto, a unidade está contemplada com alguns sanitários em dimensões adequadas para o acesso de cadeirante, oferta de barras de apoio junto às peças sanitárias e boxes de chuveiros.

A acessibilidade apresenta-se também na área coberta de embarque e desembarque de pacientes, com a facilidade de remoção de macas das ambulâncias e os cadeirantes no transporte para o interior da unidade.

\subsubsection{Flexibilidade / Expansibilidade}

A unidade apresenta-se com pouca flexibilidade espacial, isto porque na opção construtiva em estrutura de concreto armado e fechamentos em alvenaria de tijolos obteve-se uma estrutura bastante enrijecida. Observa-se ainda, que em suas fases de crescimento espacial, não houve na proposta estrutural uma modulação adequada e necessária para permitir uma maior flexibilidade quando nas necessidades de mudança do espaço.

Para atender o surgimento de novos serviços e adequações às novas normas da Vigilância Sanitária, entre outros fatores, a unidade deveria ter optado por soluções de fechamento de remoção facilitada, tecnologia mais limpa e agilidade executiva na reconstituição do novo espaço.

A oferta de forro rebaixado, construído em estrutura de perfis de alumínio e placas de PVC removíveis, na grande maioria dos ambientes, possibilitou ofertar uma melhor manutenção em toda a infraestrutura predial (elétrica, telefonia, lógica, água, gases etc.). Fator que facilita o direcionamento das instalações, à medida que haja a necessidade de se reformular os espaços. Não há shafts no plano vertical, apenas armários que abrigam quadros de energias.

A expansibilidade do serviço está garantida no sentido leste do terreno, sendo esta quase que sua única opção, tendo em vista que nas demais orientações a unidade está limitada pelas construções existentes e adjacentes a ela e, na frente do lote, limitada pela legislação urbana municipal, com respeito ao recuo frontal do lote. 


\section{I.10 Tecnologia ofertada.}

A Unidade de Urgência e Emergência possui a estrutura básica para o seu bom funcionamento e, principalmente, por meio dela ofertar segurança e conforto aos usuários deste serviço.

Esta tecnologia está assim distribuída:

- água fria e quente;

- eletricidade;

- telefonia/lógica (sistema integrado de informações);

- prevenção de incêndio, por meio de sistema de hidrantes e extintores;

- sistema de proteção contra descargas elétricas;

- sistema de aterramento de aparelhos;

- sistema gases medicinais, como: ar comprimido, oxigênio, vácuo e protóxido de azoto;

- sistema de comunicação;

- sistema de alarme;

- sistema de segurança, por meio de circuito interno de câmeras de TV;

- sistema de som;

- sistema de exaustão e ventilação mecânica.

\section{I.II Sustentabilidade.}

A unidade, dentro dos padrões e preocupações atuais na tomada de medidas que promovem o uso racional no consumo de energias, não possui um programa muito extenso.

Nas áreas de conforto térmico e acústico e iluminação natural, a unidade possui razoáveis condições de garantir a sustentabilidade à arquitetura proposta. Porém, seus recursos são limitadíssimos.

Em programas que extrapolam o campo da arquitetura, mas que se apoiam nela, como garantia do espaço adequado à sua função, encontra-se o gerenciamento de resíduos produzidos junto à Unidade. Este programa baseia-se na RDC no 306 / ANVISA - MS e hoje encontra-se bastante consolidado. O PGRSS (Plano de Gerenciamento de Resíduos dos Serviços de Saúde) estabelece a classificação e coleta dos resíduos desde sua origem. A separação ocorre para os resíduos com a classificação 
em reciclável, orgânico, infectante / perfuro-cortante e químico, entre outros.

\section{I.12 Conforto térmico e acústico}

A Unidade de Urgência e Emergência está localizada sob a orientação solar, próximo ao eixo Norte / Sul.

Neste sentido, a unidade se expõe para as faces leste e norte, já que ao sul e a oeste existem unidades adjacentes construídas. Mesmo nas faces de maior exposição, elas não possuem elementos de proteção solar, como brise-soleil, por exemplo, para minimizar a incidência direta dos raios de sol no ambiente.

Em alguns ambientes, isto tem provocado a busca de soluções paliativas, como o uso de persianas, nem sempre recomendáveis pela sua manutenção e higiene.

Mais porcondições de conforto térmico, do que por necessidade de assepsia e controle de umidade relativa do ar, a unidade dispõe de um sistema de ar condicionado e/ou exaustão em quase todos os ambientes disponíveis, até mesmo pela grande quantidade de espaços sem qualquer contato externo.

O sistema instalado é o multi-split, com a utilização de consoletes no teto e outros de parede. As condensadoras estão colocadas nas áreas externas do edifício. Neste sistema há a garantia de um controle de temperatura por ambiente em que se produz baixos níveis de ruído.

A proximidade da Unidade de Urgência e Emergência com a avenida frontal, caracterizada por alto tráfego, tem provocado principalmente para os núcleos de gineco-obstetrícia e pediatria alto índice de propagação de som, o que promove a instabilidade e desconforto aos pacientes e equipe de trabalho.

O uso do sistema de ar condicionado e exaustão em grande parte dos ambientes justifica-se pela exiguidade de terreno disponível para a unidade, limitações de áreas para construção em função dos recursos financeiros disponíveis, programa de necessidades bastante extenso, e em respeito a relação de contiguidade interna à unidade, induziram a uma proposta arquitetônica bastante compacta.

Alguns destes ambientes que ocupam a face periférica do edifício, bem como aqueles voltados aos jardins internos / poços 
de luz, possuem condições de aberturas de janelas para garantir a iluminação e a ventilação natural.

Para este caso, pode-se observar que os espaços de observação e repouso foram priorizados. Isto lhes garante melhor condição de aeração e salubridade. A total eficiência do sistema de ventilação natural fica prejudicada, pois a maioria dos espaços, com raras exceções, não possibilita o cruzamento do ar, por possuir aberturas em apenas umas das faces do ambiente.

A permanência da abertura das portas dos ambientes não se viabiliza pela razão de se garantir o isolamento do serviço, privacidade nos procedimentos, assepsia, redução dos níveis de ruídos externos, entre outros fatores. Estas considerações não promovem a circulação e a renovação do ar natural.

\section{I.13 Iluminação natural e artificial}

Pelo fato de apenas aproximadamente $43 \%$ dos espaços ofertados possuírem aberturas para o exterior, a Unidade de Urgência e Emergência tem uma baixa condição na oferta de iluminação natural. Para o restante, a incidência solar e aeração permanente são de fundamental importância para a boa salubridade do ambiente, permitindo aos usuários a noção de tempo durante sua permanência no local.

Observa-se que, em muitos casos, por decorrência da utilização das paredes que possuem aberturas para o exterior, por mobiliário e equipamentos que necessitam de instalações das mais variadas, estas aberturas ficam limitadas pelos peitoris elevados e na colocação das aberturas junto ao forro. Do ponto de vista do percurso pelas instalações isto se dá com facilidade, porém do ponto de vista de boa iluminação e ventilação natural, esta solução torna-se bastante prejudicial.

Situações como estas direcionam para elevar a necessidade de complementação da luminosidade exigida para cada ambiente, dentro da sua especificidade de uso.

Nas salas de emergência, procedimentos e suturas são comuns à utilização de focos de iluminação auxiliar e até, em alguns casos, os focos fixos com lâmpadas sialíticas.

$\mathrm{Na}$ grande maioria dos espaços, encontra-se a iluminação artificial com luminárias de lâmpadas fluorescentes, não somente 
pelo fator econômico no consumo de energia, mas também pela sua fácil manutenção.

\section{I.14 Humanização}

A arquitetura procura, neste caso, complementar o processo de humanização no atendimento ao paciente, promovido pelo pessoal médico e enfermagem.

Dentro da rigidez que a composição dos espaços da Unidade de Urgência e Emergência impõe, a arquitetura demonstra preocupações e tenta se apropriar de recursos na tentativa de minimizar o sentido de clausura e confinamento.

Neste aspecto, duas condutas tornam-se claras no sentido de conduzir para um melhor resultado na qualidade final do espaço. A primeira foi a utilização de cores suaves e claras, as quais proporcionaram maior amplitude ao ambiente e uma sensação mais positiva para o seu uso. A segunda foi a criação de algumas áreas de jardim entre os blocos, o que permitiu maior luminosidade e aeração aos ambientes, promovendo maior permeabilidade visual e conforto.

Outro fator de relevante importância no sentido de humanizar os espaços foi a determinante separação dos fluxos de pacientes ambulantes e os pacientes em estado grave. Esta cena, em muitos casos, pelas condições em que chegam os pacientes politraumatizados, acidentados, enfartados, vítimas de armas etc., tem provocado total desestabilização nas demais pessoas que estão no aguardo do seu atendimento.

Além disto, outro fator a ser considerado é a separação das áreas de espera entre adultos e crianças. Com o seu espaço definido e tratamento adequado por profissionais qualificados para esta especialidade médica, tende-se a obter melhores resultados e, principalmente, poupa-se os pequenos enfermos de cenas tão desagradáveis.

Como já exposto anteriormente, nas áreas de maior permanência do paciente, como as enfermarias para observação e repouso, são ofertadas as aberturas para o exterior no sentido de lhes permitir a real noção de tempo e clima.

As esperas intermediárias, mais internas ao serviço, não possuem este recurso, por outro lado, apropriam-se de recursos 
tecnológicos, como a instalação de TVs com programação amena, como forma de distração e para minimizar tensões.

\subsection{Unidade de Urgência e Emergência (Niagara Health System)}

\subsection{Introdução}

O objetivo de colocar como estudo de casos a proposta de Unidade de Urgência e Emergência fora do Brasil foi não somente comparar sua estrutura física-funcional com os exemplos brasileiros, mas também porque esta unidade está em fase de implantação e acredita-se ser o que há de mais atual na concepção teórica / construtiva do edifício hospitalar.

Este trabalho foi elaborado pela empresa americana/canadense Cannon Design, com vários escritórios instalados em cidades nos dois países (Baltimore, Boston, Buffalo, Chicago, Jacksonville, Los Angeles, New York, St. Louis, Toronto, Vancouver e Washington), e que ao longo de sua trajetória de produção já desenvolveu mais de 100 milhões de metros quadrados em projetos, somente na área de saúde. Esta produção não se restringiu apenas às solicitações nesta área de abrangência entre os dois países, mas também atuou em outras propostas espalhadas pelo mundo.

\subsubsection{0 papel da Empresa Cannon Design}

A contratação da mencionada empresa para o desenvolvimento dos trabalhos relativos ao Niagara Health System foi mediante licitação pública, na qual a partir de propostas apresentadas fora escolhida como a vencedora.

Sendo o Canadá um país que oferece a sua população o serviço de saúde totalmente público, a proposta, neste caso, é baseada na parceria público/privado.

Coube à Empresa Cannon Design, a partir das diretrizes políticas/sociais do governo canadense, desenvolver a proposta de negócios ou a proposta de viabilidade técnica/econômica para o empreendimento. 
A proposta do NHS (Niagara Health System) se estabelece na compreensão e atuação de uma rede de hospitais (seis) que atende a região de Toronto/Ontário - Canadá. Esta proposta regionalizada visa à assistência em caráter geral, porém, em algumas especialidades médicas (Cardiologia, Maternidade, Oncologia, entre outras) serão referência para o serviço, minimizando custos e recursos humanos.

O material fornecido pela Cannon Design, e aqui descrito e analisado, compreende apenas esta primeira fase do projeto ou Master Plan de proposta macrorregional. Este trabalho foi concluído pela empresa em agosto de 2007, com o objetivo de que, em seguida, houvesse a contratação das empresas de arquitetura e engenharia para o desenvolvimento dos projetos específicos e sua aprovação junto aos órgãos públicos.

\subsubsection{Localização do empreendimento}

A proposta de implantação da unidade hospitalar está localizada na cidade de St. Catherine, Estado de Ontário, distante $50 \mathrm{~km}$ de Toronto e a $20 \mathrm{~km}$ da fronteira com os Estados Unidos.

Esta cidade possui aproximadamente 132.000 habitantes e conta na sua área metropolitana com um número de 400.000 habitantes.

A proposta apresentada para o Niagara Health System é a construção do complexo hospitalar com área em torno de 90.000 $\mathrm{m}^{2}$, com capacidade para 400 leitos, investimentos na ordem de U\$ 300 milhões e ainda a previsão de obras para 36 meses, obras estas iniciadas em 2009.

\subsubsection{Niagara Health System}

O material apresentado a seguir é visto como um trabalho ainda não concluído, tendo em vista que a análise feita foi realizada sobre o material correspondente à primeira fase da proposta macrorregional do Niagara Health System. Com isto, o propósito é obter os projetos desenvolvidos, com maior número de detalhes das unidades que compõem o complexo hospitalar, mais especificamente a Unidade de Urgência e Emergência, para 
que efetivamente possa ser feita uma análise mais profunda e pormenorizada da unidade em foco.

\subsubsection{Memorial Explicativo sobre o Plano de Negócio - Niagara Health System}

\section{Considerações iniciais}

Durante todo o período de desenvolvimento dos trabalhos, ocorreram muitas reuniões com a equipe de governo para se chegar nesta proposta, ainda esquemática para o Niagara Health System, a ser construído na cidade de St. Catherine. Este trabalho visa a compreensão do sistema de saúde, estabelecido por 05 outros hospitais, que prestarão serviço de assistência em algumas especialidades médicas de abrangência regional.

Após exaustivo trabalho de entendimento junto com o serviço governamental de saúde de Ontário (MOHLTC - Ministry of Health and Long Term Care) e a equipe (PDC - Planning, Design and Compliance), um grande número de propostas esquemáticas foram modificadas e refinadas, para se chegar a um único "croqui esquemático", apresentado aqui neste documento.

O croqui esquemático apresentado pelo RFP (Request for proposal) oferece o discernimento sobre as colocações iniciais e dados fornecidos pelos participantes envolvidos na discussão sobre o Niagara Health System. O resultado apresentado não reflete exatamente todas as solicitações contidas no documento escrito final. Ele não representa um esquema ideal, porém, a equipe proponente chegou a um consenso sobre a concepção macrorregional da proposta.

\section{Crítica ao Croqui Esquemático apresentado}

\section{Implantação Geral - Master Plan}

Ainda na fase de desenvolvimento dos trabalhos, a RTP (Regional Traffic Planning) solicitou a transferência da entrada pela Fourth Avenue mais a oeste do terreno. Esta relocação impacta é de forma mais significativa na área mais ao norte do 
edifício, principalmente na área de embarque e desembarque e o estacionamento do Serviço de Saúde Mental (Figura 131).

A locação das entradas de acesso ao complexo hospitalar, área de embarque e desembarque de pacientes, lagos existentes, estacionamentos para veículos poderão inibir oportunidades para expansões futuras.

Foi solicitada a revisão sobre a proporção estabelecida para o edifício e sua ocupação no terreno. Isto porque poderia garantir melhores condições na disponibilidade de áreas para expansão futura.

Expansão futura para as Unidades de Internação poderá ocorrer sobre o bloco de saúde mental, embora seja possível haver soluções mais simples e de menor impacto em qualquer outro local do edifício.

A capacidade de área destinada ao subsolo está limitada ao seu programa de necessidades. Como tal, a área disponibilizada neste nível é significantemente menor que a projeção do pavimento térreo.

Porém, algumas áreas no subsolo ficarão disponibilizadas para crescimento futuro. Expansão de serviços como almoxarifado e central de esterilização de material poderá ocorrer nas áreas que são disponibilizadas neste primeiro momento.

Algumasligações opcionais, em direção a oeste do terreno, estão indicadas no croqui esquemático para o edifício. Disponibilizar estas ligações é a garantia de qualquer proposta de crescimento nesta direção.

A localização do heliponto na planta de implantação está distante do Serviço de Emergência. Ainda que seja acessível por vias internas, seria aconselhável e de preferência que ela estivesse em uma área mais próxima à unidade. Esta localização foi determinada pelo cone de aproximação de voo. Já o Serviço de Emergência foi localizado, como apresentado no croqui esquemático, próximo à Fourth Avenue e junto à área de maior concentração de acessos rápidos (ambulâncias), o que também prejudicou, a partir do estabelecimento de prioridades, a localização do heliponto mais próximo à entrada da unidade.

O croqui esquemático inclui múltiplas entradas ao edifício no pavimento térreo. Isto pode ser considerado como benéfico ao 
acesso imediato aos diversos serviços médicos ofertados e ainda diminuindo distâncias e percursos.

\section{Circulação no edifício}

O croqui esquemático separa a circulação de público em geral da circulação mais privativa de pacientes, funcionários e serviços, por meio dos eixos e blocos de circulação vertical (subsolo/ serviço, térreo/público e primeiro, segundo e terceiro pavimentos para pacientes internos e funcionários). $\mathrm{O}$ sucesso deste esquema conta com a disciplina do uso dos elevadores (usos específicos) no transporte de pacientes e serviços de apoio logístico e o envolvimento com a circulação maior de público em geral.

A mais significativa solução é encontrada na concentração de elevadores destinados ao transporte de pacientes internos e funcionários junto à área de diagnóstico e tratamento.

Outra alternativa interessante de registro é a solução encontrada para circulações paralelas, tanto no nível térreo como no primeiro pavimento. Isto permitirá a circulação de público em geral, como também de pacientes e funcionários, sem conflitos nestes dois pavimentos de tráfego intenso.

O croqui esquemático mostra a entrada principal no nível térreo (Figura 133), localizada próximo a diversos serviços ambulatoriais encurtando assim percursos pela população. Porém, esta entrada está distante de algumas unidades de pacientes internados (Maternidade, Pediatria e serviços de alta complexidade), a qual requer percorrer longas distâncias pelos visitantes. Reduzir estas distâncias seria considerado como uma evolução bem-vinda ao desenvolvimento do croqui esquemático.

Comentário sobre o Programa

Os programas para a Maternidade, Pediatria, Oncologia e Cardiologia não são considerados apenas para atender a demanda local, mas também para atender o potencial da região que abrangerá o serviço do Niagara Health System. 
O programa regional do NHS (Niagara Health System) aumentaria a área destas unidades, expandindo seus espaços sobre a área de salas de aula.

O programa físico para o edifício prevê vários "soft spaces" (incluindo a área destinada aos serviços administrativos), totalizando uma área de aproximadamente $2.800,00 \mathrm{~m}^{2}$. Ainda que muitos destes espaços flexíveis tenham sido alocados juntos aos serviços de diagnóstico e tratamento, seria interessante disponibilizá-los também junto aos serviços ambulatoriais, tais como: Doenças Crônicas do Rim, Endoscopia, Citoscopia, Oncologia, entre outros.

A localização dos serviços de tecnologia de informação no croqui esquemático poderá ser problemática para as futuras expansões de alguns serviços de diagnóstico e tratamento. Ainda que seja boa para atender suas necessidades, ela possui componentes de difícil remoção e transferência. Sendo assim, seria recomendável a sua locação em área que não venha a interferir no crescimento futuro das unidades de diagnóstico e tratamento.

O serviço de Ortopedia junto à unidade ambulatorial está distante do Centro de Diagnóstico por Imagem. A proximidade entre as duas unidades seria recomendável.

O croqui esquemático busca a inter-relação entre as áreas de jardins com os serviços de Oncologia e Radioterapia, unidades estas alocadas no bloco de serviços ambulatoriais (NRCC Niagara Regional Cancer Centre).

A expansão da unidade de Radioterapia no NRCC (Niagara Regional Cancer Centre) para as salas de exames com o acelerador linear está limitada pelo eixo de circulação principal. Será recomendável alguma alternativa para o crescimento futuro que não venha a obstruir, bem como a desestruturar o principal eixo de circulação.

O serviço de Oncologia (composto pela clínica médica e serviços de internação cirúrgica) está locado no terceiro pavimento nos croquis esquemáticos. Esta localização tem duas considerações: pacientes transferidos do NRCC (Niagara Regional Cancer Centre) necessitam dos dois tipos de circulação (horizontal e vertical). Isto poderá melhorar significativamente se for eliminado qualquer movimento vertical; a necessidade do contato externo foi considerada mediante oferta do espaço do terraço. Porém, este espaço é limitado devido estar no nível 
superior. Isto poderia ser melhorado se esta unidade estivesse no nível térreo e com acesso direto para o exterior.

\section{Proposta alternativa: conectar ou não o Serviço de Saúde Mental}

O croqui esquemático estabelece na sua proposta que o Serviço de Saúde Mental estará posicionado apenas no pavimento térreo do complexo hospitalar. Esta localização foi considerada como de boa resolução pela equipe clínica, atendendo ao modelo desejado.

Como solução alternativa, o Serviço de Saúde Mental poderá ser locado em um edifício separado com alguma conexão física através do eixo principal de circulação. Para esta proposta, o serviço de Saúde Mental necessitará um bloco de um ou dois pavimentos. Ainda com a separação física dos espaços internos e externos, esta alternativa poderá oferecer melhor privacidade e isolamento para os pacientes desta unidade.

A proposta de um bloco exclusivo para o Serviço de Saúde Mental poderá criar potencialmente uma identidade ao edifício. Neste raciocínio, a proposta afeta o desenho do edifício remanescente destinado aos demais serviços: as Unidades de Internação seriam locadas em duas torres, as quais começariam do térreo; os Serviços de Cuidados Críticos (UTIs) necessitam permanecer no mesmo nível do Serviço Cirúrgico/Internação Cirúrgica e Serviços em Cardiologia; a circulação de público em geral necessitaria uma reprogramação no nível térreo para eliminar o contato com os pacientes internos e funcionários (isto pelo fato de que nesta solução as Unidades de Internação estarão agora no pavimento térreo). $\mathrm{O}$ projeto final a ser proposto deverá buscar alternativas, porém garantindo que todas as exigências estabelecidas deverão ser mantidas.

\section{Memorial Descritivo sobre a proposta do croqui esquemático}

\section{Considerações iniciais}

O croqui esquemático será aqui apresentado com este memorial descritivo e ainda com alguns desenhos que possam 
melhor esclarecer sua organização geral da proposta arquitetônica. Os desenhos apresentados são:

| Figura 131 - Implantação geral

| Figura 132 - Macrozoneamento/subsolo

| Figura 133 - Macrozoneamento/Pavimento Térreo

| Figura 134 - Macrozoneamento/Primeiro Pavimento

| Figura 135 - Macrozoneamento/Segundo Pavimento

| Figura 136 - Macrozoneamento/Terceiro Pavimento

| Figura 137 - Unidade de Urgência e Emergência -

Macrozoneamento com fluxos internos e externos.

| Figura 138 - Unidade de Urgência e Emergência

| Figura 139 - Perspectiva externa 01

Figura 140 - Perspectiva externa 02

| Figura 141 - Vista atual da obra

O memorial descritivo do croqui esquemático procura abordar vários aspectos a serem observados, como a organização do edifício no lote, a articulação das unidades nos pavimentos e ainda o sistema de circulação proposto.

Todas as abordagens neste memorial têm o objetivo de ajudar na compreensão da proposta e não estabelece como prerrequisito para o desenvolvimento do projeto do edifício hospitalar.

Este memorial não tem o objetivo de abordar o detalhe, mas sim focar, em um plano maior do projeto, os critérios para se atingir melhor desempenho de rendimento.

\section{Considerações sobre a Implantação Geral}

O memorial descritivo a seguir sobre a Implantação Geral (Figura 131) do complexo hospitalar não constitui qualquer requisito para o projeto do edifício hospitalar. 













Sobre o terreno

O terreno está dividido em duas zonas distintas, seccionado pela Richardson/Francis Creek Drainage Channel. Olado escolhido para a implantação do projeto foi fortemente influenciado pela potencialidade que a área apresenta.

A área remanescente, seccionada pelo mesmo canal, permanecerá como reserva no desenvolvimento dos trabalhos no RFP (Request for proposal).

Sobre a área escolhida, o croqui esquemático implanta o edifício na face leste do terreno.

A localização do edifício estabelece como pontos principais de acesso, os serviços ambulatoriais (NRCC - Niagara Regional Cancer Center) pela face leste do terreno e na lateral as área de carga e descarga de mercadorias, bem como áreas para estacionamento de veículos de público externo.

O esquema ilustrado coloca as Unidades de Internação ao longo da face oeste, com aberturas para todo o cinturão verde, margeando o canal.

Ao sul do terreno existe a linha da estrada de ferro (Canadian National Railway). Outros componentes de geração de ruído foram colocados nesta face do lote que são as áreas das docas de carga e descarga e ainda o heliponto.

O Serviço de Emergência foi locado na face norte, ao final do edifício, com acesso imediato das ambulâncias por uma das entradas principais do edifício.

\section{Sobre a expansão}

O croqui esquemático incorpora na proposta as duas soluções para o crescimento futuro, isto é: tanto a médio, como a longo prazo.

Três hipóteses de crescimento estão previstas como possíveis expansões e mostradas na continuidade do edifício. Uma delas é apresentada na face sul do edifício para abrigar as necessidades futuras do NRCC (Niagara Regional Cancer Centre), com área de aproximadamente $2.300,00 \mathrm{~m}^{2}$ por pavimento. A segunda poderá ocorrer no bloco localizado ao norte do terreno para atender 
às necessidades de crescimento dos Serviços de Diagnóstico e Tratamento, principalmente o Serviço de Emergência no nível térreo, com área de aproximadamente 2.300,00 $\mathrm{m}^{2}$ também nos demais pavimentos. Por último, um outro bloco adjacente às torres de Internação, permitindo a ampliação da capacidade de oferta de leitos, com a construção da quarta torre de internação.

As áreas de estacionamento para veículos foram locadas na face leste do terreno, o que também disponibilizará qualquer reorganização do edifício.

\section{Sobre os acessos/fluxos}

\section{- Acessos ao lote}

O lote tem quatro principais acessos, citados abaixo: a principal entrada está locada junto a First Street Louth, ao longo da margem leste do terreno. A entrada de ambulâncias à unidade de emergência está locada na Fourth Avenue. A entrada de serviço está locada ao final do lote pela First Street Louth. O acesso de funcionários está locado no extremo do terreno, pela Forth Avenue.

\section{- Acesso ao edifício}

Os vários pontos de acesso ao edifício estão descritos abaixo e demonstrados nos croquis esquemáticos, pelas figuras 131, 132 e 133. A principal entrada está locada ao longo da face leste do edifício, posicionada entre o bloco de Serviço de Diagnóstico e Tratamento e o Ambulatório de Oncologia (NRCC). A entrada do Serviço Ambulatorial está na face leste, oferecendo um acesso confortável tanto para pacientes, como aos visitantes. Outra entrada está locada junto ao serviço do Niagara Regional Cancer Centre na face leste do edifício, com área coberta para embarque e desembarque de pacientes. Foi ainda disponibilizada uma entrada exclusiva pela face sul no bloco do NRCC, oferecendo o acesso a pacientes que virão transferidos de outras unidades hospitalares ou ainda de casa e que não são casos emergenciais.

O principal acesso de serviço está locado na face sul do edifício ao final do bloco de Diagnóstico e Tratamento. Este acesso será 
pelo nível inferior, isto é, pelo subsolo através de rampas para tráfego de pessoas e veículos pesados. A entrada de funcionários por esta área do edifício, ao final do bloco de Diagnóstico e Tratamento, utilizarão a área de estacionamento próximo ao Richardson/Francis Creek Drainage Channel.

$\mathrm{Na}$ face nordeste do edifício está a entrada de pacientes ambulantes (urgência) e ao serviço de emergência. Esta área é servida por grande estacionamento de acesso coberto, e ainda pela passagem de veículos para embarque e desembarque de passageiro. Na face norte do edifício está a entrada da Unidade de Emergência. Ainda aos acessos do serviço de emergência está locada uma área para o estacionamento de veículos como suporte à unidade. Ainda junto a esta face do edifício, foi ofertado um confortável acesso ao Serviço de Saúde Mental.

\section{Sobre as áreas de estacionamento para veículos}

A principal área de estacionamento está locada ao longo da face leste do terreno, a qual servirá para atender ao público em geral e pessoal interno.

Parte do estacionamento locado mais a sudoeste do lote será destinado aos pacientes de Oncologia, e dispondo de várias vagas para portadores de necessidades especiais. Parte do estacionamento locado mais ao nordeste do lote será destinada ao público em geral. Ao longo da face leste do edifício foram disponibilizadas pequenas áreas de estacionamento para visitas de curta permanência, pacientes ambulantes, médicos e ainda ao Serviço de Emergência.

Foi ainda disponibilizado um pequeno estacionamento para atender ao público do Serviço de Saúde Mental. Outro pequeno estacionamento foi locado junto à entrada de pacientes transferidos com acesso ao serviço do NRCC (Niagara Regional Cancer Centre). Estacionamento coberto para ambulâncias foi locado ao norte do Serviço de Emergência. Neste local também foi disponibilizado estacionamento aos policiais.

A oeste do lote foi locado um grande estacionamento para atender às necessidades de funcionários e pessoal interno. 


\section{Sobre a circulação}

\section{- Geral/veículos}

Acesso de público ao terreno será pela First Street Louth, onde a entrada principal arborizada é a que direciona ao estacionamento locado a leste do edifício. Esta entrada arborizada também conecta com as vias norte/sul que corta longitudinalmente o terreno.

A via norte/sul de duas pistas é considerada a mais importante no traçado viário interno. Ela se liga ao acesso principal do edifício, permite a conversão dos veículos, e ainda estabelecendo uma área coberta de referência para embarque e desembarque de passageiros para melhor recepcioná-los, ofertando conforto e bem estar. Esta via conecta ainda com pequenas áreas de estacionamento de curta permanência.

\section{- Ônibus}

Uma circulação contínua para tráfego de ônibus está prevista, com acesso pela Fourth Avenue, seguindo até a face sudeste do edifício onde está locada a entrada de serviço. A principal parada do ônibus está locada no centro do terreno, exatamente a leste do edifício, onde se encontra a entrada principal do complexo hospitalar. A segunda parada de ônibus está prevista na entrada do bloco NRCC (Niagara Regional Cancer Centre) para atender aos pacientes que utilizarão dos serviços ambulatoriais.

\section{- Ambulância}

As ambulâncias entrarão pela Fourth Avenue, seguindo diretamente para a entrada coberta da Unidade de Emergência. Esta área coberta é prevista para um tráfego tranquilo $\mathrm{e}$ desimpedido de veículos.

\section{- Helicópteros}

O heliponto está localizado a sudoeste do empreendimento, com acesso pavimentado. 


\section{- Serviço Embarque/Desembarque de mercadoria}

Os veículos de serviços entrarão pela face sudeste do terreno, seguindo em linha reta, passando paralelamente à face sul do edifício hospitalar. Rampas de acesso ao subsolo foram ofertadas para atingir as áreas de carga e descarga de mercadorias.

\section{Outras considerações}

Um caminho para pedestre foi disponibilizado na face oeste do edifício, junto às Unidades de Internação. Este caminho foi previsto como a oportunidade dada aos pacientes, familiares, funcionários de utilizarem o espaço exterior. Este caminho é percorrido através do cinturão verde colocado à margem do Richardson/Francis Creek Drainage Channel.

Dois grandes jardins internos foram disponibilizados entre o bloco de Diagnóstico e Tratamento e as Unidades de Internação. Estes espaços de jardins oferecerão uma área de descanso adicional aos pacientes e funcionários, como também é o elemento de referência para a circulação de público em geral que trafegarão pelos eixos de conexões. O paisagismo cria uma barreira entre as duas maiores vias que margeiam o terreno, e ainda oferece dois grandes lagos.

Duas pontes ligam os lados leste e oeste do terreno que está dividido pelo Richardson/Francis Creek Drainage Channel. Estas pontes conectar-se-ão com a área de estacionamento para veículos dos funcionários, facilitando o acesso diretamente ao hospital.

\section{Considerações sobre o edifício dentro da proposta dos croquis es- quemáticos apresentado}

A descrição aqui apresentada, com respeito aos croquis esquemáticos não constitui qualquer requisito para o projeto do edifício. Croqui esquemático está organizado baseado em três pontos importantes, macrozoneamento, como se segue.

- Bloco ambulatorial/Oncologia: este bloco abriga os programas ambulatoriais importantes, tais como o Niagara Regional Cancer Centre, cuidados ambulatoriais, Serviço de 
Endoscopia e Citoscopia, Doenças Crônicas do Rim e ainda o Niagara Diabetes Centre.

- Bloco de Diagnóstico e Tratamento: este bloco representa o "coração" dos serviços do hospital, incluindo os serviços de Emergência, Diagnóstico por Imagem, Centro Cirúrgico/ suítes cardiológicas, serviços em Cardiologia, serviços em Doenças Respiratórias, Laboratórios e Farmácia.

- Bloco de Internação: este bloco abriga todos os leitos disponíveis no hospital, incluindo as unidades médicas/ cirúrgicas, serviços em Pediatria, Maternidade e Neonatologia, Serviços em Saúde Mental e ainda os Serviços de Cuidados Críticos.

A divisão do edifício em três blocos distintos serve para distribuir os serviços de procedimentos comuns, requisitos estruturais, modelo de circulação e serviços gerais. A separação também promove a economia no potencial construtivo, combinando elementos similares. Esta divisão tripartite tornouse a principal alavanca do partido arquitetônico e na geração dos croquis esquemáticos.

\section{Bloco do NRCC - Niagara Regional Cancer Centre}

Este bloco, em função dos diversos serviços ambulatoriais ofertados foi localizado de forma que seu acesso fosse facilmente identificado. Possui ainda, próximo a ele, área para estacionamento de veículos, área abrigada para embarque e desembarque de pacientes e público em geral. É ofertada também entrada exclusiva para pacientes referenciados de outras unidades hospitalares que estejam acamados, porém sem a necessidade de atendimento emergencial. Devido à natureza (crônica, idade e debilidade) de muitos pacientes que se utilizam deste serviço, há preocupação em ofertar o melhor conforto na chegada, acesso e recepção dos enfermos.

Este bloco divide-se em uma das faces com a entrada principal do hospital. O saguão de entrada principal está subdividido em áreas de chegada do paciente, com os seus familiares e outra que abriga a circulação geral de entrada e saída, oferecendo assim um melhor nível de privacidade e dignidade ao paciente. 
Este bloco disponibilizará um elevador para transporte de pacientes referenciados que atende aos quatro pavimentos, permitindo que pacientes em macas cheguem às unidades de atendimento sem passar pelas áreas com o envolvimento do público em geral. Os dois primeiros pavimentos serão utilizados pelo NRCC (Niagara Regional Cancer Centre). Isto oferece a identidade ao edifício, criando forte visibilidade. O pavimento térreo abrigará a Unidade de Radioterapia, o que permitirá o acesso em nível dos pacientes que se utilizarão deste serviço. Esta estrutura é composta por alguns "bunkers", aceleradores lineares. $\mathrm{O}$ primeiro pavimento abrigará o atendimento ambulatorial em Oncologia e o Serviço de Quimioterapia.

O segundo pavimento deste bloco abrigará os serviços de Endoscopia e Citoscopia. O agrupamento destes dois serviços no mesmo pavimento permitirá maior flexibilidade operacional, locação e uso de espaços e ainda alguma capacidade de disponibilidade espacial. O posicionamento deste serviço neste bloco permitirá rápido acesso aos pacientes ambulatoriais e uma simples e única recepção. Esta área disponibilizará ainda o serviço de coleta de amostra ambulatorial, a qual estará interligada com o Serviço do Centro Cirúrgico Ambulatorial. Pacientes internados que se dirigirem ao Serviço de Endoscopia e Citoscopia deve chegar ao setor pela circulação do bloco de Diagnóstico e Tratamento, minimizando e evitando assim o contato com o público em geral e áreas de recepção e espera.

O terceiro pavimento conterá o Serviço de Doenças Crônicas do Rim e o serviço em Diabetes. Muitos pacientes que fazem diálise são também diabéticos e esta proximidade de serviços permitirá abrigar o acesso destes pacientes por uma única porta de entrada e recepção. O Niagara Diabetes Centre é uma unidade caracterizada como de uso "leve" naquilo que trata os espaços do ambulatório, o que lhe permitirá remanejar espaços sem grandes impactos no sistema operacional do edifício. Isto permitirá que o Serviço de Doenças Crônicas do Rim cresça no futuro, com a construção do bloco previsto para expansão. Há disponibilidade de ligação entre a Unidade de Nefrologia com a Unidade de Cuidados Médicos/Cirúrgicos às Unidades de Internação.

O bloco de serviços ambulatoriais/Oncologia também possui um subcomponente de aproximadamente $580,00 \mathrm{~m}^{2}$ por pavimento de "espaços flexíveis" (café, estar e administração). 
Esta distribuição permitirá remanejamentos futuros nas unidades com tendência de crescimento.

\section{Bloco de Diagnóstico e Tratamento}

Este bloco foi locado no centro do edifício e serve como o "coração" do hospital. Sua localização torna-se a ponte entre o serviço ambulatorial/Oncologia e o bloco das Unidades de Internação e ainda muitos serviços, como o cateterismo, que servem tanto aos pacientes internos como externos. Este bloco foi idealizado para permitir que os dois tipos de público (interno e externo) trafeguem por ele e minimizem percurso.

O nível térreo abrigará o Serviço de Emergência, Diagnóstico por Imagem, Serviços em Cardiologia e serviços ao público em geral. O Serviço de Emergência neste nível é o ideal para o acesso rápido e imediato tanto para pacientes procedentes por ambulâncias ou ambulantes. O posicionamento da unidade no extremo do edifício, também permitirá expansão futura, como já previsto e mostrado no croqui esquemático.

Proximidade do Serviço de Emergência com o Centro de Diagnóstico por Imagem. Esta contiguidade permitirá rápida transferência do serviço ambulatorial, como também do Serviço de Ortopedia e Trauma para as principais modalidades de diagnóstico.

O Serviço de Medicina Nuclear, componente do Serviço de Diagnóstico por Imagem estará próximo ao serviço de Cardiologia para se beneficiar do teste de esforço (ergometria).

Para acomodar futuro crescimento desta unidade, foram disponibilizadas áreas caracterizadas como "espaços flexíveis" que permitirão o remanejamento e a expansão do serviço.

O primeiro pavimento deste bloco contém os serviços do Centro Cirúrgico, serviços em Cardiologia e Angiografia. Neste pavimento também serão abrigadas as facilidades acadêmicas. $\mathrm{O}$ principal objetivo no "layout" deste nível é permitir a proximidade de serviços em Cardiologia, com outros procedimentos, entre eles o de Angiocateterismo. Os serviços atendem tanto aos pacientes ambulantes como internados, os quais têm acesso às unidades de elevadores distribuídos pelo hospital. Este pavimento está projetado para permitir crescimento futuro em todas as unidades 
previstas, por meio da oferta de "soft spaces" (espaços flexíveis) que disponibilizarão áreas para expansão.

O segundo pavimento contém vários serviços de suporte, incluindo os Serviços Pneumo-Respiratórios, Laboratórios e Farmácia.

Serviços de Pneumorrespiratórios serão no final do bloco, próximo ao serviço ambulatorial/Oncologia (NRCC). Esta localização oferece proximidade de acesso com a principal entrada do hospital, e ainda estará interligada com os elevadores do ambulatório, destinados aos pacientes ambulantes. Esta localização também permitirá o acesso de pacientes que utilizarão os serviços de Pneumologia, com ligação direta às Unidades de Internação.

Tanto a Farmácia como os Laboratórios estarão na área central do edifício como facilidade e equidistância para abastecer outras unidades do hospital.

\section{Bloco de Internação}

O bloco de internação está situado na face oeste do terreno, junto ao cinturão verde. O bloco está dividido em três distintas torres (com a possibilidade da expansão para a quarta torre), cada uma delas interligada ao bloco de diagnóstico.

O nível térreo estará destinado ao Serviço de Saúde Mental. Será disponibilizada área externa e contígua para todas as Unidades de Serviço de Saúde Mental e estará totalmente separada de qualquer circulação geral de pacientes e visitas alheias à unidade. A localização da unidade no pavimento térreo permitirá interligar com o Serviço de Emergência, para rápida transferência do paciente internado na Unidade de Saúde Mental. Como não haverá nenhum trânsito na Unidade de Saúde Mental e o resto do bloco de Diagnóstico, o nível térreo será aberto à circulação de público em geral, ao longo dos dois jardins internos.

O primeiro pavimento abrigará duas unidades de Internação de cuidados médicos/cirúrgicos, como também a Unidade de Cuidados Críticos. A localização da Unidade de Cuidados Críticos estará vinculada horizontalmente com a unidade de Serviços de Cardiologia, preparo pré-operatório do paciente e Centro Cirúrgico. A caixa de elevadores para pacientes internados, 
como também o acesso às Unidades de Cuidados Críticos, estará interligada com o serviço de Emergência. As duas unidades de Cuidados Críticos deverão atender pacientes cirúrgicos no mesmo nível, dado pela proximidade com a plataforma de serviços do bloco de Diagnóstico e Tratamento.

O segundo nível abrigará a Maternidade e o Serviço de Neonatologia, Pediatria e ainda uma Unidade de Cuidados Críticos. A Maternidade e a Neonatologia estarão localizadas ao final do bloco, próximo à caixa de elevadores que será interligada com os serviços pré-operatórios e cirúrgicos no nível abaixo. Maternidade e Neonatologia irão compartilhar o espaço com a Pediatria.

O terceiro pavimento abrigará três unidades de Cuidados Críticos. Como este nível não tem nenhuma conexão horizontal com o bloco de Diagnóstico e Tratamento, ele poderá ser melhor utilizado como um pavimento para isolamento no caso de qualquer princípio de epidemia.

Considerações sobre os croquis esquemáticos com relação à circulação interna do edifício hospitalar

A descrição aqui apresentada com respeito aos croquis esquemáticos não constitui qualquer requisito para o projeto do edifício.

\section{- Circulação no subsolo}

O nível do subsolo foi organizado para que ficasse totalmente isolado das circulações do público em geral, pacientes internados, entre outros. O pavimento do subsolo tem a oferta de área para carga e descarga de produtos (Figura 132). Outras considerações foram feitas. Áreas de recebimento de produtos foram disponibilizadas para o Serviço de Nutrição, com caráter regional, bem como para a cozinha interna. Áreas separadas para a guarda de resíduos procedentes do Serviço de Nutrição, serviços hospitalares e ainda produtos recicláveis. O nível do subsolo estará interligado através dos eixos de circulação horizontal e vertical com todos os serviços de apoio logístico. Os elevadores oferecerão uma distribuição eficiente para todas as áreas clínicas, 
minimizando o serviço e rotas de transporte logístico e ainda eliminando qualquer conflito com a circulação do público em geral e pacientes internados.

O morgue estará localizado no subsolo. Para o acesso a este serviço deverá ser utilizado o elevador de serviço. A retirada e transferência do paciente em óbito deverão ser através da doca coberta para recebimento de material. A circulação entre as áreas cirúrgicas e a Central de Esterilização de Material será feita através do elevador (via limpa e suja do elevador da CEM) até os serviços do preparo pré-operatório do paciente, Centro Cirúrgico e Unidades Cirúrgicas. Por meio de uma conexão direta dos elevadores para transporte de material limpo e sujo, áreas estéreis e sujas serão mantidas também nas unidades do Centro Cirúrgico, Central de Esterilização de Material e Unidades Cirúrgicas. Será ainda considerada uma separação adicional para a disciplina de fluxos na circulação de resíduos, transporte de material para apoio logístico, para que não interfira na circulação de pacientes, funcionários e público em geral.

\section{- Circulação no pavimento térreo}

A circulação no pavimento térreo será destinada para os Serviços Ambulatoriais, pacientes ambulantes e visitantes. Como ilustrado na figura 133, todos os pontos de recepção das unidades e todas as caixas de elevadores para público estarão acessíveis, porém, sem cruzar com a circulação de serviço e pacientes internados. Uma única e linear circulação para público direcionará os visitantes que terão acesso pela entrada principal, através do eixo de circulação ao lado do jardim interno. Esta circulação proporcionará uma abertura de luz natural, principalmente nas áreas de recepção, que estarão interligadas a todas as caixas de escadas e elevadores.

Separar as entradas do serviço do Niagara Regional Cancer Centre e o Ambulatório será uma conduta interessante, tendo em vista o alto índice de fluxo ao serviço de Doenças Crônicas do Rim. Foi proposta a separação dos fluxos pelos elevadores de suporte do NRCC e o Ambulatório, porém, todos os pacientes poderão acessar todos os pavimentos, permitindo assim que pacientes de Oncologia acessem outros serviços ambulatoriais, bem como serviços clínicos de apoio. 
Separar o acesso de pacientes referenciados para o Ambulatório teve como objetivo proporcionar acesso adequado para pacientes transportados por ambulâncias ou vans para o NRCC, e ainda para pacientes portadores de doenças crônicas dos rins. Este acesso também poderá ser usado para dar alta aos pacientes póscirúrgicos.

Serviços clínicos serão organizados no principal bloco de Diagnóstico e Tratamento. Serviços de Emergência, Diagnóstico por Imagem, serviços de diagnóstico em Cardiologia possuem cada um deles áreas imediatamente colocadas nas rotas de circulação de público em geral.

Facilidades públicas incluirão o auditório, o saguão principal, café, serviços administrativos e centro de serviço ao paciente, e todas estarão disponíveis na entrada principal do edifício.

A entrada principal estará conectada com a espera do Serviço de Emergência pela circulação geral de público. Pacientes ambulantes e visitantes poderão acessar o saguão de entrada principal através do Serviço de Emergência sem transpor para qualquer área clínica.

Foram separadas as entradas de pacientes ambulantes e pacientes procedentes através de ambulâncias ao Serviço de Emergência. Outro acesso para atender pacientes potencialmente contaminados (infectados), pelo fluxo da descontaminação (higienização) que estará distante apenas 10 metros da principal entrada de ambulância, com o objetivo de evitar a contaminação da principal entrada de emergência.

Como ilustrado, três grandes caixas de escadas e elevadores servirão os pavimentos superiores. Estes elevadores ofertarão acesso às Unidades de Internação.

Um destes eixos de circulação vertical será para atender às Unidades de Cuidados Críticos que estará junto à Unidade de Emergência. Estes elevadores disponibilizarão acesso ao Serviço de Diagnóstico por Imagem, serviços de Cardiologia, Angiocateterismo, Angiografia, Centro Cirúrgico, Unidades de Cuidados Críticos, Maternidade e Neonatologia, e ainda a Unidade de Cuidados Críticos para pacientes cirúrgicos.

Instalações para o Serviço de Saúde Mental estarão disponibilizadas na face oeste do edifício e no nível térreo. Acesso a esta unidade estará disponível tanto pela entrada principal do 
serviço (ao lado do Serviço de Emergência), como também pela entrada principal do edifício.

Também como mostrado na figura 133, foi disponibilizada a entrada ao NRCC (Niagara Regional Cancer Centre), e a oferta de elevadores para atender aos demais níveis do bloco ambulatorial.

\section{- Circulação no primeiro pavimento}

O primeiro pavimento está organizado para oferecer a intercomunicação e acesso entre as Unidades de Cuidados Críticos e ainda minimizar os conflitos de tráfego entre público geral, serviços, pacientes em macas e funcionários.

Como ilustrado (Figura 134), o primeiro pavimento poderá ser acessado diretamente do saguão da entrada principal, usando para isto os elevadores destinados ao público em geral, localizados junto às unidades do Ambulatório. Poderá também acessar pelos elevadores destinados ao público, nas três caixas de escadas e elevadores, conectadas com as Unidades de Internação. Áreas de espera para o NRCC - Niagara Regional Cancer Centre e unidades de serviços Cirúrgicos, como também as áreas administrativas serão disponibilizadas diretamente da circulação do público geral, de forma que não venham a intervir na circulação restrita a pacientes internados e funcionários.

Visitantes ao primeiro pavimento com o objetivo de acesso às Unidades de Internação ou aos serviços de Cuidados Críticos deverão ser direcionados às recepções através de circulações específicas. A chegada do visitante à unidade deverá ser próxima ao serviço de enfermagem para que haja o controle de acesso, minimizando conflitos com pacientes internados, funcionários ou circulação de serviço. Pacientes internados, funcionários e elevador de serviços estarão disponibilizados para o mínimo de interferência no transporte de pacientes durante o dia, alimentação, roupa limpa e outros serviços de apoio logístico.

Elevadores para atender aos serviços das áreas críticas estarão locados ao norte do edifício para atender o acesso direto aos serviços de Diagnóstico por Imagem, Serviço de Emergência, Serviços de Cardiologia, Angiocateterismo, Angiografia, Serviços Cirúrgicos, Unidades de Cuidados Críticos, Maternidade e Neonatologia, Centro Obstetrício e áreas de Internação. 


\section{- Circulação no segundo pavimento}

O acesso aos serviços de Endoscopia e Citoscopia pelos pacientes do ambulatório deverão proceder pela entrada principal do NRCC (Figura 135), através do elevador destinado ao público em geral. Os pacientes internados que se dirigirão a estes serviços, deverão percorrer as rotas de circulação no mesmo pavimento.

As Unidades de Farmácia e Laboratório terão acesso direto a todas as Unidades de Internação. O abastecimento destas unidades será feito através do elevador de serviço, adjacentes às Unidades de Internação. $\mathrm{O}$ abastecimento de material e o fornecimento de material/instrumental às Unidades de Farmácia e Laboratórios deverão ocorrer em horários preestabelecidos.

Elevadores e escadas poderão dar apoio ao acesso de médicos e transporte de pacientes.

\section{- Circulação no terceiro pavimento}

Os serviços do Niagara Diabetes Centre e Doenças Crônicas do Rim serão acessados pelo elevador destinado ao público em geral, e disponibilizado junto à entrada principal do Ambulatório. Para estas unidades haverá também elevadores de serviço.

As três Unidades de Cuidados Críticos, bem como a unidade de pacientes cirúrgicos, locadas neste pavimento terão o seu acesso pelo elevador específico junto à caixa de elevadores e escada. Como mostra o croqui esquemático (Figura 136), os elevadores estão separados por fluxos de pacientes internados, funcionários, serviços em geral e público. 








Figura 141 - Niagara Health System - vista aérea: estágio da obra (2011) (Fonte: Cannon Design)

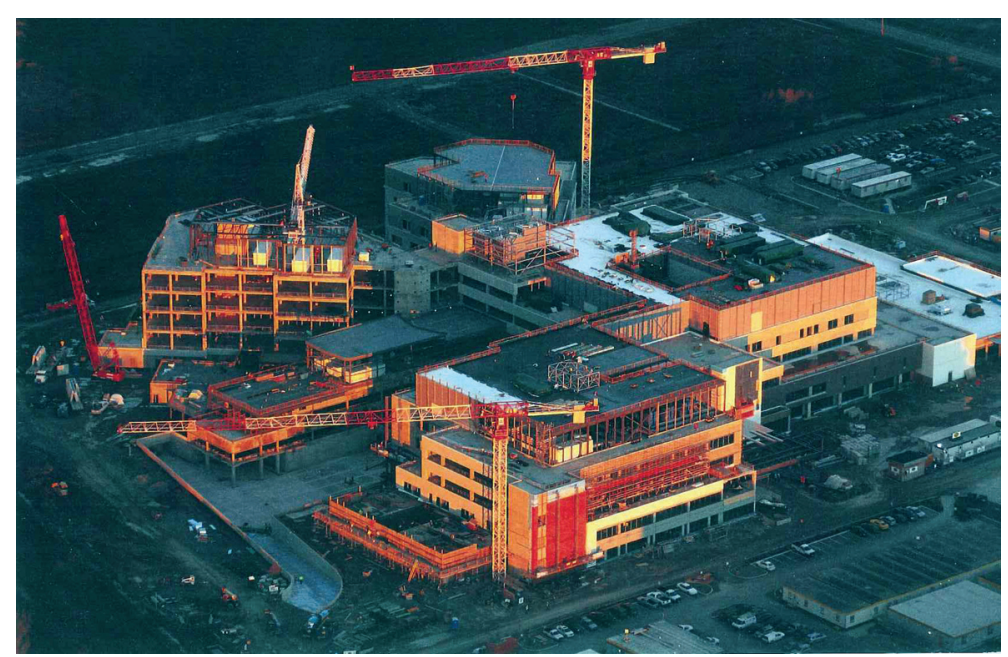

\subsection{Unidade de Urgência e Emergência em alta complexidade (Hospital São Luiz/Anália Franco - São Paulo-SP)}

\subsection{Introdução}

A unidade em estudo está agregada ao Hospital São Luiz, unidade Anália Franco no bairro do Tatuapé, região leste de São Paulo. Esta unidade faz parte da rede de Hospitais e Maternidade São Luiz, instalada com o objetivo de atender aos pacientes procedentes desta região, tendo em vista as dificuldades de deslocamento até as duas outras unidades estabelecidas na região sul - Morumbi e Itaim Bibi - da capital paulista. (Figura 142).

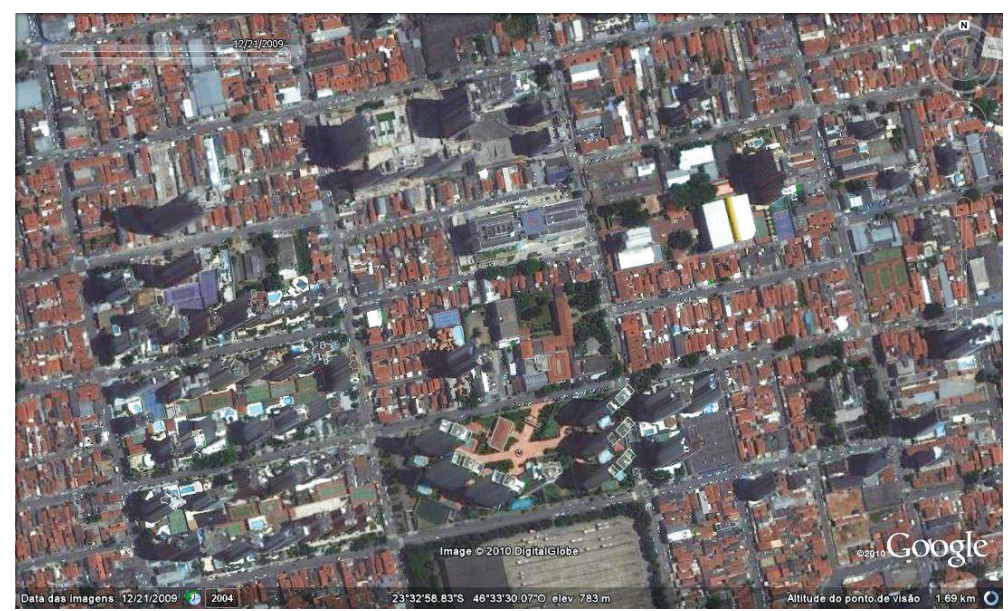


O complexo hospitalar dispõe de 180 apartamentos e aproximadamente 280 leitos, com área total construída de $43.800,00 \mathrm{~m}^{2}$, instalado num terreno de 7950,00 $\mathrm{m}^{2}$, onde disponibiliza ainda de 380 vagas para veículos abrigadas no subsolo do edifício.

Com a proposta de atendimento para alta complexidade médica, o referido hospital oferece 18 salas cirúrgicas e 11 salas de parto. Compõem ainda a infraestrutura hospitalar as unidades de Terapia Intensiva Geral e Neonatal.

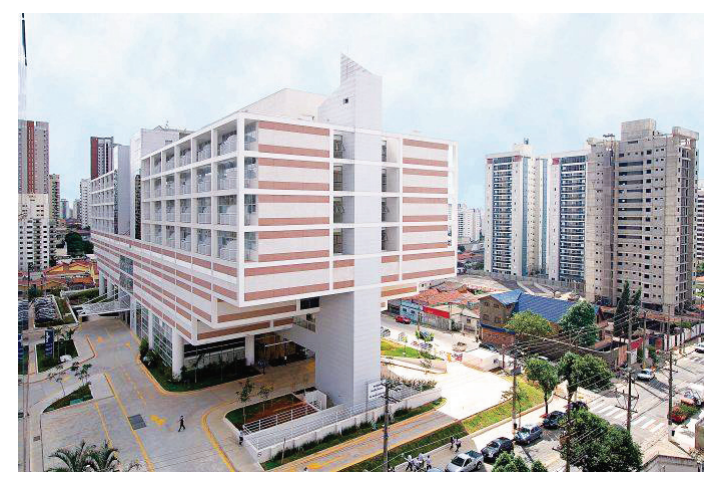

A Unidade de Urgência e Emergência ou Pronto-Socorro, como denominado, esta localizado no nível do primeiro subsolo, permitindo desta forma o acesso a ela pela Rua Antonio Camardo. A estrutura física desta unidade possui aproximadamente 1700,00 $\mathrm{m}^{2}$. (Figura 143).

Figura 143 - Hospital São Luiz/ Anália Franco - vista geral do edifício

(Fonte: disponível em <www. arcoweb.com.br>)

\subsubsection{A unidade hospitalar no contexto urbano}

A proposta de crescimento da rede hospitalar São Luiz foi iniciada no ano de 2000, com o objetivo de ampliar seu atendimento médico a toda população da região leste da cidade de São Paulo. Naquele momento, haviam duas unidades já instaladas na região sul, Morumbi e Itaim Bibi, justificando, portanto, a implantação de um novo serviço para o bairro do Tatuapé e região, o qual possui um adensamento

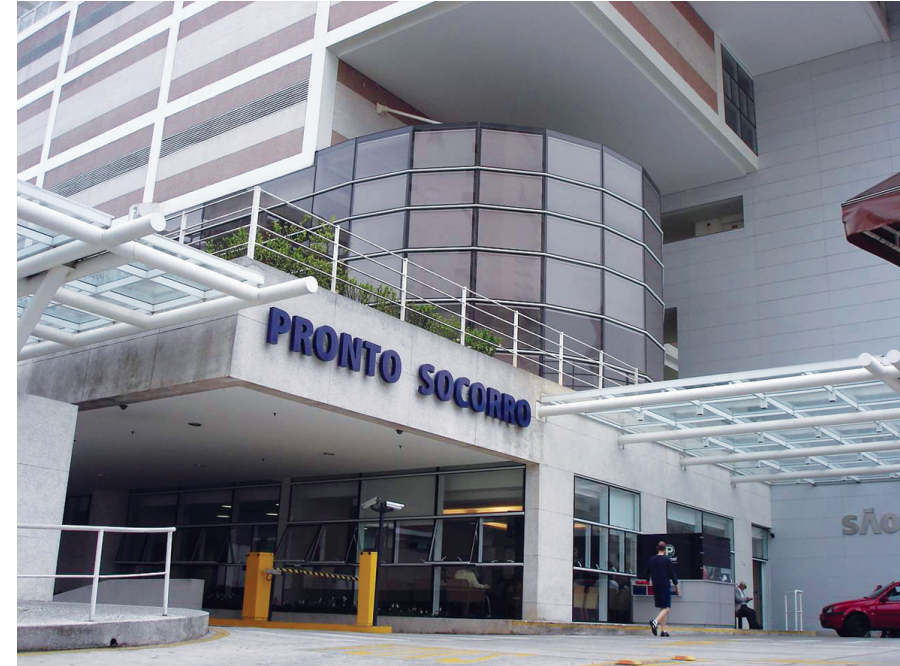
populacional bastante elevado.

Comojáobservado,oacessoàunidadedeUrgênciaeEmergência ocorre no nível do primeiro subsolo, convenientemente colocado para o melhor aproveitamento da declividade do terreno e vias de entorno. Seu acesso ocorre de forma isolada e autônoma pela Rua Antonio Camardo. (Figura 144).

A implantação do complexo hospitalar respalda-se na legislação, municipal no que se refere aos afastamentos das vias para veículos e pedestres, taxa de ocupação e coeficiente de aproveitamento do lote, pertinentes ao zoneamento do lote.
Figura 144 - Entrada da Unidade de Urgência e Emergência

(Fonte: foto do autor) 
Os afastamentos do edifício, em relação às vias públicas e ainda aos balanços monumentais contemplados na arquitetura, proporcionam maior absorção visual, leveza e beleza aos olhos dos pedestres que circulam pelo seu entorno.

A partir daquela data, foram iniciados estudos paraimplantação do novo complexo hospitalar, tendo como responsável pela coordenação e gerenciamento dos trabalhos o arquiteto Siegbert Zanettini. A obra foi concluída em janeiro de 2008 após vencer vários desafios estruturais e arquitetônicos propostos pelo arquiteto.

É localizado no bairro do Tatuapé, região leste da capital paulista, com características de bairro residencial e comércio local, sendo este terreno abastecido por vias de tráfego para veículos e pedestres com dimensões não muito generosas, tendo em vista a magnitude e importância do empreendimento.

\subsubsection{Concepção e Volumetria}

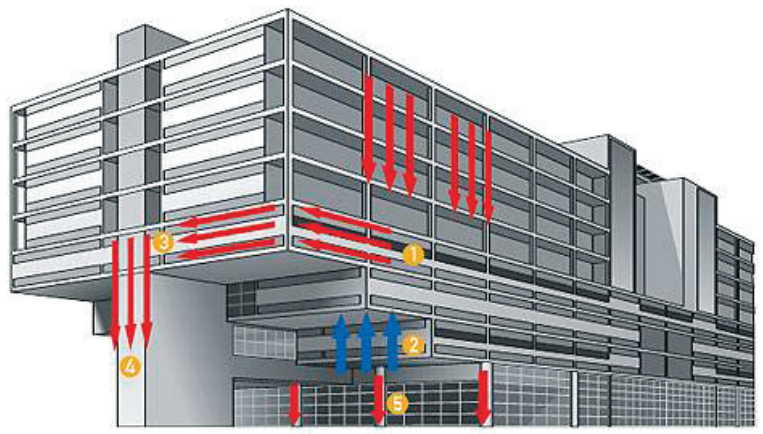

(1) Parede lateral, que tem função estrutural, retransmite parte da carga do edifício às paredes frontais do $3^{2}$ pavimento.

(2) A estrutura do primeiro, do segundo e do terceiro pavimento está pendurada por tirantes presos a vigas de transição no quarto pavimento.

(3) Parede frontal, uma viga de mais de $3 \mathrm{~m}$ de altura, apóia-se no pilar principal, na extremidade do edifício, e retransmite a ele os esforços do edifício.

(4) Pilares em "U", nas extremidades do edifício, recebem maior parte de sua carga.

(5) Parte do carregamento é distribuída aos pilares do térreo, cada um com 1,5 m de diâmetro.

Figura 145 - Proposta esquemática do sistema estrutural empregado

(Fonte: disponível em $<$ www. revistatechne.com.br/engenharia-civil >)
Segundo relato do arquiteto Zanettini (2008), autor do projeto, a concepção do edifício objetivou a busca da leveza estética à acentuada volumetria horizontal, contendo varandas, passarelas, panos de vidro e cores na fachada, "Mas o grande desafio proposto pelo projeto de arquitetura foi a criação de planos escalonados em balanço, que exigiam análises rigorosas dos esforços em pontos críticos da estrutura”. (SILVA, 2008, p. 02). (Figura 145).

Como que em um processo de subtração volumétrica provocada pela retirada do volume escalonado inferior, esta proporciona exatamente o sentido de leveza ao conjunto arquitetônico, conforme proposta pelo autor do projeto. 
A ousadia arquitetônica demandou soluções complexas de engenharia para viabilizar a construção da estrutura em concreto armado. Do ponto de vista do projeto estrutural, foi preciso "pendurar" os primeiros andares a uma estrutura mais rígida, no quarto pavimento. (FARIA, 2008, p.o1 - Figura 146).

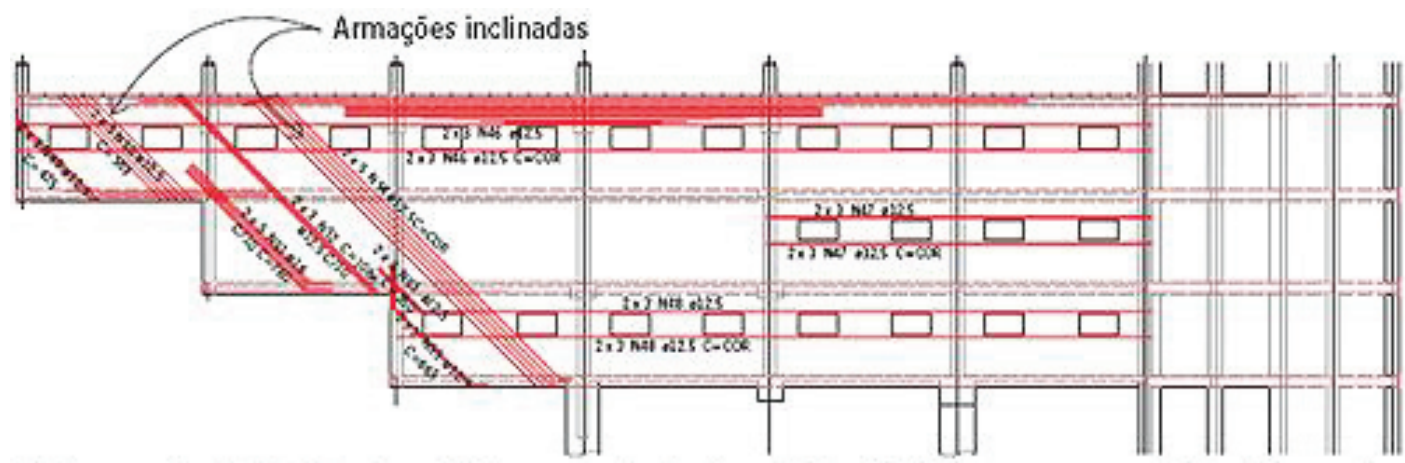

Bielas comprimidas inclinadas a $45^{\circ}$ foram a solução do projetista Virgílio Ramos para reduzir a deformação lenta da estrutura na regiâo dos balanços

Figura 146 - Proposta esquemática do sistema estrutural empregado

(Fonte: disponível em <www.revistatechne.com.br/engenharia-civil >)

O coroamento do edifício ocorre por meio da instalação do heliponto, local para pouso e decolagem de helicópteros no transporte de pacientes graves e/ou acamados.

\subsubsection{Implantação e fluxos externos}

Fazendo a leitura dos fluxos externos por meio da sua implantação, é possível enxergar claramente a disciplina dos acessos, melhor aproveitamento da topografia do lote, do sistema viário, como também a hierarquia das vias de acesso propostas pelo arquiteto. (Figura 147).

A entrada principal para o edifício está voltada para a Rua Francisco Marengo e pela rua lateral encontram-se também os acessos ao restaurante e à maternidade. 




\subsubsection{A Unidade de Urgência e Emergência no contexto do} complexo hospitalar

A unidade em estudo compõe a estrutura hospitalar do Hospital e Maternidade São Luiz, com acesso independente, em que na organização física conta com a separação de fluxos de Urgência e Emergência. (Figura 148 e 149).

Figura 148 - EntradaàUnidadefluxo de urgência (Fonte: foto do autor)

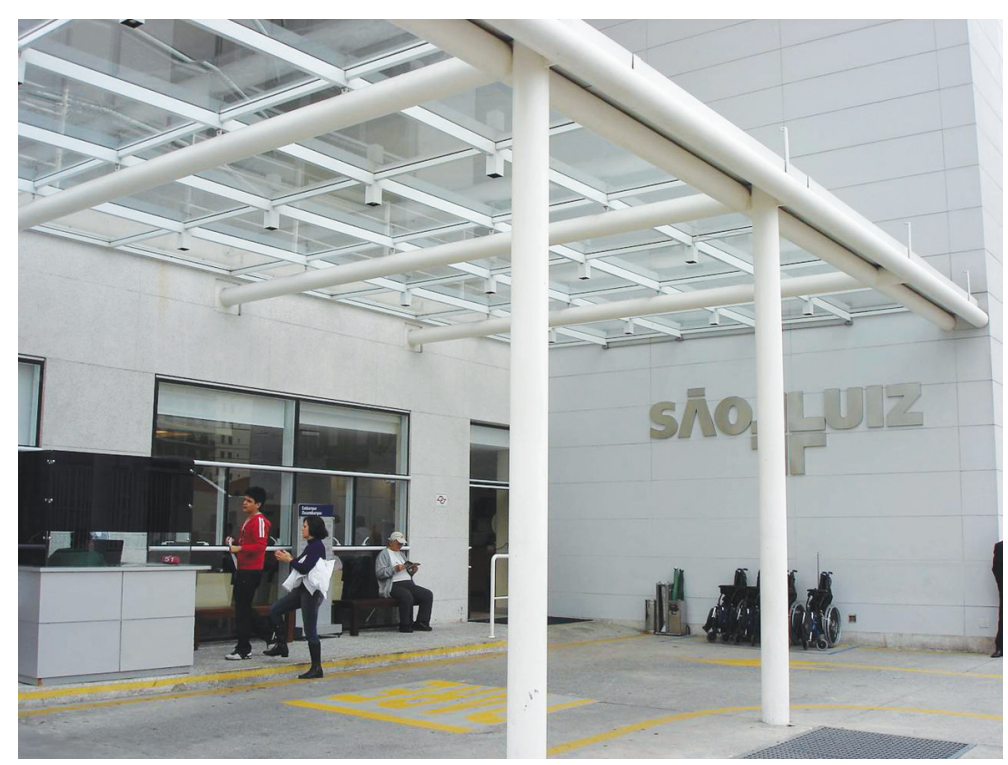

Figura 149 - EntradaàUnidadefluxo de emergência (Fonte: foto do autor)

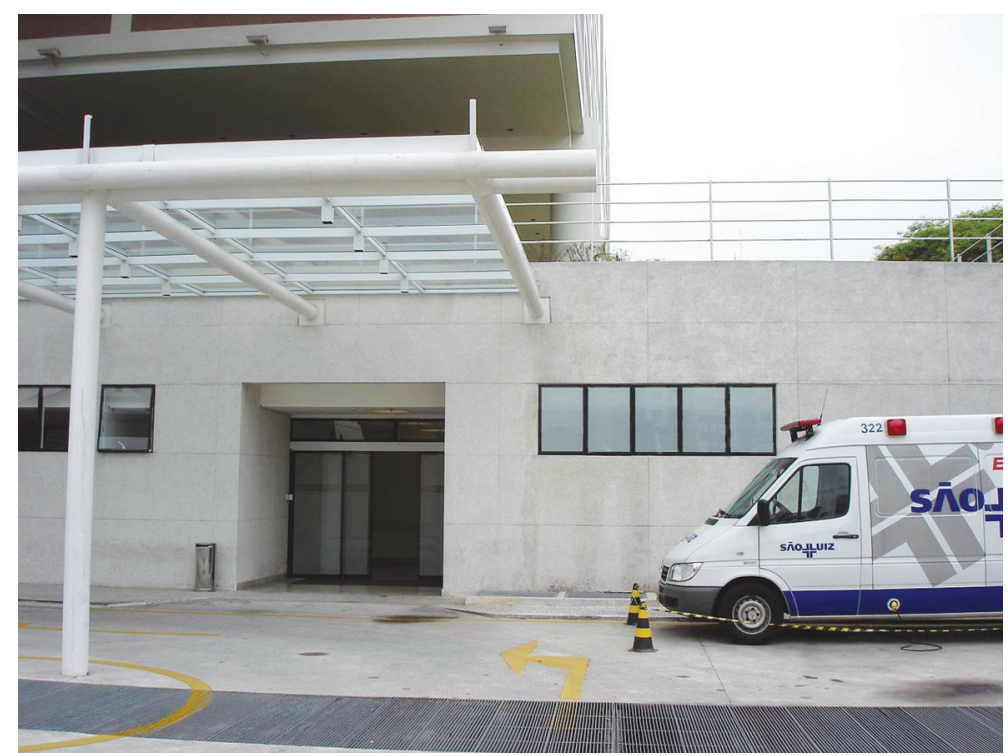


Sua estrutura organizacional (macrozoneamento) procura estabelecer a melhor definição de territórios de atuação entre os serviços de urgência e emergência, objetivando facilidade na atuação dos profissionais envolvidos, correta disciplina de fluxos e relações de contiguidade espaciais mais adequadas.

As áreas de apoio logístico servem os serviços de assistência ao paciente de forma mais compartilhada, o que lhe permite uma utilização mais racionalizada, evitando-se a duplicidade de área física, equipamentos e aumento do número de profissionais da saúde e colaboradores técnico-administrativos.

Anexo à Unidade de Urgência e Emergência, encontra-se o Centro de Diagnóstico por Imagem, o qual com sua larga oferta de equipamentos de última geração permite atendimento rápido e imediato aos pacientes em estado crítico. (Figura 150). 


Este posicionamento é bastante salutar na organização do macrozoneamento hospitalar, onde ao mesmo tempo que permite a conexão com o pronto-socorro possibilita o acesso independente aos pacientes que necessitam de exames agendados e eletivos.

As três outras unidades de grande importância na relação direta ao serviço de Urgência e Emergência são os Centros Cirúrgico e Obstétrico e as Unidades de Tratamento Intensivo, localizadas no primeiro e segundo pavimentos, onde se interligam ao sistema através das galerias (circulação horizontal) e conjunto de elevadores para leitos.

O conjunto de elevadores de serviço também permite à unidade em estudo fácil conexão as áreas de apoio logístico como: lavanderia, serviço de nutrição e dietética, almoxarifado, farmácia e instalações em geral; as quais ofertam fácil abastecimento pelo fluxo independente, necessário para a boa funcionalidade e assepsia exigidas.

\section{- Estrutura física instalada}

Com a preocupação em cumprir as solicitações básicas contidas na RDC $n^{\circ}$ 50/ANVISA, mas também e principalmente com o objetivo de complementar, inovar e atender às necessidades do grupo empreendedor, operacional e ao público alvo bastante seletivo, a arquitetura propõe para a Unidade de Urgência e Emergência uma melhor organização funcional e estética.

A estrutura física de aproximadamente $1695,00 \mathrm{~m}^{2}$, a qual representa $3,87 \%$ da sua área total, esta assim distribuída:

I) Atendimento de Emergência:

- marquise (embarque e desembarque de pacientes);

| área de estacionamento para ambulâncias;

| sala de Emergência (três boxes) (Figura 151);

- duas salas de suturas (Figura 152);

| duas salas de curativos;

| sala de inalação/medicação;

| posto de enfermagem (Figura 153);

| sala de emergência pediátrica (Figura 154). 

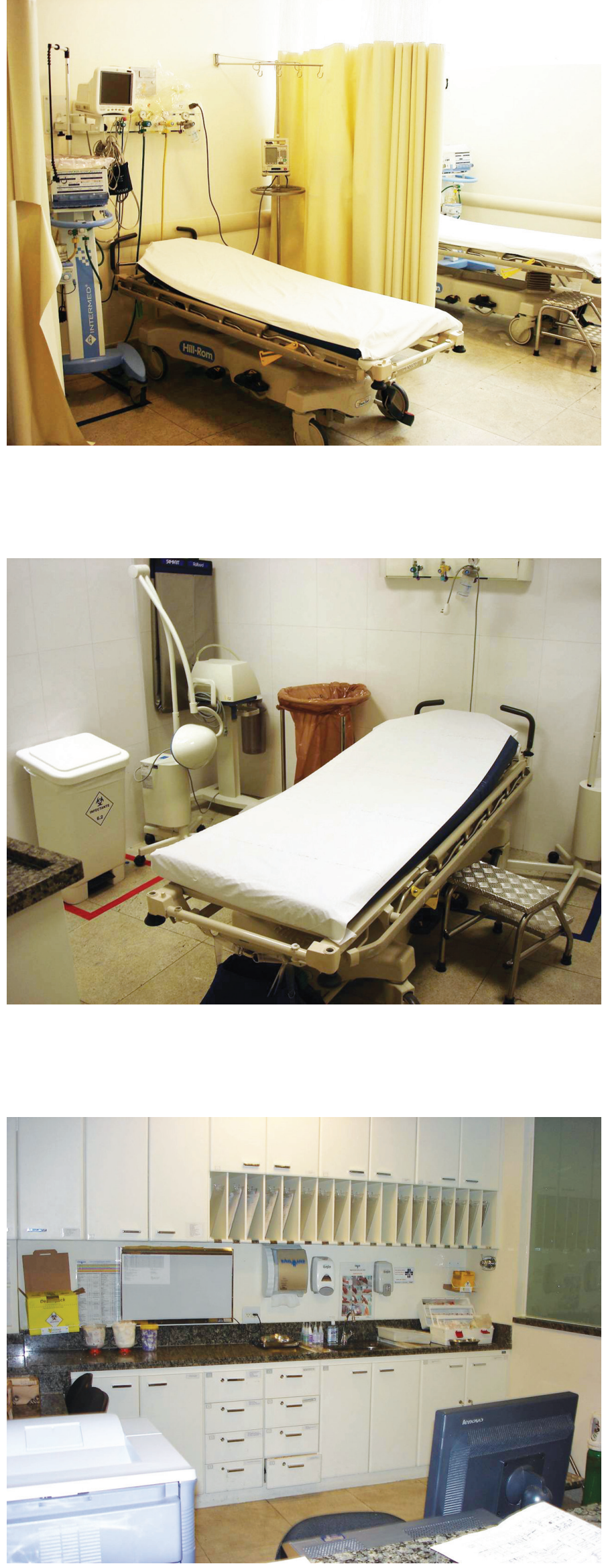

Figura 151 - Sala de emergência (três boxes)

(Fonte: foto do autor)

Figura 152 - Sala de suturas

(Fonte: foto do autor)

Figura 153 - Posto de enfermagem

(Fonte: foto do autor) 
Figura 154 - Sala de emergência pediátrica (Fonte: foto do autor)

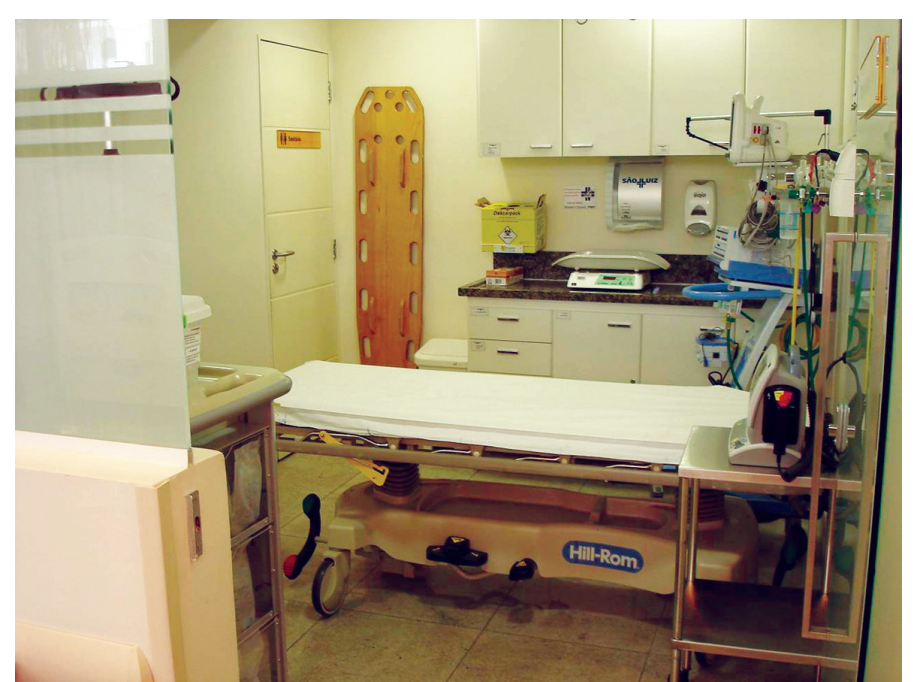

II) Atendimento de Urgência:

- marquise (embarque e desembarque de pacientes);

- recepção (8 guichês);

- sala de espera para adultos com sanitário;

- sala de espera pediátrica com fraldário e sanitário;

- três consultórios pediátricos;

- sala de espera para gineco-obstetrícia com sanitários;

- consultórios para gineco-obstetrícia com sanitários;

- sala de ultrassonografia;

- sete consultórios indiferenciados;

- sala para lavagem intestinal com sanitário;

- três consultórios de ortopedia;

- duas salas de gesso;

- sala de inalação e medicação;

- posto de enfermagem.

III) Áreas de observação e repouso:

- unidades para pacientes adultos contendo 16 boxes (Figura 155);

- apartamento para isolamento adulto com sanitário;

- unidade para pacientes pediátricos contendo o6 leitos (boxes) (Figura 156);

- apartamento para isolamento pediátrico com sanitário;

- posto de enfermagem com área de serviço e prescrição médica. 

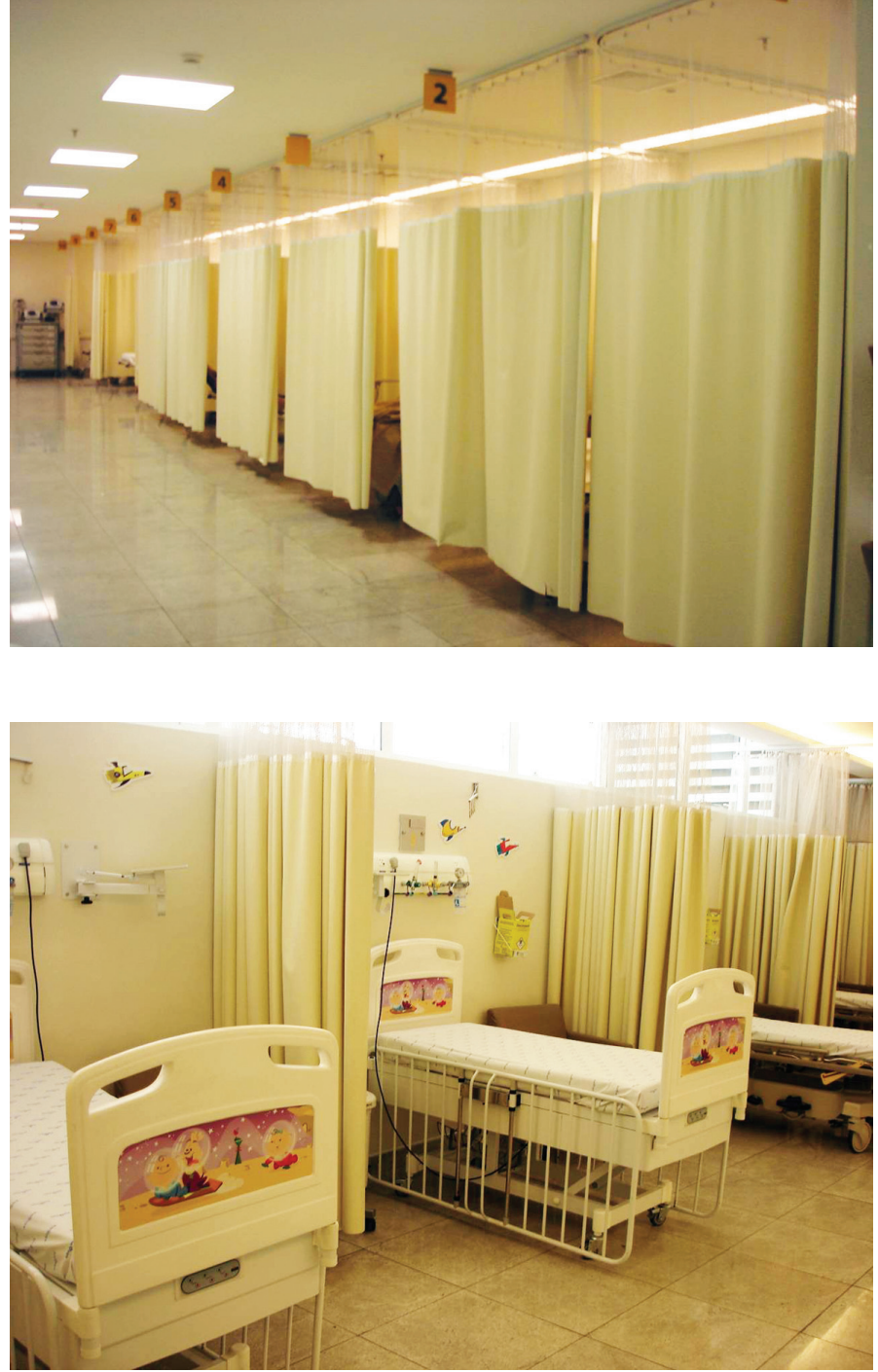

Figura 155 - Áreadeobservaçãoe repouso adulto

(Fonte: foto do autor)

Figura 156 - Áreadeobservaçãoe repouso pediátrica

(Fonte: foto do autor)

IV) Área de uso comum e compartilhado:

- sala de triagem;

- sala de supervisão;

- farmácia;

- expurgo;

- guarda de resíduos;

- sala de reuniões e discussões de casos;

- depósito de material de limpeza;

- sanitários para funcionários;

- sala de agendamentos de consultas;

- quartos para plantonistas com sanitários;

- rouparia;

- depósito de roupa suja;

- sanitários para pacientes;

- sala para coleta laboratorial e classificação de amostras. 


\subsubsection{Relação de contiguidade funcional e fluxos internos}

A contiguidade entre espaços se dá entre dois diferentes níveis, sendo que o primeiro ocorre na relação macro, isto é, na abrangência da Unidade de Urgência e Emergência com as demais unidades que compõem o complexo hospitalar. O segundo nível se estabelece apenas na abrangência do serviço de Urgência e Emergência, considerando-se as relações de proximidade entre os espaços que compõem a própria unidade.

Como analisado anteriormente, no sentido macro, a unidade estabelece relações de proximidade imediata com o Centro de Diagnóstico por Imagem e ainda alguns serviços de apoio logístico, como Conforto de Pessoal, Serviço de Nutrição e Dietética, Laboratórios etc. A partir dos eixos verticais de circulação, através de elevadores para leitos e de serviço, a referida unidade conecta-se com as demais unidades de apoio ao serviço naquilo que se refere à assistência ao paciente. Estas unidades são: Centro Cirúrgico e Obstétrico, Unidades de Terapia Intensiva Geral e Neonatal, Central de Esterilização de Material e Unidades de Internação.

Dentro da disciplina de fluxos estabelecida pela arquitetura, encontra-se o fluxo independente para a retirada dos resíduos, roupa suja e remoção do paciente em óbito, até o morgue.

No âmbito da Unidade de Urgência e Emergência suas relações de contiguidade funcional e fluxos se estabelecem a partir da compreensão de como esta se organiza. Por meio da planta anexa, pode-se observar que a estrutura física da unidade esta composta por cinco núcleos integrados, sendo o primeiro definido pelo atendimento emergencial, o segundo pelo atendimento ambulatorial, seguido do apoio logístico, o quarto pelo suporte ao diagnóstico, concluindo com as áreas de repouso e observação. Para cada uma destas atividades, é possível observar sua estrutura de apoio ofertada, espaço do posto de enfermagem e serviço como um elemento catalisador da assistência. (Figura 157). 



A sala de emergência tem capacidade para atender até 03 pacientes simultaneamente, sendo localizada próxima à entrada da Unidade de Emergência, o qual oferece total eficiência, rapidez e qualidade da assistência ao paciente em estado crítico. Parte integrante deste conjunto de assistência imediata são as salas de suturas e curativos.

A organização eficiente proposta pela arquitetura, no que se refere aos fluxos ambulatoriais de pacientes adultos, gestantes e pediátricos, é a garantia da boa funcionalidade da unidade, preservando as tipologias de atendimento, bem como os melhores enquadramentos do serviço de forma mais adequada à faixa etária do paciente.

As áreas destinadas aos leitos de observação e repouso dos pacientes estão localizadas mais ao fundo da unidade, como que o último estágio do processo de atendimento, antes da tomada de decisão, para que seja feito o seu encaminhamento às Unidades de Internação, Centro Cirúrgico, Obstétrico, UTI's, Morgue e/ou simplesmente a volta para sua casa.

O conjunto de espaços para o repouso dos plantonistas é colocado de forma adequada entre a área efetivamente de emergência e a área de permanência do paciente em observação, para facilitar assim o seu deslocamento na realização e supervisão dos procedimentos junto a esses.

\subsubsection{Acessibilidade}

A Unidade de Urgência e Emergência está implantada em apenas um nível, no pavimento térreo, o que facilita em muito o deslocamento e acesso de pacientes portadores de necessidades especiais, idosos, gestantes e ainda àqueles que são transportados em macas ou cadeiras de rodas.

Não somente para atender às exigências da NBR 9050, em se tratando de acessibilidade, mas, principalmente, para garantir conforto e segurança aos pacientes que nesta unidade de estudo, na maioria das vezes, estão debilitados fisicamente, a unidade está contemplada com alguns sanitários em dimensões adequadas ao acesso de cadeirantes, oferta de barras de apoio junto às peças sanitárias e boxes de chuveiros. 
A acessibilidade apresenta-se também na área coberta de embarque e desembarque de pacientes, com a facilidade de remoção de macas das ambulâncias e no transporte de cadeirantes para o interior da unidade.

\subsubsection{Flexibilidade e Expansibilidade espacial}

Uma das condicionantes projetuais de maior importância para a concepção dos edifícios hospitalares está na organização, com a disciplina do sistema estrutural. Este sistema, concebido simultaneamente com a concepção arquitetônica, é proposto de forma modular (vãos 7,20 m), o qual permite a flexibilidade necessária às unidades do edifício, principalmente pela dinâmica dos serviços, aquisição de novos equipamentos e ainda pelas mudanças ocorridas nos métodos de trabalho.

Aliadas ao sistema modular estrutural, o partido arquitetônico procurou utilizar outros recursos, como a transição de pilares nos níveis inferiores da edificação e, ainda, o uso de paredes em drywall como elemento de vedação dos ambientes. Este material proporciona grande mobilidade de remoção e fácil reorganização espacial.

De acordo com as observações do Engenheiro Virgilio Ramos (2008, p.03), responsável pelo projeto estrutural:

Por serem dinâmicos e constantemente mutantes, os edifícios hospitalares demandam flexibilidade de Layout. Dessa forma, as lajes precisam ser concebidas de maneira a atender eventuais necessidades de cortes e furos para novas instalações. Por este motivo, nenhuma das lajes do edifício conta com protensão: todas são planas, apoiadas sobre pilares espaçados de $7,20 \mathrm{~m}$.

A oferta do forro rebaixado, construído em estrutura de perfis de alumínio e placas removíveis nas áreas de circulação, possibilita a esta unidade facilidade de manutenção, expondo toda sua infraestrutura predial (rede elétrica, hidráulica, lógica, água, gases medicinais etc.). Com isto, torna-se mais fácil o redirecionamento das instalações na medida em que haja necessidade da reorganização espacial. Com a previsão dos shafts 


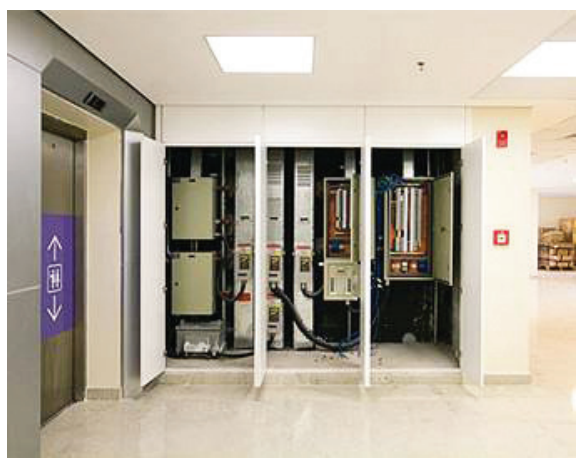

(plano vertical) para abrigar a infraestrutura predial, permite ainda a flexibilidade e expansibilidade desejada ao edifício. (Figura 158).

\subsubsection{Tecnologia ofertada}

A Unidade de Urgência e Emergência possui a estrutura básica para o seu bom funcionamento e,

Figura 158 - Vista dos shafts para instalações prediais

(Fonte: disponível em <www. revistatechne.com.br/engenharia-civil>) principalmente, por meio dela, ofertar segurança e conforto aos usuários deste serviço.

Esta tecnologia está assim distribuída:

- água fria e quente;

- eletricidade;

- telefonia/lógica (sistema integrado de informações);

- prevenção de incêndio, pelo sistema de hidrantes e extintores;

- sistema de proteção contra descargas elétricas;

- sistema de aterramento de aparelhos;

- sistema gases medicinais, como: ar comprimido, oxigênio, vácuo e protóxido de azoto;

- sistema de comunicação;

- sistema de alarme;

- sistema de segurança, por meio de circuito interno de câmeras de TV;

- sistema de som;

- sistema de exaustão e ventilação mecânica.

\subsubsection{Sustentabilidade}

A concepção do projeto arquitetônico procurou contemplar diversas soluções que venham a contribuir para o uso eficiente de energia. Ofertar grandes aberturas aos espaços externos, aproveitando a luz natural, e uso de soluções para as esquadrias com a utilização de vidro duplo e reflexivo para se obter o isolamento acústico e térmico são algumas das inovações que a arquitetura propõe. (Figuras 159 e 160). 

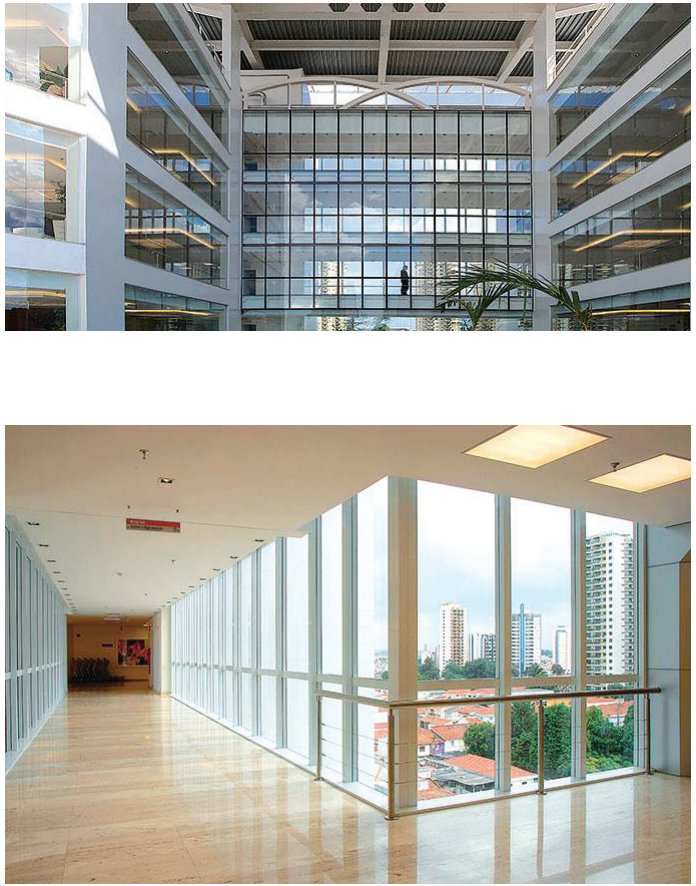

Figura 159 - Vista do atrium central

(Fonte: disponível em $<$ www. arcoweb.com.br $>$ )

Figura 160 - Vista do corredor interno

(Fonte: disponível em $<w w w$. arcoweb.com.br>)

A colocação de persianas internas/entre vidros é a garantia da dosagem certa sobre a incidência do raio solar nos ambientes, bem como o controle da assepsia.

Nos programas que extrapolam o campo da arquitetura, mas que se apoiam nesta como garantia do espaço adequado à sua função, encontra-se o gerenciamento de resíduos produzidos junto à Unidade. Este programa baseia-se na RDC n ${ }^{\circ}$ 306/ ANVISA - MS, que hoje encontra-se bastante consolidado. O PGRSS (Plano de Gerenciamento de Resíduos dos Serviços de Saúde) estabelece a classificação e coleta dos resíduos desde sua origem. A separação ocorre para os resíduos com a classificação em reciclável, orgânico, infectante/perfurocortante e químico, entre outros.

\subsection{Humanização}

A arquitetura proposta, pela sua magnitude e ousadia, busca refletir no edifício o nível de modernidade e contemporaneidade para que possa atender à tecnologia hospitalar ofertada, e colocálo no mesmo plano dos avanços da medicina.

As salas de espera traduzem a preocupação com o conforto dos usuários. Com suas dimensões amplas, divididas por tipologia e faixa etária e com a oferta de equipamentos, como televisão e 
periódicos, proporcionando bem-estar ao paciente. Estas salas, na sua maioria, estão interligadas ao espaço exterior, o que lhes permite maior luminosidade e transparência, permitindo assim dar noção de tempo, clima e principalmente condições e oferta de ventilação natural.

Em algumas áreas, principalmente junto à unidade pediátrica, foram utilizadas cores e desenhos relativos ao repertório da criança, objetivando romper a imagem hospitalar e a hostilidade do espaço. (Figura 161).
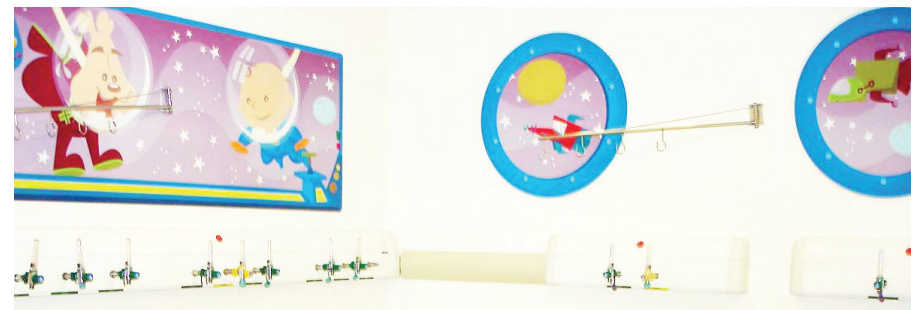

$\pm$

Figura 161 - Área demedicaçãoe inalação pediátrica (Fonte: foto do autor)

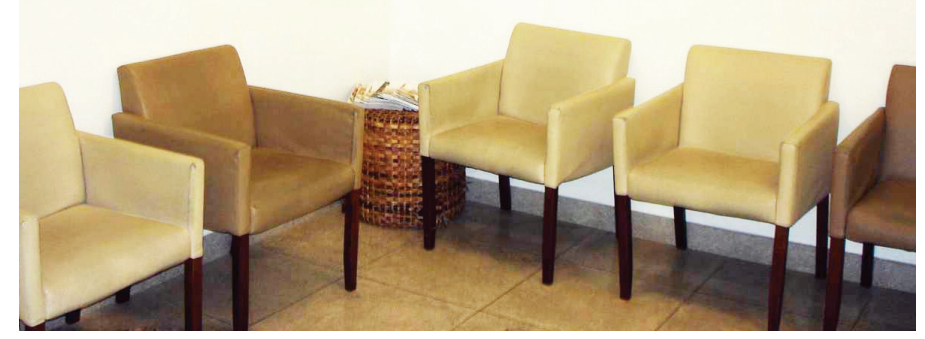

Nas áreas de procedimento, atendimento emergencial, suturas, curativos, observação e repouso, entre outras, a arquitetura oferece a definição do espaço a ser utilizado, com o objetivo de garantir a privacidade e a individualidade ao paciente. Isto de alguma forma proporciona, por consequência, maior segurança e confiança nos serviços ofertados ao enfermo. 



\section{DIRETRIZES \\ PROJETUAIS NA GERAGAO}

DA ARQUUTETURA PARA UNDDADES DE URGENCA EMERGENCIA 

A plena compreensão sobre a Unidade de Urgência e Emergência passa, sem dúvida alguma, pelo completo conhecimento sobre o complexo hospitalar, no que se refere ao seu papel no contexto de atenção à saúde local e/ou regional e seu desempenho frente aos usuários, prestadores de serviços e grupo profissional.

Como objeto deste estudo, a Unidade de Urgência e Emergência de alta complexidade visa, inicialmente, estabelecer um foco de atenção específico a uma das unidades que compõem o edifício hospitalar, não somente pela particularidade do atendimento, mas também pelos níveis e variedades de sentimentos e emoções, em que todos os seus personagens (pacientes, familiares, profissionais de saúde, grupo operacional) estarão envolvidos.

Como colocado, é premissa desvendar o todo para se conhecer a parte. A visão sistêmica sobre a produção arquitetônica a ser desenvolvida é de fundamental importância, isto porque muitas decisões a serem tomadas terão o impacto no conjunto, podendo colocar-se aqui alguns deles, como: sistema operacional, métodos de trabalho, relações de contiguidade ao nível inter e intrafuncional, oferta de tecnologia, infraestrutura predial, flexibilidade e expansibilidade espacial, para citar apenas alguns deles. 
Muito antes da geração da arquitetura, caberá, no âmbito das discussões do grupo gestor, a arquitetos, engenheiros e demais profissionais envolvidos compreenderem como a instituição irá produzir os serviços de atenção analisando e estudando com descontínuo quais tendências futuras que impactarão sobre o processo, e em decorrência sobre o edifício, de sorte a projetá-lo para a modernidade. (BROSS, 1999 , p. 01).

Para tentar desvendar este cenário, é preciso investir em planejamento, que, se inicialmente físico, poderá decorrer ao operacional, patrimonial, recursos humanos, gestão administrativa e assistencial. Planejar é preciso.

Tanto para as unidades novas como também e principalmente para os complexos hospitalares já existentes, é necessário que se estabeleça um Plano Diretor de Organização e Expansão Física que possa nortear as decisões futuras, com a consistência necessária para se evitar erros e maximizar acertos. Isto se justifica quando falamos de uma das mais complexas estruturas administrativas e operacionais, o hospital. Complexidade que se exprime, nos vários níveis institucionais, financeiros, tecnológicos, gerenciais, ambientais e de infraestrutura, exigente de uma abordagem projetual embasada no próprio paradigma da complexidade. (REIS, 2000, p. 30).

Após a discussão e formatação do modelo de atenção a ser implantado para o serviço de urgência e emergência é que o processo projetual deverá ocorrer. Este processo, por meio dos primeiros croquis, esboços e materialização do pensamento arquitetônico, é que consolida a tradução dos anseios da comunidade hospitalar envolvida e, desta forma, é que os arquitetos, com o objetivo de promover a discussão até a sua exaustão, propõem o modelo físico-assistêncial desejado.

Esta fase do projeto de arquitetura é extremamente rica e maravilhosa, pois toda a força conceitual, conhecimento técnicoconstrutivo e a latente sensibilidade dos profissionais envolvidos, unem-se, sinergeticamente, para a obtenção de resultados da alta qualidade projetual.

Para melhor ilustrar este cenário, e demonstrar a riqueza e o domínio projetual do arquiteto, colocam-se aqui alguns croquis do arquiteto Figueiras Lima (Lelé), os quais enriquecem e nos referenciam como produção arquitetônica. (Fig. 162 e 163). 


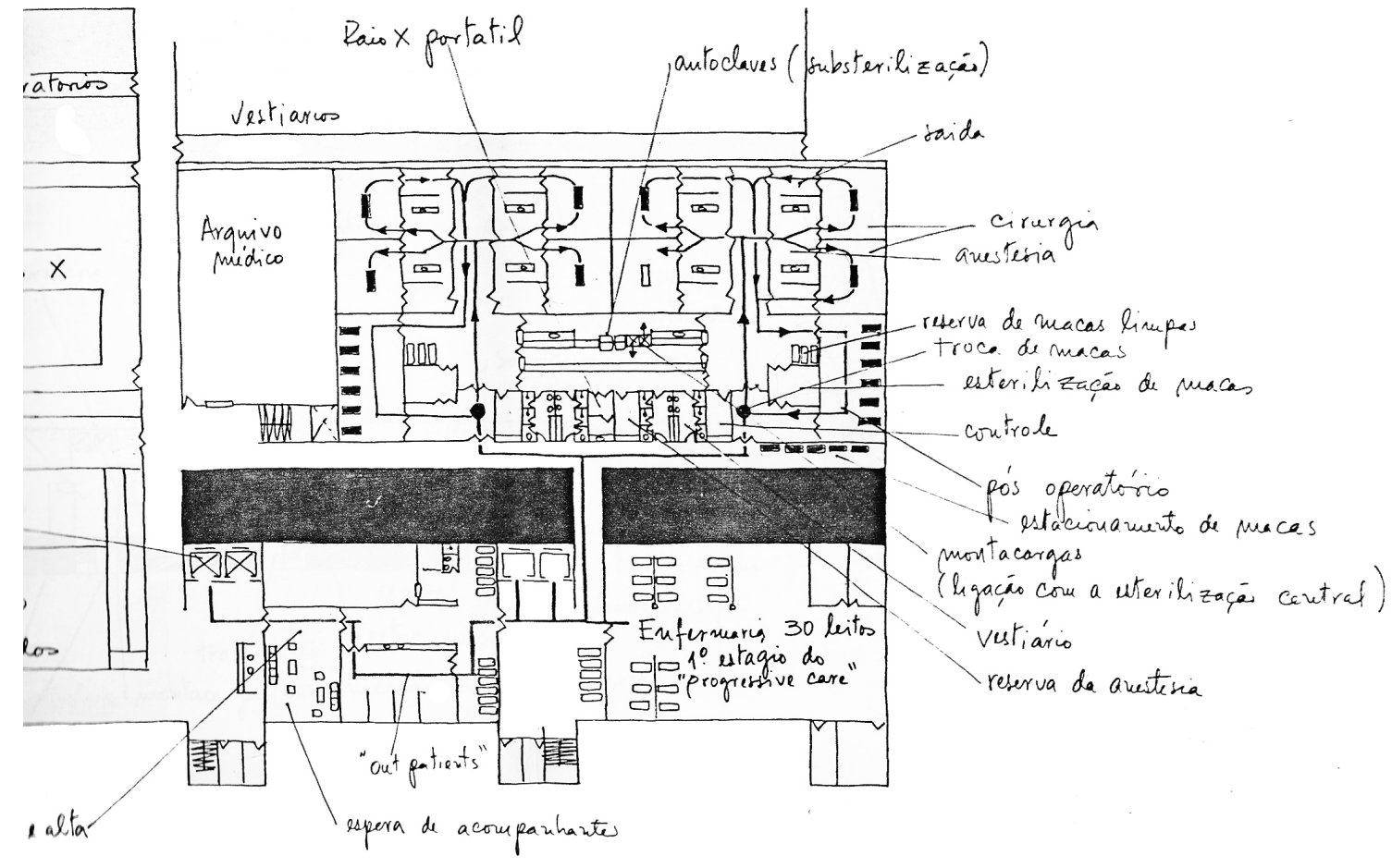

Figura 162 - Croqui planta Hospital Sarah / Brasília - DF

(Fonte: autor, 1985)

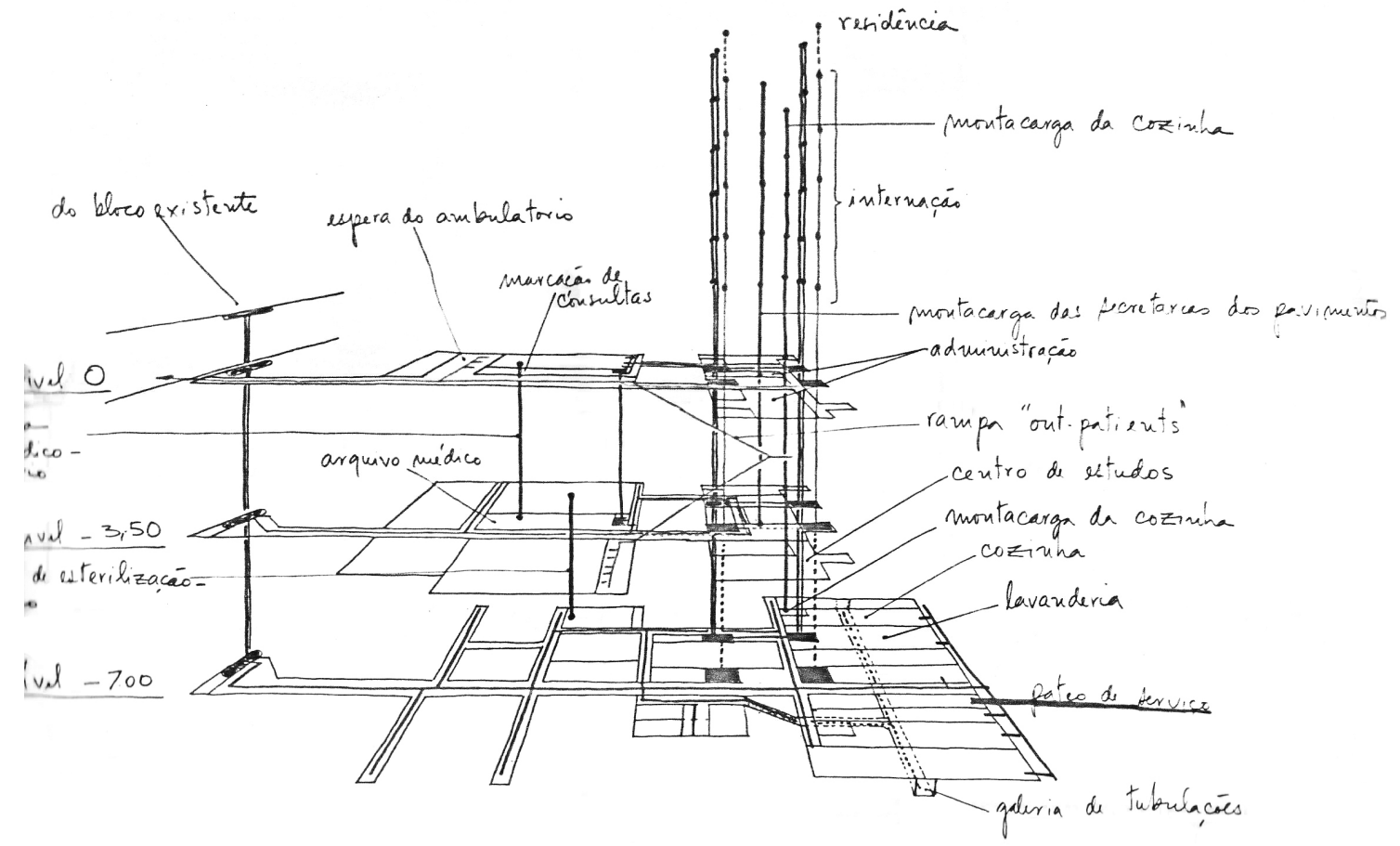

Figura 163 - Croqui corte esquemático/ perspectivado. Hospital Sarah/ Brasília - DF

(Fonte: autor, 1985) 
Para o desenvolvimento da arquitetura do complexo hospitalar ou da Unidade de Urgência e Emergência, o processo metodológico é o mesmo. Ao se estabelecer, no conteúdo deste trabalho, um conjunto de diretrizes projetuais para a unidade em tela, procura-se nortear uma linha de raciocínio, buscando a reflexão sobre cada item observado, os quais se colocam como imprescindíveis para o bom funcionamento da unidade em foco. De longe, de muito longe, pensou-se que esta proposta de trabalho deva ser enxergada como um roteiro metodológico de projeto, ou um "check list" ou ainda "uma receita de bolo". No entanto, ele foi elaborado para abrir espaços e contribuir com a melhoria da qualidade projetual na conquista de unidades de urgência e emergência eficientes.

\section{I A Inserção da Unidade de Urgência e}

\section{Emergência no Contexto Político de Atenção a Saúde do Paciente em Estado Crítico}

A proposta da inserção de uma nova unidade hospitalar de alta complexidade, objeto deste estudo requer muito além do entendimento de organização funcional, pois passa primeiramente pelo papel que esta unidade irá desempenhar no contexto da política assistencial de saúde do município e/ou região em que será implantada.

Em se tratando de Unidade de Urgência e Emergência de alta complexidade, esta estará sempre atrelada aos hospitais gerais ou especializados de grande porte. Isto significa, pela sua magnitude e importância, a necessidade de uma leitura mais profunda e cuidadosa no que se refere à sua introdução ao sistema hierárquico de saúde.

Com olhar mais abrangente, torna-se imprescindível a leitura de vários fatores, anteriores à definição da arquitetura, quando do momento da sua concepção. Alguns desses fatores, a serem discutidos e analisados pelo grupo gestor, estão aqui elencados.

- A necessidade da população em consonância com as diretrizes do Conselho Municipal de Saúde.

- Indicadores de saúde como:

| taxa de natalidade; 
| taxa de mortalidade geral;

| taxa de mortalidade infantil;

| doenças sazonais (dengue, $\mathrm{H}_{1} \mathrm{~N}_{1}$, gripes, alergias respiratórias, meningite meningocócica, pneumonias etc.);

| taxa do crescimento populacional;

densidade demográfica na área de abrangência;

| perfil do serviço a ser ofertado;

| existência de outros serviços com as mesmas características assistenciais;

| existência de serviço pré-hospitalar;

| existência de recursos humanos capacitados e qualificados para o suporte operacional;

| número de leitos ofertado no município e região;

| indicadores de segurança e violência urbana;

| indicadores de acidentes e volume de tráfego de veículos e motos, entre outros;

Estes indicadores preliminares, após serem analisados com bastante profundidade, poderão substanciar as decisões futuras.

Com essas características, o hospital, bem como a Unidade de Urgência e Emergência, estará atuando ao nível terciário de assistência à saúde, como referência e contrarreferência do sistema hierarquizado municipal e/ou regional de saúde.

\subsection{A Inserção da Unidade de Urgência e Emergência no Contexto Urbano}

Com o perfil claro de assistência em que a unidade hospitalar irá atuar, sua localização será de suma importância para que se atinja os objetivos inicialmente propostos.

A escolha do terreno terá papel decisivo no desdobramento de todo o processo; sendo assim, a análise de algumas opções de lotes é sempre benéfica. Isto permitirá estabelecer, para cada uma das opções, seus pontos positivos e negativos para a implantação do edifício. Algumas experiências equivocadas neste sentido têm demonstrado que o processo é abortado ainda na sua fase inicial, ou em um curto período de operação após o seu funcionamento. Portanto, algumas considerações deverão nortear esta escolha para que se possa ofertar maior potencialidade de êxito ao empreendimento. 
Pelas características da unidade em estudo, é importante ressaltar que, no âmbito do lote e do espaço urbano, esta deve possuir boas condições de acessibilidade aos usuários, como também clara identidade visual para que o direcionamento ao serviço ocorra no menor espaço de tempo.

Como medida facilitadora neste processo, é recomendável que a unidade esteja conectada ao sistema viário urbano principal, através de fluxo rápido (viasarteriais) ecom dimensões satisfatórias para o acolhimento e escoamento do tráfego mais intenso. Esta solução permitirá a acessibilidade (veículos próprios, motos, táxis ou transporte coletivo) de forma mais tranquila e segura, ocasionando ainda boas condições para remoção e transferência de pacientes para outras unidades hospitalares, bem como a saída de ambulância no resgate de pacientes externos.

Outra consideração importante é quanto à oferta de infraestrutura urbana ao lote. Isto é, que ele seja abastecido por rede de água potável, rede de esgoto, energia elétrica, telefonia, pavimentação, coleta de resíduos, transporte coletivo, entre outros.

Evitar a proximidade de vizinhos indesejáveis como parque de diversões, ginásios ou estádios de esportes, quartéis, indústrias poluidoras (fumaça, odor, e/ou poeira), aeroportos, sede do corpo de bombeiros, indústrias de alto risco, depósito de resíduos ou produtos tóxicos e perigosos, cemitérios (efeito psicológico negativo), outras fontes de ruídos etc., é sempre imprescindível.

Analisar a predominância dos ventos na região para que este fator não prejudique o empreendimento quando colocado à jusante ao parque industrial. Isto poderá trazer, mesmo que não seja pela vizinhança imediata, permanente desconforto aos usuários do complexo hospitalar, pelo direcionamento de odor, fumaça, poeira etc.

Outra consideração a ser feita é quanto às dimensões do lote. É importante ressaltar que o hospital pela sua complexidade, magnitude e dinâmica dos serviços prestados está em mutação contínua. Isto significa adaptações às áreas existentes e, principalmente, expansões para atender às demandas reprimidas e/ou implantação de novos serviços.

Sendo assim, é sempre recomendável que sua ocupação inicial não seja maior que 30 a 35\% da área total do terreno. Esta é uma 
decisão importante no início do processo, pois é o que garante um crescimento mais disciplinado.

Considera-se ainda que a composição das áreas verdes e edificadas seja de forma equilibrada, para que permita condições necessárias e satisfatórias de ventilação e insolação aos ambientes externos e internos.

Outra condicionante importante a ser considerada é o que se trata da legislação urbana, no que se refere ao lote em estudo, isto é: taxa de ocupação, coeficiente de aproveitamento de lote, gabaritos de altura do edifício, cone de voo de aeronaves, recuos frontais e laterais etc., os quais serão determinantes na escolha do lote, para que este atenda às necessidades atuais e futuras do empreendimento.

Ainda como ponto de análise do lote urbano, deverá ser verificado o nível de intervenção que o complexo hospitalar possa provocar no entorno edificado e/ou natural. Fatores como o aumento do volume de tráfego de veículos e motos, uso de infraestrutura urbana, surgimento de novos serviços, como lanchonetes, restaurantes, farmácias, laboratórios, clínicas, entre outros, nos demais lotes do bairro, proporcionarão um impacto de vizinhança bastante significativo. Tais serviços tendem a gravitar no entorno do edifício hospitalar já nos primeiros anos de sua implantação e operação. Isto significa que a curto prazo ocorrerá um nível de adensamento populacional bastante elevado na região, provocando assim a sobrecarga na infraestrutura urbana instalada.

Por tratar da questão de fluxo de veículos e motos, é necessário que a região e o complexo hospitalar disponibilizem áreas para estacionamento a todos os tipos de veículos (pequenos, médios, grandes, vans, ambulância, ônibus e motos), contemplando assim as necessidades de todos os usuários. Os veículos particulares há muito tempo deixaram de ser apenas um conforto, tornando-se para muitos um essencial instrumento de trabalho.

Conforme salienta Toledo (2004, p. 12),

[...] outro ponto de importância na escolha de um terreno é sua topografia. Áreas urbanas com altas ou moderadas declividades podem tornar as implantações dispendiosas, quando não afetarem a funcionalidade do edifício. O parâmetro de $10 \%$ de declividade para soluções horizontais é aceitável. 
Tirar partido da declividade do terreno é sempre um desafio para os arquitetos, porém, os diferentes níveis estabelecidos junto a este poderão contribuir para a disciplina e hierarquia de fluxos. Pode ainda, a declividade do terreno, mesmo aquelas mais acentuadas, proporcionar ao arquiteto maior liberdade de criação para a composição volumétrica final do edifício em estudo.

Diagnosticar as condições do solo é sempre recomendável para se obter informações sobre o nível de afloramento de rocha e/ou lençol freático, fatores estes que influenciam diretamente sobre os custos da edificação, acentuando as dificuldades técnicaconstrutivas.

A composição de cinco fatores como declividade do terreno, vias de acesso (sistema viário ofertado), ângulos visuais interessantes, insolação e predominância dos ventos irão influenciar em muito a concepção do partido arquitetônico. Isto poderá significar a escolha mais verticalizada para o edifício, onde a base terá a função de abrigar a todos os serviços de atendimento ao paciente e familiar de forma ambulatorial, como também serviços de apoio ao diagnóstico, hospital-dia e serviços de apoio logístico e operacional. Por sua vez, a "torre" terá o papel de alojar os serviços que acolhem os pacientes por um período mais longo, como as UTI's e as Unidades de Internação. Este modelo clássico (base, torre e coroamento) tem-se consolidado na grande maioria de soluções verticalizada ou mistas.

Terrenos mais planos e favorecidos pela oferta de vias de acesso podem oferecer boas condições para implantação de edifícios com soluções mais horizontalizadas.

Solução como esta poderá melhorar as condições de expansão futura de unidades já edificadas, bem como favorecer ainda soluções modulares na medida em que a implantação seja gradativa dos blocos que compõem o complexo hospitalar, sem que com isto venha a comprometer o sistema operacional do edifício já em operação.

As vias de acesso podem disciplinar os fluxos externos de forma decisiva para o bom funcionamento da unidade hospitalar. Portanto, deve-se estabelecer pelo menos três acessos como número mínimo, para garantir a disciplina desejada:

- acesso principal ao complexo hospitalar;

- acesso à unidade de urgência e emergência; 
- acesso aos serviços gerais (abastecimento logístico e operacional).

Para hospitais-escola, pode-se considerar também a possibilidade de um quarto acesso a alunos e professores envolvidos diretamente com as atividades de ensino e pesquisa, mas ainda interligados com o hospital.

\subsection{A Inserção da Unidade de Urgência e Emergência na Abrangência do Lote}

As unidades em estudo, pelo perfil do seu atendimento, sempre estarão agregadas aos grandes complexos hospitalares com serviço de alta complexidade.

No contexto do hospital, é necessário que a Unidade de Urgência e Emergência esteja isolada da circulação de pessoas estranhas ao serviço e que possua também independência de fluxos às áreas de apoio e diagnóstico e ou logístico, tais como: Centro Obstétrico e Cirúrgico, Unidades de Internação, UTI's, Diagnóstico por Imagem, Lavanderia, Nutrição, entre outros.

Pelas características do atendimento imediato, a unidade em estudo é localizada ao nível térreo, no extremo da edificação, colocada perifericamente ao conjunto hospitalar. Nestas condições lhe permitirá maior facilidade de expansão futura e conexão com a Unidade de Diagnóstico por Imagem, sendo que para esta também é recomendável que esteja neste pavimento por facilidade de instalações prediais e contiguidade funcional com a Unidade de Emergência, bem como na realização de exames eletivos.

O acesso à Unidade de Urgência e Emergência deve ocorrer por vias amplas e livres de congestionamentos, providas de placas indicativas e vias de desaceleração. Os bolsões para paradas do transporte coletivo deverão sempre ser posterior à entrada da unidade, para que não obstruam o tráfego, consequentemente bloqueando os fluxos de atendimento emergencial.

A coligação entre o uso da comunicação visual urbana e busca de maior identidade ao acesso da Unidade de Emergência é sempre recomendável. Segundo Kohlsdorf (2005, p.56) 
[...] esses indivíduos têm, geralmente, menos tempo de experiência com os edifícios em questão, do que o pessoal que neles trabalha, e ainda uma decodificação rápida do estabelecimento de saúde reduz tempo de acesso ao mesmo, o que é de vital importância em função do tipo de atendimento fornecido por ele.

Outros fatores poderão influenciar positivamente na identidade visual desejada. Vale lembrar, aqui, que esta identidade não passa apenas pelo valor meramente estético, mas sim no sentido de se estabelecer a fácil visualização ao adentrar o serviço de emergência.

Sendo assim, quando do fechamento da composição volumétrica da proposta arquitetônica, é recomendável que a unidade em estudo tenha, dentro da hierarquia estabelecida, papel relevante e personalidade própria para a conquista do objetivo proposto.

A permeabilidade visual, desde o espaço urbano até as áreas de embarque e desembarque de pacientes em emergência, como também os recuos frontais imediatos à unidade em estudo, permitirão maiores condições de absorção visual do edifício, contribuindo substancialmente para a visualização do conjunto arquitetônico.

Evitar a competitividade formal e volumétrica com outros edifícios do entorno imediato poderá contribuir para sua melhor identidade.

Devem-se buscar soluções que venham compor as áreas de estacionamento para veículos, vias de acesso e áreas verdes de forma equilibrada, tanto no aspecto da diminuição do calor, como também no sentido compositivo das massas vegetais.

Grandes áreas pavimentadas de estacionamento, junto às unidades de emergência, exalam continuamente o calor, principalmente em regiões mais quente do país, elevando a níveis insuportáveis de temperatura. Além disso, apropriar-se de jardins bem cuidados, com manutenção periódica, escolha de plantas e flores adequadas, proporcionará efeitos positivos a todos os usuários da unidade hospitalar, evidenciando sua beleza natural.

A massa vegetal existente, em que se relaciona com tipos de árvores nativas e de grande valor paisagístico, será forte condicionante na concepção do projeto arquitetônico. Sua 
preservação poderá contribuir favoravelmente no desdobramento de soluções para o conforto termoacústico e luminoso do ambiente hospitalar.

Conforme salienta Oliveira e Ribas (1995, p.22):

$\mathrm{O}$ ambiente projetado, respeitando as características ambientais da área onde se insere, só tem a ganhar em termos de qualidade ambiental. Os sistemas de controle das condições de conforto térmico, acústico e luminoso a serem desenvolvidos encontram dessa forma um terreno fértil, um palco onde as condicionantes ambientais negativas já foram suprimidas ou reduzidas, tornando-se, portanto mais eficientes.

\subsection{Fluxos Externos}

$\mathrm{O}$ acesso à Unidade de Emergência sempre é caracterizado como crítico. Para o paciente que chega a esta, com dor, angústia, sofrimento, incerteza e insegurança, depara-se com um mundo alheio ao seu dia a dia. As áreas de espera e recepção, naquele primeiro momento, refletem repulsa e aversão. Porém, é neste local que poderão solucionar seus problemas.

Por distorções do sistema de saúde, em que os níveis primários e secundários de atenção não cumprem verdadeiramente seus papéis, as unidades terciárias de emergência sofrem com a superlotação do serviço à busca da resolutividade tão preconizada na teoria, no entanto, encontra-se só na teoria.

Como ressalta Elza Costeira (2003, p.117),

A grande procura dos atendimentos de urgência e emergência, dos hospitais municipais, acaba gerando distorções nas suas entradas e a necessidade de ampliação do numero de salas de triagem (avaliação de risco), nos acessos e "portas de entrada" de suas estruturas, ocasionando mistura de perfis de pacientes e patologias, para o devido encaminhamento aos consultórios e serviços.

Para tais distorções, a arquitetura é apenas um instrumento do processo. Sem a conquista de um sistema de saúde adequado e totalmente operante torna-se difícil a obtenção da qualidade desejada. Com as dificuldades estabelecidas pelo sistema, pela 
sazonalidade das doenças em determinados períodos do ano (dengue, meningite meningocócicas, gripes, resfriados etc.) e o surgimento de bactérias superesistentes, como a kpc (Klebsiella Pneumoniae Carbapenemase), por exemplo, é na concepção e no bom dimensionamento dos espaços que o arquiteto deverá ofertar bons resultados. Romper com a distemia instalada e inerente ao ambiente hospitalar é o desafio maior dos responsáveis pelo projeto arquitetônico.

Para a Unidade de Urgência e Emergência, os fluxos externos, vinculados a partir da entrada ao serviço, devem separar os acessos de urgência (sem risco de vida) da emergência (paciente em estado crítico), bem como a separação do fluxo à obstetrícia e pediatria é sempre recomendável.

No acesso à urgência, após sua identificação e registro, o paciente será encaminhamento à sala de avaliação e classificação de risco, para que possa ser dimensionada a gravidade da sua enfermidade. Esta avaliação é feita por um médico e/ou uma enfermeira.

Quanto ao acesso de emergência, este deverá ocorrer de forma imediata e diretamente à sala de emergência, pronta para receber o paciente em estado grave. Com o pleno funcionamento do sistema SAMU, o resgate pré-hospitalar deverá comunicar à Central de Regulação Médica, que irá indicar qual unidade de emergência hospitalar terá total condição de receber este paciente.

Para este caso, a concepção do projeto arquitetônico deverá contemplar o acesso independente, distante dos agrupamentos de pessoas no sentido de facilitar a remoção e o encaminhamento do referido paciente.

\subsection{Programa Físico-Funcional}

A partir do completo entendimento sobre o perfil de assistência que a Unidade de Urgência e Emergência irá atuar é que darse-á o inicio das discussões com o grupo gestor e/ou equipe multidisciplinar, na elaboração do programa físico-funcional ou programa de necessidades.

Com pleno conhecimento sobre a realidade local para que se obtenham bons resultados e eficiência do serviço, a montagem do programa físico passa por uma discussão profunda, considerando 
assim as particularidades e/ou especificidades operacionais a serem respeitadas.

Considerações iniciais com base na resolução RDC n50/ ANVISA, e toda a legislação pertinente nas três esferas de gestão, as quais deverão fazer parte do processo de concepção do edifício hospitalar.

Distorções apresentadas e decorrentes do falho sistema de saúde deverão ser analisadas pelo grupo gestor, pois esses influenciarão em muito os primeiros estudos da unidade hospitalar.

Alguns exemplos relacionados abaixo podem demonstrar o grau de interferência na montagem das necessidades funcionais:

- dimensões generosas para as áreas de espera geral (todos os tipos de pacientes) ou específica (adultos, pediatria, obstetrícia, idosos) para abrigarem a grande demanda da população que busca o serviço de emergência (nível terciário) por total falha do sistema de saúde. Isto é: Não encontra a solução do seu problema nas UBS’s (primário) ou hospitais locais (secundários) e que por consequência se dirigem aos hospitais de grande porte, na certeza de serem atendidos. Por consequência os sanitários anexos a essas áreas também deverão ser dimensionados para o contingente populacional;

- permanência longa do paciente ao leito, a qual ultrapassa o limite máximo de 24 horas, preconizado como necessário para a rotatividade do atendimento de emergência, traz por consequência a superlotação, o desconforto e o estresse.

- Este fator está muito relacionado com a baixa oferta de leitos nas Unidades de Internação e Unidades de Terapia Intensiva. Isto poderá significar que, em alguns casos, os boxes de atendimento aos pacientes em estado crítico serão ocupados por pacientes "internados" em estado grave, os quais deveriam estar ocupando leitos na UTI;

- permanência prolongada de pacientes pediátricos e geriátricos, sobre os quais se preconiza o acompanhamento do familiar junto ao leito, poderá contribuir para as distorções de uso. Isto significará na oferta de espaços físicos, como sanitários com chuveiros, área de estar, copa e local para guarda de pertences, para que a funcionalidade não seja comprometida e garanta o nível de humanização e acolhimento desejável a todos; 
- a previsão de espaços para atividades específicas como áreas de referência para médicos, enfermeiras e técnicos será sempre benéfica à boa funcionalidade hospitalar;

- espaço para discussões de casos, principalmente para os edifícios voltados ao ensino e pesquisa, será necessário disponibilizá-lo para que o docente e o grupo de alunos possam fazer uma avaliação mais criteriosa do caso e em condições mais adequadas e confortáveis;

- espaços para o acolhimento da família, para que em caso de esclarecimento sobre o real nível de gravidade do qual se encontra o paciente, é importante que isto não ocorra nos corredores, ou junto ao leito do referido paciente. Espaços como estes poderão abrigar os familiares, quando receberem a noticia do falecimento do ente querido, onde poderão permanecer por algum tempo para assimilação da triste notícia. Vale reforçar, aqui, que é neste mesmo momento, quando já constatada a morte cerebral do paciente, que o médico ou a enfermeira dará a notícia com pesar, solicitando aos familiares, logo em seguida, a doação de órgãos;

- dimensionar adequadamente o número de consultórios médicos para o atendimento à população ao nível de urgência é também bastante importante. Isto significa levar em consideração as especialidades médicas de maior demanda pela população assistida;

- por problemas internos operacionais, as áreas de almoxarifado, farmácia e depósito de material médicohospitalar, muitas vezes, por falhas de abastecimento, passam pela necessidade de abrigar produtos por períodos mais longos de estocagem, como garantia de não haver sua falta na assistência ao enfermo. Questões administrativas e operacionais como estas devem ser avaliadas e corrigidas para que não promovam falhas ao sistema.

De acordo com Gomes (2004, p.11): "A complexidade das unidades de emergência cria a necessidade de uma adequação de seu uso aos recursos humanos e materiais disponíveis, para que haja contínua avaliação e adaptação das práticas assistenciais".

Para que o atendimento ao paciente seja satisfatório, indo de encontro às suas necessidades, é importante considerar alguns aspectos gerais: 
- definição da área física e de facilidades;

- atitudes novas e dinâmicas em relação à atuação em áreas emergenciais;

- enfermagem permanente, com treinamento específico;

- pronta avaliação médica, com ações contínuas e rápidas interferência nos processos críticos;

- estabelecimento de funções, normas, tipos de condutas, padrões de avaliação e execução das diferentes atividades;

- manutenção de um alto padrão nos cuidados médicos e de enfermagem;

- contato constante e direto entre pacientes, seus familiares e equipe de saúde.

Com este tipo de abordagem, indica que o processo de concepção, materialização e operação da unidade em estudo para sua eficaz e eficiente implantação, é necessário que se tenha uma visão sistêmica sobre a realidade operacional e o perfeito desempenho dos diversos tipos de "atores" envolvidos neste desafio. Somente assim poderá ser alcançada a resolutividade e o alto padrão de qualidade e produtividade desejado.

\subsection{Macrozoneamento / Setorização}

Como já exposto no capítulo cinco deste trabalho, a unidade de emergência abrange na sua organização funcional cinco subsistemas. É importante possuir bom entendimento das diversas atividades que ocorrem junto à referida unidade para a tomada de decisões mais acertadas.

Os subsistemas são:

- recepção, acolhimento e registro do paciente;

- atendimento ao enfermo e aos familiares;

- apoio ao diagnóstico e tratamento;

- observação e repouso;

- apoio logístico e operacional.

A setorização "intramuros" dos espaços que compreendem os subsistemas acima citados poderá organizar, pela priorização na assistência ao paciente, compreensão dos diversos fluxos envolvidos (pacientes, acompanhantes, visitantes, médicos, enfermeiros, técnicos, apoio logístico etc.), obtendo assim facilidade operacional e estabelecimento dos eixos de circulação. 
Com os primeiros esboços, a consolidação dos conceitos arquitetônicos e a tradução inequívoca do entendimento sobre as relações de contiguidade espacial entre os diversos ambientes, poderá assim ser formatada a proposta espacial da unidade. A espacialização dos organogramas é sempre positiva ao processo de concepção do projeto arquitetônico. São os primeiros ensaios anterioriores à materialização do produto arquitetônico.

\subsection{Relacionamento com Outras Unidades do Complexo Hospitalar}

A Unidade de Urgência e Emergência pelo papel que desempenha na estrutura do complexo hospitalar exige, para o seu bom funcionamento e aquisição de alto nível de qualidade e resolutividade, uma boa e adequada relação com outras unidades que lhe darão o suporte necessário para se atingir os objetivos propostos.

Num primeiro plano de prioridade em atenção ao paciente, coloca-se a unidade de Imagineologia, Centro Cirúrgico e Obstétrico, e UTI's como suporte imprescindível para a sua assistência, em que o tempo nesta relação é fator determinante na realização dos procedimentos e na conquista de bons resultados sobre a preservação da vida do paciente assistido.

No plano secundário colocam-se as Unidades de Internação, Laboratório de Análises Clínicas e Morgue.

Ao nível terciário, ficarão as unidades de apoio logístico e operacional, como: Farmácia, Almoxarifado, Central de Esterilização de Material, Lavanderia, Serviço de Nutrição e Dietética, entre outros.

\subsection{Circulação e Fluxos Internos à Unidade de Urgência e Emergência}

Os eixos principais de circulação serão estabelecidos pela concepção geral do complexo hospitalar, definidos pela arquitetura e/ou pelo Plano Diretor de Organização e Expansão Física, 
principalmente para os edifícios já existentes que necessitam ainda mais desta ferramenta norteadora de crescimento futuro.

À reboque destas determinações estabelecidas pelo complexo hospitalar, a unidade em estudo deve possuir na sua organização interna a hierarquia dos eixos de circulações para que promova a boa disciplina funcional.

Segundo Matos (2008, p.64):

Um edifício que não funciona corretamente pode, por exemplo, trazer problemas de orientação aos visitantes, desgaste físico aos funcionários através do aumento das distâncias a serem percorridas e do tempo gasto na realização das tarefas, bem como aumento nos custos com sinalização, barreiras divisoras dos fluxos, controle de infecção hospitalar, segurança e vigilância, proteção contra incêndios mecanismo de preservação e saídas, entre outros.

A compreensão correta de todos os fluxos internos envolvidos e a correta determinação dos eixos de circulação são inerentes à boa prática projetual. $\mathrm{O}$ arquiteto, nesse aspecto, deve dar resposta objetiva e precisa, pois será com a boa solução arquitetônica que se garantirá a adequada funcionalidade esperada.

De acordo com Kohlsdorf (1995, p. 75),

As circulações internas dos estabelecimentos de saúde são os elementos mais importantes de seu sistema informativo, pois, ligando os diversos departamentos e os irrigando com trajetos, conduzem, naqueles, os diferentes usuários, todos responsáveis pelas atividades desenvolvidas nos hospitais. É nelas e através delas que se decodifica a estrutura funcional dessas edificações e quanto melhor for a compreensão, mais se estará contribuindo ao bom desempenho das atividades de atendimento à saúde.

A correta articulação funcional entre os eixos primários e secundários de circulação, fluxos internos dos diversos tipos de usuários, programa físico-funcional e macrozoneamento deverão ofertar as diretrizes de organização da Unidade de Urgência e Emergência imprescindíveis articulações para se atingirem bons níveis de qualidade operacional. Com isto, permitirá nortear o 
crescimento futuro e reforçará os princípios de expansibilidade que a unidade possa requerer.

Para os eixos de circulação principal interno à unidade, é importante ressaltar a separação entre a circulação de público em geral, que estará para o seu primeiro atendimento, e a circulação mais restrita ao grupo operacional e pacientes acompanhados. Esta disciplina de fluxo será um dos fatores positivos na conquista da boa funcionalidade almejada. (Figura 164).

As vias de circulação secundária serão necessárias para o encurtamento de percurso e muitas vezes para a definição do macrozoneamento funcional. Vale lembrar que as vias secundárias deverão ser tratadas de forma que não venham a romper os eixos principais e promover os conflitos de público e grupo operacional.

A Unidade de Urgência e Emergência possui, com o envolvimento dos diversos tipos de usuários que se utilizam dos seus serviços, dois grandes fluxos, aqui relacionados.

a) Fluxos interfuncionais (relação com diversas outras unidades hospitalares, como observado no item 7.6).

b) Fluxos intrafuncionais (circulação dos diversos tipos de usuários, equipamentos, apoio logístico etc.) no interior da unidade. 


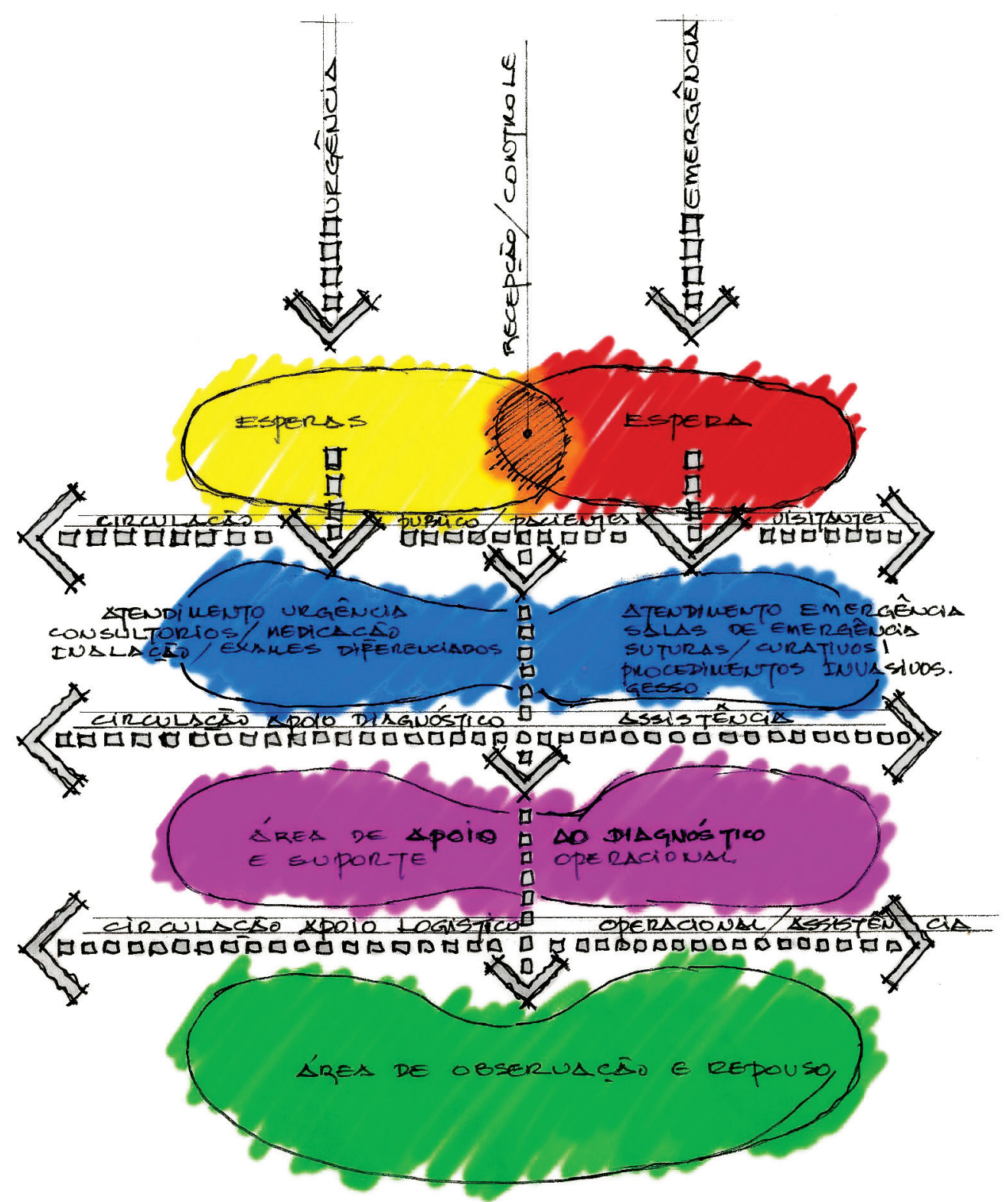

Figura 164 - Disciplina de fluxos e hierarquia dos eixos internos de circulação.

(Fonte: autor, 2011).

Para um estudo mais detalhado dos fluxos intrafuncionais, deve-se compreender a função dos principais "atores" deste cenário interno à unidade em tela.

- Paciente interno:

| o fluxo do paciente interno está relacionado ao seu tipo de assistência e acompanhamento pelo grupo operacional até o local de atividade terapêutica que poderá ser de urgência ou emergência, conforme o nível de gravidade do caso; 
o paciente quando em condições de mobilidade poderá ser encaminhado ao Centro de Diagnóstico por Imagem, para exames específicos e em seguida retornar à unidade de emergência, onde aguardará seus resultado e a avaliação médica;

| a coleta de secreções para exames laboratoriais é feita no leito de observação e repouso ou na sala de medicações. Outra possibilidade será o encaminhamento do paciente, quando em condições de deslocamento até a sala de coleta laboratorial.

- Acompanhantes:

| o familiar constituirá o fluxo interno de acompanhamento ao enfermo durante sua primeira assistência, bem como junto às áreas de observação e repouso. $\mathrm{Na}$ assistência aos pacientes de pediatria, obstetrícia e geriatria será sempre imprescindível o acompanhamento familiar.

- Visitantes:

é o grupo de pessoas que adentrará a unidade para a visita ao paciente em observação. Isto ocorre em Unidades de Urgência e Emergência que possuem pacientes em observação por mais de 24 horas. Porém, de qualquer forma deverá possuir horário estabelecido para isto e determinação das áreas onde será permitido o seu acesso para que se garanta o bom funcionamento e segurança da unidade.

- Grupo operacional:

| o grupo operacional é constituído de médicos, enfermeiros, auxiliares, farmacêuticos, assistentes sociais, psicólogos, técnicos, terapeutas, zeladoria, segurança, entre outros, os quais trafegam por toda a unidade. Estas pessoas, na sua grande maioria, são procedentes das áreas de conforto de pessoal (vestiário/sanitários/estar) junto ao setor de serviço do hospital geral.

- Apoio logístico:

| é constituído pelo abastecimento dos diversos tipos de insumos necessários para a boa funcionalidade da unidade. Este fluxo deve ocorrer necessariamente pelo eixo principal mais restrito (serviço), onde fará a distribuição 
de medicamentos, material médico-hospitalar, material de limpeza, equipamentos, entre outros, procedentes do setor de serviços gerais do hospital. Materiais esterilizados serão encaminhados a partir da Central de Esterilização de Material;

| alimentação e roupa limpa virão a partir das unidades de Nutrição/Dietética e Lavanderia respectivamente, sempre se utilizando do eixo de circulação de serviço da unidade. Vale lembrar que o transporte desses materiais é sempre recomendável em carros fechados.

- Material contaminado e resíduos:

| o material contaminado é constituído por roupa suja, louça e talheres, instrumental, acessórios e equipamentos utilizados nos diversos tipos de procedimentos, os quais retornarão as respectivas unidades de origem para serem limpos e reprocessados;

| os resíduos serão classificados na origem conforme determinação da RDC 306/ANVISA, coletados e encaminhados à Central de Resíduos para que posteriormente seja adequadamente dado o seu destino final; novamente, vale lembrar que o transporte desses materiais e resíduos deverá ser feito por meio de carros fechados, funcionários treinados e paramentados adequadamente;

| considerarainda que o abastecimento de todo equalquer tipo de insumo, bem como a retirada de material contaminado e resíduos, deverão ser sempre em horários preestabelecidos para que não ocorram conflitos, congestionamento de pessoas e carros de transporte, os quais poderão prejudicar o sistema operacional e a assistência ao doente na unidade em estudo.

- Paciente em óbito:

| pelas características e nível de complexidade da unidade, é frequente o óbito de pacientes. É importante que sua saída da unidade e encaminhamento ao morgue seja feita pela circulação mais restrita de serviço, para que o fato não crie o efeito psicológico negativo a todos os usuários envolvidos na unidade. 


\subsection{Plano Diretor de Organização e Expansão Física}

Condicionante importante a ser considerada no planejamento físico das Unidades de Urgência e Emergência, é a existência do Plano Diretor de Organização e Expansão Física, desenvolvido principalmente para hospitais existentes, estabelecendo assim o norteamento necessário para a reestruturação e crescimento do complexo hospitalar. Por motivos já observados, como a evolução da medicina, avanços tecnológicos em equipamentos e procedimentos médico-enfermagem, crescimento da demanda de assistência à saúde, modificações nos sistemas operacionais, oferta de novos serviços, entre outros, é provocado no edifício uma permanente mutação para que este se adeque a uma nova realidade e atinja a modernidade almejada.

Sendo assim, a Unidade de Urgência e Emergência faz parte deste organismo vivo, de permanente transformação. A própria unidade em estudo que, ao longo dos anos, possua a necessidade de crescimento no seu número de consultórios tem algumas possibilidades inerentes ao serviço de urgência e emergência, tais como oferta de serviços em novas especialidades médicas, crescimento na oferta de leitos de observação, aumento no número de boxes ou salas de emergência.

Embora o Plano Diretor de Organização e Expansão Física seja elaborado para o complexo hospitalar em sua plenitude, a Unidade de Urgência e Emergência estará sempre no contexto desta proposta. Princípios básicos como conceituação, concepção arquitetônica, flexibilidade, expansibilidade, programa físicofuncional, potencial de atualização, contiguidade, setorização, conformidade, fluxos, custos e humanização espacial nortearão a montagem do Plano Diretor de Organização e Expansão Física.

Segundo Miquelin (1992, p. 228): “Os objetivos básicos do Plano Diretor incluem":

- devem fazer parte deste relatório as estratégias para o financiamento dos custos da construção e equipamentos para as várias fases;

- recuperar ou implantar através das obras de reestruturação do edifício níveis adequados de eficácia de funcionamento, usualmente soterradas por sucessivas "cirurgias" não planejadas no edifício; 
- orientar as ações administrativas atuais e futuras na tarefa de reorganização física do hospital. Sem o Plano Diretor, a administração não se conduz por metas, mas sim como um bombeiro apagando os pequenos e grandes incêndios do dia a dia;

- estabelecer etapas de desenvolvimento adequadas ao parcelamento factível dos investimentos em construção, equipamentos, recursos humanos etc., conforme as possibilidades de financiamento dos custos dos investimentos;

- durante as fases de implantação do Plano, diminuir o impacto de interferência das obras com os serviços de atendimento.

Considera-se importante, pelas características abordadas no permanente processo de transformação do edifício hospitalar e, em particular, da Unidade de Urgência e Emergência, que o Plano Diretor de Organização e Expansão Física seja reavaliado periodicamente e realinhado com eixos norteadores da nova realidade.

A elaboração do Plano Diretor Físico poderá abrir espaços de discussões sobre o empreendimento em geral, com o desencadeamento de novos caminhos de gestão, abordando as áreas de recursos humanos, patrimônio, políticas administrativooperacionais, modelo gerencial e assistencial.

\subsection{Expansibilidade e Flexibilidade Espacial}

O dinamismo nos complexos hospitalares, como também em Unidades de Urgência e Emergência, está ligado à própria essência das atividades desenvolvidas no atendimento aos pacientes em estado crítico.

As questões ligadas à expansibilidade e flexibilidade espacial estão inerentes à concepção do edifício hospitalar por inteiro. Os princípios balizadores destes preceitos são também importantes para as diretrizes projetuais envolvidas com a geração do produto arquitetônico da unidade em tela. 
Algumas unidades que compõem o edifício hospitalar têm uma vocação maior para o crescimento futuro, no caso, a Unidade de Urgência e Emergência é uma delas. Caberá ao grupo gestor e/ou multiprofissional estabelecer as tendências futuras para o empreendimento, discernindo, desde a fase inicial de discussões, as metas e estratégias a serem conquistadas.

Baseado nos objetivos propostos para o complexo hospitalar, como também na visualização das carências locais e/ou regionais de serviços ofertados, e ainda na ampliação da oferta de leitos, entre outros, poderá o grupo gestor obter a ferramenta necessária para estabelecer as diretrizes de gestão e consequentemente ao produto arquitetônico desejado.

Para a arquitetura, cabe-lhe dar respostas que facilite as tomadas de decisões, buscando alternativas projetuais que venham de encontro às necessidades atuais e futuras da instituição hospitalar. Isto não significa atribuir ao arquiteto a função de futurólogo, mas sim proporcionar mecanismos de atualização e expansão dos espaços, de forma compatível, exequível e ordenada.

A hierarquia e a disciplina de fluxos internos e externos à unidade estabelecerão os eixos principais e secundários de circulação, que, quando distribuídos corretamente, poderão nortear o crescimento físico, de forma adequada, para atender às novas demandas solicitadas. Este crescimento, pelas características da unidade implantada ao nível do lote, será horizontal. Neste caso, é necessária a disponibilidade de terreno para atender tal solicitação.

Dentro desses princípios, tem se discutido muito o conceito "open building", como uma abordagem ao projeto e construção de edifícios que permite aumentar a eficiência do processo construtivo e, ao mesmo tempo, aumentar a sua flexibilidade e qualidade. Um edifício deve ser visto como uma combinação organizada de sistemas e subsistemas; o local, a estrutura, as paredes interiores, as instalações de água, esgoto, elétrica, mecânicas, o mobiliário etc., independentes, mas interdependentes. Na proposta do "open building", ao se separar os sistemas e subsistemas uns dos outros, mais facilmente se pode melhorar a organização do edifício, maior controle pode haver na sua adaptabilidade e maior flexibilidade na sua utilização. 
Outras alternativas em arquitetura têm sido adotadas com o objetivo de proporcionar a flexibilidade e expansibilidade do espaço hospitalar, como:

- estabelecer hierarquia e disciplina de fluxos externos e internos à unidade, para que se estabeleçam os eixos principais e secundários de circulação, que quando distribuídos corretamente podem nortear o crescimento físico futuro;

- ofertar junto à Unidade de Urgência e Emergência áreas adjacentes de terreno que lhe permitirão as condições de crescimento futuro;

- disponibilizar "shafts" (armários para instalações verticais), com o objetivo de concentrar instalações compatíveis entre si, facilidade de manutenção preventiva e curativa;

- utilizar materiais adequados, leves e de fácil remoção, como paredes em dry wall, gesso acartonado e estrutura de alumínio;

- ofertar espaços de forro falso nos pavimentos, principalmente nas áreas de circulação, onde as instalações prediais terão facilidade de derivações e também manutenção periódica facilitada. Nestes casos, o forro deve ser removível, colocado sobre estrutura metálica e construído em material resistente e de fácil limpeza. A articulação de uso entre o rebaixamento de forro removível e shafts poderá ter o casamento perfeito na obtenção da flexibilidade e expansibilidade desejada;

- disponibilizar "andar técnico" ou "espaço intersticial" sobre unidades de alta complexidade construtiva, sendo a Unidade de Urgência e Emergência uma delas, na qual poderá proporcionar o crescimento e a adaptabilidade almejada. Este espaço, colocado sobre a laje de forro da unidade, terá todas suas instalações aparentes, garantindo assim a total autonomia da manutenção, bem como a facilidade de redirecionamento das instalações, quando se fizer necessário;

- ofertar a modulação estrutural em conjunto com a proposta arquitetônica, de forma que se obtenham vãos mais generosos e compatíveis com as necessidades espaciais, bem como atingir o equilíbrio econômico pelo fator custo/ benefício; 
- ofertar a modulação arquitetônica, não somente como diretriz à concepção estrutural, mas também em busca de racionalização do processo de projeto e obra.

Este processo, já bastante utilizado para grandes empreendimentos por vários arquitetos, tem sido também um instrumento de trabalho para a geração do projeto do edifício hospitalar. Segundo Pantenello (apud CARVALHO; TAVARES, 2002, p. 1)

A coordenação modular consiste num sistema capaz de ordenar e racionalizar a confecção de qualquer artefato, desde o projeto até o produto final. Esta ordenação e racionalização se efetiva, principalmente, pela adoção de uma medida de referência chamada módulo, considerado como base de todos os elementos constituintes do objeto a ser confeccionado

A leitura feita sobre a produção na área hospitalar por arquitetos de reconhecida qualidade projetual (Brags, Karman, Fiorentini, Pompeu, Lelé, Zanettini, apenas para citar alguns) tem demonstrado com frequência a utilização deste instrumento na maioria da sua produção arquitetônica.

A modulação contribui para a racionalização do processo construtivo, pois garante a flexibilidade de combinação de elementos, além de favorecer uma precisão maior na definição e alcance de medidas. Também contribui para o aumento da repetição de componentes e para a produção em série, já que, ao fixar uma medida básica da qual as demais devem ser múltiplo ou mesmo submúltiplo, limita as variações dimensionais para um mesmo elemento construtivo. (CARVALHO; TAVARES, 2002, p. 2).

Os autores acima citados fazem ainda algumas observações sobre as vantagens e desvantagens no uso do sistema modular.

- Possibilita o emprego dos componentes na construção em seu espaço designado sem a necessidade de modificações do projeto para a obra, evitando gastos e perda de tempo.

- Adequa as características da construção civil aos processos de produção industrial.

- Proporciona maior produtividade da mão de obra.

- Reduz prazos para a execução da obra.

- Melhora o entrosamento entre projetistas, fabricantes de materiais e executores da obra pela adoção de parâmetros 
comuns, facilitando a coordenação do projeto e a manutenção do edifício.

- Algumas desvantagens são aqui apresentadas.

- Pode limitar a variedade de projetos e induzir a uma padronização das soluções, o que se torna um empecilho frente à diversidade de necessidades reais.

- Comumente cria uma repetitividade na aparência das edificações.

- Necessita de grande especialização da mão de obra, obrigando a contratação de profissionais de bom nível educacional, o que nem sempre existe em disponibilidade no mercado a um preço competitivo.

- Obriga a instalação de central defabricação de componentes, o que onera os custos iniciais do empreendimento, justificando apenas a execução de grande quantidade de unidades.

- Algumas soluções limitam o número de fornecedores de materiais e serviços, encarecendo o produto e levando ao risco de descontinuidade na execução.

- Para não ocorrer à obsolescência física, o edifício hospitalar necessita se adaptar e principalmente acompanhar as mudanças. No entanto, os métodos e materiais de construções tradicionais, ainda largamente utilizados nas edificações atuais, tem sido a dificuldade de dar respostas satisfatórias a estas mudanças.

A obsolescência física ocorre não somente pelo desgaste natural dos materiais, mas também quando não há manutenção periódica das instalações em geral. Por outro lado, a oxigenação permanente dos serviços ofertados, atualização de equipamentos de ultima geração e, ainda, a constante manutenção das instalações físicas requerem que a saúde financeira do complexo hospitalar esteja em plena forma. Porém, esta não é a realidade brasileira, principalmente para hospitais públicos e filantrópicos espalhados por este país afora. Por razões crônicas de investimentos na saúde, desde a distorção do uso específico de impostos para a área (CPMF, por exemplo) até o mau emprego e fiscalização do dinheiro público tem ocorrido. O sucateamento é latente.

Além disso, associada a este cenário tem-se a má gestão hospitalar, que em alguns casos observa o anacronismo de 
medidas e decisões ultrapassadas longe da realidade assistencial, operacional e mercadológico.

\section{II Conformidade}

Inerente aos conceitos de flexibilidade e expansibilidade espacial agrega-se os princípios de conformidade, que consiste em atentar para que o edifício como um todo e, em particular, a Unidade de Urgência e Emergência estejam em conformidade com as normas técnicas e posturas públicas.

Ao profissional arquiteto, cabe a preocupação e atenção em acompanhar a evolução e edição de novas normas, portarias e resoluções que tenham interferência no seu processo projetual. Estes cuidados, sobre legislação vigente, devem ser observados nas três esferas de governo (federal, estadual e municipal). Junto ao capítulo 3, deste trabalho, várias resoluções são abordadas, em particular sobre a Unidade de Urgência e Emergência.

A periodicidade nas revisões da legislação pertinente ao edifício hospitalar se faz necessária, tendo em vista a dinâmica e novas técnicas dos métodos de trabalho médico-enfermagem, evolução tecnológica e alterações no sistema gestor e operacional. Esta reavaliação deve ocorrer sistematicamente pelo poder público, junto com a comunidade organizada, para que a própria legislação não atinja níveis de obsolescência e senescência precoce.

\subsection{Arquitetura e Infecção Hospitalar}

Arquitetura e infecção hospitalar sempre caminharão juntas por conta da estreita relação entre si, bem como no permanente reflexo das atitudes geradas pela arquitetura sobre o controle da infecção hospitalar nos edifícios de saúde.

É a partir da década de 1980 que, de forma mais incisiva e aplicativa, os conceitos sobre infecção hospitalar são consolidados. Segundo o Ministério da Saúde (Portaria n²616 de 12/05/1998), "Infecção hospitalar é qualquer infecção adquirida após a internação ou mesmo após a alta, quando puder ser relacionada com a internação ou procedimentos hospitalares”. 
Durante as três ultimas décadas, vários estudos e pesquisas ocorreram, promovendo alterações em conceitos consolidados do passado e que, de forma direta ou indiretamente, refletiam na solução arquitetônica do ambiente hospitalar.

Neste período, os protocolos de rotinas de procedimentos médico-enfermagem foram se consolidando como um instrumento de se garantir as corretas atividades realizadas nas unidades hospitalares.

Preocupação como esta, a própria RDC n50/ ANVISA de Fev/2002 aborda, no seu conteúdo, uma série de cuidados que o profissional de arquitetura deverá relevar no momento da concepção e elaboração do projeto arquitetônico. Novamente aqui, levanta-se a importância do trabalho conjunto multiprofissional, tanto da área médica-enfermagem, como também da tecnologia, para atingir, por meio das experiências individuais em campos específicos de atuação, os melhores resultados para o controle da infecção hospitalar.

A arquitetura, neste cenário, novamente é um instrumento intermediador do processo de assepsia e controle sobre infecção hospitalar, pois sem o efetivo emprego dos preceitos médicoenfermagem exigidos, a arquitetura será inócua. Porém, acreditase que o verdadeiro papel da arquitetura será como parceiro ativo neste processo de prevenção à infecção hospitalar, cabendo-lhe dar respostas satisfatórias e adequadas às necessidades espaciais, funcionais e operacionais exigidas.

Segundo a referida portaria, estabelece-se a classificação dos ambientes físicos pelo nível de assepsia exigido em:

- áreas críticas: são aquelas onde existem o risco aumentado de transmissão de infecção, realizam-se procedimentos de risco ou ainda encontram-se pacientes com seu sistema imunológico deprimido;

- áreas semicríticas: são todas as áreas ocupadas por pacientes com doenças infecciosas de baixa transmissibilidade e doenças não infecciosas;

- áreas não críticas: são todas as áreas hospitalares não ocupadas por pacientes.

Para as Unidades de Urgência e Emergência, pode-se aqui classificar conforme critério acima estabelecido em: 
- áreas críticas: salas de emergência e procedimentos invasivos;

- áreas semicríticas: salas de suturas, curativos, observação e repouso, consultórios, entre outros;

- áreas não críticas: salas de apoio logístico e operacional.

Vale lembrar que, quando em situações de descontrole ocupacional, provocado pela superlotação da unidade, tendo em seus leitos de emergência boxes de observação e repouso, macas em consultórios médicos, pacientes graves com aplicação de sondas, cateteres, invasão de veias e artérias mais profundas, entubados ou ainda traqueostomizados, estes locais são considerados como áreas críticas.

A arquitetura poderá contribuir com alguns recursos na sua organização física ou disponibilidade na sua infraestrutura predial. Estes recursos serão quanto ao estabelecimento de disciplina de fluxos operacionais, organizações dos eixos principais e secundários de circulação, espaços dimensionados adequadamente para efetiva e correta realização da atividade ali determinada, bem como instalações de lavatórios para lavagem das mãos pela equipe médica-enfermagem. Outros cuidados relacionados aos materiais de acabamentos de pisos, paredes e teto, bem como a utilização de ralos escamoteáveis, equipamentos de fácil limpeza e manutenção, como trilhos para cortinas (boxes de atendimento ao paciente), porta soros, luminárias, focos cirúrgicos, telas em aberturas de janelas contra entrada de insetos, são recomendáveis para a boa qualidade espacial.

A disponibilidade de lavatórios em todos os ambientes, que assistem ao paciente, sempre será necessária pela importância das mãos no processo de transferência de agentes potencialmente contaminantes, pelo contato pessoa a pessoa.

Como recomenda Fiorentini (1995, p. 31):

Os pacientes em observação e repouso, nas Unidades de Urgência e Emergência, bem como a própria equipe hospitalar (médicos, enfermagem e outros) e, também, os visitantes, teriam proteção mais segura com a universalização da rotina de lavagem das mãos e após o ingresso no quarto, ou, antes e após o atendimento ao paciente acamado. 
A instalação dos lavatórios nos ambientes hospitalares exigidos deve possuir torneira com acionamento que não seja o do toque das mãos. Isto significa a instalação de torneiras providas de outros mecanismos, como sensor automático, acionamento por pé, ou ainda outros com semelhantes características.

O cuidado com o sistema de acionamento pelo pé, em particular a instalação fixa e incrustada no piso, poderá a borracha de proteção à válvula de comando, ao longo do tempo de sua utilização, vir a sofrer o ressecamento e soltura, provocando assim o acúmulo de água de lavagem do ambiente e, consequentemente, promovendo a criação e proliferação de fungos e bactérias.

Nas áreas que antecedem o espaço da sala de procedimentos invasivos é recomendável a instalação de lavatórios, tipos "lavabos cirúrgicos", como garantia da perfeita escovação das mãos e braços, recomendação esta inerente ao tipo de procedimento a ser realizado. O acionamento de água, dispensação de sabão temporizador líquido e de antissépticos devem ser por comando de pé, joelho, cotovelo ou sensor automático.

O sistema de ar condicionado e exaustão é também mais um personagem deste cenário, como elemento interveniente no processo de controle sobre a infecção hospitalar.

Além do sistema acima mencionado ser concebido e instalado corretamente, é inerente, à conquista do seu bom funcionamento, que seja feita a manutenção na limpeza de filtros e dutos periodicamente, utilizando métodos de higiene adequados.

A classe de filtros, número de renovações por hora, umidade relativa do ar nos ambientes hospitalares, nível de temperatura e o sistema de insuflamento e retorno devem estar condizentes com as necessidades técnica-funcionais estabelecidas em projeto específico.

Para as salas de maior controle de assepsia, deve-se trabalhar com sistema de pressão positiva do ar, promovendo assim apenas a saída do ar interno para o espaço adjacente.

Soluções com aparelhos individualizados de ar condicionado, "tipo janela", são totalmente inadequadas, pois esta possui bandejas sob o equipamento, no qual se acumula água, potencializando a criação de fungos e bactérias. Além disso, oferecem condições de calor e umidade propícias à cultura de micro-organismos. 


\subsection{Ergonomia e Acessibilidade}

O profissional arquiteto, envolvido com os diversos níveis de complexidade relacionados ao projeto arquitetônico, em muitos casos, coloca as questões sobre ergonomia em "segundo plano", até mesmo por desconhecer de forma mais profunda as atividades funcionais de cada ambiente que constitui a unidade hospitalar.

Como bem observa Souza (2000, p. 1):

A ergonomia é uma área de estudo ampla, que utiliza conhecimentos de várias ciências para constituir uma sistemática de análise e intervenção de forma a propiciar uma melhor adaptação do trabalho ao homem. Uma análise ergonômica se baseia tanto em dados físicos, antropométricos e avaliações dimensionais quanto de avaliações ao nível fisiológico, biológico e psicossocial, procurando identificar aspectos perniciosos ao homem [...].

A arquitetura deve responder às necessidades funcionais, nas quais se relacionam com a minimização dos espaços ou dispêndios gratuitos de energia, promovendo desta forma o bemestar dos usuários em geral.

A resposta esperada está diretamente ligada ao bom desempenho dos resultados nas áreas de conforto visual/ estético, luminoso, acústico, térmico, entre outros. Com as primeiras preocupações, nestes aspectos citados, na maioria das vezes voltada ao paciente, no entanto, o grupo operacional é, sem dúvida, pela sua permanente presença, o mais afetado pelos desajustes que possam ocorrer, portanto, a adaptação é necessária para atender questões não solucionadas arquitetonicamente.

A busca de soluções para estes problemas faz-se necessária ainda na fase preliminar de discussões com o grupo gestor e equipe multiprofissional para a geração da arquitetura. Colocamse aqui alguns pontos a serem observados inerentes ao processo projetual:

- dimensionar corretamente os ambientes da unidade para que sejam adequados para receber todo o mobiliário e equipamentos necessários para a realização da atividade médica-enfermagem; 
- dimensionar corretamente os ambientes da unidade para o perfeito deslocamento de macas de transporte do paciente, que quando em estado grave estará acompanhado de diversos equipamentos (respirador, bomba de infusão, soro etc.) os quais lhe darão o suporte à vida. Esta acoplagem à maca e o grupo operacional de transporte proporcionam a necessidade maior de espaço lateral;

- dimensionar corretamente os ambientes da unidade para deslocamento de cadeiras de rodas nos diversos espaços, como também e principalmente junto às instalações sanitárias. Isto significa, em particular, os cuidados com o sentar e levantar da cadeira de rodas, deslocar-se até a bacia sanitária ou ainda ao box de banho sempre é importante que sejam observados;

- disponibilizar acessórios de segurança e conforto junto às instalações sanitárias, como chamadas de enfermagem no seu interior para qualquer intercorrência médica, barras de apoio junto à bacia sanitária e box para banho. Além disso, cadeiras escamoteáveis para o banho, espelho ajustáveis para a perfeita altura do usuário (principalmente em cadeira de rodas), volantes de lavatório e ducha do tipo monocomando, volante da ducha no interior do box, colocado no seu lado oposto para melhor controle sobre o jato e temperatura da água, e ainda a instalação de ducha higiênica ao lado da bacia sanitária, são sempre recomendáveis;

- disponibilizar bacias sanitárias, com reforço extra, para atender ao paciente obeso;

- disponibilizar equipamento adequado para transporte e transferência de leito do paciente obeso;

- disponibilizar sistema de rolamento para móveis e equipamentos pesados para que se proporcione condições de remoção e/ou deslocamento facilitado;

- disponibilizar todas as instalações elétricas, telefônicas, lógica, hidro-sanitárias, fluído mecânico, entre outras de forma adequadas e compatíveis com a atividade funcional a ser realizada em cada ambiente que constitui a unidade em estudo;

- priorizar distribuição dos ambientes na Unidade de Urgência e Emergência de acordo com a classificação e hierarquização de percurso; 
- disponibilizar iluminação natural, preferencialmente para os espaços de atendimento ao paciente, como também para os ambientes de trabalho de longa permanência do grupo operacional;

- disponibilizar iluminação artificial para ambientes de curta permanência de pacientes ou operadores do sistema. Esta iluminação deve atender às condições mínimas de iluminância, para a realização satisfatória das tarefas e principalmente receber reforço adicional sobre bancadas e/ou planos de trabalhos específicos;

- disponibilizar maior integração entre o espaço interior e exterior, com o objetivo de proporcionar maior permeabilidade visual. consequentemente oferecer melhores condições de ventilação natural ao ambiente hospitalar;

- disponibilizar sistema de ar condicionado e exaustão para as áreas que não possuem ventilação natural. $\mathrm{O}$ sistema deverá atender à especificidade de uso de cada ambiente, pelo grau de assepsia necessário para a realização das atividades ali programadas. Este sistema deverá ainda possuir o controle sobre o nível de umidade relativa do ar ambiente;

- disponibilizar soluções arquitetônicas com diferentes planos de forro e paredes, como recursos para dificultar a propagação de ondas sonoras.

- disponibilizar sistema cognitivo para facilitar o direcionamento dos usuários aos espaços desejados;

- disponibilizar junto ao sistema elétrico, em alguns ambientes onde se fará necessário a colocação de dimmers, para atingir o nível de iluminância adequado para a realização da atividade programada;

- disponibilizar soluções arquitetônicas e mecânicas para minimizar vibrações e ruídos de equipamentos;

- outros.

Quando abordar questões relacionadas à ergonomia, haverá sempre uma inter-relação com a acessibilidade. Em alguns casos, esta abordagem quase que se confunde.

Considerar o paciente, principalmente aquele atendido na Unidade de Urgência e Emergência, debilitado física e emocionalmente, e que em muitos casos encontra-se 
dependente do uso de cadeiras de rodas ou como também da ajuda do acompanhante. Nessas situações, as barreiras (más soluções) arquitetônicas podem segregar este público de exercer plenamente suas atividades de forma adequada e satisfatória. Com a conscientização constante da classe de arquitetos, desde os bancos de escola, há de se atingir níveis elevados de preocupações na elaboração do projeto arquitetônico dos edifícios, e, em particular, o hospitalar. Nesse sentido, a Associação Brasileira de Normas Técnicas (ABNT) criou, em 1985, a primeira norma brasileira que enfoca a questão dos portadores de deficiência, a norma brasileira - NBR 9050/85 sobre a adequação das edificações e do mobiliário urbano à pessoa deficiente. Este trabalho foi realizado por técnicos especializados, em conjunto com portadores de deficiência e usuários dos serviços. Em 2003, foi lançada a edição revisada desta mesma norma - NBR 9050/03.

Conforme salienta Giácomo (2005, p. 71): "A arquitetura que tem como objetivo servir ao homem de forma funcional e estética, não pode seguir ignorando todo um seguimento da sociedade apenas porque ele foge aos padrões estabelecidos de normalidade".

Nesta norma, foram consideradas as pessoas portadoras de deficiência física (semiambulatória ou ambulatória total) deficientes visuais, auditivos e de expressão, deficientes de coordenação motora (paralíticos cerebrais) com problemas reumáticos ou ainda pessoas idosas. A norma abrange também as seguintes áreas de atuação: em edificações - acessos (rampas, portas); circulação interna (corredores, rampas, escadas, corrimão, guarda-corpo e elevadores); sanitários, equipamentos (bebedouros, telefones, maçanetas, ferragem, interruptores e tomadas); sinalização (acesso principal, circulação interna, estacionamento, acesso de veículos à edificação, equipamentos). Para os espaços externos e o ambiente urbano, a referida norma observa sobre calçadas, passeios, jardins, praças, rampas e escadarias, mobiliário urbano (telefones públicos, caixas de correios, bancas de jornal, caixas para lixo, bebedouros, bancos de jardim); sinalização (circulação, travessia de vias públicas, rampas, escadarias e passarelas, estacionamento e equipamento).

Todas estas considerações relativas ao ambiente interno do edifício são inerentes ao perfil do paciente que está em atendimento junto à Unidade de Urgência e Emergência. 
Portanto, cabe ao arquiteto responder adequadamente a essas reivindicações expressas pela sociedade.

\subsection{Conforto Ambiental}

Dentre as diversas condicionantes projetuais que interferem no processo de geração da arquitetura, as questões relativas ao conforto ambiental têm papel relevante sobre os bons resultados qualitativos a serem conquistados.

Para a concepção e desenvolvimento da arquitetura, é inerente a incorporação destes quesitos. Somente assim, com corretas respostas na configuração dos ambientes hospitalares, no que tange sobre o bem-estar, salubridade, agradabilidade, eficiência produtiva, eficiência energética, economia financeira e operacional é que se pode obter a qualidade desejada por todos os usuários da unidade.

Tratar sobre conforto ambiental requer um pensamento mais amplo, naquilo que intervem no processo projetual. $\mathrm{O}$ assunto não é uma questão isolada, e sim enxergar o edifício com uma visão sistêmica, integrada, incorporando elementos já apresentados aqui anteriormente como: implantação do edifício no terreno, topografia, clima, fluxos internos e externos, macrozoneamento organizacional dos espaços internos e externos, qualidade e condições geomorfológicas do terreno, entre outros. As decisões a serem tomadas sobre conforto ambiental são pautadas não somente nas observações acima mencionadas, mas também na postura projetual voltada a conceber o edifício de forma sustentável, segundo Sampaio (2005, p 27): "Significa criar espaços saudáveis, viáveis economicamente e sensíveis às necessidades sociais".

$\mathrm{O}$ assunto conforto ambiental, pela sua especificidade, requer e estabelece preocupações relevantes quanto à oferta e qualidade da iluminação natural e artificial, ventilação, cor, sinalização, mobiliário e equipamentos, conforto térmico e acústico, sendo que alguns destes são observados apenas de forma sensitiva, porém todos devem ser tratados ao mesmo nível de importância com os demais componentes técnicos do edifício hospitalar.

Por questões também já tratadas, como a permanente mutação dos ambientes hospitalares, a adaptabilidade do 
edifício às suas novas funções nem sempre se tem obtido bons resultados. Na maioria das vezes, os funcionários, o pessoal médico e enfermagem passam pela necessidade desta adaptação ao seu ambiente de trabalho, gerando desconforto, distorções ergonômicas, fadiga e desânimo. Aos pacientes e familiares, resta-lhes a absorção dos espaços frios, impessoais, cálidos e até mesmo mal-educados (agressivos), fatores esses que acentuam os sentidos de insegurança, estresse, vulnerabilidade e medo.

Conforme salienta Vianna e Gonçalves (2001, apud GIACOMO, 2005, p. 74): "os fatores que intervêm no conforto ambiental são inúmeros e diferem em magnitude, essência em seu carácter pragmático". O esquema da figura 165 exemplifica a totalidade dos fatores intervenientes no conforto ambiental das edificações, em cada uma de suas subáreas - conforto higrotérmico, insolação, iluminação natural e artificial, ventilação natural, acústica arquitetônica e urbana equacionadas em três níveis distintos: aqueles relativos ao clima e ao meio ambiente, aqueles relativos ao projeto e construção das edificações e da cidade, e, por fim, aqueles relativos ao próprio usuário.

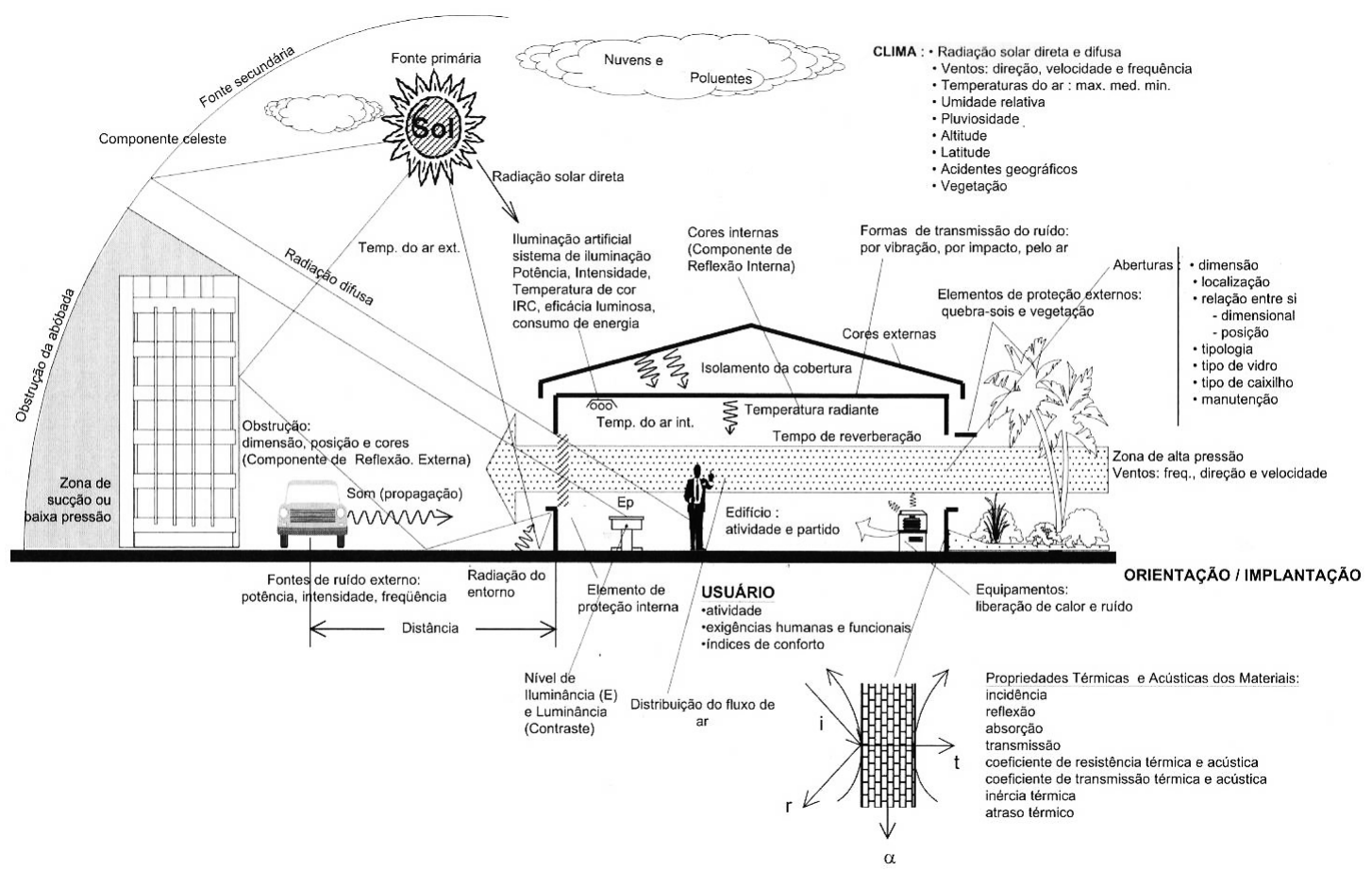

Figura 165 - Fatores intervenientes no conforto ambiental das edificações.

(Fonte: VIANNA, N.; GONÇALVES, J., 2001) 


\subsection{Conforto Térmico}

O controle da temperatura do corpo humano é feito por dois tipos de mecanismos reguladores: um mais delicado como o fluxo do sangue da pele e outro nem tanto, como arrepios e suor. As exigências humanas de conforto térmico variam razoavelmente de região para região, pela adaptabilidade do homem às condições climáticas.

O metabolismo é o fenômeno no corpo humano que controla a perda da quantidade de calor, em repouso e até àqueles momentos de atividades mais intensas e árduas. Somente será considerado como bom nível de conforto térmico quando as condições ambientais permitirem que o metabolismo (calor a ser emitido pelo corpo) ocorra normalmente.

$\mathrm{Na}$ arquitetura, o conforto térmico tem como objetivo evitar temperaturas internas elevadas no período do verão, e muito baixas no inverno. Para tanto, é necessário o controle sobre a temperatura, a ventilação e a umidade relativa do ar.

Para os edifícios de saúde, muito se tem buscado a tecnologia moderna para dar boas respostas aos níveis de conforto térmico desejado. Sem dúvida que, inerente a este pensamento, cabe a dosagem certa no seu emprego, tendo em vista que soluções mais sofisticadas requerem assistência técnica qualificada, custos mais altos de implantação e manutenção e, como conseqüência, o aumento do consumo de energia.

Os edifícios hospitalares e, em particular a Unidade de Urgência e Emergência, exigem, pelas características das suas atividades e complexidade do seu programa físico-funcional, a atenção redobrada para as soluções a serem adotadas. Caberá ao arquiteto, novamente, com pleno conhecimento sobre as atividades desenvolvidas em cada ambiente da unidade em foco, estabelecer a hierarquia e grau de prioridade na oferta de ventilação e iluminação natural. Isto possibilitará a obtenção de melhores resultados, traduzidos em bons níveis de conforto aos usuários em geral.

A hierarquia e priorização passam por estabelecer melhores condições de conforto para ambientes de longa permanência de pacientes e/ou funcionários. Em segundo plano deste cenário, estarão os espaços com características de armazenamento e apoio logístico. A própria RDC n50/ANVISA procura, no seu 
conteúdo sobre as condições ambientais de conforto, auxiliar no estabelecimento da priorização dos ambientes.

De acordo com Sampaio (2005, p. 155):

[...] o conforto térmico está relacionado a fatores pessoais do usuário do ambiente: a vestimenta que ele usa e a atividade que ele está desenvolvendo, quanto maior a atividade desenvolvida maior a produção metabólica, consequentemente, maior a dissipação de calor para o ambiente e a fatores ambientais: os elementos climáticos como temperatura, umidade e movimento do ar, insolação e radiação solar, pois esses elementos interferem diretamente nas trocas de calor entre o organismo e o ambiente, ou seja, no conforto térmico do ambiente construído.

Para a geração da arquitetura, vale considerar algumas condicionantes importantes para a obtenção de bons resultados. A orientação solar deverá ser analisada e utilizada de forma com que seu impacto, principalmente para as áreas de longa permanência, não sejam voltadas para faces de insolação direta.

A utilização de recursos arquitetônicos como o brise soleil e/ ou cobogó pode minimizar e interromper a incidência do raio solar direto sobre o espaço interior.

A conjugação de elementos como a boa orientação solar e a ventilação natural poderão trazer ótimos resultados, principalmente para regiões mais quentes. Esta articulação arquitetônica, entre outras medidas adotadas pelo arquiteto Filgueiras Lima (Lelé), tem obtido excelentes resultados em varias obras hospitalares da rede Sarah em todo o país. (Figura 166).

Figura 166 - Esquema explicativo do sistema de ventilação do Hospital Sarah Salvador, BA.

(Fonte: disponível em <www. arcoweb.com.br $>$ )

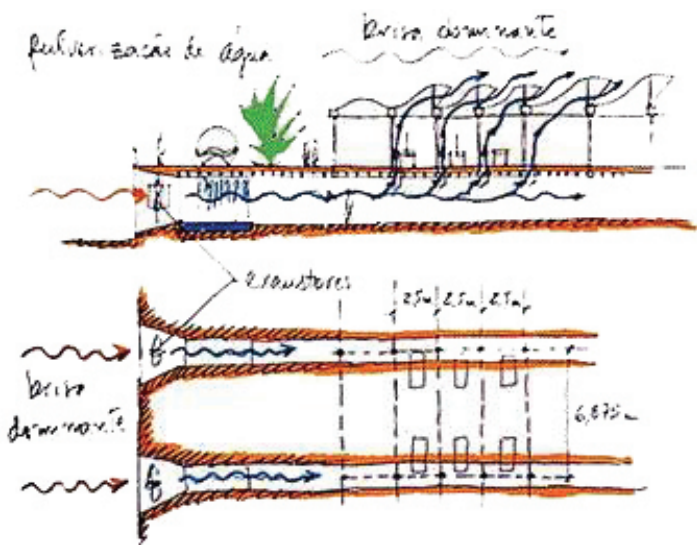


Recursos como a vegetação também poderão ser utilizados, não somente no direcionamento dos ventos dominantes, mas também na captação e contribuição do conforto visual.

A dosagem certa nas dimensões das aberturas de janelas e portas poderá contribuir significativamente nas condições de conforto. Vale lembrar que, para as janelas, a escolha dos tipos de aberturas com sistemas de controle sobre a incidência solar, e ainda a colocação de telas para proteção contra a entrada de insetos, é sempre desejável.

A escolha de materiais de construção e acabamento deve fazer o papel de resistência ao calor externo, tanto no sentido de transmissão como também na sua condução. As paredes externas deverão ser sempre um bom isolante térmico.

A análise sobre a geração de calor não se fecha apenas sobre as condições externas, mas também sobre todas as atividades, exercidas nos ambientes da unidade, como também sobre os equipamentos, como emissores de carga térmica, e ainda o número de pessoas que ali trabalham.

As coberturas das edificações, principalmente aquelas que possuem soluções com platibanda estanque, são na maioria das vezes as responsáveis pela condutibilidade e transmissibilidade de calor ao ambiente. Novamente, aqui, os exemplos apresentados por Filgueira Lima (Lelé) com soluções pelo sistema Venturi de aeração, o binômio (espaço/cobertura), têm sido referência na solução deste tipo de problema.

A simples introdução de aberturas em lados opostos, com venezianas de ventilação plena, entre a laje do ambiente construído e a cobertura propriamente dita, permitirá a retirada do ar quente deste espaço intermediário, (colchão de ar quente), diminuindo assim os seus níveis de condução e transmissibilidade. Esta solução poderá ainda contribuir na redução de uso do ar condicionado.

\subsubsection{Conforto Acústico}

A busca do conforto acústico no interior dos edifícios hospitalares é sempre desejável. Por meio da sinalização urbana, nas proximidades dos estabelecimentos de saúde, indicando não buzinar ou nas circulações e áreas internas com indicação da 
palavra "silêncio", traduz assim a necessidade dos usuários para que se ofereçam boas condições de trabalho e tranquilidade aos pacientes em assistência.

Com o crescimento, desenvolvimento e principalmente com o adensamento populacional e físico das cidades e, em especial, seu núcleo urbano, muitos hospitais localizados nestas áreas sofrem com a intensidade de tráfego ou pela poluição sonora produzida por oficinas, parque de diversões, quartéis, ou até mesmo de algumas atividades industriais.

No estabelecimento do macrozoneamento setorial das unidades que irão compor o novo edifício hospitalar, ou na proposta do Plano Diretor de Organização e Expansão Física para os complexos hospitalares já existentes, é necessária a compreensão sobre as diversas fontes internas geradoras de ruído, as quais provocarão o desconforto acústico.

Como observam Oliveira e Ribas (1995, p. 65):

Os sons são perturbações vibratórias que se propagam nos meios materiais capazes de serem detectados pelo ouvido humano. Quando detectados produzem tanto sensações agradáveis, sons musicais, que convencionou-se denominar simplesmente de som, quando som desagradáveis, não musicais, chamados de ruídos.

A instalação de equipamentos ruidosos e outros com movimento vibratório necessitam de cuidados do projetista para que não haja a propagação sonora aos ambientes que precisam da tranquilidade de trabalho, e ao paciente que debilitado possui a sua sensibilidade ainda mais aguçada.

Como recomenda Sampaio (2005, p. 171):

Numa análise acústica é importante conhecer a fonte do ruído que é onde está sendo produzido, conhecer também a forma como se dá a sua propagação, se ele está caminhando pelo ar ou pelos elementos construtivos do edifício e, finalmente, o local onde ele está sendo ouvido, para a partir daí saber como tratálo, se na fonte, na sua propagação ou na sua recepção. 
Outras recomendações precisam ser observadas no momento da concepção e desenvolvimento do projeto arquitetônico, tais como:

- escolha de materiais construtivos e acabamentos adequados para garantir o bom isolamento acústico nos ambientes que constituem a unidade em foco;

- as dimensões das esquadrias colocadas nas paredes periféricas ao edifício poderão contribuir para a entrada de ruídos. Embora este recurso seja benéfico à ventilação natural dos espaços, ele poderá ofertar uma situação de desconforto sonoro ao usuário. O equilíbrio desejado poderá ser encontrado na utilização da massa vegetal externa como bloqueio à emissão do som e ainda direcionar o posicionamento dos ventos dominantes que favoreçam a entrada do ar nos ambientes;

- a especificação de materiais para uso em piso nas áreas de circulação, hall e salas de espera, deve ser criteriosa para que sua escolha seja por passadeiras de borracha, sobre base flutuante, a fim de amortecer os ruídos dos passos, dos impactos de objetos ou do tráfego de carros de serviços. Para as paredes e forros, deve-se trabalhar com a movimentação de planos para que haja a absorção da onda sonora. Normalmente as paredes são revestidas de material liso, que facilita a limpeza, no entanto, é um potencial instrumento de reverberação sonora;

- atentar-se ao controle de ruído causado por reformas e ampliações dos edifícios existentes;

- utilizar o efeito psicológico da música ambiente, som produzido por cascata de água e ainda pela água nas precipitações pluviométricas, é sempre recomendável pelo seu resultado, que na maioria das vezes é positivo para todos os usuários.

\subsubsection{Conforto Visual}

Não é somente a visão que requer luz. A luz é um fator ambiental como o ar, água e temperatura. A luz natural tem talvez algumas centenas de efeitos importantes nas funções do corpo humano, os quais promovem um ritmo que segue o ciclo diário de claro e escuro ou dia e noite. 


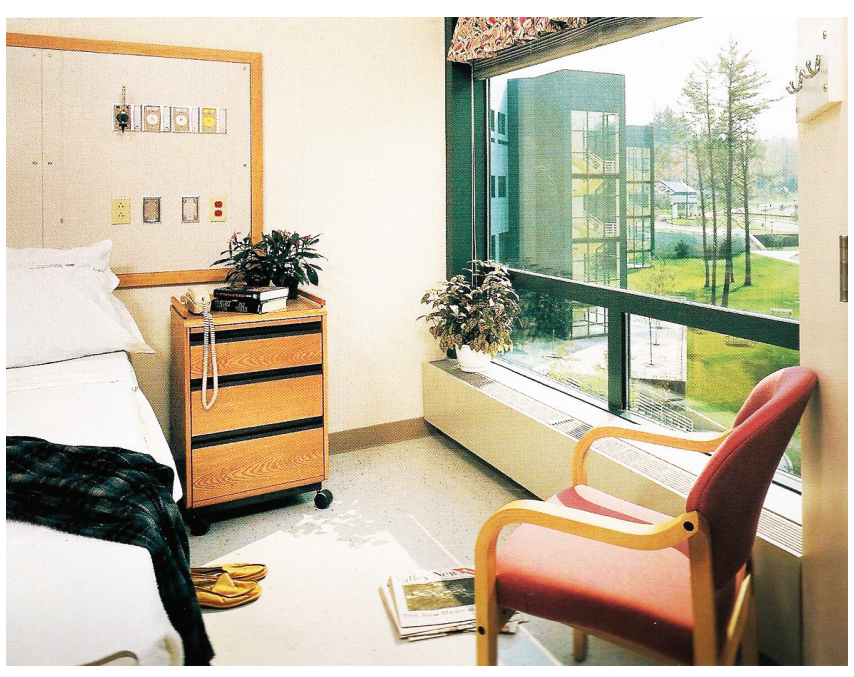

$\mathrm{Na}$ arquitetura, "permitir visuais externas e utilizar adequadamente a luz natural e a iluminação artificial, é um fator fundamental para a manutenção dos níveis de produtividade e de conforto psicológico para todos os usuários do edifício", explica Miquelin (1992, p. 209). A iluminação objetiva à obtenção de boas condições de visibilidade significa: níveis de luminância (E), distribuição de luminância pelo local, evitar

Figura 167 - DartmouthHitchcock Medical Center, Lebanon/New Hampshire,

USA.

(Fonte: Health Care Architecture, 1995). ofuscamento, considerando também os aspectos psicoestéticos como fundamentais na concepção do espaço. (VIANNA; GONÇALVES, 2001, p. 6). O equilíbrio no uso e a conjugação perfeita entre luz natural e artificial poderão contribuir de forma significativa ao conforto do paciente e que, consequentemente, será benéfico para sua recuperação. (Figura 167).

Para Costi (2002, p. 136),

[...] a luz natural é fundamental para a recuperação do paciente. É comprovado que existe a redução no tempo de internação quando o paciente tem noções de temporalidade, quando pode observar a variação da luz durante o dia e tiver a visão para o exterior.

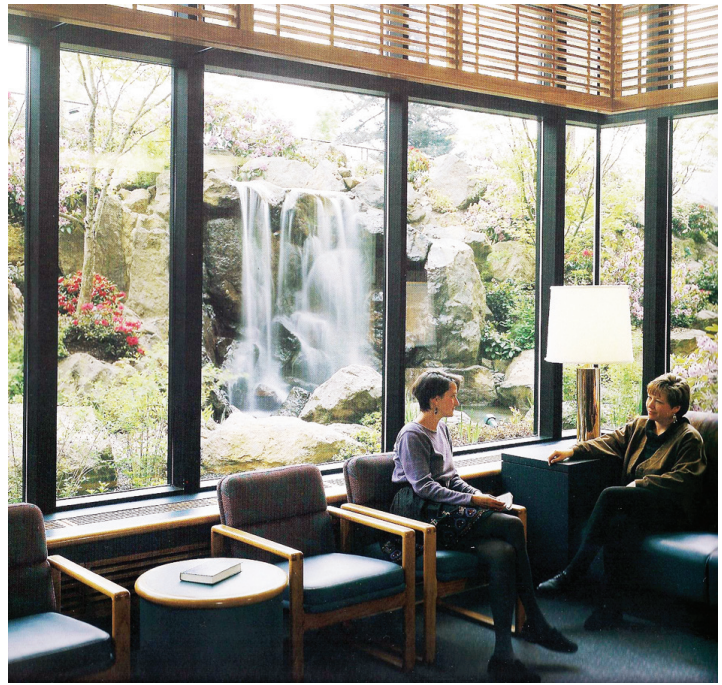

Figura 168 - St. Vincent Hospital West Pavilion, Portland/ Oregon, USA.

(Fonte: Health Care Architectu-

re, 1995).

Para a concepção e desenvolvimento da arquitetura em edifícios de saúde, é muito importante potencializar o uso de luz natural pela razão simples do alto custo da energia. (Figura 168)

Novamente aqui caberá ao arquiteto, pelo seu conhecimento e experiência, estabelecer para a Unidade de Urgência e Emergência a hierarquia de uso e a dosagem necessária de iluminação natural e/ou artificial para cada ambiente que constitui a unidade em estudo. Sem dúvida que, as áreas de observação e repouso de pacientes, que permanecem em média 24 horas na sua assistência, deverão ser os espaços considerados prioritários para receberem melhor nível de luminosidade. 
Como recomenda Sampaio (2005, p. 160), os cuidados na elaboração do projeto arquitetônico do edifício hospitalar, passam pela localização, orientação, tipo, tamanho e forma geométrica das aberturas, o tipo, a cor dos vidros que serão utilizados, as cores que serão usadas nos caixilhos, nas superfícies internas como teto, paredes e piso e nas superfícies externas, como muros, pisos e construções adjacentes, lembrando sempre que as cores claras refletem mais e difundem melhor a luz que as cores escuras, além de absorverem mais, diminuem a quantidade de luz disponível, transformando essa energia em calor, emitida por estas superfícies escuras para o ambiente. Não se deve esquecer ainda as características formais do local a ser iluminado, como a relação comprimento e largura e a altura do pé-direito, que interferirão na quantidade de luz disponível. Para projetar levando em consideração a iluminação natural, é importante conhecer primeiramente as condições climáticas locais, a disponibilidade de luz proveniente da abóbada celeste e o entorno edificado e/ou natural.

Bertolotti (2010, p. 18) ressalta que, quando for inevitável que as aberturas envidraçadas fiquem diretamente expostas à radiação solar, o ideal é utilizar vidros de baixa transmitância térmica, conhecidos no mercado como "low e" (low emissity glass). Este tipo de vidro tem uma película metálica em uma das faces que filtra a radiação solar, refletindo para fora parte da radiação infravermelha que causa o aquecimento interno dos ambientes, sem impedir a transmissão luminosa para o seu interior.

Outro recurso que a arquitetura deve disponibilizar é o uso de brises, os quais possuem como principal função controlar a entrada de radiação solar diretamente nas aberturas e assim melhorar o conforto térmico e luminoso nos ambientes.

Deve-se considerar ainda a disponibilidade tecnológica em esquadrias com vidro duplo e com persianas internas. Estas permitem o controle da entrada de luz, bem como a garantia de assepsia para este tipo de produto. $\mathrm{O}$ ar entre vidros funcionará como bom isolante térmico e acústico.

Tendo em vista que a Unidade de Urgência e Emergência tem seu programa físico-funcional extenso, muitos ambientes são distribuídos no interior da unidade, apresentando dificuldades em garantir a luminosidade natural adequada. Outras alternativas arquitetônicas para minimizar o problema têm sido adotadas, tais 
como: a utilização de sheds, domus e claraboias, vazios (jardins), poços de luz, na tentativa de ofertar aos espaços prejudicados pela sua necessidade de localização e contiguidade funcional algum grau de luminosidade e ventilação natural.

A combinação de uso da luz natural e artificial tem sido, para os profissionais, um campo interessante a ser explorado para se obter a própria valorização da arquitetura, como também proporcionar aos usuários novas sensações na utilização do espaço.

Para Sampaio (2005, p. 160), as vantagens de iluminação natural sobre a artificial são:

- qualidade da luz;

- comunicação interior/exterior;

- conservação de energia;

- benefício físico e psicológico;

- desejo de ter luz natural e sol em um ambiente construído.

Para a entrada da Unidade de Urgência e Emergência, bem como nas áreas de espera, a oferta de luz natural induz a uma leitura muito positiva do espaço, contribuindo por meio do benefício psicológico, objetivando assim, melhor conforto e bemestar aos usuários. (Figura 169). Vários estudos têm ocorrido na busca de desvendar os efeitos psicológicos da luz junto aos pacientes, sendo que uma dessas investigações tem sido por meio da cromoterapia, que trata de diversas patologias com a energia irradiada por lâmpadas coloridas.

Figura 169 - Hospital de Mestre - Mestre/Veneza, Itália.

(Fonte: New Health Facilities, 2009).

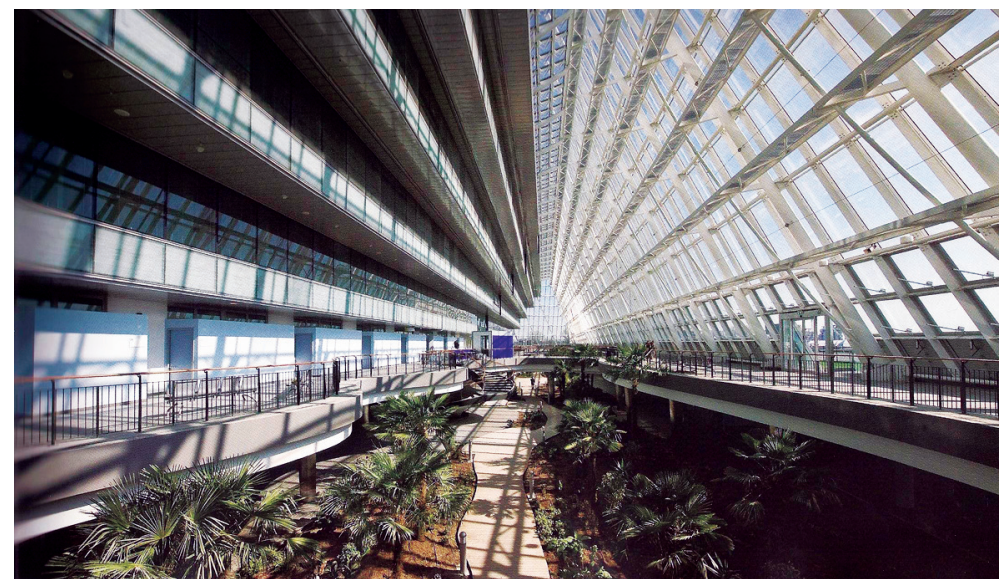

Como salienta Costi (2002, p. 111) "os padrões uniformes desinteressantes e monótonos da luz branca interferem psicologicamente, portanto, sempre que possível, variações de luz devem ser introduzidas". Estes recursos utilizados em recente 
trabalho do arquiteto Domingos Fiorentini, em conjunto com o responsável pelo projeto luminotécnico, Guinter Parschalk para o Hospital Infantil Sabará, em São Paulo (Figuras 170 e 171), procuram valorizar o ambiente na interessante conjugação da luz natural com a artificial, bem como na variação de cores e níveis de luminância para cada espaço proposto.

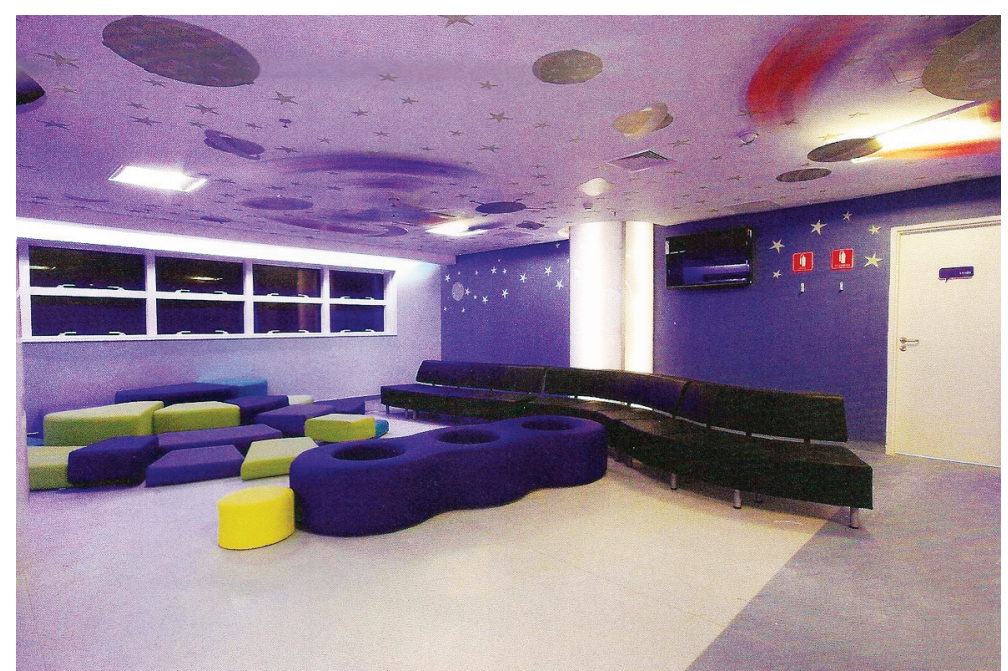

Figura 170 - Hospital Infantil Sabará - São Paulo, SP.

(Fonte: Revista $L+D$ )

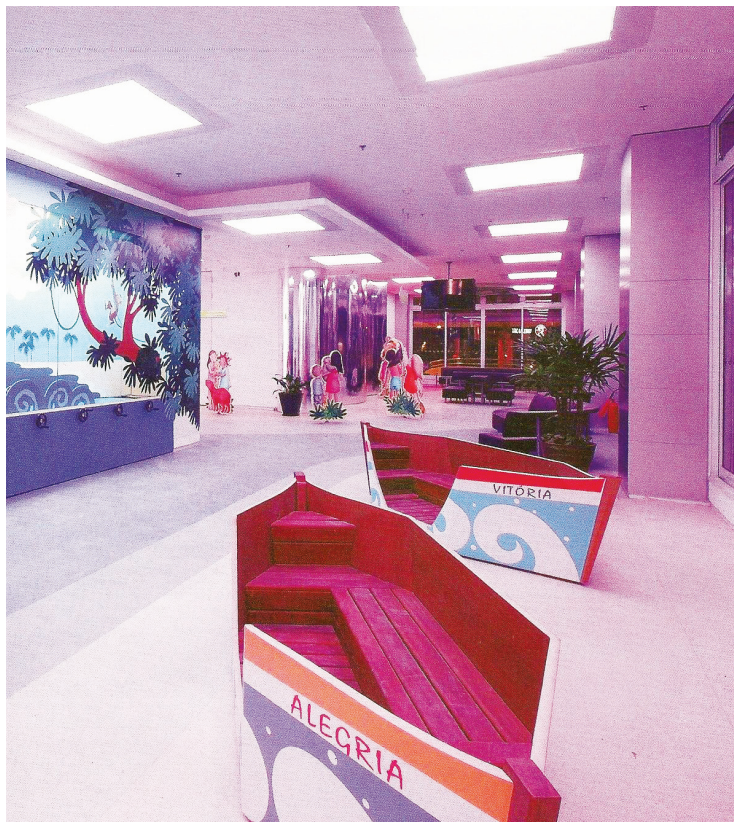

Figura 171 - Hospital Infantil Sabará - São Paulo, SP.

(Fonte: Revista $L+D$ )

A iluminação artificial tem o papel de complementar a luz natural, ou ainda ofertar iluminação total, quando o ambiente não dispuser de aberturas de janelas para o exterior. Neste caso, o profissional arquiteto deverá atentar-se na especificação de luminárias adequadas para cada tipo e uso do ambiente. 
Desde a composição de luminárias, conforme o tamanho, tipo de lâmpada, potência, tipo do refletor, quantidade de luz emitida e temperatura da cor, dimensões dos ambientes, cores utilizadas em paredes, piso e teto, todos estes elementos influenciarão na qualidade luminotécnica do espaço hospitalar.

Tais fatores transmitirão aos ambientes sensações mais relaxantes, aconchegantes, como as cores quentes (temperatura de cor mais baixa, cores mais amareladas) ou excitantes, que induzam a uma maior produtividade, como as cores mais frias (temperatura de cor mais alta, cores mais brancas). (SAMPAIO, 2005, p. 162).

Para as Unidades de Urgência e Emergência, considera-se que para as áreas de permanência de pacientes (salas de espera, consultórios, medicação, inalação, observação e repouso, por exemplo), devem-se utilizar as luminárias com lâmpadas de cor mais amareladas, proporcionando sensações de acolhimento, mais relaxantes e aconchegantes. Nestes ambientes, quando a necessidade de procedimentos médicos e/ou enfermagem, devem-se compor luminárias com lâmpadas de cor branca, com facho de luz dirigido para que possam garantir a adequada realização do serviço.

Para as áreas de serviços e apoio logístico, recomendam-se as luminárias com luz fria/brancas, as quais podem potencializar maior desempenho e produtividade.

Segundo observações de Costi (2002, p. 108), deve-se considerar para a utilização de iluminação artificial alguns aspectos aqui colocados.

- Lâmpadas e luminárias têm que ter perfeito casamento. Nem todas as luminárias podem receber lâmpadas eficientes.

- O layout, o tipo do ambiente e a funcionalidade devem ser considerados, e não simplesmente atender às normas distribuindo luminárias. O campo de trabalho deve ter luz adequada às necessidades dos usuários.

- O campo da visão de um paciente acamado é o teto e a luz direta é a fonte de desconforto ocasionando ofuscamento. A iluminação deve ser indireta, e a luminária ser adequada a tal campo de visão.

- Próximo à cabeceira dos leitos de observação e repouso, luminárias que permitam diferentes níveis de luminâncias 
e alteração do campo de iluminação podem auxiliar tanto o paciente quanto a enfermagem e permitir um exame mais acurado pelo médico.

- Para facilitar o deslocamento do grupo operacional, sem ocasionar desconforto aos pacientes, devem-se usar luminárias, com baixa luminância, tipo balizadores, próximas do nível do piso, pois quando o chão está iluminado, os deslocamentos noturnos são mais seguros.

- A iluminação baixa não é conveniente quando as superfícies têm cores saturadas, pois pode causar desconforto, além de ser antieconômico.

- O efeito estroboscópico (tremulação de luz) causado pelas lâmpadas de descarga, como consequência da intermitência da luz, é outro problema a ser evitado.

- O Índice de Reprodução das Cores (IRC) da lâmpada deve ser sempre acima de 80/85 para não interferir no exame clínico. A temperatura de cor preferida em hospitais indica entre $4000-4500 \mathrm{k}$ e o IRC em 90.

- A escolha da temperatura da cor de luz implica na valorização de determinadas cores das superfícies que irão sobressair, modificando o seu tom para uma ou outra extremidade do espectro das cores.

- A escolha da lâmpada não deve prejudicar o diagnóstico, já que a fidelidade da cor da pele é fundamental para qualquer diagnóstico ou acompanhamento do paciente quando acamado.

- A lâmpada deve fornecer um bom IRC, o mais semelhante possível da luz solar, reprodução considerada "verdadeira" por muitos.

Outras recomendações são feitas por Ferreira (2010, p. 17), no que se refere à técnica de se integrar iluminação natural com a artificial, têm-se:

- Um nível constante de iluminação, corrigindo a deficiência de luz natural no interior do ambiente em determinados períodos do ano (inverno, por exemplo). Nos períodos de maior captação de luz natural (verão, por exemplo) o IASPI (Permanente Suplementary Artificial Lighting for Interiors) possibilita a racionalização e poupança de energia com iluminação artificial mediante o uso da luz natural. 
- A luz necessária para aumentar a luminosidade aparente do local, assegurando áreas sem escurecimento e sem gastos desnecessários de energia elétrica.

- Uma iluminância adequada que contrabalance o desconforto causado pela luminância do céu visível através da janela.

Ainda como recursos para o melhor desempenholuminoso nos ambientes e com o avanço tecnológico na área de luminotécnica, novos produtos têm surgidos como as fibras óticas e os diodos emissores de luz, os Light Emitting Diodes (LEDS).

\subsection{Tecnologia}

A geração da arquitetura, já nos seus primeiros passos, deve ser conduzida, como já observado, mediante uma visão sistêmica sobre os diversos tipos de instalações que proporcionarão a boa qualidade física do edifício hospitalar. O teimoso pensamento de que estas instalações e infraestrutura são complementares a arquitetura é um grande equivoco. A arquitetura se dá na plenitude da palavra, quando concebida não somente pela definição espacial, mas também na oferta de todas as possibilidades de percursos para os diversos sistemas e subsistemas de instalações prediais.

Por estas características em complexidade tecnológica crescente, tem sido comum a formação de equipes técnicas para que num trabalho de completa sinergia, permita atingir resultados coesos e consistentes.

Novamente aqui, o desenvolvimento dos trabalhos relativos à Unidade de Urgência e Emergência, não é um caso isolado. Do todo ao particular e vice-versa, num percurso de ir e vir permanentemente, será necessário para que possa aprofundar o conhecimento sobre todos os tipos de componentes inseridos na infraestrutura predial hospitalar.

Para as edificações existentes, após minucioso estudo e diagnóstico sobre o sistema "cardiovascular" do edifício, é que se pode nortear as decisões de remanejamento e transformações dos espaços da unidade em estudo.

Para os novos edifícios, é importante objetivar a criação de espaços específicos, como a circulação das instalações prediais ao nível horizontal (forro e/ou piso falso e espaços intersticiais), como 
também vertical (shafts), os quais proporcionarão as condições ideais para frequente manutenção preventiva, maior flexibilidade, melhores condições para agregar novos equipamentos e, ainda, ofertar os dispositivos de controle e segurança e tecnologia da informação.

Para que se possa compreender a complexidade envolvida, apresentam-se aqui os sistemas e subsistemas da infraestrutura predial, em que caberá ao arquiteto o papel de discernir os elementos intervenientes junto à Unidade de Urgência e Emergência.

- Sistema de energia elétrica, telefonia e som:

cabine primária em baixa / média ou alta tensão;

geração de energia de emergência;

| iluminação interna, externa e vigilância;

| eletricidade para pontos de luz, tomadas e quadros de disjuntores;

| aterramento;

| alarme de incêndio;

| som ambiente, chamada e sinalização de enfermagem;

| proteção contra descarga atmosférica;

cabeamento para TV;

terminais para computadores;

| telefonia;

| horário unificado;

circuito fechado de televisão.

| Sistema Hidrossanitário e Prevenção de Incêndio:

| água fria;

| água quente;

| prevenção e combate a incêndios;

drenagem de águas pluviais;

- Captação e reaproveitamento de águas pluviais:

| esgoto sanitário;

| água gelada;

água destilada.

- Sistema Fluído Mecânicos:

oxigênio;

| vácuo;

| ar comprimido;

| dióxido de carbono;

| nitrogênio; 
| protóxido de azoto;

| vapor;

| gás combustível.

- Sistema de ar condicionado e Ventilação Mecânica

| ar condicionado para conforto;

| ventilação e exaustão para ambientes que não possuam ventilação direta;

| ar condicionado com filtragem absoluta nas áreas estéreis.

- Sistema Eletrônico e Processamento de Dados

| cabeamento estruturado para som, imagem e dados;

| telemetria;

| telemedicina;

| telecomunicações;

| cabeamento de fibra ótica.

- Sistema de Segurança:

| ar condicionado;

| no-break;

| baterias;

| proteção contra incêndios;

| iluminação;

| terminais de computadores.

- Outros sistemas

| tubos pneumáticos;

| elevadores;

| esteiras rolantes;

| tratamento de resíduos;

| reciclagem e reaproveitamento de energia;

| placas de captação de energia solar;

| placas fotovoltaicas.

Todos estes componentes integrados têm o papel de proporcionar ao hospital de hoje e do futuro, como também em particular a Unidade de Urgência e Emergência, conforto, acolhimento, segurança e confiança poderão estar incorporados aos anseios e direitos dos pacientes.

A incorporação da tecnologia, em qualquer momento histórico do edifício é sempre um processo traumático, porém os avanços são inerentes à sua atualização e modernização dos serviços ofertados, como também a abertura para as conexões com outros grandes centros de excelência em medicina e investigação 
científica, para troca de informações e consequentemente o acréscimo ao conhecimento.

Como ressalta Barreto (1995, p. 02):

[...] as tecnologias da área da saúde, especialmente no ambiente altamente estruturado dos hospitais, têm um importante impacto nas relações humanas e na organização dos espaços, e deve ser tomada como um fator crucial para a concepção do sistema de saúde e de seus espaços. Essa abordagem é contraposta ao modo de pensar a tecnologia de uma forma "complementar" ao problema funcional e estético dos espaços humanos. As tecnologias biomédicas definem cada vez mais a própria natureza do espaço hospitalar: o espaço também é instrumental e sua experiência (a experiência espacial) e concepção podem ser comparadas com a própria experiência e concepção de tecnologias. Ou seja: avança por meio de proposições e avaliações, busca de fundamentação cientifica e se inspira nela, persegue consistentemente $o$ alcance de determinados resultados.

Acrescenta ainda que, a própria medicina vem se tornando cada vez mais uma área de aplicação de tecnologias, depende crescentemente de tecnologias que atingem quase todas as práticas. O "médico como tecnólogo" não é, num sentido mais amplo, uma analogia descabida, pois tecnologias e medicina aplicam conhecimentos teóricos para as realizações de ações no ambiente, nas pessoas.

O hospital e a Unidade de Urgência e Emergência, como parte integrante deste complexo, assumem o papel por razões já apresentadas, e chamadas de edifícios de alta tecnologia, os quais possuem as seguintes características: (MARINELLI; CAMARGO, 2004, p. 01).

- dispõe dos serviços oferecidos pelas novas tecnologias de informação;

- integra os serviços em uma rede de comunicações; e

- realiza o controle e o gerenciamento por meio de um ou vários computadores interligados.

Ressaltam ainda que, 
[...] os edifícios destinados à saúde estão incorporando estas tecnologias prediais tanto para o seu melhor gerenciamento como para um fornecimento de infra-estrutura mais confiável, diminuindo falhas que podem ser a diferença entre a vida e a morte de um paciente e possibilitando o fornecimento de um serviço de melhor qualidade. (MARINELLI; CAMARGO, 2004, p. o1).

Com a perspectiva do uso de novas tecnologias de informação é necessário considerar temas como: organização dos sistemas de informática, sistema de gerenciamento do edifício, configuração de redes internas e externas de comunicação, integração com novos serviços de valor agregado, flexibilidade para a adaptação da rede para a mudança de uso do espaço e conexão aos serviços de comunicação.

Nos dias de hoje e ao ritmo de uma progressão geométrica nos avanços na área de tecnologia de informação, torna-se difícil a batalha do dia a dia do serviço hospitalar na permanente atualização e incorporação dos sistemas prediais. Mas isto é irreversível. Para qualquer nível de intervenção física, a incorporação desta tecnologia é inerente ao processo, pois sem ela a unidade de saúde estará fadada à obsolescência a curtíssimo prazo. Isto requer investimento, mas sem dúvida que para a equipe médica-operacional, com o papel quase ubíquo no seu serviço de assistência, necessitam da oferta da tecnologia. Somente assim se garante a agilidade no processo de diagnóstico, a tomada de decisões mais rápidas, e a oferta de maior confiabilidade, seguridade e credibilidade aos seus procedimentos.

$\mathrm{O}$ consumo da tecnologia não se esgota aqui, isto porque os sistemas construtivos e materiais de acabamentos também são inerentes ao pensamento arquitetônico, interferirindo na qualidade espacial e, por conseqüência, na assistência médicaenfermagem.

Construção modulares em estrutura metálica, sistemas prémoldados de concreto, fechamentos em dry wall ou ainda sistema em alvenaria armada são soluções mais limpas e rápidas para sua execução. As soluções convencionais em concreto armado e fechamentos em alvenaria de tijolos (ou outro produtos similares) têm sido ainda muito utilizados para a construção dos edifícios hospitales. 
Soluções mistas, na junção de dois sistemas construtivos, concreto e metálico, por exemplo, também se tornaram viáveis para atender determinadas especificidades construtivas, em que a sobrecarga estrutural tem sido significativa. Como exemplo, temos a construção do heliponto, feita em estrutura metálica leve, sobre a cobertura do edifício executado no sistema de concreto armado.

Logicamente neste momento de escolha sobre o sistema construtivo, existem outras variáveis inerentes ao processo, como: condições geomorfológicas do terreno, oferta de mão de obra adequada e qualificada, oferta de produtos industrializados, pessoal técnico capacitado, entre outros. Caberá assim, à equipe técnica diagnosticar as reais condições de execução dos projetos a serem propostos. A investigação sobre estas condições da realidade local, com o objetivo de enxergar o verdadeiro potencial na realização do produto final, deverá ocorrer já nos primeiros passos de discussão com o grupo gestor. A clareza desta potencialidade construtiva também será um condicionante bastante forte na tomada de decisão para o próprio partido arquitetônico.

A reformulação ou criação de novos espaços da unidade requer, dos profissionais envolvidos, a adequada escolha sobre os materiais de acabamentos. Isto inicialmente poderá ser considerado um procedimento simples, no entanto, para as áreas hospitalares torna-se necessário os cuidados com a facilidade de limpeza, durabilidade, permeabilidade, estética, segurança, facilidade de aplicação e reposição e ainda valor financeiro

- Facilidade de limpeza

| Especificação de materiais com superfícies lisas, sem reentrâncias e relevo, preferencialmente monolítico, como também peças retificadas e ainda com aplicação de resinas impermeabilizantes.

- Durabilidade

| Dimensionar o volume e tipo de tráfego, por meio do levantamento sobre as pessoas, equipamentos, mobiliário e carros de transporte que circulam na unidade. Verificar a resistência do material ao uso de produtos químicos para limpeza. 
- Permeabilidade

| Verificar o nível de permeabilidade do material quanto à absorção de umidade. Materiais com alto índice de absorção não são recomendáveis ao ambiente hospitalar.

- Segurança

| Para asáreas molhadas e externas, as escolhas passam sempre por pisos antiderrapantes e rugosos. A compatibilidade com as questões de higiene do material deve ser observada. Materiais incombustíveis, resistentes à propagação do fogo são imprescindíveis.

- Facilidade de aplicação e reposição

| É recomendável que a escolha de materiais passe por produtos que estejam fartamente disponíveis no mercado, e possuam a credibilidade consolidada, não tendo sua produção interrompida. Obviamente com o próprio avanço da tecnologia empregada na produção de determinados materiais, mesmo aqueles largamente aceitos, há a tendência de mudanças na sua forma, dimensão, textura, cores etc. Sem dúvida que a facilidade de reposição de determinados produtos é sempre positiva, isto porque poderá manter a sua padronização, garantindo-se com isto um menor nível de intervenção e menor custo.

- Valor financeiro

| A avaliação e escolha de determinados materiais devem passar pela análise custo/beneficio. Na maioria das vezes, os produtos mais baratos, inicialmente adquiridos, não terão a durabilidade e eficiência necessárias para o uso hospitalar. O edifício hospitalar, pelas suas características de uso 24 horas, 356 dias ao ano, não poderá estar permanentemente em confronto e refém da má especificação e qualificação dos materiais empregados.

\subsection{Sustentabilidade}

Nos últimos 40 anos, as preocupações com o meio ambiente têm sido crescentes. O progresso da ciência, a tecnologia e o conhecimento humano têm produzido avanços inimagináveis e imensuráveis, porém este crescimento tem ocorrido de forma desenfreada e principalmente voraz. 
Desde a realização das conferências em Estocolmo (1972), Vancouver (1976), Rio de Janeiro (ECO-92), Istambul (1996), todos os eventos com o aval da ONU (Organização das Nações Unidas) têm o objetivo de se discutir e montar metas e estratégiasna busca do equilíbrio do que é socialmente desejável, considerando o desenvolvimento justo de sociedades, proporcionando um nível aceitável de qualidade de vida; economicamente viável que seria o acesso aos recursos e oportunidades e aumento da prosperidade para todos; ecologicamente sustentável, pensando no equilíbrio entre a proteção do ambiente físico e seus recursos e o uso destes, garantindo uma qualidade de vida aceitável. (SAMPAIO, 2005, p. 29).

A arquitetura neste cenário tem papel fundamental no crescimento das cidades, na construção dos edifícios e consequentemente a geração de impacto ao meio ambiente. Ao longo deste período de discussões, as preocupações quanto ao crescimento sustentável têm sido difundida desde os bancos de escolas, para que se obtenha, por meio do conhecimento e conscientização, a postura e compromisso dos profissionais quanto ao equilíbrio ambiental e a justiça social.

Segundo Silva (apud SAMPAIO, 2005, p. 39):

A indústria da construção pode ser considerada a atividade menos sustentável do planeta, uma vez que absorve $50 \%$ dos recursos mundiais em materiais, utiliza $45 \%$ da energia gerada para aquecer, iluminar e ventilar os edifícios e $5 \%$ para construí-las, destina $40 \%$ da água utilizada no mundo para abastecer instalações sanitárias e outros usos nos edifícios, utiliza $60 \%$ da terra cultivável para construção e $70 \%$ dos produtos relacionados à madeira estão vinculados à construção de edifícios.

Para atender aos compromissos do desenvolvimento sustentável, consideram-se três princípios básicos que norteiam sua postura responsável: (SILVA, apud SAMPAIO, 2005, p. 40)

- Sustentabilidade econômica: aumentar a lucratividade e crescimento por meio do uso mais eficiente de recursos, incluindo mão de obra, materiais, água e energia.

- Sustentabilidade ambiental: evitar efeitos perigosos e potencialmente irreversíveis no meio ambiente por meio do uso cuidadoso de recursos naturais, minimização 
de resíduos e proteção, e quando possível melhoria do ambiente edificado e natural.

- Sustentabilidade social: responder às necessidades de pessoas e grupos sociais envolvidos em qualquer estágio do processo de construção (do planejamento a demolição), provendo alta satisfação do cliente e do usuário, e trabalhando estreitamente com clientes, fornecedores, funcionários e comunidades locais.

Com as diversas preocupações e cuidados na geração da arquitetura, a sustentabilidade tem sido determinante para a obtenção da qualidade espacial e ambiental, no que se refere à adequação do edifício ao clima, ao entorno com a eficiência energética desejável, e principalmente ofertar boa qualidade de vida e o bem-estar aos seus usuários.

Para Silva (apud SAMPAIO, 2005 p. 45), algumas medidas e reforço à postura projetual podem auxiliar na geração da arquitetura compromissada com as exigências ambientais da contemporaneidade.

- Projeto:

| a ocupação do edifício não deve se utilizar de subsolos, possibilitando o uso a partir do nível térreo para um melhor reaproveitamento da luz natural e da ventilação cruzada;

| utilizar átrios e poços de luz para permitir a entrada de luz natural e possibilitar a ventilação cruzada;

| orientar o edifício sobre o eixo leste/oeste, deixando as faces maiores, norte/sul, expostas a uma insolação controlada, para locais de clima quente;

| propor edifícios funcionalmente simples, porém flexíveis.

- Energia:

| utilizar ventilação natural, por deslocamento de ar;

| aproveitar ao máximo a luz diurna;

| utilizar elementos de proteção solar e de reflexão da luz natural;

| isolar termicamente os edifícios;

| utilizar fontes de energia renovável (solar, eólica, geotérmica ou hidroelétrica).

- Água:

| não deve ter cheiro;

| especificar mictórios e torneiras que possuam sensores; 
| reaproveitar as águas da chuva.

- Materiais:

| usar materiais recicláveis, reutilizáveis, renováveis (RRR);

| utilizar materiais locais;

| propor construções desmontáveis, flexíveis;

| utilizar materiais de alta tecnologia nas instalações de energia.

- Saúde:

| utilizar controle ambiental automatizado;

| utilizar materiais de baixa toxidade;

| propor ambientes e especificar materiais naturais;

| permitir a visualização permanente da natureza.

Embora todos os itens abordados até aqui sejam no caráter mais abrangente ao edifício hospitalar, é importante o entendimento do todo para se enxergar a parte. Portanto, qualquer intervenção ao nível "apenas" da Unidade de Urgência e Emergência tornase imprescindível que a postura e o compromisso responsável do profissional envolvido sejam inerentes ao processo projetual na geração da arquitetura.

\subsection{Humanização}

O paciente é a principal razão de ser do hospital, a humanização tem sido tema constante há mais de 30 anos, na tentativa de descaracterizar o modelo do edifício hospitalar do passado. Num primeiro momento, esse conceito veio à tona numa maior tentativa de aproximação, na relação direta, entre médicos e enfermeiras na assistência aos enfermos. A partir de então, administradores hospitalares e arquitetos apropriaram-se deste conceito, no sentido de formular uma nova proposta na arquitetura que rompesse com a imagem técnica, fria e impessoal do hospital, tornando-o mais humanizado.

Como conceitua Mezomo (1979, p. 08), a humanização dos hospitais, pode ser entendida como o estabelecimento da primazia efetiva dos direitos do paciente sobre a estrutura operacional e administrativa do hospital. Os hospitais são vistos como locais de doenças e não de saúde. Com esta visão distorcida, pode acarretar ao usuário um nível de estresse que agrava suas condições físicas e psicossomáticas. 


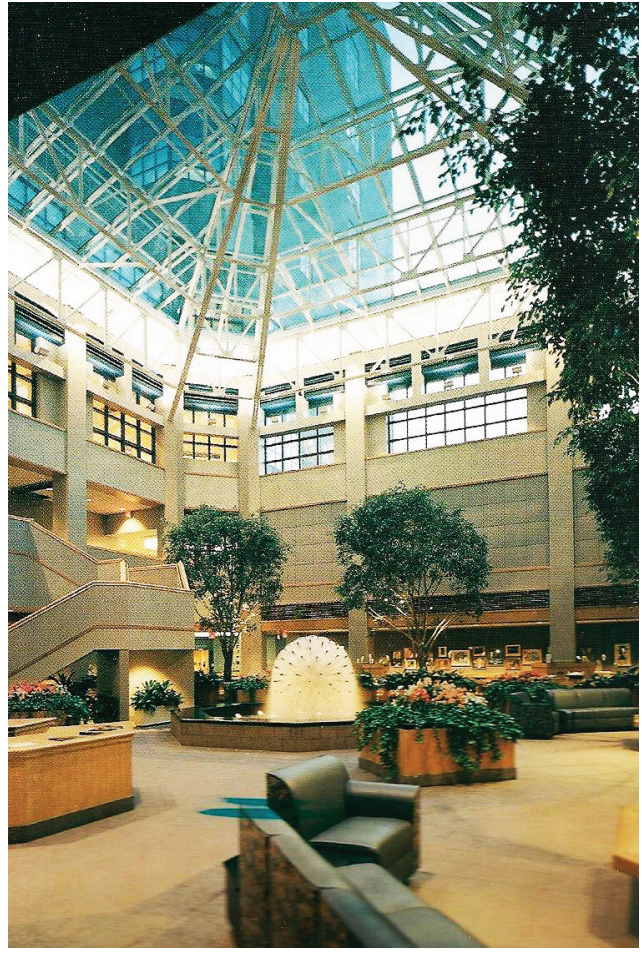

Figura 172 - Children's Hospital at Yale New Haven Hospital,

New Haven/Connecticut, USA.

(Fonte: Health Care Architecture, 1995)
Com esta abordagem, compreende-se que a arquitetura pode contribuir, por meio do psiquismo, na rápida recuperação do paciente, apropriando-se de recursos arquitetônicos saudáveis e agradáveis.

Sem dúvida que, quando se abrem as discussões iniciais sobre o edifício hospitalar, a palavra de ordem é a funcionalidade, porém, mesmo que se assegure a eficácia funcional, não se deve esquecer o conforto e bem-estar dos usuários.

Como observa Pompeu (apud CORBIOLI, 2003, p. 03), o arquiteto trabalha com a emoção, e a arquitetura tem efeito quando causa emoção no indivíduo. Esta meta pode ser alcançada mediante espaços hospitalares motivadores por formas, cores, ambientação, iluminação, som ou odores, paisagismo, entre outras possibilidades. (Figura 172).

Zanettini (2003, p. 38) acrescenta ainda que

cada vez é mais importante o aspecto emocional e psicológico do paciente. Por isso, é necessário abordar os aspetos da sensibilidade, das emoções, do encantamento que um espaço pode causar. Isso é fundamental para o projeto dentro de um hospital. Se você entra em ambiente escuro, desagradável é pior ainda. $\mathrm{O}$ paciente tem que manter uma relação boa com o espaço de permanência, no fundo isso, é dar um novo incentivo.

Acrescenta-se ainda que os hospitais de hoje se voltam para fora, com espaços mais amplos, tendendo a fazer parte do equipamento urbano como qualquer outro edifício, tendo uma relação com todo o espaço envolvente muito forte. Para isto, é importante ter ambientes mais atuais, espaços amplos, jardins, áreas verdes, paisagem, distância e perspectiva.

Os hospitais estão ganhando vida, em todos os aspectos, com seus desenhos, qualidade arquitetônica, qualidade cromática, equipamentos, instalações novas, como lanchonetes, livrarias e outros ambientes.

A reflexão que se faz sobre a humanização do ambiente hospitalar remete na aglutinação de todos os pontos até aqui abordados, que com o equilíbrio desejado, e na dosagem certa, 
a arquitetura poderá ter o papel interventor no processo de cura do paciente.

É interessante observar as considerações de Malkin (apud COSTEIRA, 2003, p. 196), quanto a uma nova postura para edifícios hospitalares, baseado em evidências (evidence based design), analogicamente com o campo da medicina (evidence based medicine), as quais procuram estabelecer diretrizes à humanização do ambiente hospitalar.

- Eliminar os fatores ambientais estressantes como ruído, falta de privacidade, iluminação excessivamente forte, baixa qualidade de ar interior.

- Conectar o paciente com a natureza através de janelas panorâmicas para o exterior, jardins internos, aquários, elementos arquitetônicos com água, como cascata, por exemplo.

- Oferecer opções e escolhas para o controle individual, incluindo privacidade versus ambiente social, controle da intensidade de luz, escolha do tipo de música no ambiente, opções de posições de sentar, silêncio e quietude versus áreas de esperas ativas.

- Disponibilizar oportunidades de socialização com arranjos convenientes de assentos que promovam privacidade aos encontros de grupos familiares, acomodações para a família e acompanhantes nos ambientes de observação e repouso.

- Promover atividades de entretenimento "positivas", como arte interativa, aquários, conexão com a Internet, música ambiente, acessibilidade a vídeos especiais com programas que possuam imagem e sons reconfortantes e adequados à assistência à saúde.

- Promover ambientes que remetam sentimentos de paz, esperança, reflexão, conexão espiritual, relaxamento, humor e bem-estar.

Todos estes recursos arquitetônicos têm o objetivo de contribuir para o conforto no seu sentido mais amplo, a todos os usuários da unidade em tela. Como já comentado, o paciente ao dar entrada no serviço de urgência e emergência, pela gravidade do seu caso, e ainda pelos sentimentos de angústia, insegurança, sofrimento, dor e medo, encontra-se resistentes à absorção do 
ambiente hospitalar. Com os familiares e/ou acompanhantes isto não é diferente.

Somente após os primeiros socorros e atingindo os níveis de estabilização dos seus sinais vitais, é que o paciente, já mais seguro e menos vulnerável, pode efetivamente "enxergar" o meio ambiente hospitalar. Neste sentido é que se coloca a arquitetura como um dos instrumentos no processo de recuperação do paciente.

Por outro lado, a equipe médica-enfermagem respaldase na boa funcionalidade, nas adequadas relações de fluxos externos e internos, na contiguidade funcional e no correto dimensionamento dos diversos ambientes que compõem a unidade para que se obtenha o resultado desejado.

Como observam Barbosa et al (2007, p. 02),

[...] no hospital, particularmente na emergência, o desamparo é ainda mais escancarado, deixando às claras a fragilidade humana-física e psíquica. Essa angústia do desamparo, atualizada nas situações de doença, muitas vezes torna-se paralisante, imobilizando e congelando nossa existência e nossa relação com o mundo. Assim, a entrada no hospital, motivada pelo adoecimento e ainda pela porta da emergência, potencializa esse impacto.

Acredita-se que o processo deva representar o trabalho harmônico entre os diversos profissionais da arquitetura, engenharia, medicina, enfermagem, assistência social, psicologia, entre outras áreas que buscam a perfeita sintonia para atingir a mais alta produtividade, qualidade e resolutividade para Unidades de Urgência e Emergência, consideradas eficientes.

Para a conquista dos objetivos, caberá aos arquitetos, detentores do conhecimento técnico, possuir também a sensibilidade necessária para expressar e dar as respostas corretas às expectativas dos usuários. 



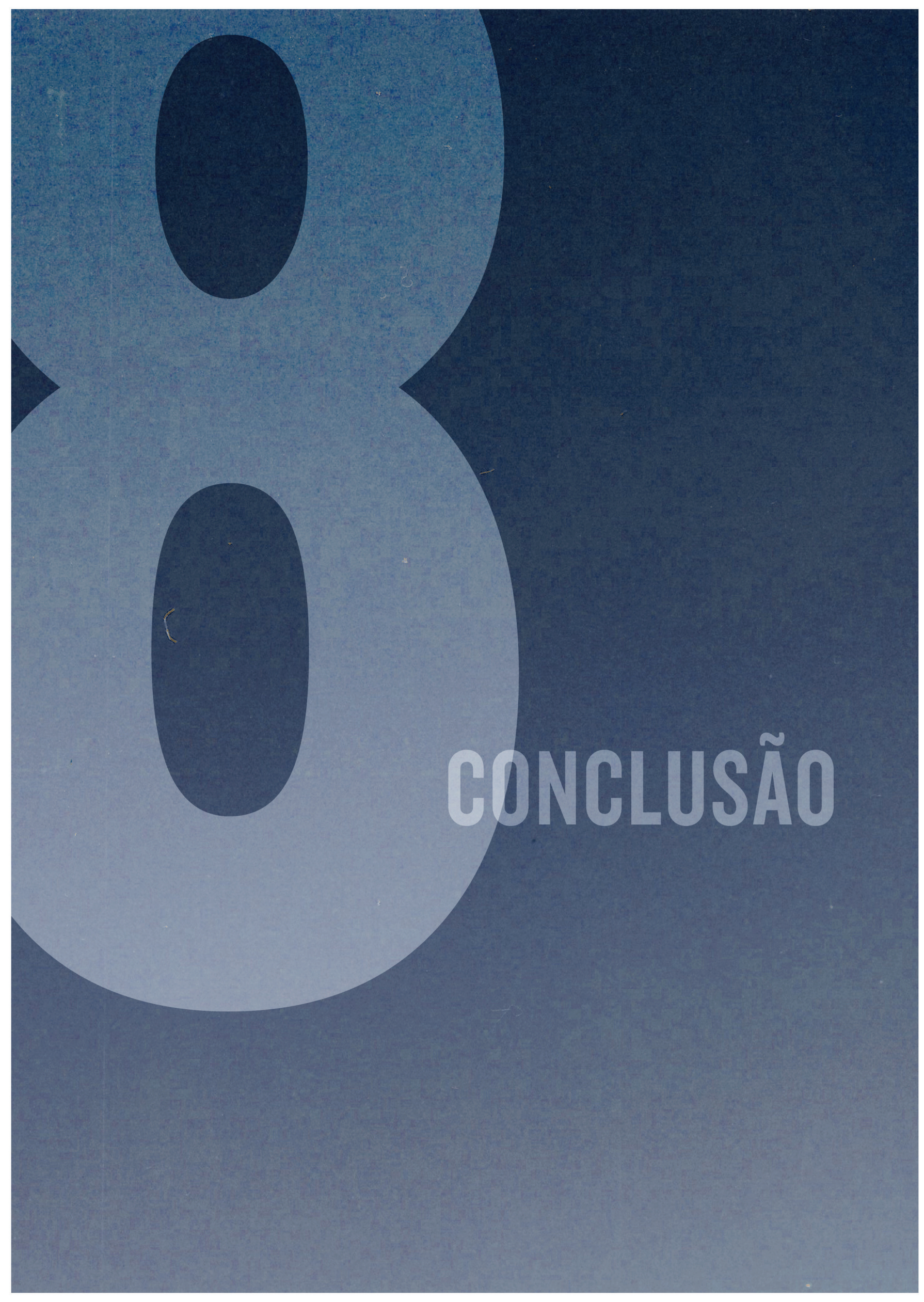



A partir das análises físicas em estruturas existentes bem como as em construção, procura-se com este trabalho orientar os profissionais de saúde, principalmente os arquitetos, na busca de soluções mais eficientes para Unidades de Urgência e Emergência de alta complexidade, adequadas à sua realidade local e/ou regional, agregando assim valores espaciais para todos os seus usuários.

Para a ordem de grandeza do trabalho que se apresenta, é necessário o envolvimento sinergético da equipe multidisciplinar de profissionais, em que arquitetos, médicos, enfermeiros, paramédicos, administradores, psicólogos, economistas, engenheiros etc., visem um trabalho integrado de pesquisa e prestação de serviço, procurando a melhoria da qualidade de vida do homem. Surge aqui, também, um novo modelo projetual do edifício, e em particular a unidade de urgência e emergência, no sentido de modificar sua metodologia, fazendo uma leitura de seus espaços, transformando uns e consolidando outros, respaldado numa clareza conceitual bastante precisa.

Esta leitura se amplia na medida em que colocar o edifício e a unidade em foco no contexto urbano, o edifício e elementos arquitetônicos do seu entorno, edificado e natural, através de ligações, correspondências formais, funcionais e espaços 
interativos, promovam a integração dos cidadãos e a intensificação da vida urbana.

O edifício deve ser convidativo, a favor de uma relação informal entre o maior número de pessoas com os espaços públicos e privados, tendo a qualidade espacial e o conforto ambiental como fim e a tecnologia como meio de obtê-los, e que o edifício se espelhe na cidade e ela o identifique como parte do seu ser.

Pela sua complexidade e especificidade, a arquitetura hospitalar, em particular envolvendo a Unidade de Urgência e Emergência, requer de todos os profissionais envolvidos completo conhecimento, competência e responsabilidade sobre sua postura projetual e inerente compromisso com a sua produção arquitetônica no cenário brasileiro.

Quando colocada a arquitetura envolvida neste contexto, esta é apenas um instrumento de articulação na complexa engrenagem do sistema hierarquizado de saúde. O já discutido, defendido, sofrido, desgastado, desmantelado, sucateado, surrado e quase apodrecido sistema de atenção à saúde brasileira não responde, de forma objetiva, sobre o seu real papel na sociedade brasileira.

A contínua informação, pelos diversos meios de comunicação por este país afora, de que Unidades de Urgência e Emergência estão superlotadas, pacientes assistidos em macas e leitos nos corredores, carência de medicamentos e insumos, equipamentos sucateados, falta de médicos nas Unidades Básicas de Saúde, baixos salários, entre outros fatores, são apenas alguns pontos neste complexo cenário que refletem diretamente o serviço emergencial brasileiro.

Caberá aos poderes de decisão a articulação séria da sociedade mudar e transformar este panorama tão decadente. Não com a "brilhante e cômoda" criação de impostos, mas sim com um planejamento honesto e consistente, gestão idônea dos recursos públicos. A sociedade está cansada do discurso pautado no trinômio "saúde, educação e segurança", que a todo evento eleitoral, os políticos, à busca de votos, teimam em rememorar mecanicamente sem nenhuma reflexão. Por outro lado, encontram-se os personagens do grupo operacional, que bravamente e muitas vezes por puro idealismo e sacerdócio oferecem condições de atendimento e acolhimento à população carente, a procura de solução para o problema de saúde. 
A arquitetura não pode estar alheia e omissa a este processo. Para tanto, é necessário ofertar respostas adequadas às soluções técnicas, ao bom dimensionamento espacial, ao conforto ambiental pleno, à qualidade do ambiente hospitalar quanto à salubridade, agradabilidade e bem-estar.

Aos arquitetos, caberá compreender plenamente todos os sentimentos que afloram no paciente e familiar, no momento de atendimento junto à Unidade de Urgência e Emergência. Desde a simples e natural insegurança ao pavor extremo, é com esta realidade que a convivência social e ambiental ocorre. E neste viez que o processo projetual emerge, pois de todos os pacientes atendidos no complexo hospitalar, o paciente em estado crítico possui o seu diferencial, sua particularidade é latente.

Será com sensibilidade que o profissional da arquitetura, em conjunto com a equipe multidisciplinar, traduzirá espacialmente as expectativas esperadas. Caberá ainda desempenhar o papel de suporte às mudanças pretendidas, não como coadjuvante, mas cumprindo com a ação de interventor, articulador e criador do espaço hospitalar. Para tanto, é necessário aprofundar seus conhecimentos, ter domínio técnico, excelência e competência profissional.

É mediante seu desempenho profissional que se conquistará o conforto e o bem-estar da população, transformando a visão de todos de ter consciência para uma vida mais digna, melhor convivência com o meio ambiente, abarcando as diferenças e diversidades e prosperando para que se atinjam níveis elevados de saúde para todos hoje, e para futuras gerações.

Neste trabalho de pesquisa, é apresentada uma série de diretrizes projetuais para a elaboração de projetos arquitetônicos para Unidades de Urgência e Emergência, no sentido de primeiramente abrir a discussão e reflexão sobre a sua especificidade; em seguida, alimentar com informações sobre os diversos componentes e variáveis que interferem no processo projetual da arquitetura, com o objetivo de melhor ofertar espaços adequados, educados, inteligentes, sensíveis e humanizados à população que procura o serviço emergencial hospitalar. 



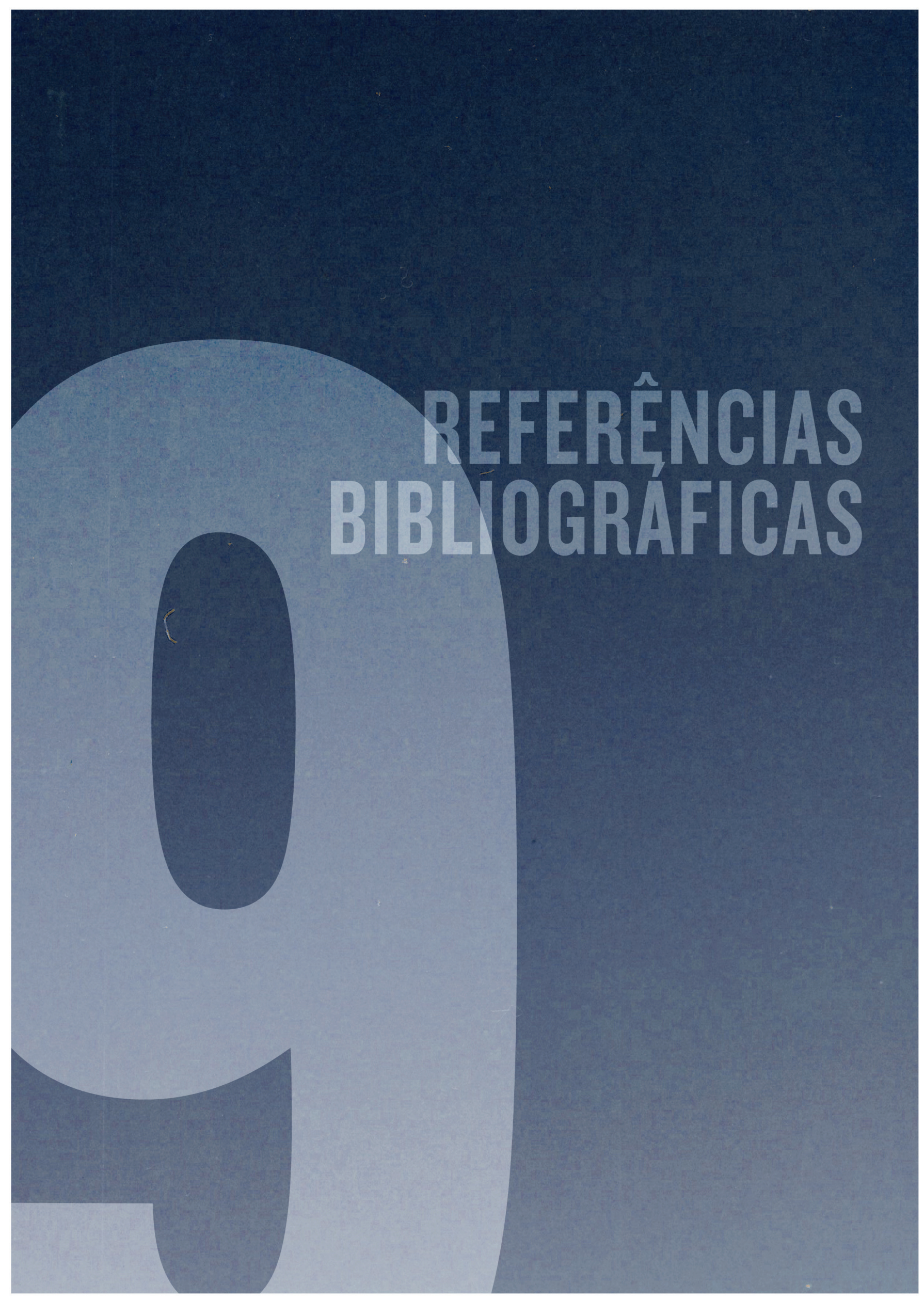



ABBÊS, Claudia; MASSARO, Altair. Acolhimento com Avaliação e Classificação de Risco; Um Paradigma Ético - Estético no Fazer em Saúde. Textos Básicos em Saúde/O.M.S., Brasília, 2004.

ALVES, Luis Augusto R. O Conceito de Lugar. Portal Vitruvius. Disponível em: <www.arquitextos.com.br/arquitextos/arq.000/esp432.asp.>Acesso em 02/08/2009.

ALMEIDA, P. Oswaldo. Idosos Atendidos em Serviço de Emergência de Saúde Mental: Características Demográficas e Clinicas. Revista Brasileira de Psiquiatria, 1999.

AMORIN, Marcelo A. Arquitetura Hospitalar em Plena Evolução para Corresponder à Modernização da Saúde. Revista Guia de Fornecedores Hospitalares, São Paulo, jan. 1998.

ANELLI, R.; GUERRA, A. Rino Levi Arquitetura e a Cidade. Disponível em: <www.vitruvius. com.br>. São Paulo, 2001. Acessado em 27/05/2006.

ARCHITECTURE FOR HEALTHCARE. Andrea Boekel. The Imagens Publishing Group, Honk Kong China, 2008.

ASSOCIAÇÃO BRASILEIRA DE NORMAS TÉCNICAS - ABNT. NBR 9050: Revisão - Acessibilidade a Edificações, Mobiliário, Espaços e Equipamentos Urbanos. Rio de jan. 2004.

BARAKAT, Soraia F. C. Caracterização da Demanda do Serviço de Emergências Clínicas de um Hospital Terciário no Município de São Paulo. 2005. Tese de doutorado. Disponível em: <www. teses.usp.br/teses/disponiveis> Acesso em: 27/12/2008.

BARBOSA, Leopoldo Nelson Fernandes; et all. Reflexões Sobre a Ação do Psicólogo em Unidades de Emergência. 2007. Disponível em: <www.pepsic.bus-psi.org.br/scielo.phd.> Acesso: $27 / 12 / 2008$.

BARRETO, Frederico F. P. Programação Arquitetônica e Projetos Complementares, Brasília, 1995.

BERTOLOTTI, Dimas; FERREIRA, Dilson B. Projeto de Iluminação Natural Busca Economia de Energia e Bem Estar dos Usuários. Revista Sistemas Prediais, Nova Técnica Editorial Ltda. São Paulo, fev/mar. 2010.

BITENCOURT, Fabio Arquitetura-Ambiente de Nascer, Editora Rios Books: Rio de Janeiro, 2008.

BITENCOURT, Fabio. A Cor como Promotor de Conforto nos Ambientes de Saúde. Disponível em: <www.mundocor.com.br.> Acesso em: 07 ago.2006.

BOEKEL, Andrea. Architecture for Healthcare, The Imagens Publishing Group: Honk Kong China, 2008.

BRASIL. Agência Nacional de Vigilância Sanitária - ANVISA. Resolução da Diretoria Colegiada - RDC no 50/ no 307. Regulamento Técnico para Planejamento, Programação, Elaboração e Avaliação de Projetos Físicos de Estabelecimentos Assistenciais de Saúde. Brasília: 2002.

. Ministério da Saúde - Política Nacional de Atenção às Urgências. Brasília: 2006. 
Agência Nacional de Vigilância Sanitária - ANVISA. Resolução da Diretoria Colegiada - RDC no 21. Regulamento Técnico para Funcionamento de Serviços de Atenção ao Paciente Crítico e Potencialmente Crítico. Brasília: 24/04/2006.

Ministério da Saúde. SOMASUS. Sistema de Apoio à Organização e Elaboração de Projetos e Investimentos em Saúde, Brasília, 2008.

BREITMAN, Irineu. A Importância de um Edifício Hospitalar Bem Planejado. Revista Guia de Fornecedores Hospitalares. São Paulo, jul. 2001.

BROSS, João Carlos. Como Construir ou Reformar Hospitais. Entrevista dada pelo arquiteto. Escola de Administração de Empresas de São Paulo, jan. 1999a.

Os Edifícios de Saúde na Virada do Século. Entrevista dada pelo arquiteto. Revista Hospitais Brasil, São Paulo, jan. 1999b.

et al. Arquitetura Hospitalar: A Qualidade no Atendimento Começa Aqui. Revista Guia de Fornecedores Hospitalares, São Paulo, p. 28-30, abr. 1999c.

O Desafio de Construir Edifícios de Saúde. Revista Guia de Fornecedores Hospitalares. São Paulo, p. 58, jun. 2000.

Mantendo o Hospital na Ponta da Modernidade. Revista Guia de Fornecedores Hospitalares, São Paulo, jul. 2004.

A Complexa Arquitetura Hospitalar. Disponível em: <www.arcoweb.com.br/entrevista.> Acesso em: 07 ago. 2006.

BROTO, Carles. New Health Facilities, Graphic Design and Prodution: Barcelona Spain 2009.

CARVALHO, Antonio Pedro. A. de. (coord.). Temas de Arquitetura de Estabelecimentos Assistenciais de Saúde. Universidade Federal da Bahia. Faculdade de Arquitetura - Curso de Especialização de Arquitetura em Sistemas de Saúde. 2a Ed. Salvador: Quarteto Editora 2003.

; TAVARES, Igor G.: Modulação no Projeto Arquitetônico de Estabelecimentos Assistenciais de Saúde: O Caso dos Hospitais Sarah, 2002.

CARVALHO, Gilson. Financiamento Para a Saúde: Definido, Definitivo e Suficiente. 2009. Disponível em: <www.ccs.uel.br/nesco/regesus/arquivos> Acesso em 23/nov/2009.

CERQUEIRA CÉSAR, Roberto. Planejamento de Hospitais - Instituto de Arquitetos do Brasil. São Paulo, 1954, p.104.

CORBIOLI, Nanci. Ambiente Hospitalar Requer Humanização e Potencial de Atualização Constante. Revista Projeto Design, São Paulo, n. 283, p. 94-98, set. 1980.

CORBIOLI, Nanci. Hospital é uma Obra Aberta. Disponível em: <www.arcoweb.com.br.> Acesso em: 16 abr. 2005. 
COSTA, José Ricardo S. de L. Espaço Hospitalar: A revolta do Corpo e a Alma do Lugar - Portal Vitruvius. Disponível em: <www.arquitextos.com.br/arquitextos/arq000/esp079.asp.> Acesso: 02/08/2009.

COSTEIRA, Elza M. A. Hospitais de Emergência da Cidade do Rio de Janeiro: Uma Nova Abordagem para a Eficiência do Ambiente Construído. Rio de Janeiro: UFRJ, 2003.

COSTI, Marilice. A Influência da Luz e da Cor em Corredores e Salas de Espera Hospitalares. Porto Alegre: EdiPUCRS, 2002.

COSTI, Marilice. Iluminação em Hospitais - Cuidados Fundamentais. Revista Lume Arquitetura, São Paulo, Ano II, n. 08, p. 16-21, jun./jul. 2004.

DIVERSOS AUTORES. Unidade de Emergência e Ambulatório. São Paulo: CEDAS - Centro São Camilo de Desenvolvimento em Administração da Saúde, 1983.

DIVERSOS AUTORES. Observação Pediátrica em Unidade de Emergência de um Hospital Universitário. Revista Ciências Médicas, Campinas, mar /abr. 2007.

DOS SANTOS, José S. Mudanças de Impacto. Revista Ser Médico - Edição Jan. / Mar. 2009 CRM-SP - disponível em: <www.cremesp.org.br>. Acesso: 08/jan/2009.

ESTELMHSTS, Priscila. Brusamarello, Tatiana, Borilla, Dayane e Maftum, A. Marluci - Emergências em Saúde Mental: Prática da Equipe de Enfermagem Durante o Período de Internação. Revista de enfermagem, Rio de Janeiro: UERJ, 2008.

FARIA, Renato. Hospital e Maternidade São Luiz - Anália Franco - Balanço Concreto. Disponível em: <www.revistatechne.com.br>. Acessado 19.12.2010.

FERREIRA, Dilson B. Projeto de Iluminação Natural Busca Economia de Energia e Bem-estar dos Usuários, Revista Sistemas Prediais, n.17, p.12-21, dez./2010. Nova Técnica Editorial - São Paulo.

FIORENTINI, Domingos M. F; LIMA, Vera H. A.; KARMAN, Jarbas B. Arquitetura na Prevenção de Infecção Hospitalar, Ministério da Saúde, Brasília, 1995.

FIORENTINI, Domingos M. F. A Alegria Como Partido. Revista L+D, São Paulo, n. 31, p. 58-63, dez. 2010.

FOLHA ON LINE, Arrecadação com CPMF bate recorde e soma 23,7 bi no ano/ 20/09/2007. Disponível em: <www.folha.com.br $>$. Acesso em 23/nov/2009.

FOUCAULT, Michel. Nascimento do Hospital, Microfísica do Poder. 7.ed. Rio de Janeiro: Edição Graal, 1988.

FUNDAÇÃO DAS PIONEIRAS SOCIAIS. Instituto Nacional de Medicina de Aparelho Locomotor - Hospital Sarah Kubitschek - Brasília, 1980.

GIACOMO, Nelson. S. de. Arquitetura: Uma Ferramenta Importante na Implantação e Operacionalização de Laboratórios. Revista Alapar, Associação dos Laboratórios de Análises Clínicas, Anatomia e Citologia do Paraná, Londrina, n. 04, p. 09-10, mar./abr. 2005. 
GIACOMO, Nelson S. Arquitetura Hospitalar, Espaços Humanizados, Rompendo Barreiras. Revista Clube de Engenharia e Arquitetura de Londrina, 1999.

GIACOMO, Nelson S. Health Care Facility in the City of Londrina, State of Paraná, Brazil. 1984. 177 p. Dissertação (Mestrado em Arquitetura Hospitalar) Tulane University, New Orleans, Louisiana, USA.

GIACOMO, Nelson. S. de; NAZIMA, K. M. Estética: O que Temos em Comum? Jornal Associação Médica de Londrina, Londrina, 2005.

GIACOMO, Talita. de. Unidades de Internação - Diretrizes para o Projeto Arquitetônico. 2005. 170 p. Monografia (Especialização em Projeto de Arquitetura para a Cidade Contemporânea). Faculdade de Arquitetura e Urbanismo, Pontifícia Universidade Católica do Paraná - PUCPR, Curitiba.

GÓES, Ronald. de. Manual Prático de Arquitetura Hospitalar. 1.ed. São Paulo: Ed. Edgard Blücher, 2004

GOMES, Alice Martins, Emergência - Planejamento e organização da Unidade - Assistência de Enfermagem, Editora Pedagógica e Universitária Ltda, 1994.

GOMES, Alice Martins de C. Timerman, A, Souza, C. A. M. Fatores prognósticos de Sobrevida Pós Reanimação Cardiorespiratoria Cerebral em Hospital Geral. Arquivo Brasileiro de Cardiologia, vol. 85, n. 4, São Paulo, 2005.

HALBREICH, Uriel; SHERWIN. B. Rule of Estrogen in Post Menopausal Depression. Neurology Magazine, 48 suppl 7:16-20. 1997.

HEALTH CARE ARCHITECTURE. Nermith, Eleanor L. Designs for the Future, The Imagens Publishing Group: Hong Konk, China, 2006.

Designs for the Future, Massachusetts, USA, 1995.

HEALTH SPACES. Review Pictorial A. v. 01. The Imagens Publishing Group, Melbourne, Austrália - 2000.

INSTITUTO DOS ARQUITETOS DO BRASIL. Planejamento de Hospitais - São Paulo, 1954.

INSTITUTO LINA BO e P. M.BARDI. João Filgueiras Lima - Lelé. Série Arquitetos Brasileiros. São Paulo. Editorial Blau, 2000.

IBGE - Instituto Brasileiro de Demografia e Estatística, Censo. 2008.

ISHITANI, Lenice; et all. Desigualdade Social e Mortalidade Precoce para Doenças Cardiovasculares no Brasil. Revista de Saúde Pública, n. 04, v. 40, São Paulo, 2006.

KARMAN, Jarbas. Manutenção Hospitalar Preditiva. São Paulo. Editora PINI, 1994.

; FIORENTINI, Domingos. A Dimensão "Economia e Custos" em Arquitetura Hospitalar.

Revista Guia de Fornecedores Hospitalares, São Paulo, jul. 1998. 
KARSTEIN, Adriano A.; et all. Analise Epidemiológica das Vitimas Atendidas pelo SIATE e Transportadas ao Hospital Cajuru, Curitiba - PR. Revista Brasileira de Ortopedia e Traumatologia, Curitiba 1996.

KOHLSDORF, Maria E. Condições Ambientais de Leitura Visual, Ministério da Saúde, Brasília, 1995.

LAMB, Paulo L. Centro Cirúrgico e Recuperação Pós-Anestésica. Porto Alegre: Gráficaplub, 2000.

LAWSON, Bryan. Evidence-Based Design for Healthcare. Revista Business Briefing, Hospital Engineering and Facilities Management, London, dez./2005.

LEI - 10216. Lei de Reforma Psiquiátrica - Lei Paulo Delgado, abr./ 2001

LERER, Bernardo. Hospital Israelita Albert Einstein - Realização de um sonho. Conselho Editorial, São Paulo, 1996.

LEVI, Rino. Arquitetura e Cidade, São Paulo: Romano Guerra editora, 2001.

LIMA, João Filgueiras. CTRS - Centro de Tecnologia da Rede Sarah: Arquiteto João Filgueiras Lima (Lelé). Brasília: Sarah Letras. São Paulo: Fundação Bienal/ProEditores, 1999.

. Entre a Arte e a Técnica. São Paulo - 2000. Disponivel: <www.arcoweb.com.br > Acessado em 22/11/2001.

MARBERRY, Sarah O. Healthcare Design. New York: John Wiley \& Sons Inc., 1997.

MARINELLI, Alexandra, CAMARGO. Azael R. O Estabelecimento de Saúde e o Edifício de Alta Tecnologia In: I Congresso Nacional da ABDEH / IV Seminário de Engenharia Clínica, 2004.

MARTINS, Vania P. A Humanização e o Ambiente Físico Hospitalar. In: I Congresso Nacional da ABDEH - IV Seminário de Engenharia Clínica, 2004.

MATOS, Rodrigo M. Circulações em Hospitais - O Caso da Unidade Hospital Presidente Dutra em São Luis - MA. UFBA: Salvador, 2008.

MATSUMOTO, Ivania - A Atuação da Equipe Multiprofissional no Atendimento da PCR. 2008. Web artigos. Disponível em:<www.webartigos.com/articles.> Acessado em 28/08/2010

MAWAKDIYE, Alberto. Pela Humanização dos Hospitais. Entrevista cedida pelo arquiteto Carlos Eduardo Pompeu. Revista Construção, São Paulo, v. 50, n. 2586, p. 08-11, set. 1997.

MELLO, Norton R. R. O Impacto da Engenharia na Prática Médica. Revista Guia de Fornecedores Hospitalares, São Paulo, p. 56, jul. 1997.

MEZOMO, João C. Hospital Humanizado. São Paulo: CEDAS - Centro São Camilo de Desenvolvimento em Administração da Saúde, 1979.

MINISTERIO, Saúde - Resolução nº 306 - ANVISA - Brasília - Dez/2004 
MIQUELIN, Lauro C. Anatomia dos Edifícios Hospitalares. São Paulo: CEDAS - Centro São Camilo de Desenvolvimento em Administração da Saúde, 1992.

MIQUELIN, Lauro C.; LING, M. Recursos Físicos: Como Aplicá-los e Administrá-los Adequadamente no Ambiente Hospitalar? Revista Guia de Fornecedores Hospitalares, São Paulo, mar. 1997.

MIQUELIN, Lauro C.; LING, M. Reforma Hospitalar: Planejamento é o Caminho mais Seguro. Revista Guia de Fornecedores Hospitalares, São Paulo, set. 1997.

NETO, Salim L. Hospitais Devem Planejar a Modernização de suas Instalações. Revista Guia de Fornecedores hospitalares, São Paulo, abr./ 1997.

NOBLE, Ann. The Next Generation of Healthcare Buildings. Revista Business Briefing, Hospital Engineering and Facilities Management, London, dez. 2005.

NOBRE, Ana L. João Filgueiras Lima: Arquitetura como Processo. Disponível em: <www.vitruvius.com.br.> Acesso em: 07 ago. 2006.

OLIVEIRA, Tadeu A.; RIBAS Otto T. Sistemas de Controle das Condições Ambientais de Conforto, Ministério da Saúde: Brasília, 1995.

PEVSNER, Nikolaus. History of Building Types. London: Thames \& Hudson, 1986.

PINHO, Leandro B.; KANTORSKI, Luciana P. Refletindo Sobre o Contexto Psicossocial de Famílias de Pacientes Internados na Unidade de Emergência. Disponível em: <www.scielo.cl.org.br>. Revista Ciência y Enfermaria. v. 10, n.01, Concepción Junho/2004. Acessado 27/12/2008.

PINHO, Paloma de S. O., ARAÚJO, Tânia Maria. Trabalho de Enfermagem em uma Unidade de Emergência Hospitalar e Transtornos Mentais - CERJ, Rio de Janeiro, 2007.

PINTO, Leandro B., KANTORSKI, Luciane P. Refletindo sobre o Contexto Psicossocial de Famílias de Pacientes Internados na Unidade de Emergência. Disponível em: <www.scielo.cl/scielo.phd $>$. Acesso em: 27/12/2008.

PINTO, Silvia C. F. Hospitais: Planejamento Físico de Unidades de Nível Secundário - Manual de Orientação. Brasília: Thesaurus, 1996.

POMPEU, Carlos. Revista CJ Arquitetura. Hospitais Edição Especial, n .24, p.34, São Paulo 1977.

REIS, Sergio P. A. Arquitetura Hospitalar: Planejamento é Fundamental. Revista Guia de Fornecedores Hospitalares, São Paulo, p. 30, fev. 2000.

REVISTA CJ ARQUITETURA. Hospitais. Edição Especial, n.15, São Paulo, 1977.

REVISTA PROJETO. Hospitais. Edição Especial, São Paulo, p. 26- 54, n. 24, nov. 1980.

REVISTA AU. Edição Especial. Hospitais - Hospital São Francisco. São Paulo. set./2002, p.30-35.

REVISTA L + D. A Alegria como Partido. Hospital Infantil Sabará, n. 31, dez./2010, p.58- 63. 
ROSENFIELD, Isadore. Hospitales Diseño Integral. México: Compañia Editorial Continental, S.A, 1965.

ROSES, Roberto E. Arquitectura Hospitalaria: Una Aproximación a los Hospitales del Futuro y las Nuevas Infraestructuras de Salud. Disponível em: <www.arquitectura.com.> Acesso em: 12 maio 2000.

SAMPAIO, Ana Virginia C. de F. Arquitetura Hospitalar: Projetos Ambientalmente Sustentáveis, Conforto e Qualidade - Proposta de um Instrumento de Avaliação. 2005. 402 p. Tese (Doutorado em Arquitetura) - Faculdade de Arquitetura e Urbanismo, Universidade de São Paulo - USP, São Paulo.

SANTOS, Mauro; BURSZTYN, Ivani. Saúde e Arquitetura - Caminhos para a Humanização dos Ambientes Hospitalares. Rio de Janeiro: SENAC, 2004.

SILVA, Maria Anice. Concepção Ergonômica dos Locais e dos Espaços de Trabalho de uma Unidade de Emergência Hospitalar, Florianópolis 1999. Disponível em: <www.eps.ufsc.br/disserta99/>. Acesso em: 8/jan/2009

SILVA, Jaime; PAIVA, Cida - Hospital São Luiz - Anália Franco - São Paulo - Disponível em: $<$ www.arcoweb.com.br/arquitetura $>$. Acessado 23.07.2009.

SILVA, Kleber P. A Idéia de Função para a Aquitetura: o Hospital e o Século XVIII - 6 partes. 2005. Disponível em: <www.vitruvius.com.br.> Acesso em: 22 nov. 2001.

SODRÉ, Marcelo. Arquitetura Colaborando com Médicos e Enfermeiros. Revista Guia de Fornecedores Hospitalares, São Paulo, p. 43, set. 1998.

SOUZA, Roberta V. G. Ergonomia e Ambiente Construído: Uma Análise de Parâmetros de Conforto Ambiental, Florianópolis: UFSC, 2000.

STORT, Alan. Healthcare Design for the Future - Developing Viable, Sustainable Design Strategies for Healthcare Buildings. Revista Business Briefing, Hospital Engineering and Facilities Management, London, dez. 2005.

TÁCSI, Yolanda R. C. e Venduscolo. Dulce M.S. A Assistência de Enfermagem no Serviço de Emergência Pediátrica. Revista Latino-Americana de Enfermagem. v. 12 n.03, RibeirãoPreto, maio/jun. 2004.

THE CANADIAN ARCHITECT. Magazine Audit Board Incorporated - Humanized High Tech - At what cost?, v. 29, p.12-18, fev. 1984. Ontario - Canadá.

THOMPSON, John D; GOLDIN, Grace. The Hospital: A Social and Architectural History. New Haven: Yale University Press, 1975.

TOLEDO, Luis Carlos; FERRER, Mario V. Urgência e Emergência: Primeiros Cuidados Projetuais. In: CARVALHO, A. P. A. (coord.). Arquitetura de Unidades Hospitalares. Universidade Federal de Bahia. Faculdade de Arquitetura, Curso de Especialização de Arquitetura em Sistemas de Saúde. Salvador: Quarteto Editora, 2004. 
TOLEDO, Luiz Carlos; Humanização do Edifício Hospitalar - Um Tema em Aberto. PROARQ - PROJETAR, Salvador 2005.

TZORTZOPOULOS, Patrícia; et al. The Gaps Between Health Care Service and Building Design: a state of the art review. University of Salford: Salford - UK, 2005.

VIANNA, Nelson; GONÇALVES, Joana. Iluminação e Arquitetura. São Paulo: Virtus S/C Ltda., 2001.

VITTONI, Gail. The Imperative for Green Healthcare Facilities. Revista Business Briefing. Hospital Engineering and Facilities Management, dez. 2005.

WEHB, Grasiela, GALVÃO, Cristina Maria. O Enfermeiro da Unidade de Emergência de Hospital Privado: Algumas Considerações. Revista latino-americana de Enfermagem, mar. 2001. Disponível em: <www.eerp.usp.br/rlaenf>.

ZANETTINI, Siegbert. A Arquitetura Hospitalar do Século XXI. Revista Guia de Fornecedores Hospitalares, São Paulo, p. 26, mar. 2000.

O Sonho que faz Evoluir as Formas e a Técnica. Revista Mais Arquitetura, São Paulo, n. 36 , p. 22, out. 2002a.

Siegbert Zanettini: Arquitetura, Razão e Sensibilidade. São Paulo: Editora da Universidade de São Paulo, 2002b.

Hospitais Investem na Modernização do Espaço. Revista Fornecedores Hospitalares. São Paulo, jun./ 2003.

ZEIDLER, Eberhard. Healing the Hospital - MC Master Health Science Centre - Its Conception and Evolution. Hamilton - Canadá1984. 